\title{
ESTRUTURA GENÉTICA E FENOLOGIA DE ESPÉCIES RARAS DE Couratari spp. (LECYTHIDACEAE) NA AMAZÔNIA CENTRAL
}

\section{NADJA LEPSCH - CUNHA \\ Bióloga}

Orientador: Prof. Dr. Paulo Yoshio Kageyama

Dissertação apresentada à Escola
Superior de Agricultura "Luiz de
Queiroz", da Universidade de São
Paulo, para obtenção do título de
Mestre em Ciências - Área de
concentração: Ciências Florestais.

P I R A C I C A B A

Estado de São Paulo - Brasil

Abril - 1996 
Dados Internacionais de Catalogação na Publicação (CIP)

DIVISÃo dE BIBLIOTECA E DOCUMENTAÇẤO - Campus "Luiz de Queiroz"/USP

Lepsch-Cunha, Nadja

Estrutura genética e fenologia de espécies raras de Couratarispp. (Lecythidaceae)

na Amazônia Central / Nadja Lepsch-Cunha. - Piracicaba, 1996.

147p. : il.

Dissertação (mestrado) - - Escola Superior de Agricultura Luiz de Queiroz, 1996.

Bibliografia.

1. Ecossistema florestal 2. Floresta tropical - Amazônia Central 3. Tauari - Genética Amazônia Central 1. Titulo

CDD

634.973323 
ESTRUTURA GENÉTICA E FENOLOGIA DE ESPÉCIES RARAS DE Couratari spp. (LECYTHIDACEAE) NA AMAZÔNIA CENTRAL

NADJA LEPSCH-CUNHA

Aprovada em: 18/04/1996

Comissão julgadora:

Prof. Dr. Dario Grattapaglia

CENARGEN/EMBRAPA

Prof. Dr. Paulo Y. Kageyama

ESALQ/USP

Prof. Dr. Rolando Vencovsky

ESALQ/USP

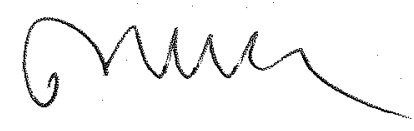

Prof. Dr. PAUlO Y. KAGEYAMA

Orientador 
À minha mãe, Maria Helena, por muito do que sou e pela ousadia de ter criado ao meus irmãos e a mim com liberdade. Ao meu pai, Eleusis (in memoriam), por ter me estimulado e ensinado a tentar responder as minhas dividas.

OFEREÇO
À memória de meu irmão Tony e dos meus grandes amigos, Fernando Corte, Roberto Ayres (Niba) e Brian Tool, e a todos aqueles que como eles lutaram com dignidade contra o estigma da AIDS. Solidariedade AIDS! 


\section{AGRADECIMENTOS}

Ao Prof. Dr. Paulo Y. Kageyama pela orientação deste trabalho, amizade e convivência, que proporcionaram-me maior criticidade sobre a conservação da diversidade biológica.

Ao Dr. Scott Mori e Dr. Peter Becker por tudo que me ensinaram, pela amizade e companheirismo durante todos esses anos, e pela pronta disposição a ajudarem-me em vários momentos em que precisei. Ao Scott eu agradeço também o estímulo e reconhecimento.

Ao Tio Romeu, Paulo Apóstolo e Antonio Ribeiro, mateiros de competência exemplar, pela disposição e amizade desde o projeto Lecythidaceae, e por tudo que me ensinaram.

Ao maridão Henrique E. Mendonça Nascimento, meu melhor amigo, pela colaboração incansável desde a fase de coleta e extração de material em Manaus, e em toda a fase de laboratório, discussão e revisão do manuscrito em Piracicaba.

Ao meu amigão, Flávio Gandara, agradeço em todas as fases deste trabalho, pelo seu auxilio nos programas, nas discussões, nas decisões necessárias, sempre disponivel. Sem ele, este trabalho seria muito mais complicado.

À Dra. Ingrid Peters, pelos conselhos e estímulo dados já há muito tempo e pela contribuição na interpretação dos zimogramas.

Ao Professor Roland Vencovsky pela grande contribuição na discussão dos dados estatísticos, e pela criticidade e leitura atenta do manuscrito da dissertação.

Aos amigos em Manaus, Ângela Imakawa pelas observaçoes fenológicas, Manolo Pacheco e Carlos Fonseca pela discussão da fenologia e pelas ótimas sugestões dadas, e Gisleine Ganade pela ajuda na coleta e envio de sementes. A todo pessoal do PDBFF, Eudalete, Norma, Ari, Cabocão, Mistis, Sr. Antônio, pelo carinho e disposição a ajudar e facilitar a vida da gente.

Ao pessoal do laboratótio, Elza Martins Ferraz pela contribuição no laboratótio durante a eletroforese, Sueli, Fininho, Marcos, por todas as ajudas, e ao Maurício Reis, pelos programas de computador cedidos e discussões em várias fases da tese.

Aos amigos em Piracicaba, Jeane Tabanez pela ajuda na revelação das fotos, Edson Namita Higashi e Erika Laura Schloemp pelo grande auxílio na edição e amizade.

A grande amiga sempre presente, mesmo que longe, Denize Alves Machado, por seus comentários picantes e por sua extraordinária capacidade de me compreender.

A minha família, pela união que sempre tivemos, tornando a vida mais prazerosa e amável. Aos meus sogros, Nelinho e Auxiliadora, que sempre auxiliaram-me em momentos de necessidade.

Todo o trabalho de campo, de laboratório e bolsa concedida por 1 ano foi financiado pelo Projeto Dinâmica Biológica dos Fragmentos Florestais (PDBFF). O CNPq concedeu 2 anos e meio de bolsa de mestrado e a Fundação Botânica Margaret Mee, bolsa auxilio por 3 meses. 


\section{SUMÁRIO}

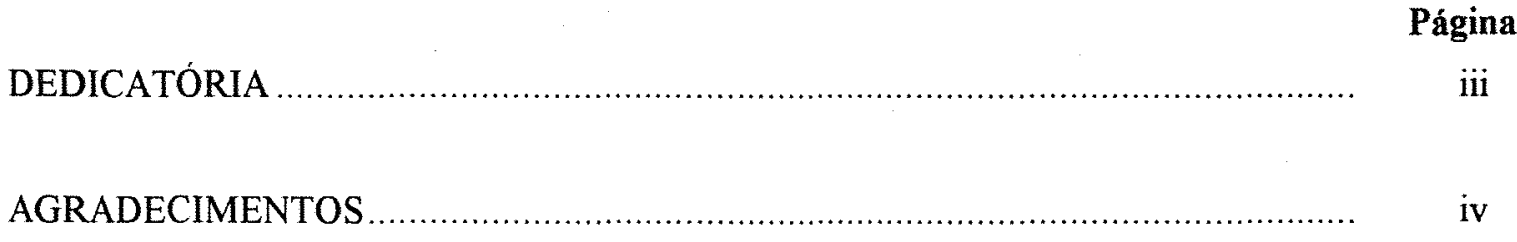

LISTA DE FIGURAS ….......................................................................... vii

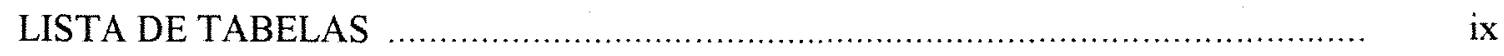

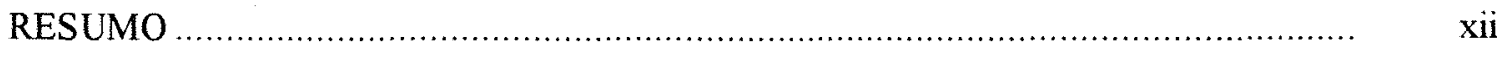

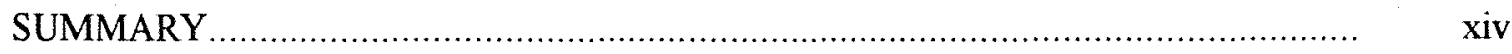

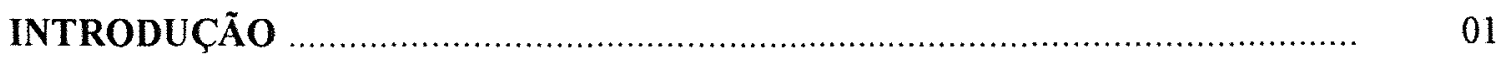

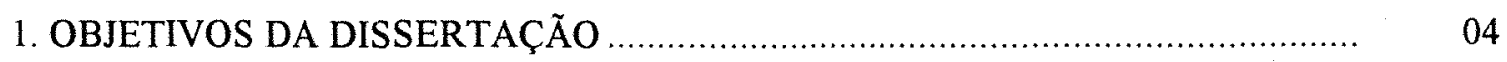

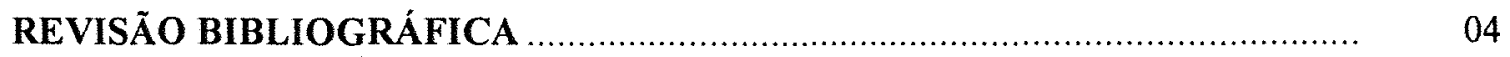

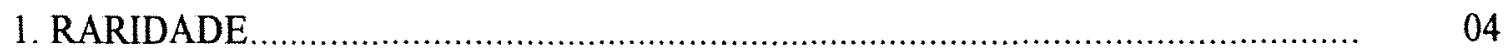

2. MEDINDO A VARIABILIDADE GENÉTICA EM POPULAÇÕES DE PLANTAS 14

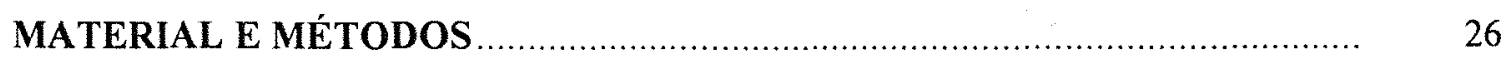

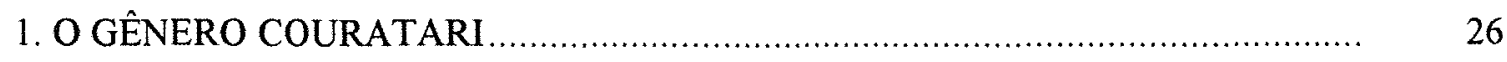

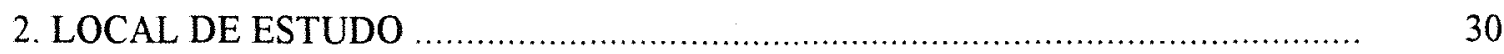


3. METODOLOGIA GERAL PARA O LEVANTAMENTO DAS ÁRVORES E DEFINIÇÃO DE CATEGORIAS DE IDADE/TAMANHO

1. VARIABILIDADE GENÉTICA INTRAPOPULACIONAL DE DUASESPÉCIES DE BAIXA DENSIDADE NA AMAZÔNIA CENTRAL: Couratari mutiflora (J.M.Smith.) Eyma e C. guianensis Aublet (LECYTHIDACEAE).

2. FENOLOGIA REPRODUTIVA E POTENCIALIDADE DE CRUZAMENTOS ENTRE INDIVÍDUOS EM UMA POPULAÇÃO DE BAIXA DENSIDADE DE Couratari multiflora (J.E.Smith) Eyma NA AMAZÔNIA CENTRAL ...........................

3. SISTEMA REPRODUTIVO DE: ESPÉCIE ARBÓREA DE BAIXA DENSIDADE Couratari multiflora (J. Smith) Eyma (LECYTHIDACEAE) NA AMAZÔNIA CENTRAL -

CONCLUSÕES

1. CONSIDERAÇÕES QUANTO À CONSERVAÇÃO

2. CONCLUSÃO FINAL 


\section{LISTA DE FIGURAS}

\section{MATERIAL E MÉTODOS}

Página

1. Parte superior da figura: sementes, plântula (A) e partes florais: capuz (B), corte longitudinal da flor $(\mathrm{C})$, cálice e ovário $(\mathrm{D})$ e corte transversal do ovário $(\mathrm{E})$ de $C$. stellata a título de exemplo pois são muito semelhantes dentro do gênero (retirado de Flora Neotropica Monograph 21(II)). Parte inferior da figura: frutos e sementes de C. guianensis e C. multiflora (retirado de Memoirs of the NYBG, 75)

2. Distribuição geográfica de C. multiflora e C. guianensis (retirado de Flora Neotropica Monograph 21(II))

3. Localização das Reservas do Projeto Dinâmica Biológica dos Fragments Florestais (PDBFF) e as fazendas onde estão inseridas. Retirado de LOVEJOY \& BIERREGAARD, 1990.

4. Localização da Reserva 1501, "km 41", na Fazenda Esteio. Retirado de LOVEJOY \& BIERREGAARD, 1990

\section{RESULTADOS - ÍTEM 1.}

1. Distribuição espacial de adultos e jovens de $C$. guianensis e $C$. multiflora. $\mathrm{n}=$ número de individuos total

2. Pág. 50-55. Padrões isoenzimáticos, locos: A. Pág. 50: EST-1, interpretado somente para C. guianensis; B. Pág. 51: MDH-1 e MDH-3 interpretado para C. multiflora, e MDH-3 para C. guianensis; C. Pág. 52: PGI-1, interpretado para ambas espécies; D. Pág. 53: PGM-1 e PGM-2, interpretados para amabas espécies; E. Pág. 54: PO-1 e PO2 , interpretados para ambas espécies nos adultos e somente PO-2 para as progênies; F. Pág. 55: SKDH-1, interpretado para ambas espécies. 1 = géis e fotos de géis; $2=$ interpretações.

\section{RESULTADOS - ÍTEM 2}

1. Fenologia geral

2. Pluviosidade durante 1993 na Reserva 1501, $\mathrm{km} 41$

3. Fenologia de todos os indivíduos reprodutivos de C. multiflora em 1993. Quando das sobreposição de eventos fenológicos, botões-flor madura e frutos imaturomaduro, priorizou-se a representação de flores e frutos maduros. As árvores-mãe utilizadas nas análises do sistema reprodutivo estão apontadas por “*”.

4. A. Porcentagem de indivíduos conforme suas respostas reprodutivas e coleta com relação à população total observada $(n=39)$. B. Número de indivíduos quanto à 
sua resposta reprodutiva e produção de flores e frutos com relação à população total observada $(n=39)$. Alta = produção alta; baixa = produção baixa.

5. Distribuição espacial dos individuos de C. multiflora observados na fenologia e suas respostas reprodutivas.

6. Número (A) e porcentagem (B) de indivíduos que floresceram conforme classes de altura.

7. Número (A) e porcentagem (B) de indivíduos que floresceram conforme classes de DAP

8. Representação da estratificação da copa com relação à quantificação da produção de flores em porcentagem da população geral (A) e da presença e ausência de florescimento para número de individuos (B).

9. Respostas quanto ao florescimento dos individuos totais observados e somente daqueles que floresceram conforme a estratificação da copa para o número (A) e porcentagem $(\mathrm{B})$ de indivíduos

10. Representação da população em geral quanto à exposição de copa à luz. Total $=$ totalmente exposta; Parcial $=$ parcialmente exposta.

11. Relação entre exposição de copa à luz e produção de flores quanto à porcentagem de indivíduos (A) e no. de individuos $(\mathrm{B})$. Total = copa totalmente exposta Parcial $=$ parcialmente exposta

12. Método a. Gráfico A. no. de indivíduos sincrônicos por árvore (TOT1) e não sincrônicos ( $\mathrm{SO}$ ) por árvore; as árvores estão em ordem de florescimento. Gráfico B. Número de indivíduos sincrônicos para cada árvore conforme classe de sobreposição em dias. 1 dia $=$ TOT1; 15 dias = TOT15;30 dias = TOT30; 45 dias $=$ TOT $45 ; 60$ dias $=$ TOT60 $($ veja Tabela 3 e 4$)$.

13. Método b. Gráfico A. no. de individuos sincrônicos por árvore (TOT1) e não sincrônicos (SO) por árvore; as árvores estão em ordem de florescimento. Gráfico B. Número de indivíduos sincrônicos para cada árvore conforme classe de sobreposição em dias. 1 dia $=$ TOT $1 ; 15$ dias $=$ TOT $15 ; 30$ dias $=$ TOT30; 45 dias $=$ TOT $45 ; 60$ dias $=$ TOT $60($ veja Tabela 3 e 4$)$

14. Distância entre indivíduos com sobreposição de floração por data fenológica .......

15. Número de pais potenciais e número cumulativo deles para cada árvore em floração sincrônica. Densidade é dada por barras

16. Números de pais potenciais sincrônicos até $1000 \mathrm{~m}$ por data fenológica. 


\section{LISTA DE TABELAS}

\section{RESULTADOS}

\section{ÍTEM 1}

1 Resultados das análises da distribuição espacial. R, C e I = indices de agregação, explicados no texto, conforme método utilizado, vizinho-mai-próximo ou $T$ quadrado; $\mathrm{z}=$ teste da distribuição normal padrão para as significâncias dos índices; ${ }^{*}=\mathrm{P}<0.05 ;{ }^{* *}=\mathrm{P}<0.01$

2. Frequências alélicas, número de individuos analisados por loco $(\mathrm{N})$, número médio de indivíduos por loco, número de alelos e locos totais, número médio de alelos por loco $(\mathrm{A})$, número efetivo de alelos $(\mathrm{Ae})$, porcentagem de locos polimórficos $(\mathrm{P})$ para progênies, jovens, adultos e total (jovem + adulto) de $C$. multiflora e $C$. guianensis.

3. Teste qui-quadrado e exato de Fisher para os desvios do equilibrio de HardyWeinberg, considerando números observados (no) e esperados (ne) dos genótipos não agrupados ( $\chi^{2}$ nagr), ou agrupados ( $\chi^{2}$ agr) em 3 classes para adultos e progênies de $C$. multiflora e adultos e jovens de $C$. guianensis. Quando a coluna "classe ou genótipo"estiver representada por números individuais , $1,2 \mathrm{e} 3$, os no e ne mostrados correspondem a genótipos agrupados conforme classes 1, 2 e 3 (abaixo). Quando os números mostrados são compostos por 2 números separados por hífen, no e ne são genótipos não agrupados ou reais. $\mathrm{P}=$ probabilidade de teste..

4. Números observados (no) e esperados (ne) pelo EENW e teste $\chi 2$ para os desvios deste modelo para adultos e progênies de $C$. multiflora. Números em parênteses iguais aos graus de liberdade.

5. Heterozigosidades e índices de fixação de Wright para adultos, jovens e progêneis de C. multiflora eadultos e jovens de C. guianensis. Teste $\chi^{2}$ para testar a significância dos valores de $\mathrm{F}$

6. Variabilidade genética e índices de endogamia de adultos (Fad) e progênies (Fprog) para espécies arbóreas tropicais

ÍTEM 2

1. Produção de flores na população para altura e DAP e suas relações com a produção. Classes conforme Figuras 6 e 7. Prod. = produção 
2. Produção de frutos na população para altura e DAP e suas relações com a produção. A coluna " $\Sigma$ " inclui também as árvores que produziram frutos, mas não foram quantificadas quanto à quantidade alta e baixa. Classes conforme Figura $6 \mathrm{e}$ 7. Prod = produção

3. Método a. Máximo de dias em floração $(f)$ índices de sincronia (Xi), no. total de árvores sobrepondo-se em floração por 0 ( $\mathrm{S} 0$ - no. de individuos não-sincrônicos), 1 (S1), 15 (S15), 30 (S30), 45 (S45) e >60 (S60) dias e no. total de árvores sobrepondo-se por no mínimo 1 dia $($ TOT1 $=\mathrm{S} 1+\mathrm{S} 15+\mathrm{S} 30+\mathrm{S} 45+\mathrm{S} 60), 15$ (TOT15), 30 (TOT30), 45 (TOT45), 60 (TOT60). DP = desvio padrão; Q3 = quartil 3; med = mediana; $\mathrm{Q} 1=$ quartil 1.

4. Método b. Máximo de dias em floração $(f i)$ índices de sincronia Xi), no. total de árvores sobrepondo-se em floração por 0 (S0 - no. de individuos não-sincrônicos), 1 (S1), 15 (S15), 30 (S30), 45 (S45) e >60 (S60) dias e no. total de árvores sobrepondo-se por no mínimo 1 dia $($ TOT1 $=\mathrm{S} 1+\mathrm{S} 15+\mathrm{S} 30+\mathrm{S} 45+\mathrm{S} 60), 15$ (TOT15), 30 (TOT30), 45 (TOT45), 60 (TOT60). DP = desvio padrão; Q3 = quartil $3 ;$ med = mediana; $\mathrm{Q} 1=$ quartil 1

\section{I'TEM 3}

1. Testes para acasalamento aletório nas familias de mães com genótipos homozigotos idênticos através da homogeneidade de números de progênies heterozigotas. ns = não significativo

2 Frequências alélicas e testes $\chi 2$ para a verificação dos desvios do conjunto ("pool") polínico ao acasalamento aleatório populacional, utilizando $F_{\text {St }}$ e considerando as familias como subpopulações.

3. Estimativas das frequências alélicas atribuídas a pólen e óvulo nas progênies de 4 árvores de $C$. multiflora e testes $\chi 2$ de heterogeneidades das duas frequências contribuindo ao "pool' gênico de sementes.

4. Máximo de dias em floração (fi), índices de sincronia (XI), número total de árvores sobrepondo-se em floração até 1(S1), 15 (S15), 30 (S30), > 45 dias (S45) e número total de árvores sobrepondo-se por no mínimo 1 dia (TOT1 $=\mathrm{S} 1+\mathrm{S} 15+\mathrm{S} 30+\mathrm{S} 45$ ) para as 4 árvores desse estudo. Total de árvores possiveis de acompanhar toda a floração $=24 . \sim$ Fam $3=$ semelhante à familia 3.

5. Teste $\chi^{2}$ para verificação do ajuste aos valores esperados pelo modelo de acasalamento misto e taxas de cruzamento para as estimativas de unilocos $\left(\mathrm{t}_{\mathrm{S}}\right)$ na população e em cada familia, com os erros padrões em parênteses. 
6. Taxas médias de cruzamento unilocos (tsmédia) e taxas de cruzamento multilocos (tm) com diferentes combinações conforme ajuste ao modelo e convergência das iterações nas estimativas das probabilidades de verossimilhança; ep = erro padrão; $(p+t)$ : frequências alélicas de pólen e óvulo estimadas para o cálculo das estimativas de tm; $\sigma 2$ : variância esperada das estimativas de taxa de cruzamento multilocos entre familias.

7. Taxas de cruzamento multilocos $(\mathrm{tm})$ para famílias individuais com frequência de pólen constante $(\mathrm{p})$

9. Taxas de cruzamento multilocos (tm) de espécies tropicais; a presença de mais de um valor significa mais que uma população ou amostragem em tempos diferentes. $t_{\mathrm{eq}}=$ taxa de cruzamento de equilibrio ou aparente, calculada a partir dos valores de F; erro padrão entre parênteses 


\title{
ESTRUTURA GENÉTICA E FENOLOGIA DE ESPÉCIES RARAS DE Couratari spp. NA AMAZÔNIA CENTRAL.
}

\author{
Autor: Nadja Lepsch-Cunha \\ Orientador: Prof. Dr. Paulo Y. Kageyma
}

Resumo

Com o objetivo de quantificar a variação genética e o sistema reprodutivo de espécies arbóreas tropicais de baixa densidade e de discutir suas implicações quanto à conservação genética, estudamos uma população de cada uma das espécies, Couratari multiflora (J.E.Smith)Eyma e Couratari guianensis Aublet, ambas de baixa densidade na área de estudo, utilizando a técnica de eletroforese de isoenzimas. Somente $C$. multiflora foi estudada quanto ao sistema reprodutivo, por ter produzido sementes durante este trabalho. As populações estão localizadas em uma das reservas de mata contínua do Projeto Dinâmica Biológica dos Fragmentos Florestais, PDBFF, cerca de 100 km de Manaus, AM, Amazônia Central.

Na Revisão Bibliográfica da dissertação discutimos as diferentes formas de raridade na floresta tropical e incluimos cada uma das espécies em dois diferentes tipos de raridade: espécies que sempre apresentam-se com baixa densidade (C. multiflora) e espécies que ora são raras ora mais comuns, conforme sua distribuição geográfica (C. guianensis).

No Ítem 1 de Resultados tratamos da variabilidade genética intrapopulacional das duas espécies que resultou em: 1. A área total do levantamento compreendeu 385 ha, com 41 e 27 individuos considerados adultos continuamente mapeados de C. multiflora e C. guianensis, respectivamente. A marcação aleatória de 26 jovens da segunda espécie e a produção de frutos da primeira (progênies), permitiram a análise das estimativas da variabilidade genética dessas duas categorias, além dos adultos. 2. Foram analisados 7 ou 8 locos isoenzimáticos, conforme categoria de tamanho. 3. 0 número médio de alelos por loco das progênies e adultos de $C$. multiflora foram iguais a 3,57 e 3,25, o polimorfismo, 85,71 e $100 \%$, as heterozigosidades esperadas e observadas média iguais a 0,429-0,380 e 0,431-0,359, e os índices de fixação médios $\left(\mathrm{F}_{\mathrm{m}}\right), 0,114$ e 0,176, respectivamente conforme categoria. Para C. guianensis, jovens e adultos apresentaram estimativas iguais a 3.00 e 2,75 para o número médio de alelos por loco, $100 \%$ de polimorfismo para ambas categorias, as heterozigosidades esperadas e observadas médias iguais a $0,415-0,258$ e $0,420-0,203$, e os índices de fixação médios $\left(F_{m}\right)$ foram 0,377 e 0,518 , respectivamente. $O$ coeficiente de endogamia para $C$. guianensis e os valores da variação genética para ambas espécies foram altos quando comparados a outras espécies arbóreas tropicais. 
No İtem 2 de Resultados tratamos da fenologia reprodutiva e potencialidade de cruzamentos no tempo e espaço para C. multiflora. A floração foi longa (6 meses), com o pico durante a estação chuvosa e o da frutificação, durante a estação seca. Cerca de $70 \%$ das árvores adultas floresceram, mas somente $41 \%$ tiveram alta produção de flores, $46 \%$ frutificaram, $23 \%$ foram vistas com frutos maduros e somente $10 \%$ delas foram coletadas para 0 estudo do sistema reprodutivo devido à alta predação dos frutos por animais, com possibilidade de aborto de frutos imaturos. As medianas das distâncias de individuos sincrônicos ficaram entre 600-1000 m durante toda a floração e, dependendo do método de quantificação utilizado, as medianas do número de indivíduos sincrônicos por data fenológica resultaram em 14-17,5 individuos por um dia, 13 por 15 dias e 3-13 por 30 dias,. Em $50 \%$ dos casos, 6-7 indivíduos foram sincrônicos até $1000 \mathrm{~m}$, com esses valores permanecendo em geral constantes durante toda a floração.

No Ítem 3 de Resultados tratamos do sistema reprodutivo de $C$. multiflora resultando em uma taxa de cruzamento multilocos igual a $t_{m}=0,953(0,040)$ e a média dos locos individuais, $t_{s}=0,968(0,133)$, com um padrão de espécie alógama. A população em conjunto resulta de acasalamentos aleatórios, com apenas 2 dos 8 locos com desvios significativos do EHW. Não ocorreu heterogeneidade nas frequências de pólen e óvulo, no entanto, o "pool" de pólen foi diferenciado entre as familias. A partir do conjunto de resultados acima juntamente com os dados da fenologia, concluímos ser a representatividade pequena de árvores maternais (4) e a variação da época e duração de florescimento de cada árvore, com duas delas florescendo no final da floração, a causa dessa diferenciação.

A nivel de heterozigosidade esperada essas duas espécies são muito semelhantes, diferindo quanto à ocorrência de endogamia para $C$. guianensis. Os resultados sugerem que essas duas populações tenham histórias de vida diferentes, mas estão adaptadas à condição de baixa densidade. No caso de $C$. guianensis, isto é sugerido pela manutenção da alta heterozigosidade esperada e a ocorrência de endogamia, desta forma, espera-se que exista pouca carga genética e consequentemente maior adaptação a oscilações na densidade populacional. Para C. multiflora, as taxas de cruzamento próximas a um e as distâncias calculadas entre os indivíduos sincrônicos evidenciam vôo a longas distâncias pelos polinizadores, sendo que distâncias de $1000 \mathrm{~m}$ entre árvores não impede fluxo de pólen. Esses resultados confirmam que esta última espécie ajusta-se à categoria das espécies uniformemente raras e, neste caso, requerem grandes áreas para sua conservação. Para $C$. guianensis, há necessidade de se conhecer sobre seu sistema reprodutivo para maiores sugestões. Se o sistema reprodutivo estiver adaptado a cruzamentos a longas distâncias como $C$. multiflora, a espécie deve suportar mais estrangulamentos populacionais e/ou fragmentação, desde que a variabilidade seja mantida pela coneç̧ão de populações. 


\title{
GENETIC STRUCTURE AND PHENOLOGY OF RARE SPECIES OF Couratari spp. IN CENTRAL AMAZONIA.
}

\author{
Author: Nadja Lepsch-Cunha \\ Advisor: Paulo Y. Kageyama, Dr.
}

Summary

To quantify the genetic variation and the mating system of tropical low density tree species and to discuss their implications for genetic conservation, we studied one population of the species C. multiflora and one of the species Couratari guianensis Aublet, both of low densities in the study area, using isozymes eletrophoresis techniques. A mating system analysis was performed only for $C$. multiflora because only this species put seeds during the field work. The populations are located in the Reserve $1501, \mathrm{~km} \mathrm{41}$, belonging to the Biological Dynamics of Forest Fragments Project, BDFFP, about $100 \mathrm{~km}$ from Manaus, AM, Central Amazonia, Brazil.

In the Bibliographic Review we discussed the different types of rarity in the tropical rainforest and includes each species in two different types of rarity: species always occurring in low density (C. multiflora) and species occurring sometimes rarely and sometimes commonly, according to their geographic distribution (C. guianensis).

In the Item 1 of Results we discussed the genetic variability within population of these two species and the resuls are: 1 . The total census area comprised 385 ha, with 41 and 27 individuals considered adults and mapped continuously for C. multiflora and $C$. guianensis, respectively. The analysis of 26 random young trees of the second species and the seed progenies of the first one permitted the estimate of genetic variability parameters of these two categories, besides the adults. 2. Seven or eight isozyme loci were used, depending on the size category. 3. The mean number of alleles per locus of the progenies and adults of the $C$. multiflora were 3.57 and 3.25 , the percentage of polimorphic loci were 85.71 and $100 \%$, and the mean expected and observed heterozigosities were $0.429 / 0.380$ and $0.431 / 0.359$, respectively. The mean fixation indices $\left(F_{m}\right)$ for progenies and adults were respectively 0.114 and 0.176 and were not significantly different from zero. For $C$. guianensis, young and adult individuals presented equal estimates of 3.00 and 2.75 for the mean number of alleles for locus, $100 \%$ of polymorphic loci for both categories and the mean expected and observed heterozigosities were $0.415 / 0.258$ and $0.420 / 0.203$, respectively. The mean fixation indices $\left(F_{m}\right)$ for youngs and adults individuals were 0.377 and 0.518 , both significantly different from zero. Estimates of genetic variation for both 
species and inbreeding coefficient for $C$. guianensis were high when compared to other tropical tree species.

In the Item 3 of Results we discussed the reproductive phenology and the mating potential in time and space for C. multiflora. The flowering period was long (6 months), with the peak occurring during the rainy season and the fruiting occurring in the dry season. About $70 \%$ of the adult trees flowered, but only $41 \%$ had high production of flowers, $46 \%$ put fruits, $23 \%$ were seen with mature fruits and only from $10 \%$ could fruit be collected for the mating system study because of the high predation by animals and the possibility of abortion of immature fruits. The median of the distances of syncronic individuals were between $600-1000 \mathrm{~m}$ during all flowering, and depending on the method of quantification utilized, $50 \%$ of the individuals shared 14-17.5 syncronic individuals in one day, 13 individuals in 15 days and 3-13 individuals in 30 days. In $50 \%$ of the cases, 6-7 individuals were syncronic until $1000 \mathrm{~m}$, with these values remaining constant during all flowering period.

In the Item 3 of Results we showed the following results: a multilocos outcrossing rate for $C$. multiflora $\mathrm{t}_{\mathrm{m}}$ of $0.953(0.040)$ and a mean single locus outcrossing rate $\mathrm{t}_{\mathrm{s}}=$ $0.968(0.133)$, indicating an preferentially alogamous species. The population presents random outcrossing, with only 2 of 8 loci with significant deviations from HWE. There are no pollen and ovule frequency heterogeneity, however, the pollen pool was different between families. These results together, jointly with the phenology data suggests the cause of that differentiation is the low number of mother trees (4) and the variaton of flowering period and lenght of each tree, with two of them flowering by the end of the period.

The expected heterozigosities of the populations of these two species are very similar and they differ by the occurrence of inbreeding in C. guianensis. This result suggests that despite of the fact that these two populations have different life histories, they are adapted to the condition of low density. In the case of $C$. guianensis this is suggested by the maintenance of high expected heterozigosity and the occurrence of inbreeding, thus, it is expected that there is low genetic load and consequentely better adaptation to oscillation of the populational density. For $C$. multiflora, the outcrossing rates next to unit and the distances calculated between syncronic individuals shows that pollinator fly long distances and the distances of $1000 \mathrm{~m}$ between trees do not avoid the pollen flow. These results confirm that $C$. multiflora falls into the category of uniformely rare species and, in this case, it needs large areas for its conservation. For $C$. guianensis, there is the necessity of to know the mating system for better suggestions. If the breeding system is adapted to crosses at long distances as $C$. multiflora, the species could support more bottlenecks and/or fragmentation, since the variability would be maintained by conections between populations. 


\section{INTRODUÇÃO}

A percepção de que nenhuma comunidade possui espécies igualmente comuns e a observação generalizada de que poucas espécies são abundantes, outras moderadamente abundantes e a maioria representada por somente poucos indivíduos, levaram ao desenvolvimento de modelos de abundância de espécies (PRESTON, 1962; MAY, 1975; 1981; SOUTHWOOD, 1978; FISHER et al., 1943). A partir desses modelos, novos conceitos foram elaborados, como o de diversidade, que considera no seu cálculo a abundância relativa das espécies (equitabilidade), além do parâmetro riqueza (número de espécies), mais utilizado anteriormente nas comparações entre localidades ou comunidades.

Conforme MAGURRAN (1988), a diversidade é geralmente examinada em relação a 4 modelos de abundância de espécies principais, que são caracterizados a partir da distribuição log-normal, da série geométrica, da série logarítmica e do modelo "broken-stick". Estas distribuições representam uma progressão da relação dominância/raridade, partindo da série geométrica, cujas espécies dominantes são poucas e a maioria delas é comum (poucas espécies), passando através das log-séries e log-normal, cujas espécies de abundância intermediária são as mais comuns, finalizando com o modelo de "broken-stick" cujas espécies são igualmente representadas, este último nunca observado na natureza.

PRESTON (1962) descreveu a distribuição log-normal canônica e mostrou que poucas espécies contém um número relativamente elevado de indivíduos. MAGURRAN (1988) cita que apesar das muitas discordâncias quanto ao valor dessa distribuição, principalmente a de MAY (1975), o qual notou a possibilidade da distribuição simplesmente responder a propriedades estatísticas de números grandes, como consequêencia do teorema do limite central, a maioria das comunidades estudadas por ecologistas mostra um padrão de abundância de espécies log-normal, indicando comunidade grande, natural, variada e madura. Este último autor posteriormente notou que comunidades estáveis em equilibrio seguem um padrão log-normal de abundância de espécies, e quando uma comunidade madura torna-se poluída (perturbada), sua distribuição de abundância de espécies muda em direção a uma distribuição menos equitável, como a série-log ou geométrica. Conclui MAGURRAN (1988), que parece provável que a log-normal permaneça uma importante ferramenta nos estudos de diversidade e sua constância ou desvios podem indicar predições sob o comportamento das comunidades. 
A conclusão de que a maioria das comunidades naturais seguem uma distribuição log-normal implica que estas apresentam espécies raras constantemente, além das intermediárias e comuns. As comunidades de florestas tropicais e os corais de recife têm sido caracterizados pelo seus altos valores de diversidade e raridade quando comparados a outras comunidades (JANZEN, 1970; CONNELL, 1971, 1973; GENTRY, 1986; 1989; 1990; HUBBELL \& FOSTER, 1986, 1990a; MYERS, 1986; RANKIN-DE-MERONA \& ACKERLY, 1987, 1990; KAGEYAMA \& GANDARA, 1993). Por essas considerações, deve ficar claro que raridade é uma característica geral de comunidades maduras e não uma peculiaridade daquelas tropicais.

BAWA \& ASHTON (1991) observaram que não existem evidências quanto aos ecossistemas tropicais florestais diferirem qualitativamente de outros mas, preferencialmente, manifestam extremos de alguns fenômenos de ecossistemas: extraordinária riqueza de espécies e, consequentemente, essas espécies têm menores densidades populacionais que as espécies arbóreas de florestas temperadas, já que o espaço é finito. Exemplificando, o padrão da distribuição de abundância de espécies arbóreas em 50 ha na floresta tropical da Ilha de Barro Colorado, Panamá, apresentou a área esquerda da curva de distribuição de abundância (espécies raras) bem maior do que esperado pelo modelo log-normal, em consequiência do excesso de espécies raras (HUBBELL \& FOSTER, 1986).

Além dos padrões de distribuição de abundância de espécies na maioria das áreas tropicais não terem sido bem documentados, o número de espécies por unidade de área é tão grande que novas espécies continuam a ser descobertas sempre nas áreas mais intensivamente estudadas (BAWA \& ASHTON, 1991). Alguns exemplos são: RANKIN-DEMERONA \& ACKERLY (1987), na Amazônia Central (PDBFF), com um terço das famílias encontradas em 31 ha representadas na sua maioria somente por uma árvore ( $\geq 10,0 \mathrm{~cm}$ DAP); HUBBELL \& FOSTER (1986), no Panamá, com um terço de todas as espécies contribuindo menos de $1 \%$ do número total de plantas $(\geq 1,0 \mathrm{~cm}$ DAP) e citam que a similaridade da comunidade diminui cerca da metade dentro de somente 200 metros com relação a qualquer ponto; ASHTON (1984), no sudeste da Ásia, e HARTSHORN (1980), em La Selva - Costa Rica, obtiveram resultados semelhantes; Poor ${ }^{1}$ (1968, cit. em BAWA \& ASHTON, 1991), na Malásia, encontrou em amostra de 22,3 ha ( $\geq 28,0 \mathrm{~cm}$ DAP), que $38 \%$ das espécies foram representadas somente uma vez. A mesma situação ocorre na Floresta Atlântica como mostra KAGEYAMA et al. (nao publicado) para vários levantamentos botânicos no Estado de São

\footnotetext{
1 POORE, M.E.D. Studies in Malaysian rain forest. 1. The forest on the Triassic sediments in Jengka Forest Reserv. J. Ecol., 56:143196,1968
} 
Paulo. Dos levantamentos amostrados, 30\% das espécies são raras, e somente $4 \%$ dos indivíduos pertencem a elas. Ao mesmo tempo, 30\% do indivíduos totais pertencem somente a 3 das espécies mais comuns.

Concluindo, a tentativa de compreensão da manutenção da diversidade nos trópicos e da distribuição de abundância de suas espécies difere de outras comunidades pela presença marcante da raridade. No entanto, raridade tem mais do que um significado como será mostrado em seguida.

Duas hipóteses têm sido apontadas para a explicação da diversidade alta de espécies arbóreas na floresta tropical: a de FEDOROV (1966) que postula que esta alta diversidade é produto de especiação não adaptativa resultante de endogamia e deriva genética. Esses dois fenômenos seriam o resultado da baixa densidade de conspecíficos e das espécies serem principalmente autopolinizadas. Esta hipótese "não adaptativa" assume que a estrutura genética de árvores tropicais é caracterizada por endogamia alta (altos índices de fixação), tamanhos populacionais pequenos e diferenciação genética espacial (EGUIARTE et al., 1992). A hipótese alternativa de "equilibrio/micronichos", originariamente proposta por DOBZHANSKI (1950), assume que a diversidade arbórea tropical resulta de adaptação das populações arbóreas a nichos muito específicos definidos tanto para componentes bióticos como abióticos (CONNELL, 1973, 1978; JANZEN, 1970; DENSLOW, 1987).

Conforme EGUIARTE et al. (1992), a estrutura genética de populações de árvores impõem limitações a estratégias de manejo e conservação. Se árvores tropicais geralmente ocorrem em populações pequenas endogâmicas como a hipótese não adaptativa prediz, então as espécies poderiam ser preservadas com poucos indivíduos de cada população vindos de muitas diferentes populações e a preservação ex situ seria prática e possível (Frankel \& Soulé, $1981^{2}$; Eguiarte \& Piñero, $1990^{3}$ ). Contrariamente, se árvores tropicais apresentam tamanhos populacionais efetivos grandes e endogamia baixa, como a hipótese de micronicho sugere, então, os efeitos deletérios de manter populações pequenas deverá ser severo a curto prazo, devido à depressão endogâmica, e a longo prazo, devido à deriva genética (Franklin, $1980^{4}$ ). Se esta última hipótese for a verdadeira, propostas de conservação viáveis devem contemplar a manutenção de reservas ecológicas grandes e a conservação ex situ torna-se impossível.

\footnotetext{
${ }^{2}$ Citado na bibliografia geral;

3 EGUIARTE, L.E. \& PIÑERO, D. Genética de la conservación: leones vemos, genes no sabemos. Ciencias, Número especial, 4:3437, 1990.

${ }^{4}$ Citado na bibliografia geral;
} 


\section{OBJETIVOS DA DISSERTAÇÃO}

Nosso objetivo geral foi quantificar a variação genética e o sistema reprodutivo de espécies arbóreas de baixa densidade em floresta tropical e discutir as implicações das estimativas desses valores com relação à conservação genética. Mais especificamente, comparar essas quantidades com espécies de mesmo gênero e características ecológicas muito próximas, porém com tendências populacionais diferenciadas: Couratari multiflora (J.E. Smith)Eyma, registrada como espécie de baixa densidade em toda sua extensão e C. guianensis, com densidades oscilantes em sua extensão geográfica. Estudamos o sistema reprodutivo somente de $C$. multiflora, por esta ter produzido sementes durante o trabalho de campo. Com o objetivo de calcular as distâncias entre os pais potenciais e o número potencial deles ao cruzamento, fizemos o acompanhamento fenológico da reprodução (produção de flores e frutos) de indivíduos contínuos na área de estudo desta última espécie.

\section{REVISÃO BIBLIOGRÁFICA}

\section{RARIDADE}

O conceito de raridade, nos meios mais leigos e muitas vezes até mesmo nos mais especializados, é confundido com outras categorias de espécies ameaçadas de extinção. O "Red Data Book", da FAO (1981), distingue 4 categorias de espécies ameaçadas: extintas (espécies não mais encontradas), ameaçadas (sobrevivência improvável se fatores causais continuem operando), vulneráveis (próximos à categoria anterior se fatores causais continuem operando) e as raras (em risco ou por habitarem áreas geográficas/habitat restritos ou os indivíduos são escassamente dispersados sobre um ampla extensão). Outras publicações de contexto conservacionista seguem em geral esses dois aspectos de raridade (REID \& MILLER, 1989): endêmica ou esparsa.

A noção de raridade está fundada, então, em duas causas diferentes, apesar de algumas vezes elas se confudirem: a primeira que reflete padrões geográficos naturais de distribuição (endemismos) e padrões naturais de densidade populacional (baixa densidade) e a segunda, que reflete alteração recente, em geral ocasionada pela destruição de habitat ou utilização de recursos pelo homem. Algumas vezes, é suposto que as "naturalmente" raras estão 
em "fim de linha", seja do ponto de vista geo-evolucionário (não adaptadas a condições atuais do ambiente ou clima - baixa densidade) ou são especializadas a ambientes atualmente restritos que tendem a desaparecer (taxa mais antigos ou relíquias - endemismos).

Conforme RABINOWITZ et al. (1986), a falta de precisão do conceito de raridade obscurece a biologia de um grupo muito heterogêneo de organismos, e antes de efetivamente proteger espécies raras, há a necessidade do entendimento dos tipos de raridade que existem e como as espécies raras diferem umas das outras. Essas espécies podem ocorrer somente em habitats raros, podem estar muito localizadas em uma pequena área, ou podem conter poucos indivíduos. Assim, as autoras distinguem 3 características classificatórias que todas as espécies possuem: 1. extensão geográfica: se uma espécie ocorre sobre uma ampla área ou se ela é endêmica a uma área particular; 2. especificidade de habitat: o grau em que uma espécie ocorre em uma variedade de habitats ou em que é restrita a um ou poucos sítios especializados; 3. tamanho populacional local: se uma espécie é encontrada em grandes populações em qualquer lugar dentro de sua extensão ou tem pequenas populações aonde quer que a encontremos. Elas dicotomizaram essas 3 características dentro de uma tabela $2 \times 2 \times 2$, resultando em uma célula somente para as espécies comuns com as células restantes representando 7 tipos diferentes de raridade. Através de informações detalhadas fornecidas por ecologistas e sistematas, elas obtiveram a seguinte tabela mostrada abaixo, resultado da análise de 160 espécies nativas bem definidas na flora das Ilhas Britânicas sem ambiguidade de critérios:

\begin{tabular}{l|cccc}
\hline Distribuição geográfica & Ampla & \multicolumn{3}{|c}{ Estreita } \\
\hline Especificidade de habitat & Generalista & Restritiva & Generalista & Restritiva \\
\hline Tamanho populacional local & & & & \\
Grande em algum lugar & 58 & 71 & 6 & 14 \\
Pequeno em todo local & 2 & 6 & 0 & 3 \\
\hline
\end{tabular}

Tabela: retirada de RABINOWITZ et al.. 1986.

Extensão geográfica, especificidade de habitat e tamanho populacional local resultaram em variáveis independentes e, segundo as autoras, esta conclusão contradiz pontos de vista de muitos ecologistas que assumem que generalistas são amplamente distribuídas e que abundância é positivamente relacionada com extensão geográfica. Existe uma aparente mas não real contradição com a generalização ecológica da distribuição log-normal de abundância de espécies, já que dentro de um único sítio poucas espécies têm populações grandes, sendo a maioria delas representadas por somente poucos indivíduos. Dessa forma, a 
maioria das espécies localmente é rara e os resultados dizem que a maioria das espécies é comum em algum lugar dentro de suas extensões. Espécies com ampla distribuição geográfica, habitats restritivos e tamanhos populacionais locais grandes pertecem à categoria mais numerosa (71) e podem ser muito numerosas na Inglaterra devido à longa costa e predominância de espécies marítimas.

\subsection{RARIDADE NA FLORESTA TROPICAL}

Não existem dados comparáveis para florestas tropicais (BAWA \& ASHTON, 1991), com exceção, em escala regional e não geográfica, da parcela de 50 ha na Ilha de Barro Colorado (IBC), Panamá. HUBBELL \& FOSTER (1986) analisaram a abundância de espécies arbóreas nesta ilha, com particular ênfase na raridade e "comunicidade" das espécies, relacionando a abundância de espécies arbóreas com especificidade de habitat e requerimentos de regeneração em clareiras. Suas conclusões parecem diferir daquelas de RABINOWITIZ et al.. (1986), mas os resultados contrastantes podem ser devidos a diferenças na escala espacial dos dois estudos.

Podemos perguntar como as comunidades de florestas tropicais responderiam a uma tabela como esta mostrada anteriormente. Opostamente às florestas tropicais, deve-se considerar que as Ilhas Britânicas têm uma flora depauperada e baixos níveis de endemismos. As autoras recomendam que raridade deve ser considerada sob uma variedade de escalas espaciais e em particular em amostras delimitadas versus censos "globais", assim que "status" de raridade de uma espécie pode mudar conforme se amplia sua extensão geográfica. Nos trópicos esse problema é complicado já que frequentemente nem sequer sabemos quais as espécies presentes e muito menos se são raras ou abundantes, ou seja, não há conhecimento básico da biologia de população local e biogeografia regional (HUBBELL \& FOSTER, 1986).

Para responder a essas questões, entre outras, HUBBELL \& FOSTER (1986) levantaram uma área de $50 \mathrm{ha}$, em IBC, onde todos os indivíduos acima de $1.0 \mathrm{~cm}$ de DAP foram mapeados e identificados. Essa grande parcela foi justificada pela necessidade de se obter amostras populacionais adequadas para a determinação do padrão de dispersão, demografia e requerimentos de regeneração de espécies raras, podendo-se então tratar as consequências da raridade das espécies arbóreas tropicais. Definindo espécies raras como aquelas com densidade média de menos de 1 indivíduo por ha (menos de 50 inds na parcela toda) encontraram que um terço das espécies estão dentro desta categoria e mais de $1 / 5$ de todas as espécies tem menos de 10 indivíduos em toda a parcela. Coletivamente a terça parte das mais raras é somente $0,6 \%$ das plantas na parcela e somente 22 espécies de dossel alcançaram 
densidades médias de mais de 1 indivíduo adulto por ha. As 303 espécies totais mostraram abundâncias muito desiguais, concluindo os autores (1992) que se as espécies raras forem ignoradas, a floresta torna-se taxonomicamente simples. Dividindo a comunidade em formas de crescimento, somente uma espécie constitui mais da metade dos arbustos, 2 espécies mais da metade das arvoretas do subbosque, 9 espécies mais da metade das árvores do subdossel, e 6 espécies mais da metade das árvores de dossel, com um total de 18 espécies. Cerca de $90 \%$ dos indivíduos de cada forma de crescimento correspondem a 9 espécies de arbustos, 16 arvoretas, 32 árvores de subdossel e 29 de dossel, totalizando somente 78 espécies, ou $1 / 4$ (25,7\%) do total de espécies na parcela. Focalizando as raras, $1 \%$ dos indivíduos são representados por 34 espécies de arbustos, 25 arvoretas, 21 árvores de subdossel e 44 de dossel. Os padrões de abundância relativa de espécies não foram os mesmos entre plantas de diferentes formas de crescimento. Existe maior dominância nas comunidades de subbosque e arvoretas de subbosque do que nas comunidades de árvores de subdossel e dossel. Entretanto, as comunidades de arbustos e de dossel tiveram um número maior e porcentagem maior de espécies raras.

De 239 espécies avaliadas, a metade (120) exibiu correlações significativas de habitat com características edáficas e topográficas, sendo as restantes indiferentes à variação do habitat. Para muitas espécies comuns a indiferença de habitat teve poder estatístico, mas não é possível dizer que qualquer espécie comum é indiferente ao habitat. Existe um grande grupo de espécies cujas arvoretas distribuíram-se indistintamente com respeito à clareira nova, velha e subbosque de fase madura (de 239 espécies, 98 ou $41 \%$ ), sendo aí incluídas novamente as espécies mais comuns (HUBBELL \& FOSTER, 1990b). Eles encontraram que a maioria das espécies raras são heliófilas extremas, muito poucas indiferentes generalistas, muitas são especializadas em igarapés, pântanos e locais mais úmidos, todos habitats raros dentro da parcela. Poucas dessas espécies foram especializadas a habitats mais abundantes dentro da parcela, tais como terra plana (plateau). O quadro para especialização de habitat é menos claro do que os nichos de regeneração, pois existem fracamente mais generalistas de habitat do que esperado entre as espécies raras. Embora muitas espécies comuns sejam generalistas e muitas raras especialistas, generalistas raras existem.

BAWA \& ASHTON (1991) numa tentativa de comparar as florestas tropicais com a classificação da tabela acima, distinguiram 4 tipos de raridade generalizados:

1. Espécies que são uniformemente raras: tais espécies tipicamente ocorrem em densidades populacionais pequenas com uma média de um indivíduo maduro ou menos por ha. Exemplo: espécies pioneiras como nos gêneros Bombax, Ceiba, Pajanelia, Oroxylum e espécies emergentes como Durio, Coelostegia. Essas espécies geralmente têm 
mecanismos de dispersão à longa distância de semente e pólen, como é o caso dos 4 gêneros acima, polinizados por morcegos e com sementes dispersadas pelo vento, com exceção a Durio, por mamíferos.

2. Espécies que são comuns em alguns locais mas raras entre eles: as áreas nas quais uma espécie é comum pode servir de "fonte" para propágulos que estabelecem-se em habitats "escoadouros" ( $\operatorname{sink)}$ onde a espécie não é abundante. Muitas espécies nas florestas tropicais em um dado sítio podem ajustar-se a esta categoria.

3. Espécies que são localmente endêmicas: em geral essas plantas são abundantes onde ocorrem e são representadas por muitas formas de vida: epífita, ervas rasteiras, em menor quantidade arbustos.

4. Espécies que são agrupadas, algumas vezes podem ocorrer em altas densidades, mas com densidade da população total muito baixa, tornando as populações fragmentadas dentro de ilhas de vários tamanhos. Os agrupamentos podem ser muito grandes, lembrando a categoria 2 ou, em outro extremo, ser muito pequeno, consistindo de poucos indivíduos.

Assim, a raridade é influenciada por 3 aspectos da distribuição espacial: se a extensão geográfica é ampla ou estreita, se a extensão ecológica é ampla ou estreita, e se as populações sempre existem em densidade efetiva baixa através de suas extensões geográficas. Neste último aspecto, a influência das atividades econômicas humanas seja eliminando ou explorando seletivamente as espécies arbóreas tropicais, pode ocasionar mudanças no comportamento natural das populações.

Considerando a grande riqueza de espécies da Floresta Tropical aliada à presença relativamente maior de espécies raras que outras comunidades, do ponto de vista teórico, podemos querer compreender como tantas espécies são mantidas, se é estática ou não essa manutenção, e o quão reguladas e complexas são as interações abiótica e biótica. De um ponto de vista pragmático, podemos querer compreender o quanto uma comunidade desse tipo suporta de perturbação, seja através da mudança da dimensão de seu tamanho, da mudança de suas características abióticas e da extinção de suas espécies e/ou colonização por outras novas. Neste último aspecto, são as espécies raras importantes na manutenção da estrutura da comunidade ou são somente uma contribuição a mais no número de espécies? São espécies que naturalmente tendem a se extinguir ou ampliar suas populações? São elas não adaptadas à condição de mata madura ou são espécies "ciganas"? Com referência a RABINOWITIZ et al.(1986), quais tipos de raras são mais representadas nas comunidades naturais tropicais? 
A discussão sobre complexidade e estabilidade de comunidades data de décadas passadas. Elton (1958) ${ }^{5}$, MacArthur $(1957)^{6}$, Margalef $(1968)^{7}$ e Hutchinson (19598; todos cit. PIMM, 1986) afirmaram que "comunidades mais complexas são mais prováveis de serem estáveis". Dessa forma, o objetivo em conservação é manter a complexidade, sendo que as consequências da simplificação podem resultar em instabilidade, perdas de espécies e posterior simplicação. Argumentos teóricos do tipo "modelos mais complexos flutuam menos e modelos mais simples são caracterizados por oscilações" (Elton, 1958) bem como "mais caminhos para a energia alcançar o consumidor, menos severa seriam as consequências na falha de qualquer caminho" (MacArthur, 1957) foram debatidos amplamente. De acordo com PIMM (1986), esses argumentos foram heterogêneos e incompletos, mas apontaram muitas questões a serem respondidas. Esses estudos usaram "estabilidade" significando no mínimo 4 abordagens diferentes: resiliência (quanto rápido variáveis retornam ao equilíbrio após perturbação), persistência (o tempo em que uma variável resiste antes de ser mudada a um novo valor), resistência ( o grau em que um sistema não é alterado por uma perturbação) e variabilidade (a variância, ou medidas similares, da densidade populacional). Apesar dos modelos utilizados gerarem diferentes respostas quanto à manutenção da estabilidade com relação à perda de espécies e adição de outras novas, o autor resume: a alta taxa de perda de espécies em ilhas, as taxas de sucesso de espécies alienígenas sobre ilhas, e seus ocasionais efeitos destrutivos são todos consequências prováveis de riqueza baixa de espécies; riqueza baixa de espécies é o ponto final mais provável para muitas comunidades continentais.

Como apontado por HUBBELL \& FOSTER (1991) e CONDIT et al. (1992a), a dificuldade de entendimento da manutenção da diversidade lenhosa nas florestas tropicais não é devida à falta de teorias, pois existem muitas, incluindo a hipótese de regeneração de nichos (Grubb, 1977) ${ }^{9}$, o modelo de loteria (Chesson \& Warner, 1981) ${ }^{10}$, a hipótese de perturbação intermediária (Connell, 1979) ${ }^{11}$, a hipótese da heterogenidade de recursos (Tilman, 1982) ${ }^{12}$, modelo de Janzen-Connell (Janzen, 197013; Connell 1971 14)

\footnotetext{
5 ELTON, C.S. The ecology of invasions by animals and plants. Chapman and Hall, London. 1958.

6 MACARTHUR, R.H. Fluctuations of animal populations and a measure of community stability. Ecology, 36:533-36, 1957.

7 MARGALEF, R. Perspectives in Ecological Theory. University of Chicago Press, Chicago, 1968

8 HUTCHINSON, G.E. Homage to Santa Rosalia, or why are there so many kinds of animals? American Naturalist, 93:145-159, 1959.

${ }^{9}$ GRUBB, P. The maintenance of species richness in plant communities: the importance of the regeneration niche. Biological Reviews of the Cambridge Philosophical Society, 52:107-145, 1977.

10 CHESSON, P.L. \& WARNER, R.R. Environmental variability promotes coexistence inlottery competitive systems. American Naturalist, 117:923-43, 1981.

11 CONNELL, J.H. Tropical rain forests snd coral reefs as open nonequilibrium systems. In: ANDERSON, R.M; TURNER, B.D.; TAYLOR, L.R., eds., Population dynamics. Blackwell Scientific, Oxford. 1979, p.141-163.

12 TILMAN, D. Resource competition and community structure. Princeton University Press, Princeton, N.J. 1982.

13 Citado na bibliografia geral;

14 Citado na bibliografia geral;
} 
chamado de hipótese de mortalidade compensatória (Condit et al.., 1992b) 15 ou hipótese de escape (Howe \& Smallwood, 1982) ${ }^{16}$, sendo que cada um desses modelos ou hipóteses postulam que existem forças de equilíbrio que mantém uma mistura particular de espécies. Modelos alternativos, hipótese da mudança climática gradual (Connell, 197817; Davis 198618) e hipótese de deriva da comunidade (Hubbell, 197919; Hubbell \& Foster, 198620), postulam que não existem forças de equilíbrio, ou elas são fracas, e as taxas de extinção local baixas são balanceadas por especiação e imigração. Todas as hipóteses têm o seu mérito, mas atualmente não existem dados disponíveis para determinar quais são importantes em qualquer floresta particular (CONDIT et al., 1992a).

Segundo HUBBELL \& FOSTER (1990b), a questão do "status" de equilíbrio ou não equilíbrio das florestas tropicais é de interesse prático para conservacionistas e manejadores de florestas. Se estandes locais de florestas representam comunidades estabilizadas bioticamente em ou próximas ao equilibrio, então a conservação e o manejo dessas florestas será uma tarefa diferente e muito mais fácil do que se elas estiverem em agrupamentos de espécies em não-equilíbrio, derivando continuamente em composição florística no tempo e espaço. Por equilibrio eles entendem um agrupamento particular de espécies arbóreas que tem estabilidade coletiva, de tal forma que a mistura de espécies tende a retornar a sua composição original se perturbada. Isto em geral implica que o crescimento populacional de cada espécie é limitado por fatores dependentes da frequência e densidade que previne-as de dominarem a comunidade completamente. Por não equilíbrio, eles se referem a uma comunidade que carece dessa estabilidade, e na qual mudanças na composição de espécies são o resultado de eventos biogeográficos e históricos únicos.

HUBBELL \& FOSTER (1986, 1992) e CONDIT et al. (1992b) discutem que a distinção entre essas alternativas requer a compreensão dos processos que determinam a abundância relativa das espécies arbóreas nestas florestas. Apesar da questão da floresta estar ou não em equilíbrio pode parecer esotérica, por outro lado, a resposta a esta questão é importante para o manejo sustentável. Se as florestas estão próximas ao equilíbrio, então esperar-se-ia que as abundâncias de espécies permanecessem relativamente constantes. Já, se a florestas tropicais estão em um agrupamento de não equilibrio, continuamente mudando em

15 Citado na bibliografia geral;

16 HOWE. H.F. \& SMALLWOOD, J. Ecology of seed dispersal. Annual Review of Ecology and Systematics, 13:201-228, 1982.

17 Citado na bibliografia gerai;

18 DAVIS, M.B. Climatic instability, time lags, and community disequilibrium. In: DIAMOND, J. \& CASE. T.J., eds., Community Ecology. Harper \& Row, New York. 1986, p.269-284.

19 HUBBELL. S.P. Tree dispersion, abundance, and diversity in a tropical dry forest. Science, 203:1299-1309, 1979.

20 HUBBELL. S.P. \& FOSTER, R.B. Biology, chance, and the history and structure of tropical rain forest tree communities. In: DIAMOND, J.\& CASE, T.J., eds., Community Ecology. Harper \& Row, New York. 1986, p.314-329, 1986. 
espécies e mudando rapidamente em resposta à mudança climática e distúrbios antropogênicos, então a conservação e estratégias de manejo serão diferentes do que se as florestas forem fortemente estabilizadas por interações bióticas. Se espécies correntemente comuns mostram sucesso reprodutivo per capita menor do que as espécies menos comuns, então ter-se-ia evidência para a estabilidade da dependência da densidade e frequência requerida para as hipóteses de equilíbrio. Neste caso, se a comunidade é perturbada, a sucessão de espécies seguindo perturbação deve ser razoavelmente previsível, e a mistura original de espécies deveria ser aproximadamente, se não exatamente, restaurada.

Entretanto, como colocado pelos autores mais tarde (HUBBELL \& FOSTER, 1992a; CONDIT et al.., 1992b), a maioria dos ecologistas agora reconhecem que o "status" de estabilidade e equilíbrio de comunidades ecológicas não pode ser significativamente discutido sem referência a uma escala temporal e espacial definida, pois a mudança na comunidade é inevitavelmente contínua e dependente da escala. Nenhuma comunidade de espécies alcança um equilíbrio estático. Espécies continuamente aumentam e declinam em abundância relativa; elas extinguem-se localmente e reimigram. Essas mudanças são devidas a forças exógenas (clima, geologia e atuação antrópica) da comunidade e mudanças endógenas ecológicas e evolucionárias. Ao mesmo tempo, diversidade alta de espécies nas comunidades tropicais arbóreas não necessariamente implica em dinâmicas e regras complexas.

Muitos são os trabalhos publicados pelo grupo de Hubbell \& Foster, com 3 censos na parcela de 50 ha $(1983,1985,1990)$ analisados e publicados, além de trabalhos que testam a dependência da densidade e da vizinhança, entre outros (além dos já citados, veja WELDEN et al.., 1991; CONDIT et al.., 1992a; HUBBELL \& FOSTER, 1994). No entanto, cabe indicar que generalizações quanto às espécies raras ainda não podem ser traçadas, considerando a não delimitação dos diferentes tipos de raridade apontados acima, a constatação que 50 ha é pouco para detectar padrões nessas espécies, a necessidade de estudos em espaços maiores de tempo, em consequência da reprodução supra-anual e em surtos de várias dessas espécies, além da falta de estudos em escala maior, geográfica.

GENTRY (1982) baseado em tabulações de distribuições de espécies neotropicais, mostrou que a grande maioria delas (71\%) caem dentro de 2 grupos bem definidos por categorias habitat-fitogeográfica: 1. taxa que são predominantemente árvores de dossel e lianas e, sem exceção, têm distribuição e centros de diversidade amazônicos; ou 2. taxa que são predominantemente epifitas, arbustos ou ervas do tipo-palmeto e têm fundamentalmente centros de diversidade extra-amazônicos. GENTRY (1986) exemplifica, a partir de divisão dos Neotrópicos em 10 regiões fitogeográficas sugerida por ele (1982), que $44 \%$ de todas as 
espécies fundamentalmente arborescentes ou famílias lianescentes são encontradas na Amazônia quando comparadas com 16\% na costa brasileira, 15\% na América Central e menos de $12 \%$ em outras regiões. Entretanto, $80 \%$ dessas espécies de ocorrência amazônica são endêmicas quando comparadas a $42 \%$ de endemismos nesses grupos na América Central. $\mathrm{O}$ padrão geral da representação extra-amazônica desses grupos, no mínimo na América Central, consiste essencialmente daquelas poucas (ca 20\%) espécies amazônicas que são mais amplamente espalhadas do que seus congêneres e, neste contexto, deve ser notado que a taxonomia de taxa lenhosos neotropicais não pode ser feita em uma base regional. Segundo o autor, claramente as florestas úmidas da América Central de terras baixas refletem recente migração em direção ao norte por espécies essencialmente amazônicas de gêneros e famílias da América do Sul. Ele exemplifica este último aspecto através do padrão de especiação de Bignoniaceae, onde uma única espécie de ampla-extensão, dispersada pelo vento, deu origem a 3 derivações dispersadas pela água e especialistas edáficas. A evolução dessa família parece ser tal diferenciação de espécies derivadas em habitats "marginais" e especializados, contrastando com a América Central que carece de especialistas de habitat.

Mais tarde, GENTRY (1990) editou "Four Neotropical Rainforests" e traçou similaridades e diferenças entre 4 diferentes sitios de floresta tropical: dois sítios na América Central, um na costa do Atlântico (La Selva-Costa Rica), floresta tropical úmida praticamente sem estação seca, e o outro do lado mais seco do Pacífico, IBC, com floresta tropical úmida e forte estação seca; dois sítios amazônicos, um na região de solos pobres do escudo guianense ( Amazônia Central-Manaus), e o outro próximo a base dos Andes (Cocha Cachu) com solos férteis aluvionais. Ele discute a existência realmente muito maior de espécies arbóreas na Amazônia, com sua ausência compensada na América Central por mais tipos de epífitas, ervas e arbustos. A Ilha de Barro Colorado é caracterizada pela sub-representação de muitas famílias como Lauraceae, Annonaceae e Sapotaceae, bem representadas nos outros sítios. Existe um complemento de epífitas, mas diferentemente de La Selva, há uma falta de taxa de árvores (quando comparado com a Amazônia) e o sítio é floristicamente empobrecido. A nível genérico, existem fortes similaridades entre os 3 sítios, mas Manaus é distintamente diferente, com a predominância de grandes gêneros de árvores. Embora ao nível de flora local a Amazônia não pareça ser mais rica do que a América Central, é muito mais rica em espécies de árvores.

Essas diferenças estão sendo apontadas, pois conclusões têm sido feitas com relação às espécies raras, muitas vezes baseadas nos censos da IBC. A tentativa é mostrar que além de 50 ha poder ser pouco para detectar os padrões dessas espécies, as diferenças 
taxonômicas e das comunidades de florestas tropicais nas suas extensões geográficas podem ser muito importantes, como exemplificado acima por GENTRY $(1986,1990)$.

\subsection{CONSEQUÊNCIAS GENÉTICAS DA RARIDADE}

Como apontado por BAWA \& ASTHON (1991), as consequências genéticas dependerão do tipo de raridade. Para espécies uniformemente raras através de toda sua extensão (tipo 1), com 1/ha indivíduo adulto ou menos, existem evidências que muitas são exogâmicas com taxas altas de cruzamento (Tabela 9, Ítem 3 de Resultados). Provavelmente possuam mecanismos eficientes de dispersão de pólen e' sementes a longas distâncias, com fluxo gênico amplo, propriedades que aumentam o tamanho e área de vizinhança. A expectativa, nesses casos, quanto à raridade é a não divergência genética e depleção da variação genética, e, de fato, populações dessas espécies podem exibir uma considerável quantidade de variação genética.

$\mathrm{Na}$ segunda categoria (tipo 2), cujas espécies têm densidades populacionais baixas em alguns locais mas comum em outros e, considerando somente as partes de suas extensões onde as densidades são baixas, as densidades populacionais podem variar no tempo e espaço, dependendo de imigração, regeneração e mortalidade. Dessa forma, as consequências genéticas dependerão grandemente da densidade populacional que prevalesce. Redução de tamanho populacional pode levar a diminuição do nível de heterozigosidade, e a sua permanència por várias gerações pode levar à fixação gênica via endogamia e deriva genética aleatória. Taxas de cruzamento parecem particularmente sensíveis a mudanças na densidade populacional. A densidade populacional diminuída nesta categoria de espécies pode resultar também em diminuição na produção de sementes e frutos, particularmente se o pólen é dispersado em curtas distâncias e se a espécie é autoincompatível e/ou dióica. Os efeitos combinados de tamanho efetivo pequeno e taxas de cruzamento reduzidas podem levar a depleção da variação genética, a qual acoplada com estocasticidade demográfica pode levar a declínio populacional posterior e eventual extinção.

$\mathrm{Na}$ terceira categoria das endêmicas (tipo 3), o tamanho populacional pode ser pequeno ou grande. Quando as populações são grandes, elas devem manter considerável variação genética a não ser que tenham sofrido um estrangulamento (bottlenecks). Os dados mostram resultados conflitantes, mas o fato de ser endêmcia não necessariamente implica em menores níveis de variabilidade genética.

$\mathrm{Na}$ quarta categoria (tipo 4), as espécies são especialmente agrupadas com pouquíssimos indivíduos dispersados entre os agregados, e mesmo nos agregados, o 
número de indivíduos pode ser baixo. Muitas dessas espécies devem ser especialistas de habitat. Se a população baixa nos agregados persiste por várias gerações pode ocorrer perda de variação genética. No entanto, troca gênica entre os agregados pode prevenir a perda da diversidade genética.

\section{MEDINDO A VARIABILIDADE GENÉTICA EM POPULAÇÕES DE PLANTAS}

\subsection{CONTEXTO BIOLÓGICO}

Um dos principais objetivos da genética de populações é descrever a quantidade da variação genética em populações e estudar o mecanismo de manutenção dessa variação (NEI, 1987). Esta variação fornece a matéria-prima para mudanças evolucionárias futuras, e níveis diferentes de variação em diferentes populações podem fornecer evidência para eventos evolucionários distintos no passado (WEIR, 1990a). Segundo este último autor, as primeiras análises de dados genéticos são aquelas de estado genotípico, e, neste nível, contagens de genótipos levam a medidas simples de variação, como o número de alelos por loco ou frequências alélicas associadas. $O$ número de alelos por loco pode ser suficiente para detectar variação, mas é difícil utilizá-lo para se inferir comparativamente sobre níveis de variação entre diferentes populações. Para tais propostas, conforme o mesmo autor, frequências alélicas geram estatísticas apropriadas que podem ser discutidas. A partir daí, pode-se incluir funções mais complexas de frequências, tal como a diversidade gênica, que considera os mecanismos para a manutenção da variação. A seguir, essas duas facetas da variabilidade genética serão discutidas.

Segundo WEIR (1990a), a análise de dados genéticos deve ser baseada em alguma teoria ou modelo, ou seja (WEIR, 1990b), em modelos biológicos. Um modelo é uma construção intelectual que procura abstrair as características essenciais do caos de detalhes que acompanham os fenômenos naturais (CLEGG, 1980). O modelo clássico de uma população infinita de cruzamento aleatório para um loco no qual não existem forças perturbadoras de mutação, migração ou seleção (Teorema de Hardy-Weinberg), permite que afirmações sejam feitas sobre estatísticas, i.e., diversidade gênica: esta quantidade é um menos a soma das 
frequências alélicas ao quadrado e é esperada ser a mesma que a frequência de heterozigotos sob o modelo clássico (WEIR, 1990b).

Uma outra consequência do modelo clássico ou de Equilíbrio de HardyWeinberg (EHW) é que a abundância relativa dos alelos $A_{i}$ não muda de uma geração para a outra; a única mudança na composição genética da população é a redistribuição dos genótipos dentro de frequências que serão mantidas em todas as gerações subsequentes (FUTUYMA, 1992). Segundo este autor, sob as condições que implicitamente foram assumidas pelo EHW uma única geração de cruzamentos ao acaso estabelece frequências genotípicas binomiais e nem essas frequências e nem as frequências alélicas irão mudar em gerações subsequentes. Assim, pode-se calcular as frequências genotípicas esperadas sob o modelo do EHW através das frequências alélicas observadas, e, consequentemente, o número esperado dos genótipos sob as mesmas pressuposições. Os desvios das proporções esperadas pelo EHW significam que alguma das pressuposições do modelo foram violadas e o refinamento deste modelo ou modelos alternativos são propostos para a verificação das possíveis causas do desvio, tais como a endogamia, seleção, migração ou mutação.

\subsubsection{Amostragem estatística e genética}

Os vários tipos de amostragem utilizados para gerar dados devem ser considerados, pois estes afetarão as propriedades de estimativas e determinarão o alcance das inferências que poderão ser feitas a partir dos dados (WEIR, 1990a).

Ao menos que uma população seja absolutamente uniforme para todos os locos sendo estudados, diferentes amostras de uma população mostrarão diferentes níveis de variação genética (WEIR, 1990b). Segundo este autor, isto é simplesmente consequência da amostragem estatística, resultante do fato de que cada amostra tenha um diferente conjunto de indivíduos. Como exemplo dado pelo autor e considerando uma amostra de $\mathbf{n}$ indivíduos de uma população de tamanho $\mathbf{N}$, a amostragem estatística refere-se a esta escolha de $\mathbf{n}$ indivíduos de N. Uma outra amostra, também de tamanho n, da mesma população, pode dar diferentes valores de quantidades, tal como frequência gênica, simplesmente porque indivíduos com genótipos diferentes podem ser amostrados (WEIR, 1990a). Conforme este autor, a maioria das análises são baseadas em amostragem multinomial, na qual todo membro da população é igualmente provável de ser escolhido em qualquer estágio para ser um membro da amostra. No entanto, 
conclui, amostragens repetidas geralmente não são feitas, e existem teorias estatísticas que predizem quanta variação poderia ser provável entre tais amostras e esta variação é levada em consideração na confecção das inferências sobre a população, tendo como base os dados amostrais.

Segundo este último autor, para dados genéticos existe outra fonte de variação a ser considerada e esta origina-se da amostragem inerente a transmissão do material genético dos pais à prole (amostragem genética). A população de tamanho $\mathbf{N}$, da qual uma amostra é tomada, pode ser considerada somente uma das muitas replicatas populacionais que poderia ter descendido da mesma referência ou população fundadora. Mesmo que todos os fatores, tais como, o tamanho populacional, estrutura de cruzamento, seleção e mutação, permaneçam exatamente os mesmos, essas replicatas populacionais diferirão porque diferentes genes podem ser transmitidos em cada loco entre gerações para diferentes réplicas.

Assim, existe variação entre réplicas populacionais devido à amostragem estatística e genética e é necessário que a teoria acompanhe essa variação (WEIR, 1990b). De acordo com este último autor, uma atividade básica em estatística é estimar a média, $\mu$, para alguma variável; se as medidas da variável são denotadas por $X$ e a média por $\bar{X}$, então $\mu$ é estimado por $\bar{X}$; a variação entre amostras é antecipada pela designação de uma variância $\sigma^{2} / n$ para esta estimativa, onde $\sigma^{2}$ é a variância da variável original; conforme o tamanho amostral fica maior, a variância entre as amostras da média amostral diminui. A teoria de genética de populações depende de outro conceito de populações replicadas que são mantidas sob as mesmas condições mas que diferem devido à amostragem genética (mesma cit.). É possível derivar variâncias para estatísticas de interesse que incluam ambos os tipos de variação, e assim, predizer o valor esperado de uma estatística, tais como frequência alélica ou heterozigosidade em uma futura população, mas não especificar o valor exato da estatística (idem cit.). Para um gene neutro em população finita é sabido que as frequências alélicas têm valores esperados constantes sobre o tempo, embora em qualquer população particular a frequência possa ter derivado a qualquer valor entre zero e um (idem cit.).

Conclui WEIR (1990b), afirmações sobre a estatística em alguma amostra futura devem levar em consideração a variação entre populações replicadas, tão bem quanto amostras replicadas de qualquer população. Assim, uma dificuldade é originada com relação às afirmações sobre deteminada estatística quando esta é calculada de uma amostra de 
uma única população, já que a magnitude da variação entre populações não pôde ser estimada. Segundo ele, a disponibilidade de vários locos pode, algumas vezes, contornar esse problema, e, embora genes em diferentes locos nunca são completamente independentes, pode ser que tenham frequências aproximadamente independentes como se fossem populações separadas. Discute o autor, que os genes nesses locos foram expostos às mesmas forças de amostragem genética entre gerações, mas podem ter diferentes "pedigrees" da mesma forma que populações replicadas. Segundo o mesmo autor acima, se o interesse é somente a população atual, é possível ignorar a amostragem genética que fez essa população diferente de todas as outras que descenderam da mesma população fundadora. Se as conclusões são para ser aplicadas a todas as populações que podem ter sido originadas sob as mesmas circunstâncias, a amostragem genética deve ser incorporada. Assim, argumentos similares são feitos na distinção entre efeitos fixos e aleatórios em modelos estatísticos, e o autor exemplifica Steel \& Torrie (1980, p. 149).

No presente estudo, a análise de uma população de duas espécies tem como réplicas os diferentes locos amostrados. A possibilidade de estudar progênies de $C$. multiflora e jovens de $C$. guianensis, permitiu uma nova fonte de variação, e portanto, a possibilidade de comparar diferentes gerações. As estatísticas das análises que incluem 0 componente entre populações não serão abordadas.

\subsection{GENES NAS POPULAÇÕES}

\subsubsection{Estimativas das frequências gênicas e genotípicas e suas distribuições com relação aos modelos do Equilibrío de Hardy-Weinberg (EHW) e Equilíbrio de Endogamia Neutro de Wright (EENW)}

A frequência alélica ou gênica é a frequência de um alelo particular em uma população (NEI, 1987). Conforme o autor, é um parâmetro fundamental no estudo da evolução, desde que a mudança genética de uma população é descrita através das mudanças nas frequências gênicas. As maiores causas da alteração nas frequências gênicas nas populações naturais são : i. deterministas: mutação, fluxo gênico (migração) e seleção natural; e ii. estocásticas: deriva genética (SHORROCKS, 1980).

As análises estatísticas da distribuição dessas frequências são baseadas em modelos biológicos (WEIR, 1990b), citados anteriormente. Segundo este autor, frequências 
populacionais são as quantidades genéticas básicas de interesse, e cuidado deve ser tomado para distinguir entre parâmetros não observados e estatísticas usadas como suas estimativas. Conforme o autor, parâmetros genéticos não são observáveis e precisam ser estimados por estatísticas que são funções dos dados. Como apontado anteriomente, existe um interesse particular em médias e variâncias dos estimadores, e em linguagem estatística a média de uma variável é o valor esperado desta variável. Os valores amostrais (observados) aqui serão inicialmente distinguidos dos valores populacionais que eles estimam por til $(\sim)$. O valor populacional refere-se a uma população particular no modelo fixo, ou a todas as populações replicadas no caso aleatório, este último, como dito, não será discutido aqui. Valores esperados serão indicados pelo símbolo $\varepsilon$ (WEIR, 1990a; 1990b).

Para alelos codominantes, tais quais os encontrados em isoenzimas, quando todos os genótipos são identificáveis, as frequências gênicas podem ser estimadas contando o número de genes na amostra (NEI, 1987), ou, o número de vezes que cada alelo é encontrado, dividindo-se pelo número total de genes na amostra (NEI, 1987; TORGGLER et. al., 1995). Quando uma população é amostrada de forma que todo membro da população tem uma chance igual de ser amostrado, e os indivíduos são amostrados independentemente, as contagens genotípicas são multinomialmente distribuídas, e como consequência a contagem de qualquer genótipo particular tem uma distribuição binomial (WEIR, 1990b), como anteriormente citado. Considerando um loco com $k$ alelos e $n$ indivíduos amostrados de uma população e tendo como base NEI (1987), BROWN \& WEIR (1983) e WEIR (1990a; 1990b), tem-se que $n_{i j}$ é igual ao número de indivíduos observados para o genótipo $A_{i} A_{j}$, com $\Sigma n_{i j}=n$ e o número total de genes igual a $2 \mathrm{n}$. Quando $\mathrm{j} \# \mathrm{i}$, as frequências de genótipos heterozigóticos e homozigóticos observadospara cada loco são dadas por:

$$
\begin{gathered}
\widetilde{P}_{i j}=n_{i j} / n \quad \widetilde{P}_{i i}=2 n_{i i} / n \\
\text { A frequência gênica de } \mathrm{A}_{i} \text { é então estimada por: } \\
\widetilde{p}_{i}=\left(2 n_{i i}+\sum_{i \neq j} n_{i j}\right) / 2 n \quad \text { ou } \quad \widetilde{P}_{i i+1 / 2} \sum_{i \neq j} \widetilde{P}_{i j}, \quad \text { com } \quad \sum \widetilde{p}_{i}=1,
\end{gathered}
$$

e considerando médias sobre todas as amostras da população a $\varepsilon \widetilde{p}_{i}=\mathrm{p}_{\mathrm{i}}$. As frequências genotípicas esperadas sob acasalamento aleatório são dadas pela expansão de $\left(p_{1}+p_{2}+\ldots p_{k}\right)^{2}$, e somente quando em EHW, as frequências dos homozigotos $A_{i} A_{i}$ e heterozigotos $A_{i} A_{j}$ esperadas são: 


$$
P_{i i}=p_{i}{ }^{2} \quad P_{i j}=2 p_{i} p_{j},
$$

onde $\varepsilon \widetilde{P} i i=P i i$.

\subsubsection{Teste para verificação do ajuste ao modelo do EHW}

A acuracia das estimativas obtidas depende do tamanho amostral, mas é também afetada por dominância, sistema reprodutivo e pelas próprias frequências gênicas (NEI, 1987). Considere agora valores esperados apontados por acento circunflexo $\left(^{\wedge}\right)$. No caso de EHW, as contagens alélicas são distribuídas binomialmente, e, como dito anteriormente, a população pode ser completamente caracterizada por frequências alélicas (WEIR, 1990b). Desta forma, para testar se a distribuição dos números observados $\left(\mathrm{n}_{\mathrm{ij}(\mathrm{o})}=\widetilde{n}_{i j}\right)$ de genótipos ajusta-se àquela dos esperados $\left(\mathrm{n}_{\mathrm{ij}(\mathrm{e})}=\widehat{n}_{i j}\right)$, dado a seguir conforme o EHW, um teste $\chi^{2}$ é empregado. $\mathrm{Na}$ realidade, este está testando se as populações podem ser caracterizadas por frequências alélicas ao invés de genotípicas (WEIR, 1990b). Assim, quando $\mathrm{j} \neq \mathrm{i}$ os números esperados de genótipos heterozigóticos e homozigóticos por cada combinação alélica diferente são dados por:

$$
\hat{n}_{i i}=n \hat{P}_{i i} \quad \hat{n}_{i j}=n \hat{P}_{i j}, \quad \text { com } \quad \sum \hat{n}_{i}=n
$$

onde $\varepsilon \hat{P}_{i i}=P i i$ e:

$$
\chi^{2}=\sum_{i} \frac{\left.\left(\tilde{n}_{i j}-\hat{n}_{i j}\right)\right)^{2}}{\hat{n}_{i j}},
$$

com o número de graus de liberdade igual $\mathrm{GL}=\left(\mathrm{n}^{0}\right.$. de genótipos -1$)-\left(\mathrm{n}^{0}\right.$. de alelos -1$)$.

Uma outra abordagem para testar os desvios das proporções do EHW pode ser feita em termos do coeficiente de endogamia F de WRIGHT $(1965,1978)$ dentro da população (WEIR, 1990b), e pode ser estimado para um loco da seguinte forma (BROWN \& WEIR, 1983):

$$
\widetilde{F}=1-(\widetilde{H} / \widetilde{h}
$$

onde,

$\widetilde{H}=1-\sum_{i} \widetilde{P}_{i i}-$ heterozigosidade observada por loco na amostra (ao nivel de zigoto);

$\widetilde{h}=1-\sum_{i} \widetilde{p}^{2}-$ heterozigosidade esperada por loco (ao nível de alelo) ou frequência panmítica; 
Um F médio para a população é também calculado pela mesma fórmula, porém utilizando-se as heterozigosidades médias observadas e esperadas (panmítica), considerando todos os locos. Essas estimativas serão melhor descritas a seguir.

Como visto, o índice de fixação $F$ ou coeficiente de endogamia de Wright, neste caso, é obtido pela relação entre frequências observadas e esperadas de heterozigotos. Dessa forma, mede a fração de redução na heterozigosidade com relação ao esperado em uma população de acasalamentos aleatórios, conforme as expectativas do equilíbrio de Hardy-Weinberg. Conforme este autor, valores de $F$ iguais a zero indicam que a população está em EHW, valores que são significativamente maiores ou menores que zero indicam respectivamente excesso de homozigotos ou de heterozigotos com respeito às populações de acasalamentos aleatórios. Para testar as significâncias de $F$ quanto ao equilibrio pode-se utilizar a estatística $\chi^{2}$ sugerida por LI \& HORVITZ (1953):

$$
\chi^{2}=n F^{2}(k-1)
$$

com $\{k(k-1)\} / 2$ graus de liberdade, $k=$ número de alelos e $\mathrm{n}=$ tamanho amostral;

Conforme discutido pelos autores, o desvio entre as proporções zigóticas do EHW, que eles chamam de modelo I, e do Equilibrio de endogamia de WRIGHT (EENW, será abordado abaixo), que eles chamam de modelo II, é causado pela existência de F, e pode ser medido pelo valor de $\chi^{2}$ usando as proporções do modelo I como "esperadas" e aquelas de II, como "observadas". Eles fazem a demonstração dessa relação, chegando à fórmula acima. Assim, se hipótese nula não é rejeitada, as proporções de ambos os modelos são iguais, e isto só ocorre em EHW.

\subsubsection{Teste para verificação de ajuste ao modelo do EENW}

De acordo com WEIR (1990b), a demonstração de que uma população não tem frequências genotípicas em EHW significa que, no mínimo, uma das pressuposições deste modelo não se ajusta àquela população: a população pode não ser grande o suficiente e não estar cruzando aleatoriamente, ou existem forças como seleção ou migração atuando. No entanto, a conformidade com o EHW não significa que todas as pressuposições estão sendo respeitadas, e exemplos de outras fontes são dados pelo autor acima, onde populações em EHW mostraram padrões de seleção ou cruzamento não aleatório. 
O EHW permite a estimativa de frequências genotípicas a partir de frequências alélicas sob panmixia ${ }^{21}$, dessa forma, um interesse básico em distribuições zigóticas tem sido estudar a proximidade delas com relação a esta lei (BROWN \& WEIR, 1983). Essas distribuições podem afastar-se daquela do EHW por fatores tais como endogamia, cruzamento diferencial ("assortativo" positivo e negativo), subdivisão da população e seleção natural (NEI, 1987). Conforme RITLAND (1983), se há razão para suspeitar que o fator primário contribuindo para qualquer desvio das expectativas do EHW é a auto-fertilização, e não a seleção, subdivisão populacional ou exocruzamento com aparentados, esses desvios podem ser descritos em termos de F. Assim, um modelo alternativo, o modelo de cruzamento misto, ou seja, modelo que considera, no sistema de reprodução, acasalamentos aleatórios e a autofecundação, segundo BROWN \& WEIR (1983), possui uma versão corrigida da lei de HW para este sistema alternativo que é o Equilíbrio de Endogamia Neutro de Wright (EENW).

$\mathrm{O}$ índice de fixação $\mathrm{F}$ pode ser positivo ou negativo, dependendo do caso. Os fatores que podem causar um valor não zero de F foram citados acima. Segundo NEI (1987), a endogamia aumenta a frequência de homozigotos, e se não houver outro fator, $\mathrm{F}$ é igual ao coeficiente de endogamia de Wright. Neste caso, F é sempre positivo. De acordo com este autor, em organismos de autofecundação, a frequência de heterozigotos é reduzida pela metade a cada geração, e eventualmente, todos os genótipos tornam-se homozigotos com $F=1$. Por outro lado, alguns organismos reproduzem-se por exocruzamento aleatório e autofecundação com certas probabilidades. Quando a probabilidade de exocruzamento é $t$, o valor de equilíbrio de $\mathrm{F}$ é $(1-\mathrm{t}) /(1+\mathrm{t})$, e a utilidade do índice de fixação, neste caso, é a consequência dele ser função do sistema reprodutivo e independente de frequências alélicas quando em EENW (BROWN \& WEIR, 1983).

É possível verificar através de testes $\chi^{2}$ o ajuste do número de genótipos observados àqueles esperados pelo equilibrio de endogamia de Wright nos locos que desviaramse significativamente do equilibrio de Hardy-Weinberg (VENCOVSKY, 1994). As frequências genotípicas de homozigotos e heterozigotos no EENW são dadas por (WEIR, 1990a) :

$$
P_{i i}=p_{i}^{2}+F p_{i}\left(1-p_{i}\right) \quad P_{i j}=2 p_{i} p_{j}(1-F),
$$

21 . Espécies panmiticas são aquelas nas quais todos os individuos, ao longo de sua distribuição geografica, formam uma população única com acasalamento aleatório (FUTUYMA, 1992) 
onde $\mathrm{F}$ pode ser estimado conforme fórmula dada anteriormente, e os graus de liberdade são iguais a $\mathrm{GL}=\left\{\left(\mathrm{n}^{0}\right.\right.$ de genótipos -1$)-\left(\mathrm{n}^{0}\right.$ de alelos -1$\left.)-1\right\}$, com um grau de liberdade perdido devido ao uso de F para o cálculo das estimativas (VENCOVSKY, 1994). O teste só é realizável quando o loco possui mais do que 2 alelos devido à computação dos graus de liberdade.

Assim, se um loco não estiver em EHW, mas encontrar-se em EENW, podemos inferir que o excesso de homozigotos observados pode ser explicado pelo sistema misto de reprodução, pela interação de cruzamentos aleatórios e autofecundação.

\subsection{VARIAÇÃO GENÉTICA}

O estudo da evolução é essencialmente a caracterização da extensão e causas da variação genética (WEIR, 1990a). Existem diferentes formas de medir esta variação, e os descritores mais simples são as frequências de alelos e genótipos, já apresentados anteriormente. Outra forma inclui a variação alélica em locos estruturais, tais como proporção de locos polimórficos, heterozigosidade, diversidade gênica e número de alelos por locos, entre outras. Segundo o autor acima, a frequência de heterozigotos é importante, desde que cada heterozigoto transporta diferentes alelos e representa a existência da variação. No entanto, conclui o autor, existem situações tais como para espécies de autofecundação, onde a variação resulta na presença continuada de homozigotos diferentes e a diversidade gênica (ou heterozigosidade média esperada) é, então, uma medida mais apropriada.

\subsubsection{Proporção de locos polimórficos}

Usualmente um loco é chamado de polimórfico quando a frequência do alelo mais comum é igual ou menor do que 0,99 ou 0,95. Esta definição é obviamente arbitrária, e há os que defendam que esta frequência seja uma das duas acima, ou mesmo que não haja nenhum critério (vários autores cit. em FUTUYMA, 1992). Esta estatística apresenta uma série de problemas incluindo a definição de polimorfismo, a dependência do tamanho amostral, e o número e tipos de enzimas incluídas na pesquisa (BROWN \& WEIR, 1983). Ainda, esta medida combina elementos dos dois conceitos de diversidade (riqueza e equitabilidade), sem focalizar nenhum dos dois propriamente ditos (mesma cit.). Conforme NEI (1987), a proporção de locos polimórficos não é uma boa medida da variação gênica; no entanto, quando um grande número 
de locos e indivíduos por loco são estudados, ela fornece um importante aspecto dessa variação dentro de populações.

\subsubsection{Número médio de alelos por loco $(\mathrm{N})$}

Esta estatística tem o mérito óbvio de enfatizar um componente da diversidade, que é a riqueza alélica (BROWN \& WEIR, 1983). Conversamente, segundo os autores, ela conta alelos igualmente, sem considerar a sua importância biológica, além de ser

muito sensível ao tamanho amostral, tornando difícil as comparações entre amostras. É uma quantidade definida e é esperada ser grande quando a extensão do polimorfismo é alta, e ainda, tem uma desvantagem séria como medida geral da variabilidade genética que é a dependência do tamanho amostral, a não ser que o tamanho amostral seja mais ou menos o mesmo para todas as amostras (NEI, 1987). Segundo este último autor, a dependência do tamanho amostral ocorre porque existem muitos alelos de baixa frequência em populações naturais, e o número de alelos observados aumenta com o tamanho amostral.

\subsubsection{Número efetivo de alelos por locos $\left(A_{e}\right)$}

Segundo NEI (1987), Kimura e Crow (1964) introduziram o conceito de $A_{e}$, ou o número efetivo de alelos por loco. O número é definido como o recíproco da homozigosidade esperada e é calculado para cada loco por $A_{e}=1 / \Sigma p_{i}^{2}$, onde $p_{i}$ é igual às frequências alélicas de cada loco i, calculando-se a média aritmética em seguida para todos os locos. Este número é igual ao número atual de alelos somente quando todos os alelos têm a mesma frequência, i.e., quando $p_{i}=1 / k(k=$ número de alelos), ou seja, quando há equitabilidade máxima. De outra forma, $A_{e}$ é menor que $A$. Esse valor inclui a equitabilidade das frequências alélicas além da riqueza (BROWN \& WEIR, 1983). Segundo MURAWSKI \& BAWA (1994), devido a suas propriedades, essa estatística reflete o número necessário dentro de um loco para manter o nivel atual de heterozigosidade. Segundo NEI (1987), esta quantidade não se comporta bem estatisticamente.

\subsubsection{Heterozigosidade observada}

É a quantidade de heterozigosidade observada em uma população, e é frequentemente calculada para um loco individual ou como uma média para todos os locos 
(WEIR, 1990a). A estimativa da heterozigosidade em um loco particular é calculada diretamente da amostra a partir das frequências genotípicas, como (BROWN \& WEIR, 1983):

$$
\widetilde{H}=1-\sum_{i} \hat{P}_{i i}
$$

e para $\mathbf{m}$ locos, a heterozigosidade média observada é:

$$
\widetilde{H}_{m}=\frac{1}{m} \sum^{m} \widetilde{H}
$$

Esta medida de variação sumariza distribuições zigóticas diplóides para locos individuais, e o fundamental é a heterozigosidade atual preferencialmente à heterozigozidade panmítica esperada (BROWN \& WEIR, 1983), conforme discutido a seguir.

\subsubsection{Diversidade gênica ou heterozigosidade média esperada}

Segundo NEI (1987), a heterozigosidade média ou diversidade gênica é uma medida mais apropriada da variação gênica, pois não depende da definição arbitrária de polimorfismo e pode ser definida em termos de frequências gênicas. Considerando uma população de acasalamento aleatório, onde $\mathrm{p}_{\mathrm{i}}$ é igual a frequência populacional do iésimo alelo em um loco. A heterozigosidade para este loco é então definida como:

$$
\widetilde{h}=1-\sum_{i=1}^{k} \widetilde{p}_{i}^{2},
$$

onde $\mathbf{k}$ é o número de alelos. A heterozigosidade média $\left(\widetilde{h}_{m}\right)$ é a média desta quantidade para todos os locos. Devido à somatória para todos os locos, um segundo subscrito é necessário na sua formulação, assim, $p_{i j}$ denota a frequência do iésimo alelo no jésimo loco, onde m é o número total de locos (BROWN \& WEIR, 1983):

$$
\widetilde{h}_{m}=1-\sum_{i} \sum_{j}^{m} p_{i j}^{2} / m
$$

As frequências gênicas amostrais nessas equações, segundo WEIR (1990a), fornecem a diversidade gênica do método dos momentos, que é uma estatística esperada. Assim, podemos considerar esta quantidade como a média da heterozigosidade esperada por loco (proporção de heterozigotos por loco) quando dois gametas aleatoriamente escolhidos de uma população são comparados (heterozigosidade panmítica) (BROWN \& 
WEIR, 1983), ou também, segundo NEI (1987), a proporção esperada de locos heterozigóticos em um indivíduo aleatoriamente escolhido. Segundo este último autor, ela tem um significado biológico definido, não sendo aplicável em indivíduos haplóides ou poliplóides. Mesmo em indivíduos diplóides, $\widetilde{h}_{m}$ não é igual à proporção média de heterozigotos se as frequências genotípicas não se encontrarem nas proporções do EHW. Entretanto, podemos considerar a probabilidade que dois genes escolhidos randomicamente de uma população sejam diferentes, e esta probabilidade é equivalente à heterozigosidade em uma população diplóide de acasalamento aleatório e pode ser definida em termos de frequências gênicas da mesma forma como a heterozigosidade. Nei (197322, citado em NEI 1987) chamou esta quantidade de diversidade gênica e indicou que esta palavra pode ser usada para qualquer organismo, haplóide, diplóide, poliplóide, em qualquer tipo de sistema reprodutivo (acasalamento aleatório, autofecundação ou reprodução assexual). Neste caso, a diversidade gênica é simplesmente uma medida da variabilidade genética, porém continua com uma boa propriedade estatística.

Segundo WEIR (1990a), $\widetilde{h}_{m}$ é a medida mais apropriada da variabilidade para populações endogâmicas onde existem muito poucos heterozigotos, mas pode existir muitos tipos de homozigotos diferentes. Para populações de cruzamento aleatório, esta quantidade estará próxima em valor à heterozigosidade. Conclui o autor, que embora a diversidade gênica seja calculada a partir de frequências gênicas, é bom lembrar que os dados são geralmente coletados ao nível genotípico; portanto, propriedades amostrais da diversidade gênica dependerão do genótipo tão bem quanto das frequências gênicas.

As principais vantagens desta medida são a relativa insensibilidade ao tamanho amostral quando comparada a proporção de locos polimórficos e número de alelos por loco, e é prontamente compreensível em termos genéticos (BROWN \& WEIR, 1983). Segundo NEI (1987), é também afetada pelo tamanho amostral em alguma extensão, mas o efeito é muito pequeno, desde que alelos de baixa frequência dificilmente contribuem para esta quantidade. Sua maior desvantagem é a grande dependência das frequências dos dois alelos mais comuns (BROWN \& WEIR, 1983).

22 NEI, M. Analysis of gene diversity in subdivided populations. Proc. Nat. Acad. Sci. USA, 70(12)part 1:3321-23, 1973. 


\section{MATERIAL E MÉTODOS}

\section{O GÊNERO COURATARI}

O gênero Couratari Aublet pertence à familia Lecythidaceae, na qual incluem-se espécies como a castanha-do-pará, jequitibá, sapucaia, jarana (Bertholetia excelsa Humboldt \& Bonpland. Cariniana legalis (Martius)Kuntze, Lecythis pisonis Cambessedes, Lecythis zabucaja Aublet, respectivamente). Essa familia é muito diversificada em número de espécies e é bem representada em número de individuos em toda a Amazônia, sendo sempre citada em levantamentos fitossociológicos como uma das principais familias ( PRANCE et al., 1976; DANTAS et al., 1980; MORI \& cols., 1987; RANKIN-DE-MERONA \& ACKERLY, 1987, GENTRY, 1988; MENDES et al., 1992).

Couratari possui a flor mais complexa e especializada dentro das lecitidáceas, caracterizando-se por uma flor altamente assimétrica, androceu modificado que enrola-se duas vezes formando uma espiral, com uma volta para dentro e outra para fora, e somente produção de néctar como recurso energético aos polinizadores (Fig. 1). Em geral, floresce quando sem folhas e frutifica próximo à caducidade. Devido a estas características, mais o fato de ser representado pelas maiores árvores da floresta amazônica, teve inicialmente vários problemas taxonômicos, sendo confundido com espécies como Lecythis. Cariniana, Allantoma (MORI \& PRANCE, 1990).

Cariniana e Couratari são os dois gêneros de Lecythidaceae que possuem sementes aladas, dispersadas pelo vento. Os outros gêneros possuem outros tipos de arilo adaptado à dispersão por animais. Outra tendência evolutiva comum é o desenvolvimento de cotilédones como folhas, diferentemente de outros gêneros que, em geral, não possuem cotilédones bem-desenvolvidos. Esta característica é citada por MORI (1989 - p.321) como uma possível adaptação a dependência a pequenas clareiras para seu estabelecimento.

Distribui-se predominantemente pela Amazônia e Guiana, com uma espécie estendendo-se ao norte até Costa Rica, duas ( uma delas C. guianensis) alcançando o Panamá, outras da Venezuela e Guianas até a Amazônia, e ao sul, na região costal do Brasil alcançando o Rio de Janeiro. O gênero é ausente no Brasil Central. 

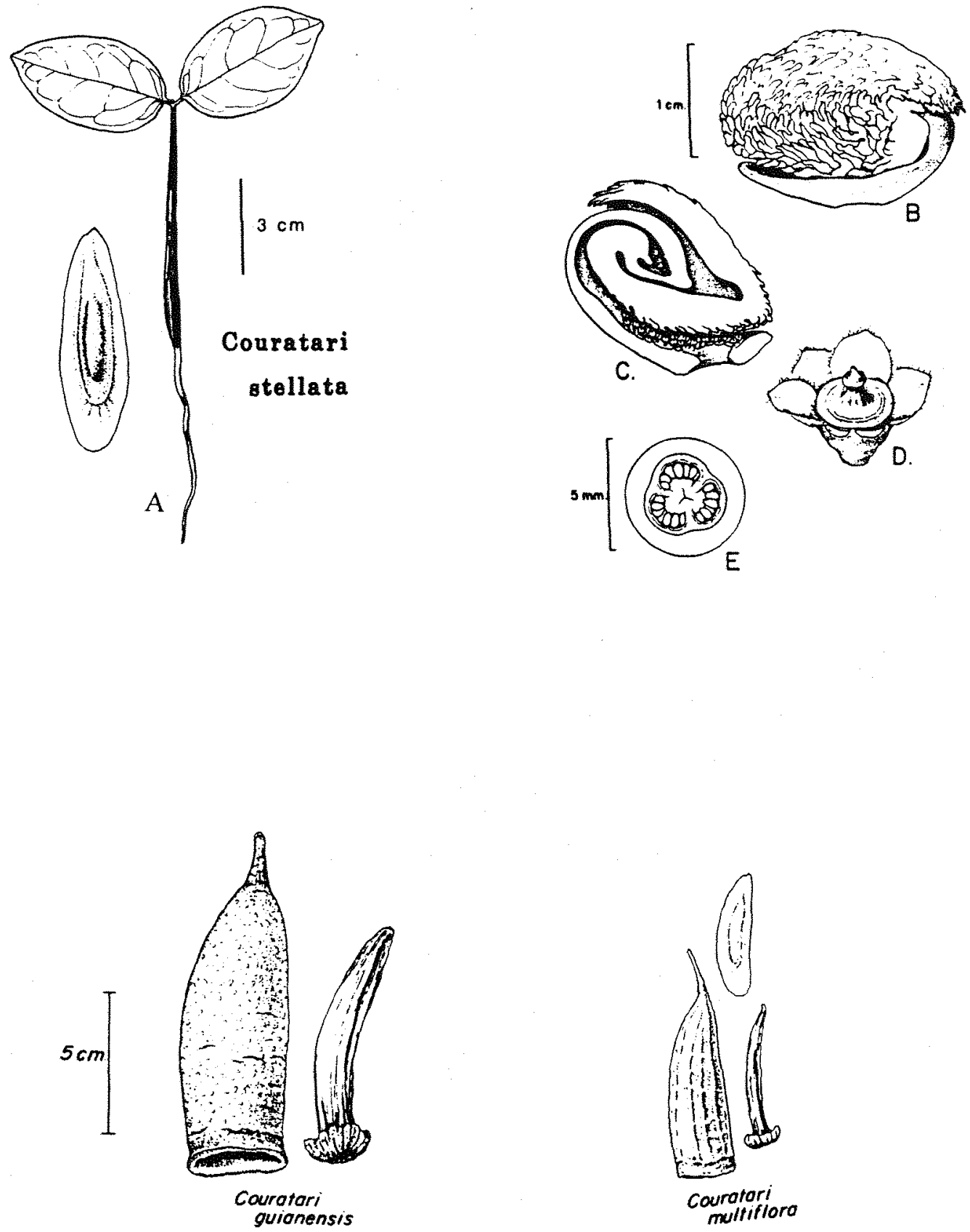

Figura 1. Parte superior da figura: semente, plântula (A) e partes florais: capuz (B), corte longitudinal da flor (C), cálice e ovário (D) e corte transversal do ovário (E) de C. stellata, a título de exemplo pois as flores são muito semelhantes dentro do gênero (retirado de Flora Neotropica Monograph 21(II)). Parte inferior da figura: frutos e sementes de $C$. guianensis e C. multiflora (retirado de Memoirs of the NYBG, 75). 

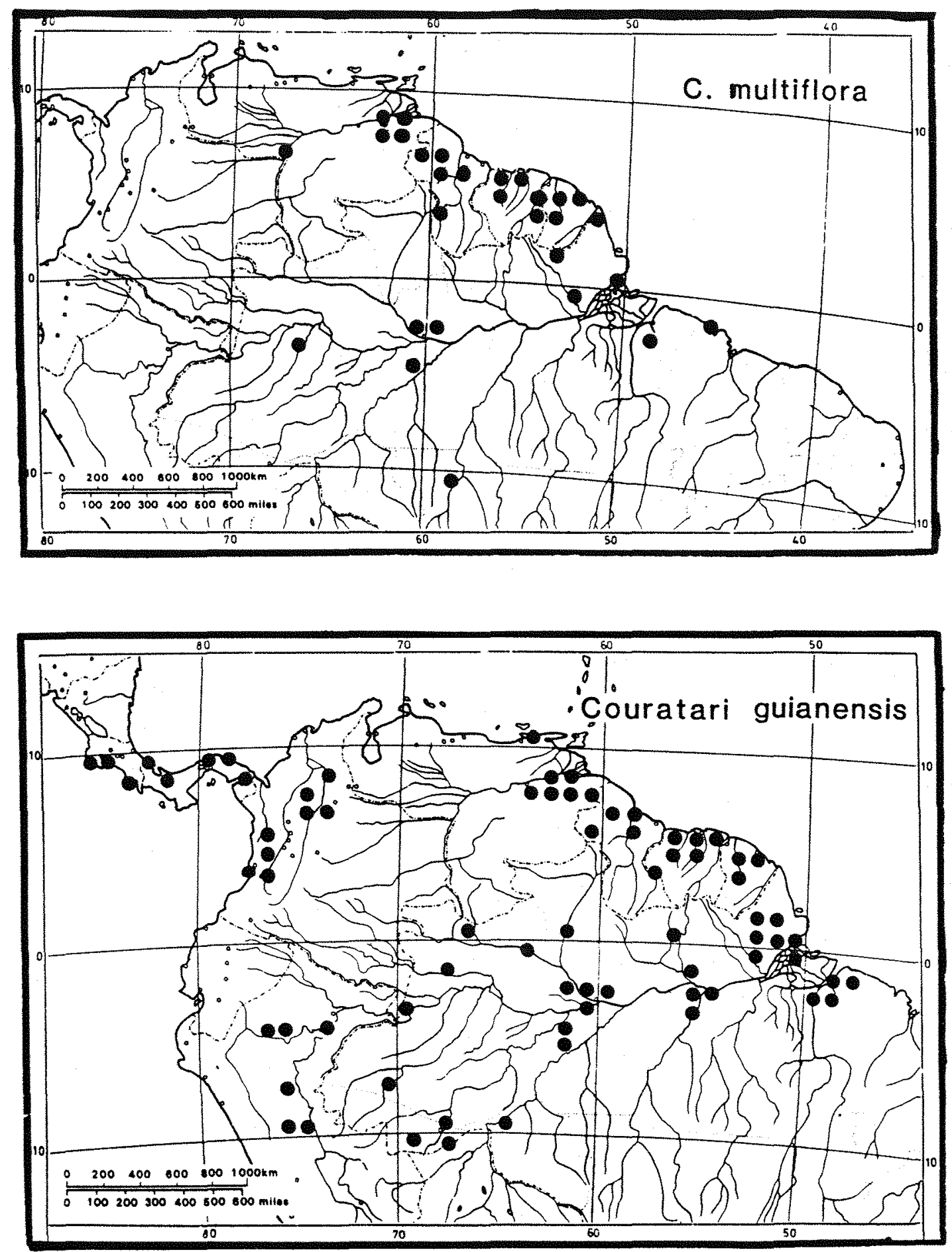

Figura 2. Distribuição geográfica de C. multiflora e C. guianensis (retirado de Flora Neotropica Monograph 21(II)). 
Esse genêro foi tratado taxonomicamente por vários autores e mais recentemente por EYMA (1932), KNUTH (1939), e atualmente por MORI \& PRANCE (1990). Esses dois últimos autores consideraram 19 espécies, sendo que na área de estudo ocorrem 5 delas, C. guianensis Aublet, C. multiflora (J.E.Smith) Eyma, C. longipedicellata W. Rodrigues, C. stellata A.C.Smith e C. tauari Berg (MORI \& LEPSCH-CUNHA, 1995). A maioria das espécies são de habitat de terra firme e florestas tropicais úmidas de terra baixa. No Brasil é chamada vulgarmente como tauari. A casca interna é usada para confecção de cigarros pelos índios e nativos das Guianas e Venezuela, e a madeira é prontamente trabalhável (idem citações anteriores).

\subsection{Couratari multiflora $\mathrm{E}$ C. guianensis}

Conforme MORI \& PRANCE (1990) e MORI \& LEPSCH-CUNHA (1995), Couratari guianensis e C. multiflora são espécies representadas por árvores, em geral, emergentes chegando a 40-50 metros de altura, sendo a primeira mais volumosa e com sapopemas bem mais desenvolvidas. $C$. guianensis possui folhas características com pêlos estrelados na face abaxial; flores com cerca de $2-3 \mathrm{~cm}$, cor vinho com partes mais claras; frutos cilíndricos, $12-17 \mathrm{x}$ $6 \mathrm{~cm}$. Floresce de junho a fevereiro, com o pico entre setembro e novembro. C. multiflora possui folhas com peciolos longos, flores menores, cerca de 1,0-2,0 cm, cor-de-rosa; frutos também menores, cilíndricos, 4-6 $\times 2-3,5 \mathrm{~cm}$. Floresce de janeiro a março e frutifica de julho a novembro. São espécies amplamente distribuídas (Figura 2), com C. guianensis estendendo-se desde a Costa Rica, espalhando-se por toda Amazônia, e C. multiflora pela Venezuela, Guianas e Amazônia brasileira.

\subsection{EVOLUÇÃO DA FLOR E POLINIZAÇÃO}

A familia Lecythidaceae possui dois tipos básicos de flores: actinomórficas e zigomórficas que diferem pela estrutura do androceu. Na zigomórfica, o anel estaminal é prolongado em um dos lados com uma área livre de estames chamada de lígula, a qual termina em um capuz carregado de apêndices. Em algumas espécies, esse capuz permanece aberto, ficando um espaço entre ele e o topo do ovário, em outras, permanece fechado, fortemente pressionado contra este último. As courataris estudadas aqui são representantes deste último caso.

Como cita MORI \& BOEKE (1987) e MORI et al. (1980), em geral, as flores zigomórficas são visitadas por poucos e mais específicos tipos de polinizadores. Isso é especialmente verdadeiro para aquelas espécies produtoras de néctar que sempre possuem seus 
esconderijos de néctar no ápice da longa espiral e com o androceu fechado, devido à forte pressão contra o anel estaminal. Consequentemente, somente abelhas fortes com linguas compridas são aptas a abrir e extrair néctar. Abelhas euglossines são importantes na polinização dessas espécies zigomórficas e as distribuições geográficas desses tipos de lecitidáceas e dessas abelhas euglossines são restritas aos neotrópicos, onde suas extensões são aproximadamente idênticas. Euglossines devem ter tido uma função importante na evolução desse tipo único de flor. Dentre as flores especializadas de Lecythidaceae, a de Couratari é a mais complexa, estando no topo de linha evolutiva.

NELSON et al. (1985) observaram os visitantes de Bertholletia excelsa (castanha-do-pará) e de Couratari tenuicarpa, esta com flor zigomórfica mais especializada que aquela tanto a nivel de forma como de recursos energéticos, produzindo além de pólen, néctar.

Concluiram que somente grandes abelhas são capazes de desenrolar o androceu floral e efetivamente polinizar essas espécies. Os resultados mostraram que a polinização de Couratari foi efetuada por abelhas maiores e mais especializadas, com a presença de pólen praticamente só desta espécie no dorso das abelhas. Em contrapartida, B. excelsa foi visitada por uma variedade maior de abelhas, com pólen proveniente de um número maior de espécies. C. tenuicarpa, da mesma forma que $C$. guianensis e $C$. multiflora, é representada por densidades muito baixas de individuos na sua região de ocorrência. PRANCE (1976) também observou abelhas euglossines obtendo néctar de C. atrovinosa Prance.

Como mostrado por JANZEN (1971), as abelhas euglossines podem viajar distâncias como $23 \mathrm{~km}$ na floresta tropical e, aparentemente, visitam as mesmas plantas repetidamente ao longo de uma rota de alimentação. Ao contrário das abelhas selvagens que forrageam árvores com muitas flores, as euglossines conseguem néctar e pólen de plantas grandes que, em geral, ocorrem em baixas densidades, sendo exemplificadas por algumas espécies de Lecythidaceae. Isto poderia causar fecundação cruzada das espécies de baixas densidades como as courataris estudadas aqui.

\section{LOCAL DE ESTUDO}

Realizamos este estudo no Projeto Dinâmica Biológica dos Fragmentos Florestais (PDBFF), em Manaus-AM-BRASIL. Este projeto é mantido pelo Instituto Nacional de Pesquisas da Amazônia (INPA - Manaus-AM) e Smithsonian Institution (SI - Washington, DCEUA). Suas reservas estão localizadas a $70-90 \mathrm{~km}$ de Manaus ( $2^{\circ} 30^{\circ} \mathrm{S}, 60^{\circ} \mathrm{W}$ ); no Distrito 
Agropecuário, uma área de aproximadamente 500.000 ha de terra firme, relativamente não perturbada, atravessada pela BR 174, com as seguintes características: $80-110 \mathrm{~m}$ acima do nivel do mar; $26^{\circ} \mathrm{C}$ de temperatura média, máxima de $35-39^{\circ} \mathrm{C}$, mínima de $19-21^{\circ} \mathrm{C} ; 1900-2300 \mathrm{~mm}$ de chuva anual; estação chuvosa de dezembro-abril, estação seca de maio-novembro em média, (Annual Report PDBFF, 1987-8823; LOVEJOY \& BIERREGAARD, 1990) (Figura 3 e 4). O decreto presidencial no. 91.884 (DIÁRIO OFICIAL de 5 de novembro de 1985), através da SUFRAMA, protege essas áreas do rápido desflorestamento. Estudos de carvão no solo sugerem que a área do PDBFF foi habitada pré-historicamente (LOVEJOY \& BIERREGAARD, 1990), porém não tem sido habitada recentemente.

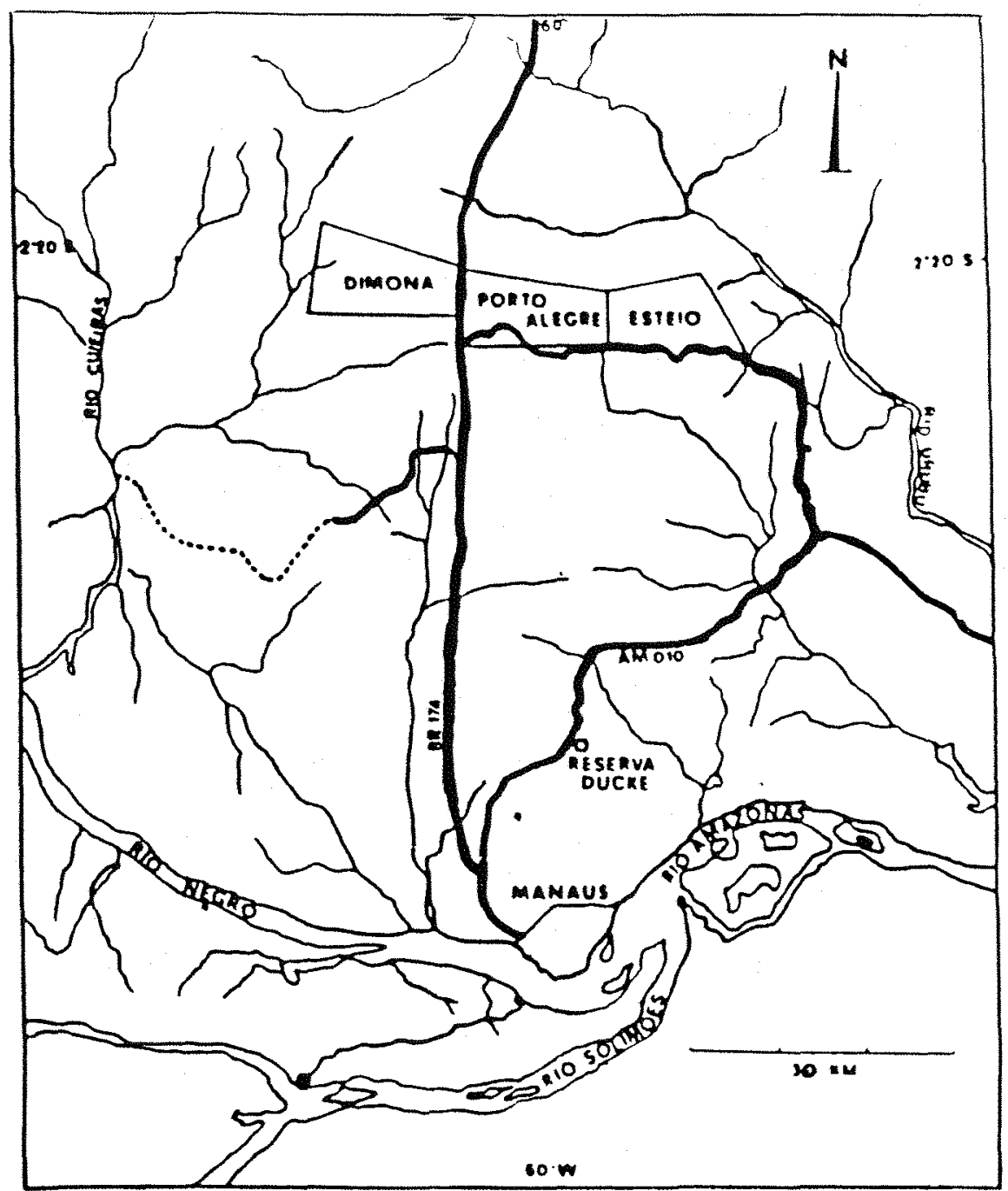

Figura 3. Localização das Reservas do Projeto Dinâmica Biológica dos Fragmentos Florestais (PDBFF) e as fazendas onde estão inseridas. Retirado de LOVEJOY \& BIERREGAARD, 1990.

${ }^{23}$ PDBFF/MCSE - INPAWWF - Ninth Annual Report. 1987-88. 


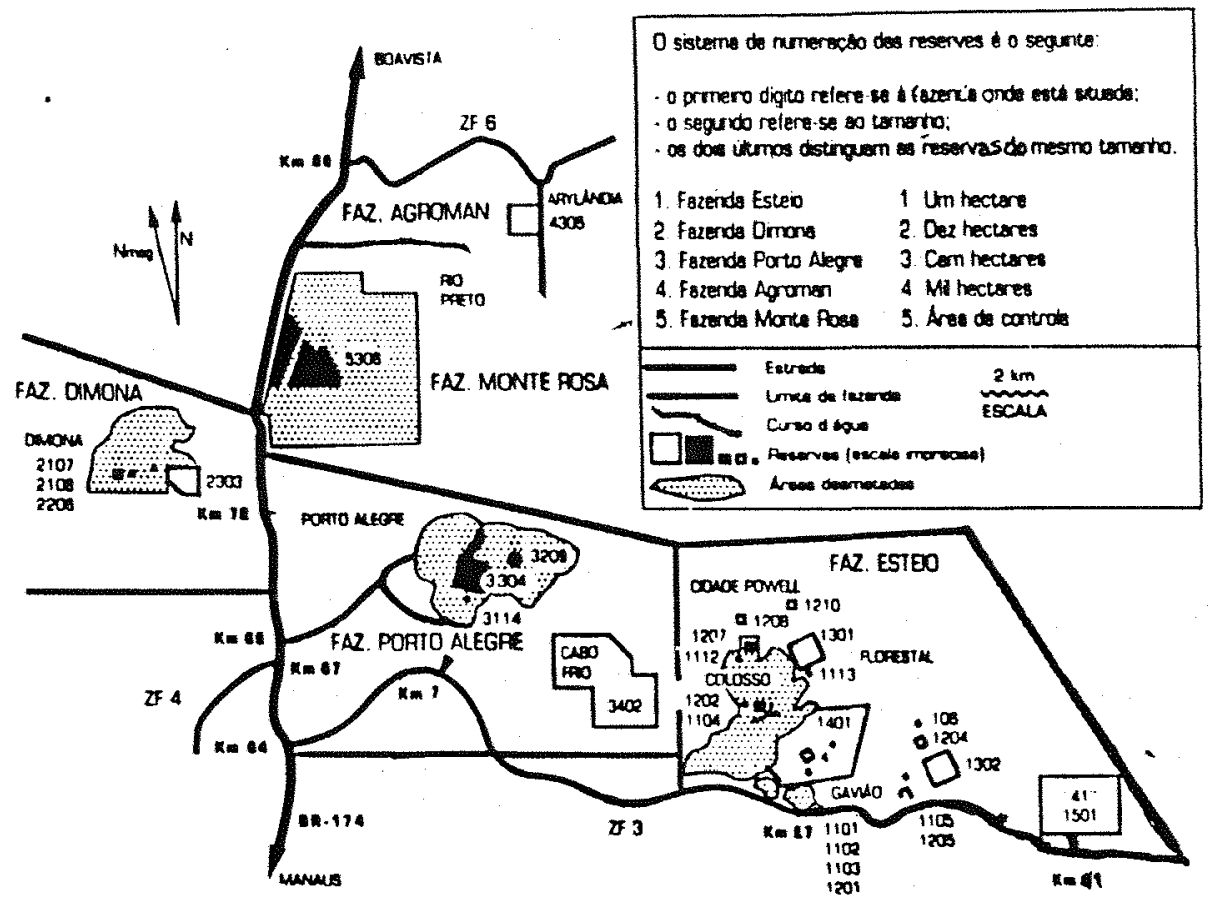

Figura 4. Localização da Reserva 1501, "km 41", na Fazenda Esteio. Retirado de LOVEJOY \& BIERREGAARD, 1990.

O PDBFF tem como um dos maiores objetivos estudar a fragmentação florestal e seus efeitos. Para isto, isolou reservas de 1, 10,100 e 1000 hectares através de desmatamento, ocasionado por corte, corte e fogo, com abandono ou formação de pastos posteriormente e, além dessas, reserva de 10.000 ha demarcada em mata contínua, fornecendo área controle (LOVEJOY et al., 1986). RANKIN \& ACKERLY (1987) e GENTRY (1990) dão várias informações botânicas, zoológicas e ecológicas sobre o local. 
Um dos subprojetos do PDBFF, o subprojeto Lecythidaceae, coordenado pelos pesquisadores S. Mori (The New York Botanical Garden) e P. Becker (Universiti of Brunei), foi nosso ponto de partida para a escolha de espécies de baixa densidade na área. Este subprojeto delimitou, em reserva de mata continua, uma parcela de $100 \mathrm{ha}$, a qual foi piqueteada a cada $20 \times 20 \mathrm{~m}$, onde todos os indivíduos acima de $10 \mathrm{~cm}$ de DAP (diâmetro a $1,30 \mathrm{~cm}$ de altura) desta família foram marcados, mapeados e identificados, resultando em 39 espécies e cerca de 8000 indivíduos (MORI \& LEPSCH-CUNHA, 1995). A partir dessas informações e utilizando esta parcela de 100 ha como referência, procuramos continuamente os outros individuos necessários ao estudo das duas espécies escolhidas. A área está localizada na reserva 1501 , "km 41 ", reserva de 1000 ha não isolada do PDBFF (fig. 2, à direita), a qual é utilizada como área controle.

\section{METODOLOGIA GERAL PARA O LEVANTAMENTO DAS ÁRVORES E DEFINIÇÃO DE CATEGORIAS DE IDADE/TAMANHO}

Procuramos todos os individuos considerados adultos, ou os $\geq 20,0 \mathrm{~cm}$ de DAP, das duas espécies, em área circundante à parcela de 100 ha do subprojeto Lecythidaceae. A definição de individuos reprodutivos a partir desse DAP mínimo é consequência de experiência de campo. Nesta parcela já haviam sido levantados 24 individuos totais $\geq 10,0 \mathrm{~cm}$ DAP e $18 \geq 20,0$ cm DAP para C. multiflora (6 jovens), e 21 individuos totais $\geq 10,0 \mathrm{~cm}$ DAP, $6 \geq 20,0 \mathrm{~cm}$ DAP para C. guianensis (15 jovens) (MORI \& LEPSCH-CUNHA, 1995). Nosso objetivo foi localizar continuamente todos os individuos considerados adultos, até a obtenção de 30 matrizes. Mapeamos as árvores utilizando trena e bússula com referência às picadas e piquetes da reserva, localizados a cada $100 \mathrm{~m}$. A localização do número desejado de indivíduos adultos de ambas as espécies, apesar de necessitar áreas relativamente grandes, foi compensada pela facilidade de visualização dos mesmos, pois estes são emergentes ou de diâmetros grandes e possuem um tronco vermelho liso bem característico, com desprendimento da casca em forma de "envira", soltando tiras longitudinais fibrosas.

A facilidade maior de localizar individuos jovens de $C$. guianensis, devido às suas folhas grandes pilosas características, resultou na amostragem de vários indivíduos menores de 20,0 cm de DAP (11 indivíduos), além daqueles da parcela do subprojeto Lecythidaceae $(15+11=26$ individuos jovens no total). Consequentemente pudemos distinguir essa categoria ${ }^{24}$, diferenciando-a dos adultos. Já C. multiflora, apesar de ser facilmente reconhecida 
em estágio adulto, é confundida com sapotáceas quando jovem, em função disto, não encontramos nenhum individuo jovem além daqueles mapeados dentro da parcela de Lecythidaceae. No entanto, esta última espécie foi a única a frutificar durante a fase de trabalho de campo, produzindo sementes e, consequentemente, progênies.

A partir desses resultados, pudemos quantificar a variabilidade genética no item 1. de Resultados (LEPSCH-CUNHA \& KAGEYAMA, 1996b) para progênies (semente/plântulas filhas de uma árvore-mãe) e adultos de C. multiflora, e para jovens e adultos de C. gilianensis. Os poucos jovens da primeira espécie foram analisados neste item no sentido único de discutir amostragem (6 individuos). No ítem 3 de Resultados (LEPSCH-CUNHA \& KAGEYAMA, 1996d) analisamos o sistema reprodutivo via progênies desta espécie e a fenologia reprodutiva no item 2 de Resultados (LEPSCH-CUNHA \& KAGEYAMA (1996c).

Os itens 1, "Variabilidade Genética Intrapopulacional de duas Espécies de

Baixa Densidade na Amazônia Central: Couratari multiflora e Couratari guianensis", 2, "Fenologia Reprodutiva e Potencialidade de Cruzamentos entre Individuos em uma População de Baixa Densidade de C. multiflora na Amazônia Central" e 3, "Sistema Reprodutivo de uma População de Baixa Densidade de Couratari multiflora na Amazônia Central”, incluídos na seção de Resultados da dissertação, tratam especificamente suas metodologias particulares. 
RESULTADOS 


\section{VARIABILIDADE GENÉTICA INTRAPOPULACIONAL DE DUAS ESPÉCIES DE BAIXA DENSIDADE NA AMAZÔNIA CENTRAL: Couratari mutiflora (J.M.Smith) Eyma e Couratari guianensis Aublet (LECYTHIDACEAE).}

\subsection{INTRODUÇÃO}

O significado do tamanho das populações quanto às dinâmicas evolucionárias, estruturas genéticas e reprodutivas é amplamente reconhecido e é hoje um foco central na biologia da conservação. Um dos objetivos de muitos programas de conservação, em adição à preservação do habitat, é a manutenção dos níveis existentes da variação genética nas espécies raras ou ameaçadas de extinção (FRANKEL \& SOULÉ, 1981; SIMBERLOFF, 1988). Existem dados empiricos e especulações teóricas de que a perda da variação genética reduz a habilidade das populações adaptarem-se a ambientes em mudança e de aumentarem suas susceptibilidades a pressões de pragas e doenças (ELLSTRAND \& ELLAM, 1993).

A importância relativa das quatro forças evolucionárias, mutação, seleção natural, migração e deriva aleatória genética difere entre espécies e grupos ecológicos (BARRETT \& KOHN, 1991). As populações de baixa densidade podem sofrer dois fenômenos genéticos: i. a deriva genética, a qual provoca a perda da variação genética mais rapidamente que em populações maiores e, ii. a endogamia, ou acasalamento entre parentes, que pode significar perda de heterozigosidade e, alguns casos, consequentemente de "fitness" (CHARLESWORTH \& CHARLESWORTH, 1987).

A distribuição e a quantidade da diversidade genética dentro e entre populações de plantas raras dependem provavelmente da constância da raridade no tempo e espaço, ou, se essas espécies têm sempre sido raras ou tornaram-se raras recentemente, como resultado da influência antrópica (BARRETT \& KOHN, 1991) ou estocasticidades naturais (SCHENSKE et al., 1994). Espécies que naturalmente ocorrem distribuidas esparsamente podem possuir sistemas genéticos ajustados à endogamia, bem como adaptações que sobreponham a desvantagem de raridade, como por exemplo, sistemas reprodutivos mais especializados. Já populações historicamente grandes e exogâmicas que declinaram de repente a poucos indivíduos, em geral, experimentam viabilidade e fecundidade reduzidas, conhecida como depressão endogâmica (LANDE, 1988). 
Couratari multiflora e C. guianensis, espécies amplamente distribuidas, são representadas por populações de baixa densidade no local de estudo, com 1 indivíduo adulto a cada 10 ha para a primeira e 1 a cada 15 ha, para a segunda. A segunda espécie, através de sua distribuição geográfica, sofre mudanças nos seus tamanhos populacionais, conforme apontado por MITCHEL \& MORI (1990). As informações disponiveis para a primeira espécie aparentemente demonstram densidades populacionais constantes.

LEPSCH-CUNHA \& KAGEYAMA (1996a) discutiram a questão da raridade em florestas tropicais e dentre os 4 tipos de raridade tropical apontados por BAWA \& ASHTON (1991), as courataris aparentemente se encaixam $\mathrm{em}$ duas delas. C. multiflora estaria na categoria de espécie uniformemente rara através de sua ampla extensão geográfica ( 1 indivíduo ou menos por ha) e, conforme sugerido pelos autores, nesta categoria a expectativa é de exogamia com altas taxas de cruzamento, mecanismos eficientes de dispersão de pólen e sementes a longas distâncias. Já C. guianensis pertenceria a categoria de espécies que possuem densidades populacionais baixas $\mathrm{cm}$ alguns locais, comuns $\mathrm{em}$ outros, $\mathrm{e}$ as consequências genéticas dependerão grandemente da densidade populacional predominante da espécie. Os autores propõem, que a redução populacional pode levar à diminuição no nível de heterozigosidade, e se o tamanho populacional persistir por muitas gerações, a fixação de alelos pode ocorrer via endogamia e deriva genética.

Neste trabalho estamos testando a hipótese de que ambas espécies têm variabilidade genética próximas e proporções de endogamia diferentes. As predições baseadas nas informações e suposições dos tamanhos populacionais das duas espécies são que C. multiflora apresentará índices de fixação próximos a zero, tendendo a um sistema de cruzamento aleatório, enquanto $C$. guianensis apresentará alguma proporção de endogamia, tendendo a um sistema misto de reprodução como resultado de adaptação a oscilações populacionais. A especialização das flores, a dispersão pelo vento e a distribuição geográfica ampla predizem variabilidade alta para ambas espécies.

Nossos objetivos são estimar os parâmetros de diversidade genética e os indices de fixação intrapopulacional de cada uma das duas espécies, comparando esses índices entre progênies, jovens e adultos, quando possivel. A relação entre essas categorias de idade pode informar sobre o caminho da seleção, se estiver ocorrendo, bem como a possível trajetória populacional dessas populações. 


\subsection{MATERIAL E MÉTODOS}

\subsection{1. ÁREA E NÚMERO DE INDIVÍDUOS ANALISADOS NAS CATEGORIAS DE IDADE/TAMANHO}

Para a realização deste trabalho utilizamos uma área total de 385 ha, onde 27 individuos considerados adultos $(\geq 20,0 \mathrm{~cm}$ DAP) de $C$. guianensis e 41 indivíduos considerados adultos $C$. multiflora, respectivamente, foram continuamente localizados e mapeados. Além desses, 6 jovens desta última espécie e 26 jovens $(<20.0 \mathrm{~cm}$ DAP) daquela foram amostrados. Isto significa que todos os adultos localizados nessa área foram analisados quanto às estimativas dos parâmetros genéticos aqui calculadas, não ocorrendo o mesmo com os indivíduos jovens. Analisamos a categoria de progênies de $C$. multiflora, pois esta espécie frutificou durante trabalho de campo. Fizemos as análises a partir de 4 famílias somente pela dificuldade de coleta de sementes maduras viáveis, em função da alta predação por animais e/ou aborto de frutos imaturos, conforme trabalho de fenologia reprodutiva de LEPSCH-CUNHA \& KAGEYAMA (1996c). A facilidade de visualização de indivíduos jovens de C. guianensis permitiu a amostragem de vários deles, não ocorrendo o mesmo para $C$. multiflora, cujo baixo número de indivíduos jovens (6) foram analisados somente com o intuito de discutir amostragem. Assim, pudemos analisar quantitativamente e comparar as categorias de progênies e adultos desta espécie e as de jovens e adultos daquela.

\subsubsection{ANÁlISE DA DISTRIBUIÇÃO ESPACIAL}

Para esta análise, consideramos os indivíduos maiores de $20,0 \mathrm{~cm}$ de DAP para as duas espécies, pois somente estes foram continuamente levantados em toda a área. Utilizamos dois métodos de distâncias, e retiramos das análises de ambos, 100 metros de borda da área levantada para eliminar a tendência de organismos próximos às bordas terem distâncias ao vizinho mais próximo maiores do que os internos a ela, desta forma, a análise procedeu sempre com um número menor de indivíduos do que o realmente levantado. Métodos: 1) vizinho-mais-próximo descrito por CLARK \& EVANS (1954), no qual são consideradas as seguintes medidas: (a) $r_{A}=$ distância média ao vizinho mais próximo, (b) $r_{E}=$ distância esperada ao vizinho mais próximo, (c) $\tau=$ densidade de indivíduos. Mede-se o desvio do padrão observado com relação ao padrão aleatório pela razão índice de agregação: (d) $R=r_{E} / r_{A}$. Para $R=1, R=O$ e $\mathrm{R}=2,85$ o padrão é dito respectivamente, aleatório, agregado ou uniforme, testando $\mathrm{R}$ através da significância estatística de $\mathrm{z}$ da distribuiçao normal padrão; 2) distância do T-quadrado, 
descrito em Diggle (1976', cit. LUDWIG \& REYNOLDS, 1988), com os pontos amostrais feitos em malha regular dentro da área, onde duas distâncias são medidas em cada ponto aleatório: distância $\mathrm{x}$, do ponto $(\mathrm{O})$ ao vizinho mais próximo $(\mathrm{P})$ em qualquer direção; distância $\mathrm{y}$, onde uma linha perpendicular à linha $\mathrm{OP}$ no ponto $\mathrm{P}$ é feita, e a distância y é medida do indivíduo (P) ao seu vizinho mais próximo (Q) acima da metade do plano criado pela perpendicular. O padrão é dito aleatório, agrupado e uniforme, quando o quadrado esperado das distâncias ponto-indivíduo (índice $\mathrm{C}$ ) é aproximadamente igual $1 / 2,>1 / 2 \mathrm{e}<1 / 2$ do quadrado esperado das distâncias vizinho-mais-próximo do T-quadrado, respectivamente. Além do índice (C), foi utilizado o índice (I) da distância da dispersão (Johnson \& Zimmer, 1985², cit. em LUDWIG \& REYNOLDS, 1988), onde para I $=2$, I $<2$ e I $>2$, respectivamente, o padrão é esperado ser aleatório, uniforme ou agrupado. Para testar C e I computa-se $\mathrm{z}$ diferentemente e a significância estatística é obtida através da distribuição normal padrão. Para este último método, utilizamos o programa TSQUARE incluído no livro dos últimos autores.

\subsubsection{COLETA, EXTRAÇÃO DE ISOENZIMAS, TRANSPORTE DE MATERIAL, ESTAQUIA E ENXERTIA}

$\mathrm{Na}$ época de marcação e mapeamento, coletamos folhas de alguns individuos e "rapidamente" transportamo-as em caixa de isopor com gelo para Piracicaba para testes iniciais de protocolos isoenzimáticos. Posteriormente, coletamos galhos, estacas e folhas de todos os indivíduos das duas espécies. Enviamos os galhos e estacas a Piracicaba conforme estes eram coletados para a tentativa de enxertia e estaquia respectivamente, com o objetivo de se obter folhas jovens próximas ao laboratório. Fizemos estaquia e enxertia para cerca de 100 indivíduos (1/2 de cada espécie aproximadamente), com 3 repetições de cada.

Maceramos as folhas em Manaus com tampão de extração completo do Dr. Namkoong-Liriodendron sp. (ALFENAS et al., 1991, pg 41), comumente utilizado para espécies tropicais, utilizando-se PVPP (Polivinil Polipirrolidona) e areia lavada. Filtramos a solução extraída em "wicks" (papel filtro próprio para eletroforese), conforme recomendado por KEPHART (1990), ou o suco armazenado em "ependorfs". Armazenamos os "wicks" e sucos em freezer a $-70^{\circ} \mathrm{C}$ (INPA), transportamo-os em caixas de isopor no gelo seco a $-70^{\circ} \mathrm{C}$ e armazenamo-os em Piracicaba em freezer a $-20^{\circ} \mathrm{C}$ e bujão de nitrogênio a menos de $-120^{\circ} \mathrm{C}$.

\footnotetext{
${ }^{1}$ DIGGLE. P.J.; BESAG, J.;GLEAVES, J.T. Statistical analysis of spatial point patterns by means of distance methods. Biometrics, 32:659-667, 1976

2 JOHNSON, R.B. \& ZIMMER, W.J. A more powerful test for dispersion using distance measurements. Ecology, 66:1084-85, 1985.
} 
Os procedimentos de transporte, armazenamento, coleta de galhos, estacas e folhas no campo para fins de enxertia, estaquia e extração direta estão pormenorizadamente descritos em FERRAZ et al. (1994).

\subsubsection{PROCEDIMENTOS DE ELETROFORESE}

Realizamos as análises eletroforéticas preliminares com 5 sistemas tampões gel/cuba: Litio-citrato (SCANDALIOS, 1969), Borato (POULIK, 1957), Citratomorfolina (CLAYTON \& TRETIAK, 1972), Histidina (BROWN et al., 1975) e Tris-citrato (SOLTIS et al., 1983). Testamos 26 sistemas isoenzimáticos a saber: álcool desidrogenase (ADH - EC 1.1.1.1), aldolase (ALD - EC 4.1.2.13), catalase (CAT - EC 1.11.1.6), endopeptidase (ENP - EC 3.4.-.-), enzima málica (ME - EC 1.1.1.40), alfa-Esterase ( $\alpha$-EST - EC 3.1.1.1), betaEsterase ( $\beta$ EST - EC 3.1.1.1), fosfatase ácida (ACP - EC 3.1.3.2), fosfatase alcalina (ALP - EC 3.1.3.1), 6-fosfogluconato desidrogenase (6PGDH - EC 1.1.1.44), fosfoglucose isomerase (PGI - EC 5.3.1.9), fosfoglucomutase (PGM - EC 2.7.5.1), fosfoglucose-isomerase (PGI - EC 1.1.1.44), gliceraldeído-3-fosfato desidrogenase (G3PDH - EC 1.2.1.12), glicerato-2 desidrogenase (G2DH - EC 1.1.1.29), glucose desidrogenase (GLUDH - EC 1.1.1.47), glucose6-fosfato desidrogenase (G6PDH - EC 1.1.1.49), glutamato desidrogenase (GDH - EC 1.4.1.3), glutamato-oxaloacetato (GOT - EC 2.6.1.1), isocitrato desidrogenase (IDH - EC 1.1.1.42), leucina aminopeptidase (LAP - EC 3.4.11.1), manitol desidrogenase (MADH - EC 1.1.1.67), malato desidrogenase (MDH - EC 1.1.1.37), peroxidase (PO - EC 1.11.1.7), sorbitol desidrogenase (SDH - EC 1.1.1.14), superóxido dismutase (SOD - EC 1.15.1.1) e xiquimato desidrogenase (SKDH - EC 1.1.1.25).

Após testes preliminares combinando-se concentrações diferentes de receitas fornecidas por ALFENAS et al. (1991, vários autores), MURPHY et al. (1990, vários autores) e SOLTIS \& SOLTIS (1990, vários autores), os melhores resultados obtidos para os adultos das duas espécies foram: MDH, PGI, PGM, PO e SK, com excessão a EST, que apesar de ter sido revelada em ambas, somente em $C$. guianensis ocorreu coloração de todos os indivíduos. Nas progênies de $C$. multiflora o resultado foi o mesmo, com excessão a EST que não mostrou coloração alguma. As enzimas 6PGDH, IDH e ACP também apresentaram bons resultados em alguns géis, principalmente nas folhas dos rebrotos das estacas e progênies, exceto $\mathrm{ACP}$, somente nas progênies. Porém, no geral, foram muito claras na coloração ou com muitos indivíduos ausentes, dessa forma devem ser bem promissoras com material fresco e/ou jovem. 
As enzimas IDH, PGM, MDH, EST e ACP tiveram melhores resultados no tampão gel/cuba descontínuo Histidina, enquanto PO no tampão contínuo citrato-morfolina. As enzimas 6PGDH, PGI e SKDH responderam igualmente para os dois tampões e também no sistema tampão tricitrato. Todas essas enzimas mostraram polimorfismo.

Testamos a inclusão ou não de mercaptoetanol e DDT para o tampão de extração nos rebrotos de adultos, com melhores resultados na presença de ambas substâncias. No entanto, nas progênies, a enzima PO não respondia na presença de mercaptoetanol, tendo sido retirado. As enzimas restantes responderam como nos adultos. Para o material fresco, a conservação de "wicks" em freezer a -20C por 2 semanas ou mais para adultos e progênies não mostrou diferenciação quanto ao material recém extraído (no mesmo dia da corrida).

$\mathrm{Na}$ confecção do gel, utilizamos penetrose de amido a 13\%, com a inclusão de sacarose a $4 \%$ no tampão de gel Histidina, com resultados bem melhores para a enzima MDH. Testamos gel feito com amido da SIGMA e aparentemente não houve diferença na revelação.

Após a coloração e revelação, inicialmente lavamos os géis com água destilada, fixamo-os com glicerina a $10 \%$ e transparentizamo-os com folhas de acetato em bastidores para a secagem. Após maior certificação dos padrões isoenzimáticos, passamos a utilizar a fotografia e em ambos procedimentos utilizamos filme de plástico onde as bandas eram copiadas com canetas de retroprojetor por sobreposição ao gel, guardando as dimensões originais. Procuramos sempre incluir 1 e/ou 2 individuos repetidos (sempre os mesmos) em todos os géis para padronização, e as mães nos géis com as progênies.

Para as corridas eletroforéticas utilizamos $35-40 \mathrm{~mA}$ de corrente constante e voltagem 250-300 V conforme a corrente do gel para ambos sistemas tampões, nunca superior a $6 \mathrm{~mA}$ por $\mathrm{cm}$. O tempo de corrida para todas as enzimas com excessão a MDH eram de 5-6 horas, e de 7-8 horas para esta última, resultando em $8-10 \mathrm{~cm}$ de migração do marcador bromofenol.

\subsubsection{Tampões de gel/cuba}

1. HISTIDINA: cuba: $0,2 \mathrm{M}$ de tris, $0,05 \mathrm{M}$ de ácido cítrico e $1000 \mathrm{ml}$ de água; gel: 0,05M histidina, titular com Tris $1 \mathrm{M}$, diluir com água a 1:9, adicionar sacarose a 4\%. 2. CITRATO-MORFOLINA pH 6.1: cuba: Ácido cítrico 0,04M, $1000 \mathrm{ml}$ de água, titular com morfolina; gel: 1:20 de água. 


\subsubsection{Sistemas enximáticos}

1. $\alpha$-EST: Solução A: $1 \mathrm{ml}$ de $\alpha$ naftil acetato(1\%) (40mg em $1 \mathrm{ml}$ de acetona a $100 \%)+40 \mathrm{ml}$ tampão fosfato de sódio $0,05 \mathrm{M}$ ( $0,2 \mathrm{M}$ de fosfato de sódio monobásico $+0,38 \mathrm{M}$ de fosfato de sódio bibásico) pH 6.0; Solução $\mathrm{B}: 10 \mathrm{ml}$ de tampão fosfato de sódio $\mathrm{pH} 6.0+80 \mathrm{mg}$ de fast garnet GBC (salt) dissolvido em $4.0 \mathrm{ml}$ de propanol. Adicionar solução A sobre o gel por 20', após isto adicionar solução B; Melhor fatia: qualquer uma. 2. $\mathbf{M D H}: 50 \mathrm{ml}$ de tris- $\mathrm{HCl}$ 0,2M pH $8.0+$ DL-ácido málico 2,0M pH 8.0 (titular com $\mathrm{NaOH}$ ) $+10 \mathrm{mg}$ de NAD $+5 \mathrm{mg}$ de MTT + 10 mg de PMS; Melhor fatia: as duas primeiras. 3. PGI: $50 \mathrm{ml}$ de Tris- $\mathrm{HCl} 0,1 \mathrm{M} \mathrm{pH} 8.0+40 \mathrm{mg}$ de frutose-6-fosfato, $\mathrm{Na}_{2}+10 \mathrm{mg} \mathrm{NADP}+10 \mathrm{mg}$ de MTT $+1 \mathrm{mg}$ de PMS + $10 \mathrm{mg}$ de $\mathrm{MgCl} 2$ $(1 \%)+20$ unidades de glucose-6-fosfato desidrogenase. Melhor fatia: qualquer uma. 4. PGM: $50 \mathrm{ml}$ de Tris- $\mathrm{HCl} 0,1 \mathrm{M} \mathrm{pH} 8.5+140 \mathrm{mg}$ de glucose-1-fosfato, $\mathrm{NA}_{2}+25 \mathrm{mg}$ de EDTA +10 mg de NADP + 10 mg de MTT, + 10 mg de PMS + 10 mg de $\mathrm{MgCl} 2+20$ unidades de glucose6-fosfato desidrogenase. Melhor fatia: $2^{\mathrm{a}}$. 5. PO: $30 \mathrm{mg}$ de 0-Dianisidina bi- $\mathrm{HCl}+1 \mathrm{ml}$ de $\mathrm{H}_{2} \mathrm{O}_{2}$ a $3 \%+50 \mathrm{ml}$ de tampão acetado de sódio $0,1 \mathrm{M} \mathrm{pH} 4.5$ (ajustar com ácido acético) $+2 \mathrm{ml}$ $\mathrm{CaCl} 2$ a $1 \%$. Incubar e após $30^{\prime}$ colocar a solução de $\mathrm{H}_{2} \mathrm{O}_{2}$; Melhor fatia: $2^{\text {a }}$. 6. SKDH: $50 \mathrm{ml}$ de Tris-Hcl 0,1M ph $8.0+50 \mathrm{mg}$ de ácido xiquímico + $10 \mathrm{mg}$ de NADP e $+10 \mathrm{mg}$ de MTT +2 mg de PMS; Melhor fatia: $3^{\mathrm{a}}$.

-Observações: fizemos os géis para produzirem 5 fatias, a primeira sendo sempre descartada. Assim, $2^{\mathrm{a}}$ fatia corresponde a primeira fatia (superior) a ser corada e assim sucessivamente, sendo a quarta a última. Incubamos todos os sistemas a 35-37 $\mathrm{C}$ por cerca de 1 hora, com excessão a PO que deve ser interpretada logo após colocação de água oxigenada. Alguns sistemas podem ser lidos no dia seguinte mas perdem muito em definição. A concentração a $3 \%$ $\mathrm{H}_{2} \mathrm{O}_{2}$ para $\mathrm{PO}$ não deve ser ultrapassada pois não responde efetivamente e a solução deve ser feita na hora. A quantidade de ácido xiquímico também não respondeu bem a maiores concentrações. $\mathrm{MDH}, \mathrm{PGM}$ e SKDH respondiam melhor quando incubadas no escuro.

\subsubsection{ANÁLISE DA VARIABILIDADE GENÉTICA ${ }^{3}$}

Utilizamos o programa BIOSYS (SWOFFORD \& SELANDER, 1989) para a geração das estimativas de frequências alélicas e genotípicas, heterozigosidade observada e esperada por loco, medida da diversidade gênica ou heterozigosidade média, número médio de

\footnotetext{
3 Descriçào detalhada do cálculo dos estimadores dos parâmetros genéticos e discussão sobre suas propriedades e testes estatísticos estđo em LEPSCH-CUNHA \& KAGEYAMA, 1996a.
} 
alelos por loco (A), porcentagem de locos polimórficos (P) e índices de fixação ou coeficientes de endogamia $F$ de WRIGHT $(1965,1978)$ por loco e para a populacão $\left(F_{m}\right)$. Este programa calcula as estimativas dos parâmetros genéticos considerando como loco polimórfico aquele com frequência do alelo mais comum não excedendo 0,95 .

As estimativas são calculadas conforme BROWN \& WEIR (1983) e NEI (1987) da seguinte forma: 1. a porcentagem de locos polimórficos (P) pela divisão do número de locos polimórficos pelo número total de locos analisados; 2 . o número médio de alelos por loco (A) pela soma de todos os alelos observados e dividindo-a pelo número total de locos; 3 . o número efetivo de alelos $\left(\mathrm{A}_{\mathrm{e}}\right)$ para cada loco por $\mathrm{A}_{\mathrm{e}}=1 / \Sigma \mathrm{p}_{\mathrm{i}}^{2}$, onde $\mathrm{p}_{\mathrm{i}}$ é igual à frequência alélica do loco i, calculando-se a média aritmética em seguida para todos os locos.

O programa BIOSYS calcula também os desvios da distribuição do número de genótipos observados $\left(\mathbf{n}_{\mathbf{0}}\right)$ e esperados $\left(\mathbf{n}_{\mathfrak{e}}\right)$ sob as pressuposições do equilibrio de Hardy-Weinberg (EHW). Para isso, o programa calcula três testes: o teste exato de Fisher e mais dois testes $\chi^{2}$, um utilizando todos os genótipos individualizados (nagr, não agrupados), cujas frequências esperadas em geral são muito pequenas nas células, e calcula um outro, combinando os genótipos em classes (agr, categorias afins), e assim obtendo células com valores esperados maiores. O agrupamento é feito da seguinte forma: classe 1 - número de homozigotos para o alelo mais comum; classe 2 - número de heterozigotos entre o alelo mais comum e os alelos raros; classe 3 - número de homozigotos raros e outros heterozigotos. As significâncias dos testes foram consideradas conforme melhor representatividade das frequências nas células, priorizando-se o qui-quadrado sem agrupamento, seguido do agrupado e exato de Fisher respectivamente.

Os testes exatos são geralmente usados para tamanhos amostrais pequenos, quando há uma maior chance de ter números esperados pequenos no teste quiquadrado (WEIR, 1990a). Conforme este autor, mesmo em amostras moderadamente grandes, a existência de alelos raros no loco resulta em números esperados pequenos e, neste caso, os testes exatos são preferiveis. Apesar de básico, no entanto, nem sempre considerado, cabe salientar que o teste qui-quadrado não é recomendado de acordo com regras que dependem do tamanho amostral $\mathbf{n}$ e das frequências ou números esperados mínimos $\left(\mathbf{n}_{\mathbf{e}}\right)$. Segundo Cochran 
$\left(1952^{4}\right.$, cit. em GOMES, 1990) ele não deve ser usado quando $\mathrm{n}<20$ e quando $20<\mathrm{n}<40 \mathrm{com}$ frequência mínima $<5$. Em todos os casos, a frequência esperada mínima não deve ser $<1$. GOMES (1990) recomenda que a frequência esperada mínima não deve ser $<1$ e em poucos casos < 5. SIEGEL (1975) e SOKAL \& ROHLF (1983) aconselham que 20\% das células não devem ser $<5$. Quando essas regras não se aplicam, o teste exato de Fisher deve ser empregado, pois tem menores restrições quanto às frequências esperadas (SIEGEL, 1975). A partir dessas recomendações vindas de várias fontes, percebe-se a necessidade de prestar atenção nessas regras.

Na Tabela 3 , os números observados $\left(\mathbf{n}_{\mathbf{0}}\right)$ e esperados $\left(\mathbf{n}_{\mathfrak{e}}\right)$ correspondem às estimativas do teste empregado, ou seja, com ou sem agrupamento de genótipos. Neste último caso, o que está sendo mostrado são os genótipos e seus números e, naquele, as classes com os números dos genótipos agrupados conforme 1,2 e 3 acima.

O índice de fixação F de WRIGHT $(1922,1965)$ é obtido pela relação entre frequências observadas $\left(H_{o}\right)$ e esperadas $\left(H_{e}\right)$ de heterozigotos (descritas abaixo) e mede a fração de redução da heterozigosidade com relação ao esperado em uma população de acasalamentos aleatórios, conforme as expectativas do EHW. Ele é dado pela expressão:

$$
F=1-\left(H_{o} / H_{e}\right)
$$

Utilizamos outro teste citado na literatura para testar as significâncias de $F$ quanto ao EHW, através da estatística $\chi^{2}$ sugerida por LI \& HORVITZ (1953):

$$
\chi^{2}=F^{2} n(k-1)
$$

com $\{k(k-1)\} / 2$ graus de liberdade, $k=$ número de alelos e $n=$ tamanho amostral;

Fizemos o teste para o índice médio de fixação $\left(F_{m}\right)$ para cada categoria utilizando o tamanho amostral médio ou número (no.) médio de indivíduos, considerando todos os locos (parte inferior Tabela 2) e o número médio de alelos por loco $\left(\mathrm{A}=\mathrm{k}_{\mathrm{m}}\right.$, Tabela 2$)$. Os graus de liberdade resultaram em números fracionados em função de A ser fracionado também, assim, escolhemos o menor valor desse número para a consulta da Tabela de qui-quadrado. Exemplo, gl=2.4, consultamos gl=2, ou com possibilidade maior de rejeição da hipótese nula.

Fizemos uma combinação de todas as probabilidades do teste de Fisher conforme sugerido por Steel \& Torrie $\left(1980^{5}\right.$, cit. em SANTOS, 1994) para testar se a

\footnotetext{
${ }^{4}$ COCHRAN. W.G. The $\chi 2$ test of goodness of fit. Ann. Math. Stat., 23:315-345, 1952.

${ }^{5}$ STEEL, R.G.D. \& TORRIE, J.H. Principles and procedures of statises, $2^{2}$ ed., New York, MacGraw Hill, 1980, 475p.
} 
população em conjunto está em equilibrio, de forma que $\chi 2=\Sigma\left(-2 \ln \mathrm{P}_{\text {Fisher }}\right)$, onde $\ln \mathrm{P}_{\text {Fisher }}$ é igual ao logaritmo natural da probabilidade do teste de Fisher para cada loco, com os graus de liberdade iguais $(\mathrm{gl})$ à somatória dos $\mathrm{gl}(\Sigma \mathrm{gl})$ individuais de cada loco do teste de Fisher. Em função destes cálculos, todas as probabilidades de Fisher estão indicadas na Tabela 2. Quando esta probabilidade foi igual a 0,000 , consideramos o valor 0,001 para os cálculos. Em função desse teste combinado e o tamanho amostral pequeno para a maioria das categorias, apresentamos na Tabela 3 as probabilidades de Fisher para todos os locos.

A heterozigosidade observada $\left(H_{o}\right)$ para cada loco foi estimada por:

$$
H_{o}=1-\sum P_{i i}
$$

onde $P_{i i} \quad$ é igual a frequência de genótipos homozigotos observados para cada loco, e a heterozigosidade média observada é calculada pela média aritmética considerando-se todos os locos.

A heterozigosidade esperada $\left(H_{e}\right)$ para a população no equilibrio de Hardy-Weinberg, ou a proporção de heterozigotos esperados sob suas pressuposições foi computada para cada loco pela expressão de BROWN \& WEIR (1983) dada por:

$$
H_{e}=1-\sum \widetilde{p}_{i}^{2}
$$

- onde $\widetilde{p}_{i}$ é a frequência alélica estimada do alelo i. Para se calcular a heterozigosidade média, considera-se a média desses valores para todos os locos analisados (NEI, 1987). Consideramos as heterozigosidades tendenciosas dadas pelo programa BIOSYS, pois é com essa quantidade que este calcula os índices de fixação F.

Fizemos testes $\chi 2$ para os locos que rejeitaram a hipótese nula de ajuste ao EHW para verificação de ajuste ao EENW, conforme sugerido por VENCOVSKY (1994). Este teste é feito através da comparação do número de genótipos observados com aqueles esperados, calculados conforme as expectativas deste último modelo, que inclui o índice de fixação nos cálculos das frequências genotípicas esperadas (cruzamento aleatório mais autofecundação), onde a frequência de homozigotos $\left(A_{i} A_{i}\right)$ e heterozigotos $\left(A_{i} A_{j}\right)$ são iguais a:

$$
P_{i i}=p_{i}{ }^{2}+F p_{i}\left(1-p_{i}\right) \quad P_{i j}=2 p_{i} p_{j}(1-F),
$$

Quando o loco possui apenas 2 alelos, não existe graus de liberdade $(=0)$, devido ao emprego de F para o cálculo além das frequências alélicas estimadas.. As regras com relação ao uso dos testes qui-quadrado são consideradas aqui. 


\subsection{RESULTADOS}

\subsubsection{DISTRIBUIÇÃO ESPACIAL DOS INDIVÍDUOS}

A densidade resultante é de 1 indivíduo adulto por 10 ha para $C$. multiflora e 1 a cada 15 ha para $C$. guianensis. A Figura 1 mostra a distribuição espacial das duas espécies.

Analisamos o padrão de distribuição espacial a partir de somente 28 indivíduos de $C$. multiflora e 24 de $C$. guianensis, pois vários deles foram excluídos por estarem incluídos na borda de $100 \mathrm{~m}$ (Tabela 1) da área do levantamento. Os resultados dos dois métodos de análise estão na Tabela 1.

O padrão espacial dos indivíduos de $C$. multiflora foi considerado agregado nos dois métodos e o de $C$. guianensis aleatório para o método do vizinho mais próximo, e agregado para o método do T-Quadrado, com $\mathrm{P}<0,01$ para o índice I e $\mathrm{P}<0.05$ para o índice $\mathrm{C}$.

Para o caso de árvores espaçadas, e considerando que a área amostrada é relativamente grande para uma população de árvores, parece que o melhor método de análise é olhar o mapa de distribuição espacial dos indivíduos, que mostra alguns individuos em agrupamentos mais definidos de C. multiflora, com outros indivíduos esparsos, o mesmo ocorrendo com C. guianensis de maneira menos pronunciada quanto ao agrupamento.

Tabela 1. Resultados das análises da distribuição espacial. R, C e I = índices de agregação, explicados no texto, conforme método utilizado, vizinho-mais-próximo ou T-quadrado; $\mathrm{z}=$ teste da distribuição normal padrão para a significância dos indices; $*=\mathrm{P}<0.05$; $* *=\mathrm{P}<0.01$.

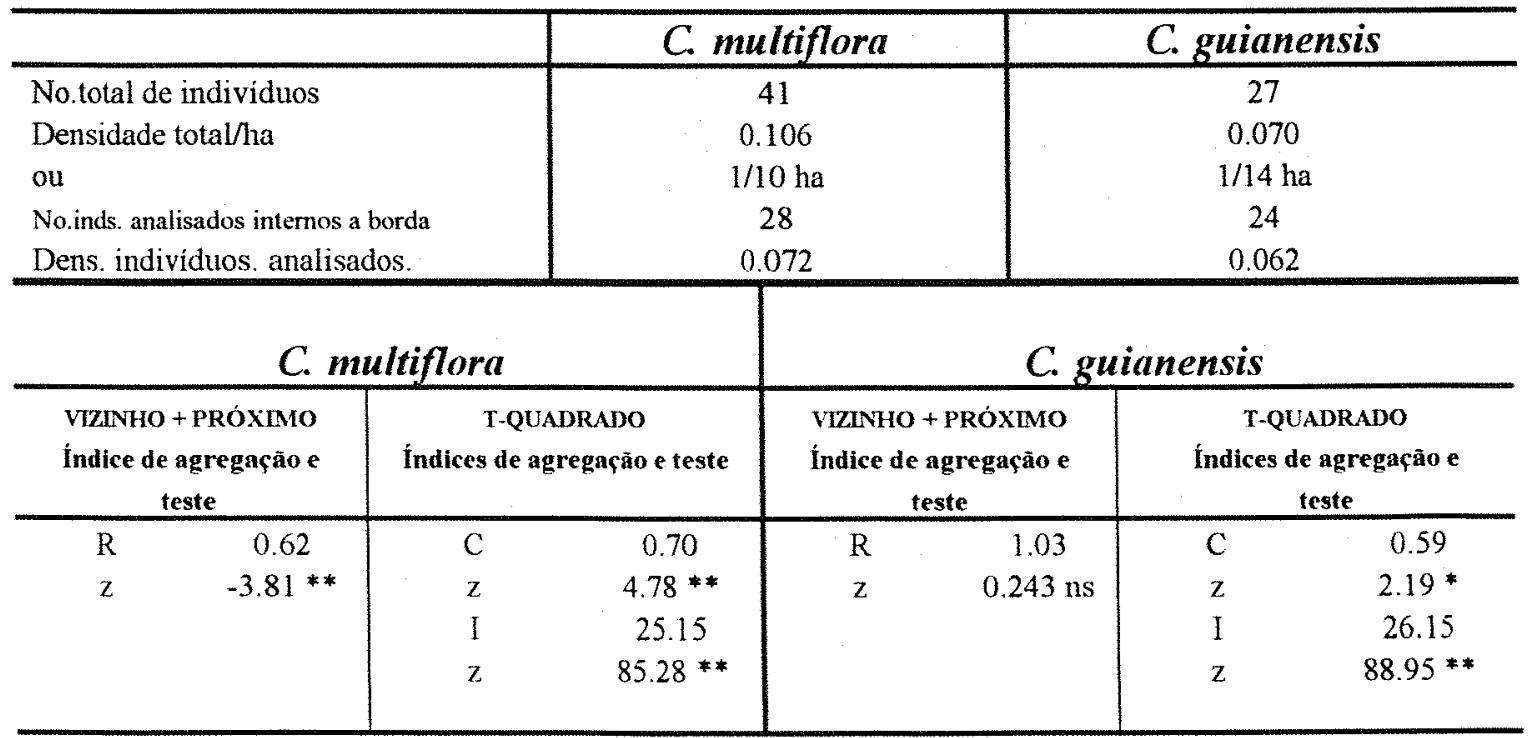




\section{C. multiflora}

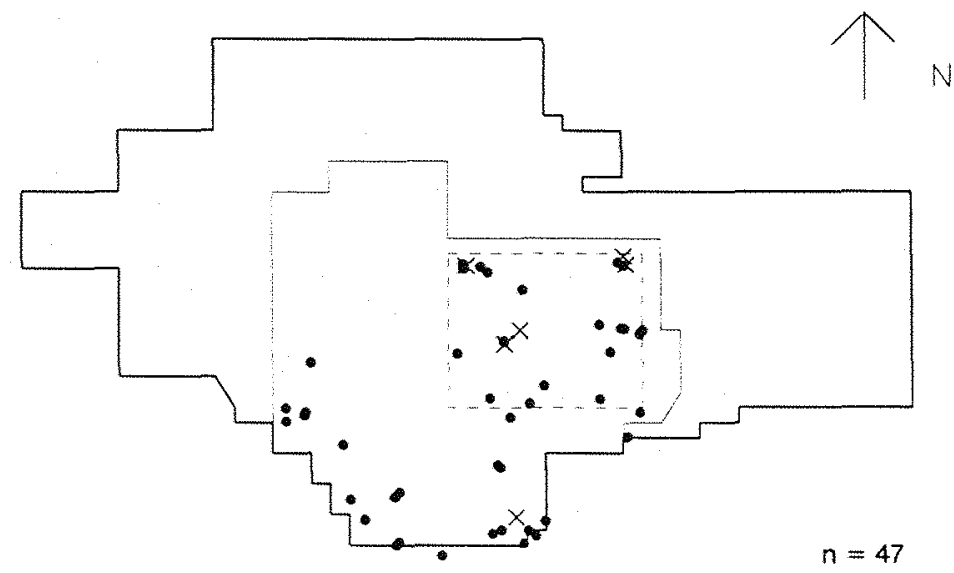

- Area da reserva - 1000 ha
- Parcela Lecythidaceae - 100 ha
- Levantamento totał - 400 ha

$\frac{11}{100 \mathrm{~m}}$

C. guianensis

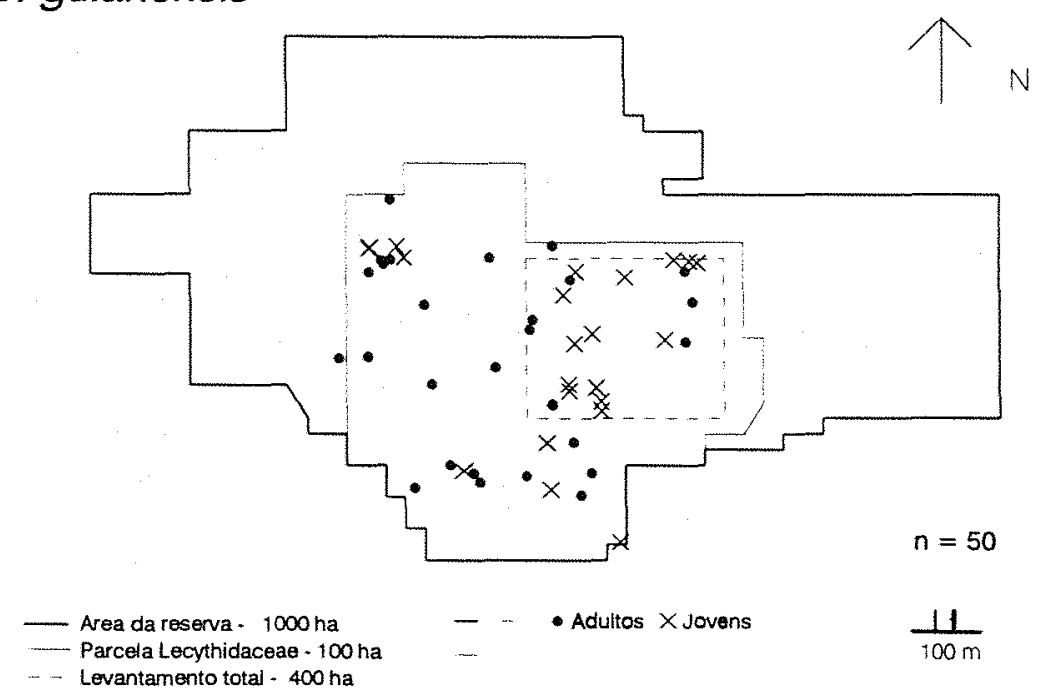

Figura 1. Distribuição espacial de adultos e jovens de $C$. multiflora e $C$. guianensis. $\mathrm{n}=$ número de individuos total. 


\subsubsection{ENXERTIA, ESTAQUIA E MATERIAL ESTOCADO:}

Da estaquia de galhos dos 100 individuos somente 17 rebrotaram e cerca de 1 mês depois, morreram, não desenvolvendo raizes. De qualquer forma, as folhas dos que rebrotaram foram utilizadas durante os testes de protocolos eletroforéticos, e a extrações armazenadas em "wicks" no freezer a $-20^{\circ} \mathrm{C}$. Comparações com as folhas dos mesmos individuos coletados em Manaus não revelaram nenhuma diferença nos padrões isoenzimáticos. A enxertia não deu resultado algum.

Do material trazido de Manaus, "wicks" e suco, aqueles armazenados no freezer a $-20^{\circ} \mathrm{C}$ responderam por cerca de 3 meses, perdendo muito em definição com relação aos armazenados no nitrogênio líquido depois desse tempo. Esses últimos foram utilizados por mais 2 meses com boa resolução. Não ocorreu diferença de resolução entre os "wicks" e suco armazenados.

\subsubsection{INTERPRETAÇÃO GENÉTICA E PADRÕES DA VARIAÇÃO ISOENZIMÁTICA}

Baseamos as interpretações dos seis sistemas enzimáticos nos padrões observados na população adulta, nas progênies e em consultas de material publicado. A interpretação das progênies permite maior certeza dos padrões já que há a necessidade de se confirmar o genótipo das mães com a segregação mendeliana nas progênies, ou seja, no mínimo cada progênie tem que apresentar um alelo da mãe. Isto só foi possível para $C$. multiflora. Os padrões estão na Figuras 2

Fizemos no mínimo 3 repetições das revelações de cada indivíduo adulto com o objetivo de certificação das interpretações, já que individuos coletados em Manaus não apresentavam folhas com o mesmo estado de saúde, o armazenamento foi relativamente longo, e há a possibilidade de mistura de materiais genéticos de fungos ou outros microrganismos.

A interpretação do padrão de bandas para cada espécie foi individualizada (Figuras 2,3,4,5,6 e 7), ou seja, apesar de mostrarem o mesmo padrão geral, os alelos com mesmos números não são necessariamente os mesmos, pois não fizemos comparações ao nível de espécie. As enzimas utilizadas foram as seguintes:

- $\alpha$ - EST (Alfa - esterase): As duas espécies mostraram o mesmo padrão, porém somente os individuos de $C$ guianensis foram constantes na revelação das bandas. Este sistema exibiu 3 zonas de coloração, com as duas mais externas, a mais lenta e a mais rápida na migração, consistentes com estrutura de subunidade monomérica. A zona mais rápida foi a única possível de 
interpretação, já que a mais lenta apresentou sempre vários indivíduos sem revelação, e a do meio não mostrou nitidez. A zona mais rápida foi interpretada como um único loco com 4 alelos.

- MDH - (Malato desidrogenase): Em ambas espécies, o sistema revelou 3 zonas, 2 delas, a mais rápida e a mais lenta consideradas como locos individuais e consistentes com um padrão dimérico. A zona interna, algumas vezes parecia dimérica outras monomérica, devido a sobreposição de bandas com as zonas externas. Todas as hipóteses quanto sua interpretação falharam em algum momento, portanto esse loco foi descartado das análises em ambas espécies. As zonas separaramse menos em C. guianensis, com MDH-1 e MDH-2 sobrepondo-se em muitos indivíduos e com possibilidade de interpretação duvidosa. Foram também retiradas das análises. Assim, MDH-1, com 2 alelos, e MDH-3, com 3 alelos, foram incluídas nas análises de $C$. multiflora e somente MDH-3, com 3 alelos, nas de C. guianensis. Nas progênies de C. multiflora MDH-1 apresentou 3 alelos, com o primeiro ausente nos adultos e MDH-3, 3 alelos, como nos adultos.

Figura 2. Pág. 50-55. Padrões isoenzimáticos, locos: A. Pág. 50: EST-1, interpretado somente para C. guianensis; B. Pág. 51: MDH-1 e MDH-3 interpretado para C. multiflora, e MDH-3 para $C$. guianensis: C. Pág. 52: PGI-1, interpretado para ambas espécies: D. Pág. 53: PGM-1 e PGM-2, interpretados para ambas espécies; E. Pág.54: PO-1 e PO-2, interpretados para ambas espécies nos adultos e somente PO-2 para as progênies; F. Pág. 55: SKDH-1, interpretado para ambas espécies. 1 $=$ géis e fotos de géis: 2 interpretações 
A
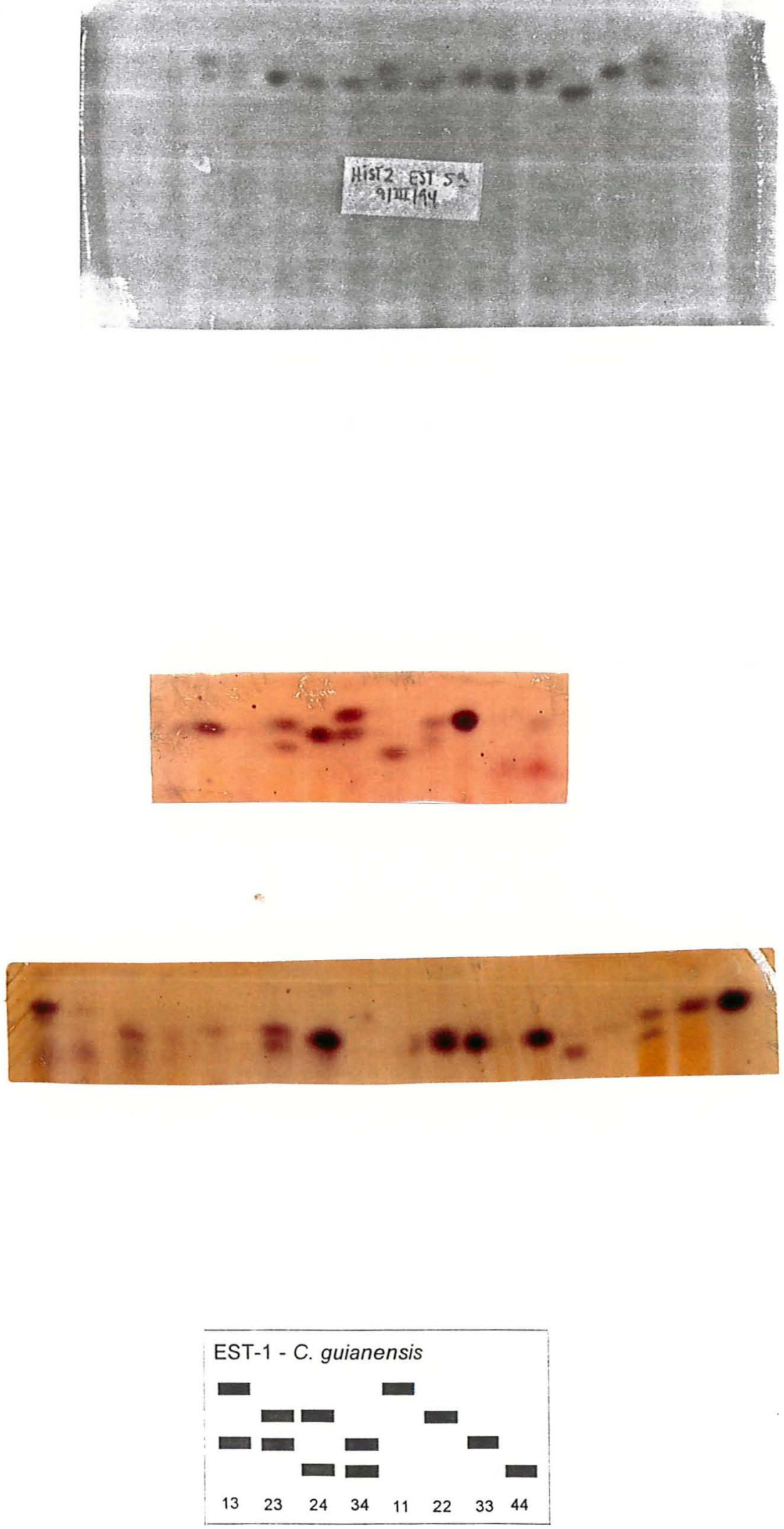


\section{B}
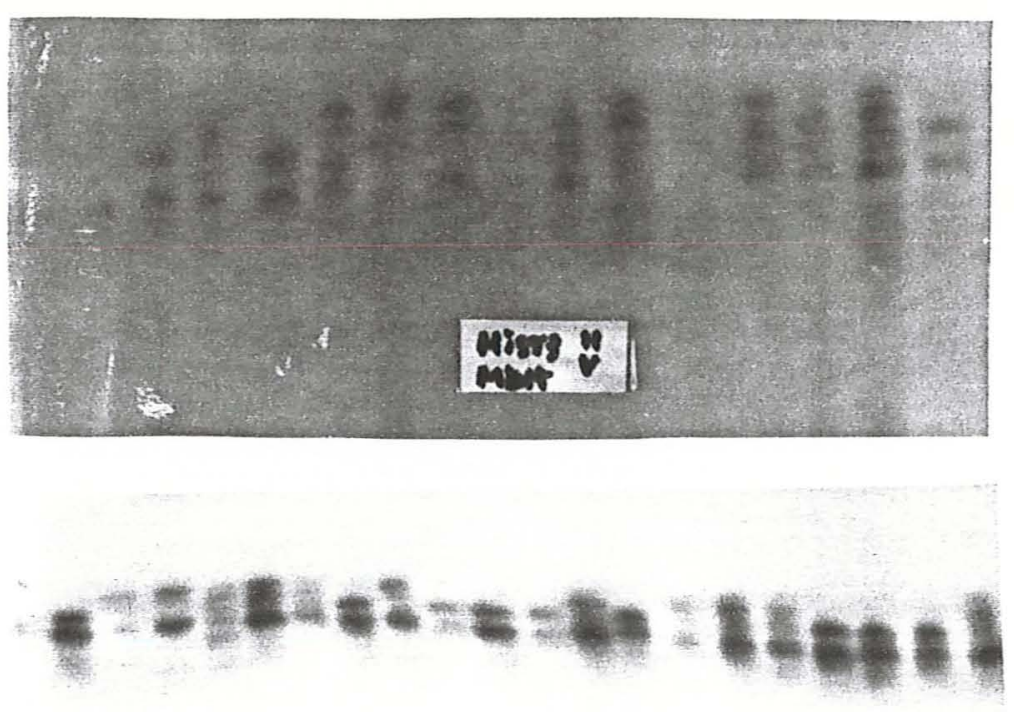

\section{H1 MDd \\ $23 \mathrm{~V}$}
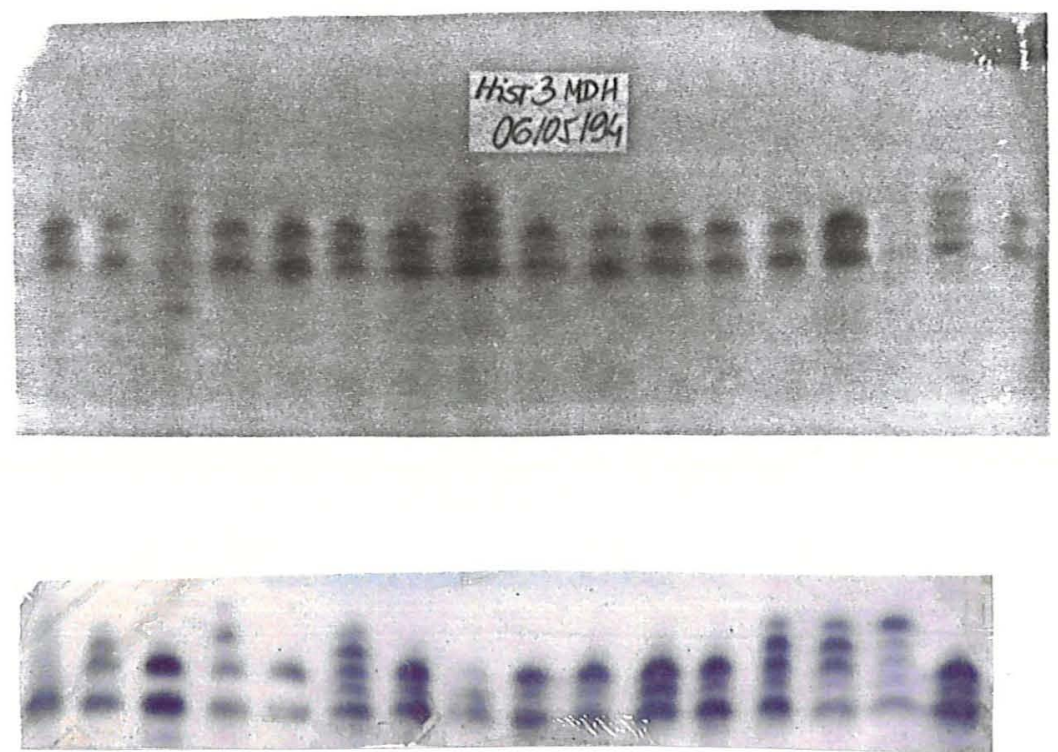

MDH-1 e MDH-3 - C. multiflora
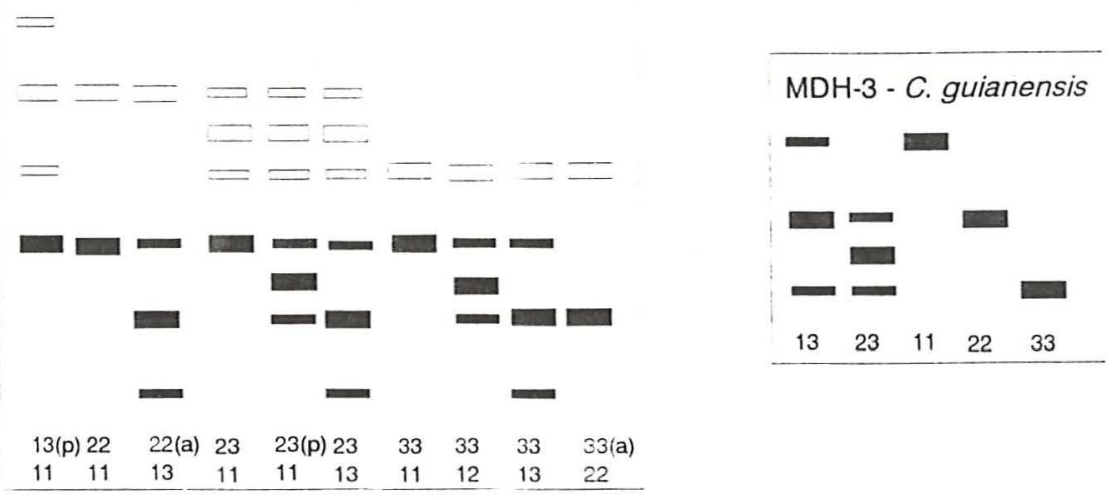

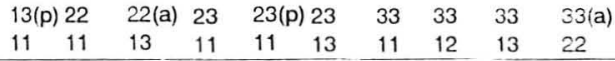


C
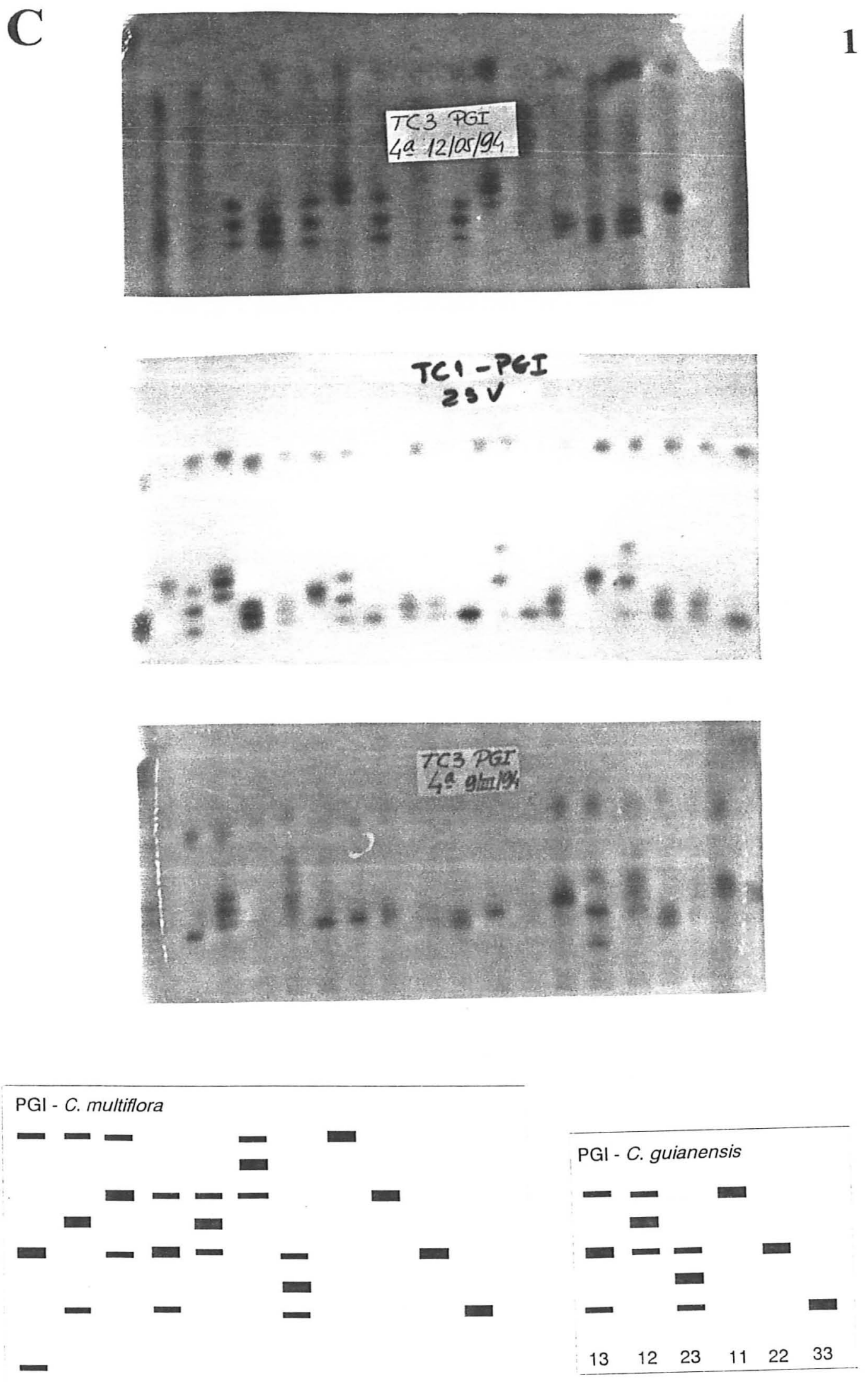

$\begin{array}{llllllllll}15 \text { (a) } & 14 & 13 & 24 & 23 & 12 & 34 & 11 \text { (a) } 22 & 33 & 44\end{array}$ 

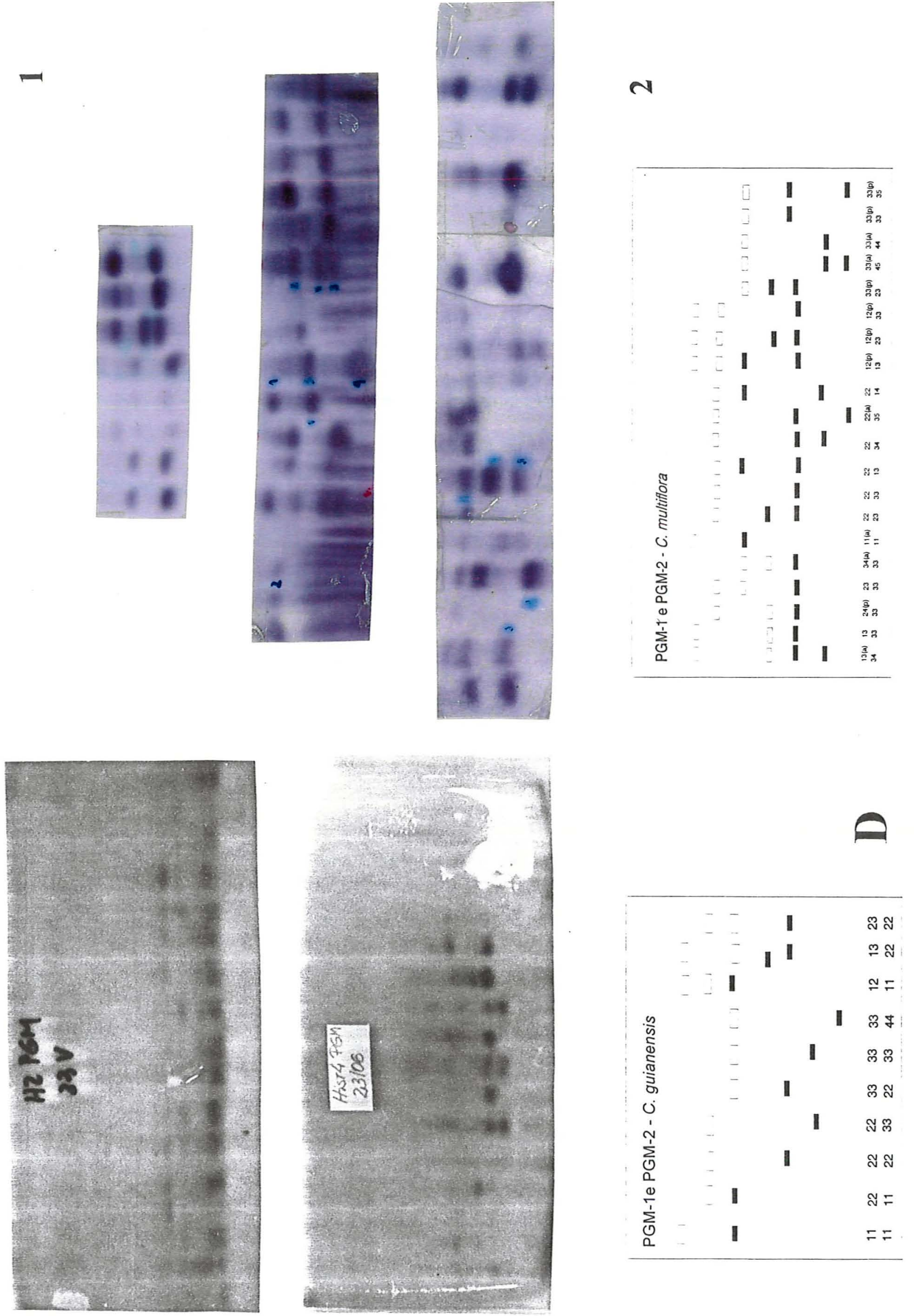
E
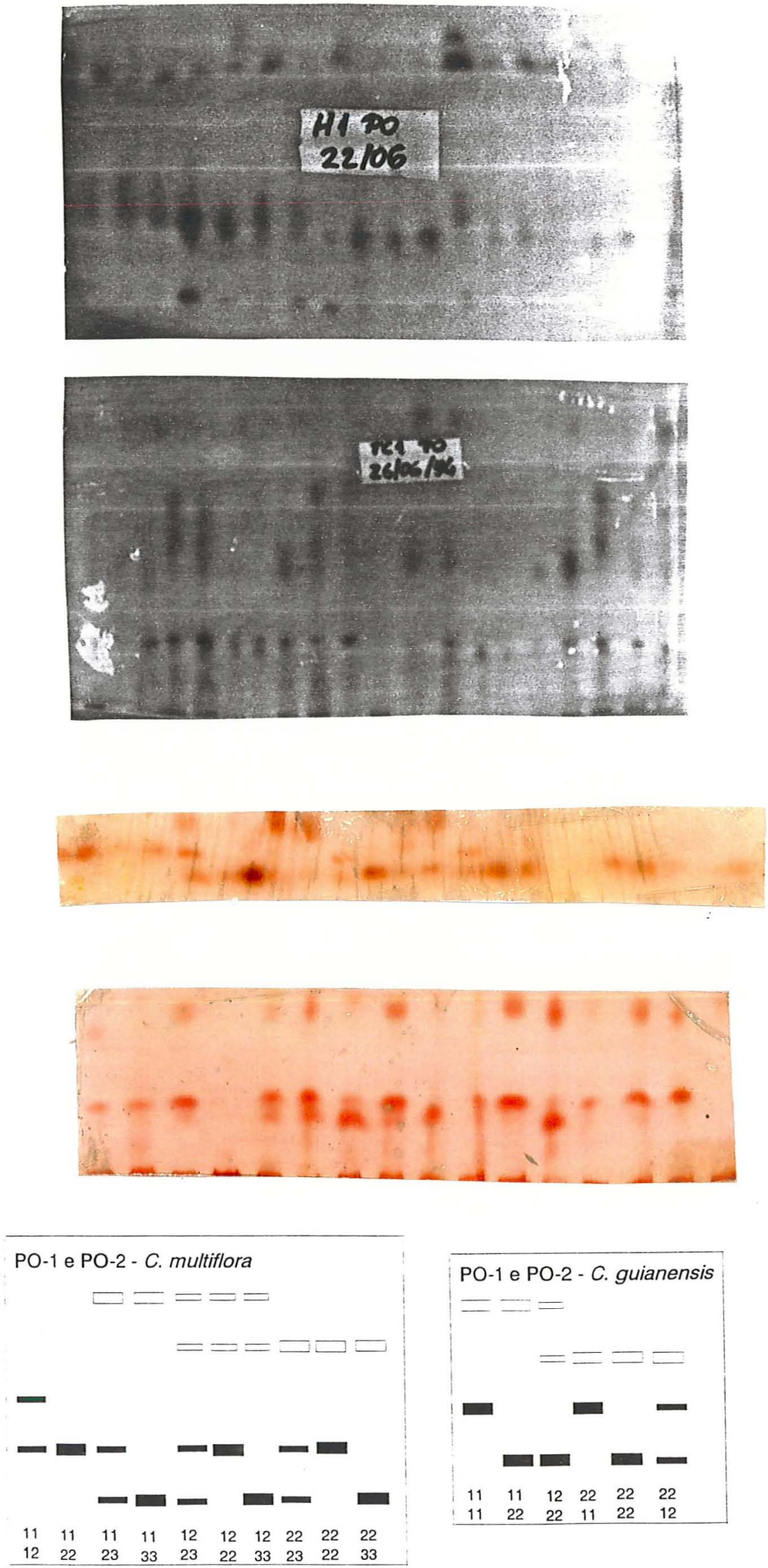

PO-1 e PO-2 - C. guianensis

$= \pm$

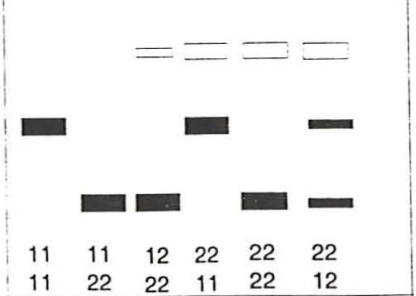


F
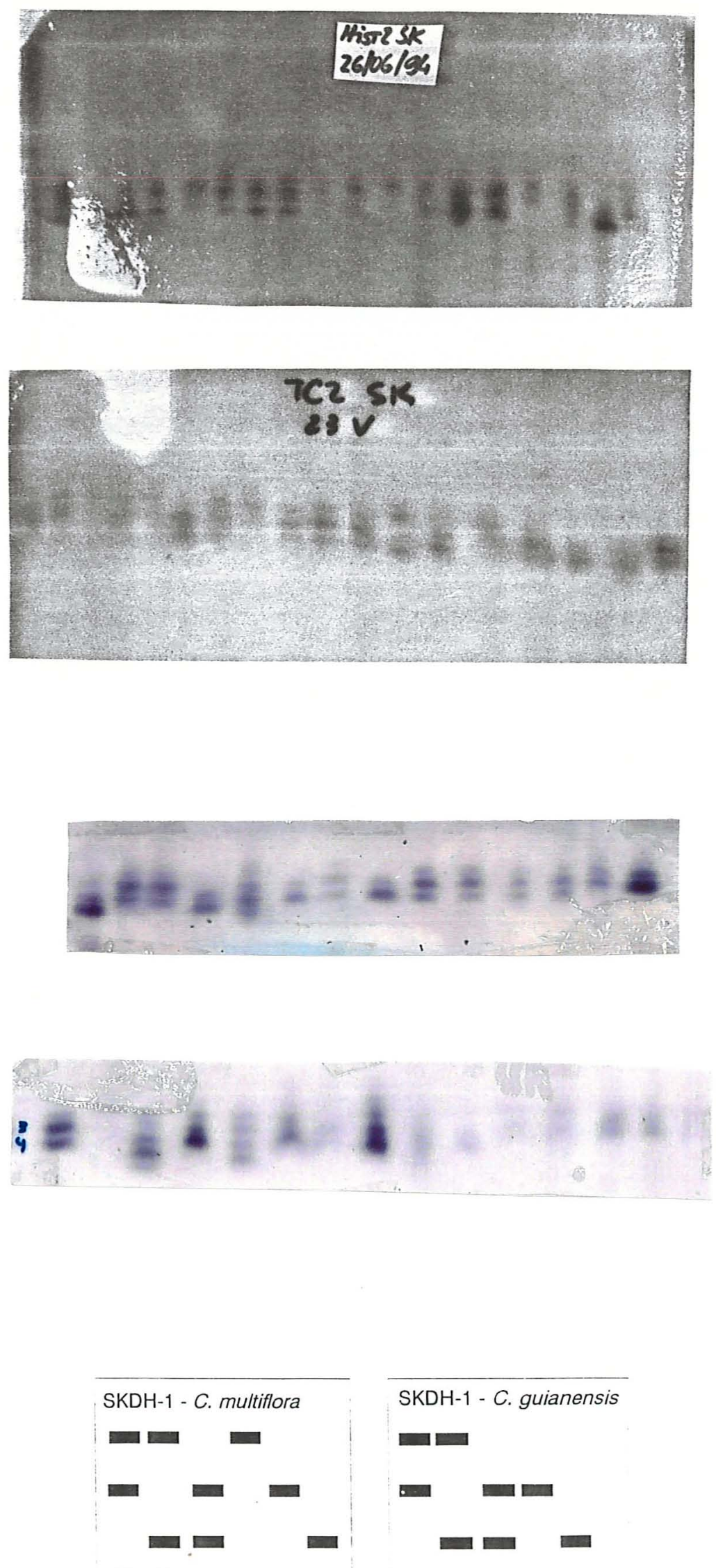

SKDH-1 - C. guianensis

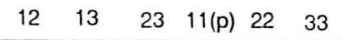

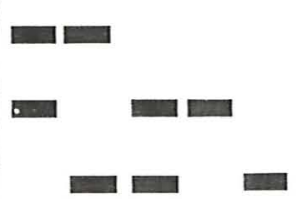

$\begin{array}{lllll}12 & 13 & 23 & 22 & 33\end{array}$ 
- PGI - (Fosfoglucose isomerase) - em ambas espécies, o sistema revelou 2 zonas polimórficas, consideradas como 2 locos, uma monomérica mais rápida, pouco constante e borrada, a qual foi descartada, e outra dimérica, com padrão muito bem definido utilizada nas análises. $\operatorname{Em} C$. multiflora, os adultos apresentaram 5 alelos e as progênies 4. C. guianensis apresentou um padrão menos variável com 3 alelos.

- PGM - (Fosfoglucomutase) - ambas espécies apresentaram 2 zonas bem distintas, consideradas como 2 locos monoméricos. Em adultos e progênies de C.multiflora, o loco 1, MDH-1 e o loco 2, MDH-2, apresentaram respectivamente 4 e 5 alelos. Em $C$. guianensis ambos locos apresentaram 3 alelos.

- PO - (Peroxidase) - ambas espécies apresentaram 3 zonas, as duas externas, a mais rápida e a mais lenta consideradas como 2 locos distintos, e a do meio sem distinção, com bandas borradas ou com rastros, muitas vezes parecendo representar mais do que 1 loco. Nos adultos de ambas espécies foi possivel interpretar com precisão PO-1 e PO-3, ambos locos com 2 alelos. Nas progênies de $C$. multiflora, somente PO-3 foi bem revelado, com a presença de 3 alelos.

- SKDH - (Xiquimato desidrogenase) - em ambas as espécies o sistema apresentou um padrão com 2 zonas, uma de coloração mais forte e outra mais fraca. Depois de estudada várias hipóteses e do exame criterioso da segregação das progênies, concluímos que este padrão é representado ou por dois locos, conforme a coloração, ou as bandas mais claras representam bandas fantasmas do loco de cor escura. WEEDEN \& GOTTLIEB (1980) descrevem para esse sistema padrão monomérico duplicado o qual corresponde ao padrão visto aqui. De qualquer forma, o loco de cor escura mostrou-se individualizado e, em função da incerteza quanto às bandas claras, decidiu-se interpretar somente o primeiro. Apesar dessas bandas se interporem, sempre o loco de coloração mais clara era o mais rápido, assim que o loco analisado representa o loco 2, SKDH-2. Ambas espécies e progênies apresentaram 3 alelos cada uma.

\subsubsection{VARIABILIDADE GENÉTICA}

1.3.4.1. Frequências alélicas, polimorfismo e número médio e efetivo de alelos por loco

As frequências alélicas, o número de individuos e suas categorias (progênies, jovens e adultos) analisados por loco, polimorfismo, número de alelos médio e efetivo por loco das duas espécies estão na Tabela 2. Vale repetir, que os jovens de $C$. multiflora estão 
sendo considerados somente com o intuito de discutir amostragem pequena, pois o pequeno número de indivíduos analisados (6) não permitem generalizações sobre a categoria em si.

Tabela 2. Frequências alélicas, número de indivíduos analisados por loco $(\mathrm{N})$, número médio de individuos por loco, número de alelos e locos totais, número médio de alelos por loco (A), número efetivo de alelos $\left(\mathrm{A}_{\mathrm{e}}\right)$, porcentagem de locos polimórficos $(\mathrm{P})$, para progennies, jovens, adultos e total (jovem + adulto) de $C$. multiflora e $C$. guianensis.

\begin{tabular}{|c|c|c|c|c|c|c|c|c|}
\hline \multirow[b]{2}{*}{ LOCO } & \multirow[b]{2}{*}{ ALELO } & \multicolumn{4}{|c|}{ C. multiflora } & \multicolumn{3}{|c|}{ C. guianensis } \\
\hline & & $\begin{array}{l}\text { Adulto } \\
\geq 20 \mathrm{~cm} \\
\end{array}$ & $\begin{array}{l}\text { Jovem } \\
<20 \mathrm{~cm}\end{array}$ & Progênie & $\begin{array}{c}\text { TOTAL } \\
\text { (Ad+Jov) }\end{array}$ & $\begin{array}{c}\text { Adulto } \\
\geq 20 \mathrm{~cm}\end{array}$ & $\begin{array}{l}\text { Jovem } \\
<20 \mathrm{~cm} \\
\end{array}$ & $\begin{array}{c}\text { TOTAL } \\
\text { (Ad+Jov) }\end{array}$ \\
\hline EST-1 & $\begin{array}{l}1 \\
2 \\
3 \\
4 \\
\mathrm{~N}\end{array}$ & $\begin{array}{l}. \\
. \\
.\end{array}$ & $\begin{array}{l}\cdot \\
\cdot \\
\cdot \\
\cdot\end{array}$ & . & $\begin{array}{l}\cdot \\
\cdot \\
\cdot \\
\cdot\end{array}$ & $\begin{array}{c}0.100 \\
0.300 \\
0.460 \\
0.140 \\
25\end{array}$ & $\begin{array}{c}0.079 \\
0.211 \\
0.605 \\
0.105 \\
19\end{array}$ & $\begin{array}{c}0.091 \\
0.261 \\
0.523 \\
0.125 \\
44\end{array}$ \\
\hline $\mathrm{MDH}-1$ & $\begin{array}{c}1 \\
2 \\
3 \\
\mathrm{~N}\end{array}$ & $\begin{array}{c}\frac{0.000}{0.200} \\
0.800 \\
40\end{array}$ & $\begin{array}{c}\frac{0.000}{0.083} \\
0.917 \\
6\end{array}$ & $\begin{array}{c}0.005 \\
0.359 \\
0.636 \\
103\end{array}$ & $\begin{array}{c}\frac{0.000}{0.185} \\
0.815 \\
46\end{array}$ & $\begin{array}{l}. \\
. \\
.\end{array}$ & $\begin{array}{l}. \\
. \\
.\end{array}$ & $\begin{array}{l}. \\
. \\
.\end{array}$ \\
\hline $\mathrm{MDH}-3$ & $\begin{array}{c}1 \\
2 \\
3 \\
\mathrm{~N}\end{array}$ & $\begin{array}{c}0.744 \\
0.159 \\
0.098 \\
41\end{array}$ & $\begin{array}{c}0.583 \\
0.417 \\
\frac{0.000}{6}\end{array}$ & $\begin{array}{c}0.951 \\
0.024 \\
0.024 \\
103\end{array}$ & $\begin{array}{c}0.723 \\
0.191 \\
0.085 \\
47\end{array}$ & $\begin{array}{c}0.444 \\
0.259 \\
0.296 \\
27\end{array}$ & $\begin{array}{c}0.522 \\
0.304 \\
0.174 \\
23\end{array}$ & $\begin{array}{c}0.480 \\
0.280 \\
0.240 \\
50\end{array}$ \\
\hline PGI-1 & $\begin{array}{l}1 \\
2 \\
3 \\
4 \\
5 \\
\mathrm{~N}\end{array}$ & $\begin{array}{c}0.232 \\
0.256 \\
0.378 \\
0.122 \\
0.012 \\
41\end{array}$ & $\begin{array}{l}0.167 \\
0.167 \\
0.667 \\
\frac{0.000}{0.000} \\
6\end{array}$ & $\begin{array}{l}0.049 \\
0.102 \\
0.500 \\
0.350 \\
\frac{0.000}{103}\end{array}$ & $\begin{array}{c}0.223 \\
0.245 \\
0.415 \\
0.106 \\
0.011 \\
47\end{array}$ & $\begin{array}{c}0.111 \\
0.796 \\
0.093 \\
\cdot \\
. \\
27\end{array}$ & $\begin{array}{c}0.114 \\
0.818 \\
0.063 \\
. \\
22\end{array}$ & $\begin{array}{c}0.112 \\
0.806 \\
0.082 \\
. \\
49\end{array}$ \\
\hline
\end{tabular}


Continuação da Tabela 2.

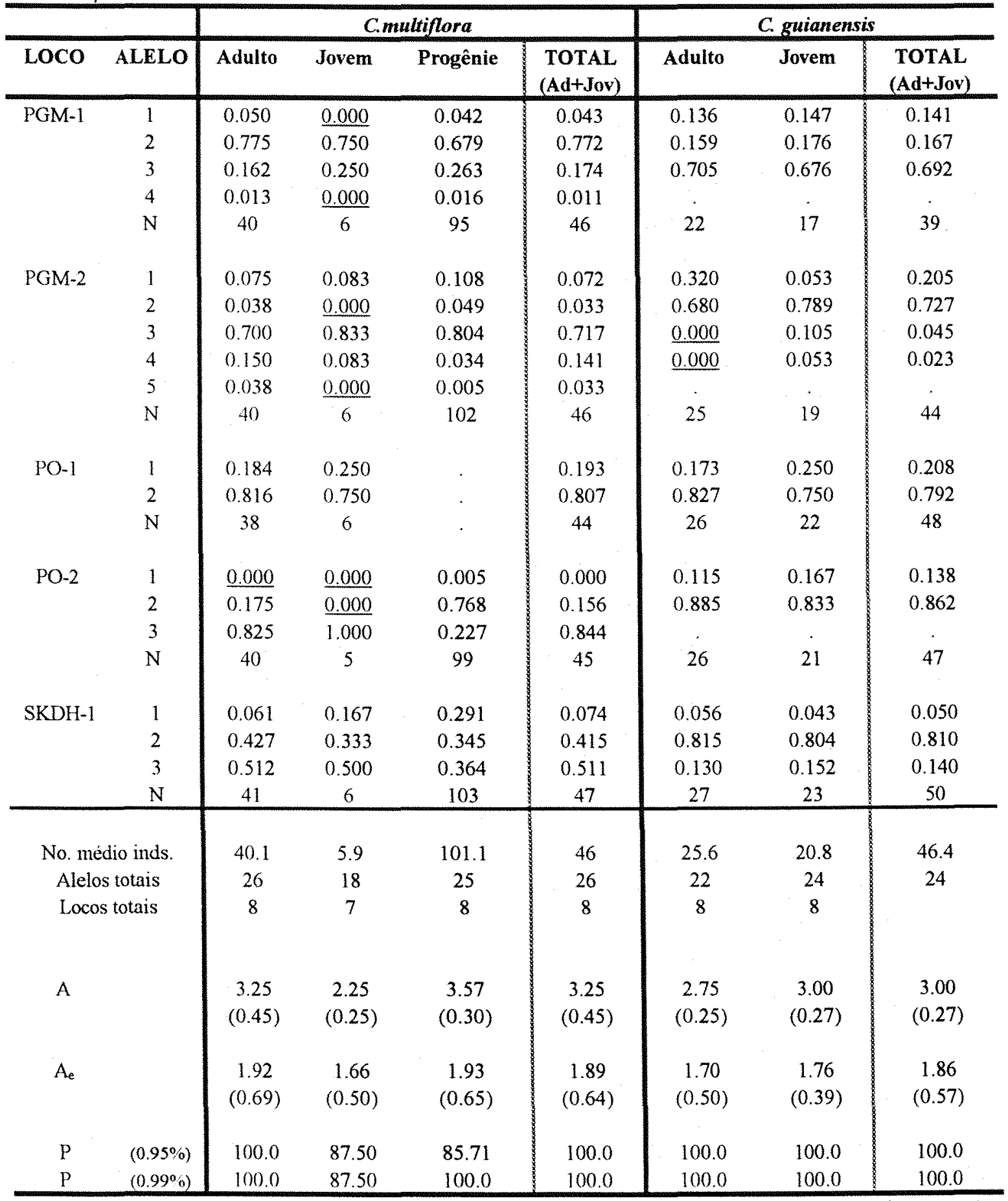

$\mathrm{N}$ = número de individuos analisados por loco; desvios padrões em parênteses; os alelos com frequência zero estão sublinhados. 
Para C. multiflora foram analisados 8 locos nos adultos e jovens, e 7 locos nas progênies. Os 6 jovens apresentaram 8 alelos a menos que os adultos e 10 alelos a menos com relação ao total, incluídas as progênies, resultado esperado devido à amostragem. As progênies possuem 2 alelos ausentestes nos adultos (alelo 1 de $\mathrm{MDH}-1$ e $\mathrm{PO}-2$ ) contra um somente presente nos adultos (alelo 5 de PGI). Os locos considerados monomórficos foram PO-2 nos jovens, com o alelo 3 fixado, e nas progênies, $\mathrm{MDH}-3$, porém sem fixação de alelos, com 2 alelos com frequências menores a $5 \%$. O número médio de alelos por locos $(\mathrm{A})$ das progênies, jovens e adultos foram respectivamente $3.57,2.25$ e 3.25 e os números efetivos de alelos $\left(A_{e}\right), 1.93,1.66 \mathrm{e}$ 1.92. A diferença entre $A$ e $A_{e}$ revela a presença de alelos de baixa frequência, e a diferença menor nos jovens $(0.59)$ quando comparada aos adultos e progênies $(1.64 ; 1.33)$ mostra a perda de alelos mais raros. pois a equitabilidade é maior nos jovens. Para os adultos. $100 \%$ dos locos examinados foram polimórficos e para os jovens e progênies, $87.5 \%$ e 85.71 , respectivamente. pelo critério de $95 \%$.

Para C. guianensis, 8 locos foram utilizados para as ambas categorias. Os 27 jovens apresentaram 2 alelos a mais no loco PGM-2 (grifado na Tabela 2) e ambos com frequências maiores a 5\%. Este loco possui um total de 4 alelos na população, 4 nos jovens e 2 nos adultos, e ambas as categorias não possuem heterozigotos (veja Tabela 5). Os homozigotos jovens para este loco que possuem alelos ausentes nos adultos não são, portanto, filhos de nenhum individuo da população atual. O número médio de alelos por loco (A) para jovens e adultos foi igual a 3.00 e 2,75, e os números efetivos de alelos $\left(A_{e}\right), 1,76$ e 1,70, respectivamente. As diferenças entre $\mathrm{A}$ e $\mathrm{A}_{\mathrm{e}}$ foram menores que na espécie anterior: $1.24 \mathrm{e} 1.05$, para jovens e adultos respectivamente. Ambas as categorias apresentaram 100\% de polimorfismo e, portanto, sem alelo fixado.

\subsubsection{Verificação da distribuição do número de genótipos observados com relação aos esperados pelo EHW e pelo EENW}

A Tabela 3 mostra o número observado e esperado dos genótipos reais (não agrupados, nagr) ou agrupados em 3 classes (agr), e os resultados dos testes de aderência para os desvios desses valores ao EHW. Não foram incluídos os jovens de C. multiflora pois não consideramos a amostragem representativa. 
Tabela 3. Teste qui-quadrado $(\chi 2)$ e exato de Fisher para os desvios do equilibrio de HardyWeinberg, considerando números observados (no) e esperados (ne) dos genótipos não

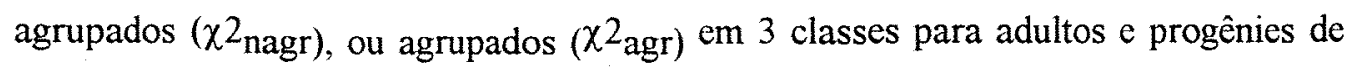
C. multiflora e adultos e jovens de C. guianensis.. Quando a coluna "classe ou genótipo" estiver representada por números individuais, 1,2 e 3, os no e ne mostrados correspondem a genótipos agrupados conforme classes 1, 2 e 3 (abaixo). Quando os números mostrados são compostos por 2 números separados por hífen, no e ne são genótipos não agrupados ou reais. $\mathrm{P}=$ probabilidade do teste.

\begin{tabular}{|c|c|c|c|c|c|c|}
\hline \multicolumn{7}{|c|}{ Adultos de $C$. multiflora } \\
\hline LOCO & $\begin{array}{l}\text { Classe ou } \\
\text { genótipo }\end{array}$ & no & ne & $\begin{array}{l}\chi^{2} \text { nagr } \\
\mathrm{P} \chi 2_{\text {nagr }}\end{array}$ & $\begin{array}{l}\chi^{2} \text { agr } \\
P \chi_{\text {agr }}\end{array}$ & $P_{\text {Fisher }}$ \\
\hline $\mathrm{MDH}-1$ & $\begin{array}{l}2-2 \\
2-3 \\
3-3\end{array}$ & $\begin{array}{c}1 \\
14 \\
25\end{array}$ & $\begin{array}{c}1.600 \\
12.800 \\
25.600\end{array}$ & $\begin{array}{c}0.045 \\
(1) \\
0.832 \mathrm{~ns}\end{array}$ & - & $1.000 \mathrm{~ns}$ \\
\hline $\mathrm{MDH}-3$ & $\begin{array}{l}1 \\
2 \\
3\end{array}$ & $\begin{array}{c}20 \\
21 \\
0\end{array}$ & $\begin{array}{l}22.689 \\
15.622 \\
2.689\end{array}$ & - & $\begin{array}{c}3.516 \\
(1) \\
0.061 \mathrm{~ns}\end{array}$ & $0.041^{*}$ \\
\hline PGI-1 & $\begin{array}{l}1 \\
2 \\
3\end{array}$ & $\begin{array}{c}7 \\
17 \\
17\end{array}$ & $\begin{array}{c}5.860 \\
19.280 \\
15.860\end{array}$ & - & $\begin{array}{c}0.260 \\
(1) \\
0.610 \mathrm{~ns}\end{array}$ & $0.508 \mathrm{~ns}$ \\
\hline PGM-1 & $\begin{array}{l}1 \\
2 \\
3\end{array}$ & $\begin{array}{c}28 \\
6 \\
6\end{array}$ & $\begin{array}{c}24.025 \\
13.950 \\
2.025\end{array}$ & - & $\begin{array}{c}10.445 \\
(1) \\
0.001^{* *}\end{array}$ & $0.001^{* *}$ \\
\hline PGM-2 & $\begin{array}{l}1 \\
2 \\
3\end{array}$ & $\begin{array}{c}20 \\
16 \\
4\end{array}$ & $\begin{array}{c}19.600 \\
16.800 \\
3.600\end{array}$ & - & $\begin{array}{c}0.005 \\
(1) \\
0.942 \mathrm{~ns}\end{array}$ & $0.718 \mathrm{~ns}$ \\
\hline PO-1 & $\begin{array}{l}1-1 \\
1-2 \\
2-2\end{array}$ & $\begin{array}{c}3 \\
8 \\
27\end{array}$ & $\begin{array}{c}1.289 \\
11.421 \\
25.289\end{array}$ & $\begin{array}{c}1.941 \\
(1) \\
0.164 \mathrm{~ns}\end{array}$ & - & $\begin{array}{c}0.084 \mathrm{~ns} \\
\text { (a) }\end{array}$ \\
\hline $\mathrm{PO}-2$ & $\begin{array}{l}2-2 \\
2-3 \\
3-3\end{array}$ & $\begin{array}{c}4 \\
6 \\
30\end{array}$ & $\begin{array}{c}1.225 \\
11.550 \\
27.225\end{array}$ & $\begin{array}{c}6.623 \\
(1) \\
0.010^{* *}\end{array}$ & $=$ & $0.008 * * a$ \\
\hline SKDH-1 & $\begin{array}{l}1 \\
2 \\
3\end{array}$ & $\begin{array}{l}15 \\
12 \\
14\end{array}$ & $\begin{array}{c}10.756 \\
20.488 \\
9.756\end{array}$ & - & $\begin{array}{c}5.854 \\
(1) \\
0.016^{*}\end{array}$ & $0.011^{*}$ \\
\hline
\end{tabular}


Continuação da Tabela 3.

\begin{tabular}{|c|c|c|c|c|c|c|}
\hline \multicolumn{7}{|c|}{ Progênies de $C$. multiflora } \\
\hline LOCOS & $\begin{array}{l}\text { Classe ou } \\
\text { Genótipo }\end{array}$ & no & ne & $\begin{array}{l}\chi 2_{\text {nagr }} \\
\mathrm{P} \chi 2_{\text {nagr }}\end{array}$ & $\begin{array}{l}\chi^{2} \\
\mathrm{P} \chi^{2}{ }_{\text {agr }}\end{array}$ & $P_{\text {Fisher }}$ \\
\hline $\mathrm{MDH}-1$ & $\begin{array}{l}1 \\
2 \\
3\end{array}$ & $\begin{array}{l}43 \\
45 \\
15\end{array}$ & $\begin{array}{l}41.653 \\
47.694 \\
13.653\end{array}$ & & $\begin{array}{c}0.171 \\
(1) \\
0.679 \mathrm{~ns}\end{array}$ & $0.670 \mathrm{~ns}$ \\
\hline $\mathrm{MDH}-3$ & $\begin{array}{l}1 \\
2 \\
3\end{array}$ & $\begin{array}{c}93 \\
10 \\
0\end{array}$ & $\begin{array}{c}93.243 \\
9.515 \\
0.243\end{array}$ & & $\begin{array}{c}0.000 \\
(1) \\
1.000 \mathrm{~ns}\end{array}$ & $1.000 \mathrm{~ns}$ \\
\hline PGI-I & $\begin{array}{l}1 \\
2 \\
3\end{array}$ & $\begin{array}{l}36 \\
31 \\
36\end{array}$ & $\begin{array}{l}25.750 \\
51.500 \\
25.750\end{array}$ & & $\begin{array}{c}15.150 \\
(1) \\
0.000^{* *}\end{array}$ & $0.000^{* *}$ \\
\hline PGM-1 & $\begin{array}{l}1 \\
2 \\
3\end{array}$ & $\begin{array}{l}44 \\
41 \\
10\end{array}$ & $\begin{array}{c}43.792 \\
41.416 \\
9.792\end{array}$ & & $\begin{array}{c}0.000 \\
(1) \\
1.000 \mathrm{~ns}\end{array}$ & $1.000 \mathrm{~ns}$ \\
\hline PGM-2 & $\begin{array}{l}1 \\
2 \\
3\end{array}$ & $\begin{array}{c}67 \\
30 \\
5\end{array}$ & $\begin{array}{c}65.922 \\
32.157 \\
3.922\end{array}$ & & $\begin{array}{c}0.176 \\
(1) \\
0.675 \mathrm{~ns}\end{array}$ & $0.528 \mathrm{~ns}$ \\
\hline $\mathrm{PO}-2$ & $\begin{array}{l}1 \\
2 \\
3\end{array}$ & $\begin{array}{c}59 \\
34 \\
6\end{array}$ & $\begin{array}{c}58.343 \\
35.313 \\
5.343\end{array}$ & & $\begin{array}{c}0.024 \\
(1) \\
0.878 \mathrm{~ns}\end{array}$ & $0.777 \mathrm{~ns}$ \\
\hline SKDH-1 & $\begin{array}{l}1-1 \\
1-2 \\
1-3 \\
2-2 \\
2-3 \\
3-3\end{array}$ & $\begin{array}{l}12 \\
12 \\
24\end{array}$ & $\begin{array}{c}8.738 \\
20.680 \\
21.845 \\
12.235 \\
25.850 \\
13.653\end{array}$ & $\begin{array}{c}13.107 \\
(3) \\
0.004^{* *}\end{array}$ & - & $\begin{array}{l}0.200 \mathrm{~ns} \\
\text { (a) }\end{array}$ \\
\hline
\end{tabular}


Continuação da Tabela 3.

\begin{tabular}{|c|c|c|c|c|c|c|}
\hline \multicolumn{7}{|c|}{ Adultos de $C$. guianensis } \\
\hline LOCOS & $\begin{array}{l}\text { Classe ou } \\
\text { freq. gen. }\end{array}$ & no & ne & $\begin{array}{l}\chi^{2} \text { nagr } \\
\text { P } \chi^{2} \text { nagr }\end{array}$ & $\begin{array}{l}\chi^{2} \text { agr/ } \\
\mathrm{P} \chi \chi_{\mathrm{agr}}\end{array}$ & PFisher \\
\hline EST-1 & $\begin{array}{l}1 \\
2 \\
3\end{array}$ & $\begin{array}{l}7 \\
9 \\
9\end{array}$ & $\begin{array}{c}5.290 \\
12.420 \\
7.290\end{array}$ & - & $\begin{array}{c}1.164 \\
(4) \\
0.281 \mathrm{~ns}\end{array}$ & $0.226 \mathrm{~ns}$ \\
\hline $\mathrm{MDH}-3$ & $\begin{array}{l}1 \\
2 \\
3\end{array}$ & $\begin{array}{c}9 \\
6 \\
12\end{array}$ & $\begin{array}{c}5.333 \\
13.333 \\
8.333\end{array}$ & - & $\begin{array}{c}6.586 \\
(1) \\
0.010^{*}\end{array}$ & $0.005 * *$ \\
\hline PGI-1 & $\begin{array}{l}1 \\
2 \\
3\end{array}$ & $\begin{array}{c}18 \\
7 \\
2\end{array}$ & $\begin{array}{l}17.120 \\
8.759 \\
1.120\end{array}$ & - & $\begin{array}{c}0.318 \\
(1) \\
0.573 \mathrm{~ns}\end{array}$ & $0.270 \mathrm{~ns}$ \\
\hline PGM-1 & $\begin{array}{l}1 \\
2 \\
3\end{array}$ & $\begin{array}{c}14 \\
3 \\
5\end{array}$ & $\begin{array}{l}10.920 \\
9.159 \\
1.920\end{array}$ & - & $\begin{array}{c}7.571 \\
(1) \\
0.006^{* *}\end{array}$ & $0.003^{* *}$ \\
\hline PGM-2 & $\begin{array}{l}1-1 \\
1-2 \\
2-2\end{array}$ & $\begin{array}{c}8 \\
0 \\
17\end{array}$ & $\begin{array}{c}2.560 \\
10.880 \\
11.560\end{array}$ & - & - & $0.000 * @$ \\
\hline PO-1 & $\begin{array}{l}1-1 \\
1-2 \\
2-2\end{array}$ & $\begin{array}{c}3 \\
3 \\
20\end{array}$ & $\begin{array}{c}0.779 \\
7.442 \\
17.779\end{array}$ & $\begin{array}{c}6.058 \\
(1) \\
0.014^{*}\end{array}$ & - & $0.010 * a$ \\
\hline $\mathrm{PO}-2$ & $\begin{array}{l}1-1 \\
1-2 \\
2-2\end{array}$ & $\begin{array}{c}3 \\
0 \\
23\end{array}$ & $\begin{array}{c}0.346 \\
5.308 \\
20.346\end{array}$ & $\overline{-}$ & - & $0.000 * @$ \\
\hline SKDH-1 & $\begin{array}{l}1 \\
2 \\
3\end{array}$ & $\begin{array}{c}20 \\
4 \\
3\end{array}$ & $\begin{array}{l}17.926 \\
8.148 \\
0.926\end{array}$ & - & $\begin{array}{c}4.448 \\
(1) \\
0.035^{*}\end{array}$ & $0.022^{*}$ \\
\hline & & & Joven & e C. guian & & \\
\hline EST-1 & $\begin{array}{l}1 \\
2 \\
3\end{array}$ & $\begin{array}{l}7 \\
9 \\
3\end{array}$ & $\begin{array}{l}6.961 \\
9.079 \\
2.961\end{array}$ & - & $\begin{array}{c}0.000 \\
(1) \\
1.000 \mathrm{~ns}\end{array}$ & $1.000 \mathrm{~ns}$ \\
\hline $\mathrm{MDH}-3$ & $\begin{array}{l}1 \\
2 \\
3\end{array}$ & $\begin{array}{l}9 \\
6 \\
8\end{array}$ & $\begin{array}{c}6.261 \\
11.478 \\
5.261\end{array}$ & $=$ & $\begin{array}{c}3.913 \\
(1) \\
0.048^{*}\end{array}$ & $0.034^{*}$ \\
\hline PGI-1 & $\begin{array}{l}1 \\
2 \\
3\end{array}$ & $\begin{array}{c}15 \\
6 \\
1\end{array}$ & $\begin{array}{l}14.727 \\
6.545 \\
0.727\end{array}$ & - & $\begin{array}{c}0.000 \\
(1) \\
0.986 \mathrm{~ns}\end{array}$ & $0.538 \mathrm{~ns}$ \\
\hline PGM-1 & $\begin{array}{l}1 \\
2 \\
3\end{array}$ & $\begin{array}{l}9 \\
5 \\
3\end{array}$ & $\begin{array}{l}7.779 \\
7.441 \\
1.779\end{array}$ & - & $\begin{array}{c}0.865 \\
(1) \\
0.352 \mathrm{~ns}\end{array}$ & $0.260 \mathrm{~ns}$ \\
\hline
\end{tabular}


Continuação da Tabela 3

\begin{tabular}{|c|c|c|c|c|c|c|}
\hline LOCOS & CLASSE & no & ne & $\begin{array}{l}\chi^{2} \text { nagr } \\
\text { P } \chi^{2} \text { nagr }\end{array}$ & $\begin{array}{l}\chi^{2} \text { agr } \\
\mathrm{P} \chi \chi^{2} \mathrm{agr}\end{array}$ & $\mathrm{P}_{\text {Fisher }}$ \\
\hline PGM-2 & $\begin{array}{l}1 \\
2 \\
3\end{array}$ & $\begin{array}{c}15 \\
0 \\
4\end{array}$ & $\begin{array}{l}11.842 \\
6.316 \\
0.842\end{array}$ & - & $\begin{array}{c}14.341 \\
(1) \\
0.000^{* *}\end{array}$ & $0.000^{* *}$ \\
\hline PO-1 & $\begin{array}{l}1-1 \\
1-2 \\
2-2\end{array}$ & $\begin{array}{c}2 \\
7 \\
13\end{array}$ & $\begin{array}{c}1.375 \\
8.250 \\
12.375\end{array}$ & $\begin{array}{c}0.081 \\
(1) \\
0.776 \mathrm{~ns}\end{array}$ & - & 0.568 ns $(\mathfrak{a})$ \\
\hline $\mathrm{PO}-2$ & $\begin{array}{l}1-1 \\
1-2 \\
2-2\end{array}$ & $\begin{array}{c}3 \\
1 \\
17\end{array}$ & $\begin{array}{c}0.583 \\
5.833 \\
14.583\end{array}$ & $\begin{array}{c}9.769 \\
(1) \\
0.002 * *\end{array}$ & - & $0.002 * * a$ \\
\hline SKDH-1 & $\begin{array}{l}1 \\
2 \\
3\end{array}$ & $\begin{array}{c}16 \\
5 \\
2\end{array}$ & $\begin{array}{c}14.880 \\
7.239 \\
0.880\end{array}$ & - & $\begin{array}{c}0.880 \\
(1) \\
0.348 \mathrm{~ns}\end{array}$ & $0.165 \mathrm{~ns}$ \\
\hline
\end{tabular}

O teste $\chi^{2}$ nagr é priorizado com relação ao $\chi^{2}$ agr quando todos os genótipos são representados por mais de 5 indivíduos nas células de números esperados; quando os números esperados para o $\chi^{2}$ nagr são também baixos. o teste de Fisher é o considerado; @ os números esperados não estão mostrados para o teste em questão: Classes: 1 - número de homozigotos para o alelo mais comum; 2 - número de heterozigotos entre o alelo mais comum e os alelos raros; 3 - número de homozigotos raros e outros heterozigotos: P: probabilidade de ajuste para a distribuição $\chi 2$, com os graus de liberdade em parênteses. $* \mathrm{P}<0.05 ; * * \mathrm{P}<0.01$.

Nos adultos de C. multiflora ocorreu rejeição da hipótese nula de EHW em $50 \%$ dos locos (MDH-3, PGM-1, PO-2 e SKDH-1) e em 28.6\% nas progênies (PGI-1 e SKDH1). Com exceção do loco MDH-3, todos os desvios foram por excesso de homozigotos.

$\mathrm{O}$ teste qui-quadrado agrupado para o loco $\mathrm{MDH}-3$ nos adultos, este com uma das classes de números esperados $<5 \mathrm{e}>1$, resultou em não significativo para este teste e significativo para o teste de Fisher. Neste caso, de baixas frequências, o teste de Fisher deve ser priorizado, conforme explicado na metodologia. Nas progênies, o teste qui-quadrado não agrupado (nagr, genótipos reais), priorizado em função da boa representatividade dos números esperados para o loco SKDH-1, resultou em altamente significativo, enquanto que os testes agrupados (agr, em classes) e o de Fisher (também em classes) não rejeitaram a hipótese nula do EHW. Este loco, quando em classes agrupadas (classe $1=17$; classe $2=41$; classe $3-45$ ), resulta $\mathrm{em}$ um valor alto de indivíduos na classe 3 (homozigotos raros e outros heterozigotos). Esses exemplos mostram a necessidade de exame mais acurado da representatividade das células esperadas e do possivel resultado "artificial" em função do agrupamento em classes. 
Nos adultos de C. guianensis, houve rejeição da hipótese nula de EHW em $75 \%$ dos locos, sendo exceções somente EST-1 e PGI-1, e nos jovens $37.5 \%$, com os locos MDH3, PGM-2 e PO-2 significativos. Em todos os casos ocorreram excesso de homozigotos.

A Tabela 5 mostra os testes para desvios da distribuição do EHW com os valores de qui-quadrado deduzidos a partir dos valores de F (LI \& HORVITZ, 1953). Estes testes resultaram em menor rejeição da hipótese nula do EHW com relação aos anteriores. Para os adultos de $C$. multiflora houve uma redução de 50 para $37.5 \%$ de locos rejeitando o modelo (MDH-3 ns). Não houve mudança com relação às progênies. Para $C$. guianensis a redução foi de 75 para $62,5 \%$ (MDH-3 e SKDH ns; EST **), não ocorrendo mudanças com relação aos jovens. Considerando o conjunto de locos como um todo este teste respondeu de forma bem parecida aos anteriores. Este qui-quadrado pode resultar em valores baixos quando o número de indivíduos analisados é pequeno e mesmo que os números esperados não estejam sendo analisados diretamente, o teste é um qui-quadrado, e portanto, o número mínimo do tamanho amostral deve ser considerado. Os valores de qui-quadrado não alteram-se muito com relação ao tamanho amostral quando $\mathrm{F}$ é baixo $(\sim 0.05)$, mas conforme $\mathrm{F}$ torna-se maior, o aumento do tamanho amostral resulta em significância. Em função disto, este teste, quando empregado em locos com tamanho amostral pequeno, parece rejeitar menos a hipótese nula mesmo com valores de $\mathrm{F}$ altos. Nesses casos duvidosos e com tamanho amostral pequeno a melhor opção é o uso do teste de Fisher

Os testes para a verificação do ajuste ao EENW nos locos que desviaramse do EHW não foram possiveis, com exceção a um loco nas progênies em C. multiflora, pois para todos os outros locos apontados acima os números esperados nas células foram muito baixos, próximos a zero ou com muitas células com números baixos. Como este tipo de resultado é esperado, a elaboração de um teste de Fisher ou um qui-quadrado com agrupamentos em classes para esse modelo seria bem importante também. $\mathrm{Na}$ Tabela 4 estão indicadas os números observados dos genótipos e esperados pelo EENW do loco SKDH-1 de progênies e adultos de $C$. multiflora. 
Tabela 4. Números observados (no) e esperados (ne) pelo EENW e teste $\chi 2$ para os devios deste modelo para adultos e progênies de $C$. multiflora. Números em parênteses iguais aos graus de liberdade.

\begin{tabular}{|c|c|c|c|c|c|}
\hline LOCO & GENÓTIPO & \multicolumn{2}{|c|}{ ADULTOS } & \multicolumn{2}{|c|}{ PROGENIES } \\
\hline & & no & ne & no & ne \\
\hline \multirow[t]{6}{*}{ SKDH-1 } & $1-1$ & 0 & 1.05 & 12 & 13.50 \\
\hline & $1-2$ & 2 & 1.32 & 12 & 16.03 \\
\hline & $1-3$ & 3 & 1.59 & 24 & 16.91 \\
\hline & $2-2$ & 12 & 11.30 & 21 & 17.50 \\
\hline & $2-3$ & 9 & 11.10 & 17 & 20.05 \\
\hline & $3-3$ & 15 & 14.65 & 17 & 19.01 \\
\hline$x^{2}$ & & & & & \\
\hline
\end{tabular}

Para ambas categorias, progênies e adultos, não houve rejeição da hipótese nula de EENW, podendo o excesso de homozigotos ser explicado pelo sistema misto de reprodução. Isto foi revisto com relação ao sistema reprodutivo em LEPSCH-CUNHA \& KAGEYAMA (1996d). De forma mais rígida, nem o teste dos adultos seria viável, por ter $50 \%$ das células com números esperados menores que 5 .

O teste conjunto para todos os locos, combinando todas as probabilidades do teste de Fisher de cada loco (Steel \& Torrie, 1980, cit. em SANTOS, 1994), para verificação do ajuste populacional ao EHW, não se mostrou satisfatório para este caso e, portanto, os resultados foram omitidos. A presença de um ou poucos locos com probabilidades baixas "estoura" o qui-quadrado conjunto e, consequentemente, esta estatística resulta em significativa, e preferencialmente a validade do teste torna-se duvidosa. Este teste, segundo VENCOVSKY (com. pessoal, 1996), é mais recomendado quando as probabilidades individuais não são significativas, mas com valores relativamente altos e há o questionamento quanto a não rejeição do modelo do EHW com relação a população em conjunto.

\subsubsection{Heterozigosidades, diversidade gênica e indices de fixação $(F)$ dentro da população}

A Tabela 5 apresenta as heterozigosidades observadas e esperadas por loco, heterozigosidade média observada, diversidade gênica (heterozigosidade média ou panmítica), indices de fixação de Wright para cada loco e médio e os testes qui-quadrado proposto por LI \& HORVITZ (1953) e já discutidos anteriormente. 
Tabela 5. Heterozigosidades e indices de fixação de Wright para adultos, jovens e progênies de $C$. multiflora e adultos e jovens de $C$. guianensis. Teste $\chi 2$ para testar a significância dos valores de $\mathrm{F}$.

\begin{tabular}{|c|c|c|c|c|c|c|}
\hline & & \multicolumn{3}{|c|}{ C. multiflora } & \multicolumn{2}{|c|}{ C. guianensis } \\
\hline $\mathrm{LOCO}$ & & Adulto & Jovem & Progênie & Adulto & Jovem \\
\hline EST-1 & $\begin{array}{l}\mathrm{H}_{\mathrm{o}} \\
\mathrm{H}_{\mathrm{e}} \\
\mathrm{F} \\
\chi^{2}\end{array}$ & . & 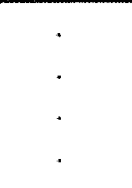 & . & $\begin{array}{c}0.360 \\
0.669 \\
0.462 \\
43.548(6)^{1 * *}\end{array}$ & $\begin{array}{c}0.526 \\
0.572 \\
0.080 \\
0.365(6) \mathrm{ns}\end{array}$ \\
\hline MDH-1 & $\begin{array}{c}\mathrm{H}_{\mathrm{o}} \\
\mathrm{H}_{\mathrm{e}} \\
\mathrm{F} \\
\chi^{2}\end{array}$ & $\begin{array}{c}0.350 \\
0.320 \\
-0.094 \\
0.353(1) \mathrm{ns}\end{array}$ & $\begin{array}{c}0.167 \\
0.153 \\
-0.091\end{array}$ & $\begin{array}{c}0.437 \\
0.467 \\
0.064 \\
0.844(3) \mathrm{ns}\end{array}$ & . & . \\
\hline $\mathrm{MDH}-3$ & $\begin{array}{c}\mathrm{H}_{\mathrm{o}} \\
\mathrm{H}_{\mathrm{e}} \\
\mathrm{F} \\
\chi^{2}\end{array}$ & $\begin{array}{c}0.512 \\
0.412 \\
-0.243 \\
4.842(3) \mathrm{ns}\end{array}$ & $\begin{array}{l}0.167 \\
0.486 \\
0.657\end{array}$ & $\begin{array}{c}0.097 \\
0.094 \\
-0.038 \\
0.297(3) \mathrm{ns}\end{array}$ & $\begin{array}{c}0.444 \\
0.647 \\
0.314 \\
5.324(3) \mathrm{ns}\end{array}$ & $\begin{array}{c}0.348 \\
0.605 \\
0.425 \\
8.309(3)^{*}\end{array}$ \\
\hline PGI-1 & $\begin{array}{c}\mathrm{H}_{\mathrm{o}} \\
\mathrm{H}_{\mathrm{e}} \\
\mathrm{F} \\
\chi^{2}\end{array}$ & $\begin{array}{c}0.634 \\
0.723 \\
0.123 \\
2.481(10) \mathrm{ns}\end{array}$ & $\begin{array}{l}0.333 \\
0.500 \\
0.333\end{array}$ & $\begin{array}{c}0.485 \\
0.615 \\
0.211 \\
13.757(6) *\end{array}$ & $\begin{array}{c}0.296 \\
0.345 \\
0.141 \\
1.073(3) \mathrm{ns}\end{array}$ & $\begin{array}{c}0.273 \\
0.313 \\
0.129 \\
0.732(3) \mathrm{ns}\end{array}$ \\
\hline PGM-1 & $\begin{array}{c}\mathrm{H}_{0} \\
\mathrm{H}_{\mathrm{e}} \\
\mathrm{F} \\
\chi^{2}\end{array}$ & $\begin{array}{c}0.225 \\
0.370 \\
0.392 \\
18.440(6)^{* *}\end{array}$ & $\begin{array}{c}0.500 \\
0.375 \\
-0.333\end{array}$ & $\begin{array}{c}0.442 \\
0.468 \\
0.055 \\
0.862(6) \mathrm{ns}\end{array}$ & $\begin{array}{c}0.182 \\
0.460 \\
0.604 \\
16.052(3) * *\end{array}$ & $\begin{array}{c}0.294 \\
0.490 \\
0.399 \\
5.413(3) \mathrm{ns}\end{array}$ \\
\hline PGM-2 & $\begin{array}{c}\mathrm{H}_{0} \\
\mathrm{H}_{\mathrm{e}} \\
\mathrm{F} \\
\chi^{2}\end{array}$ & $\begin{array}{c}0.450 \\
0.479 \\
0.061 \\
0.595(10) \mathrm{ns}\end{array}$ & $\begin{array}{c}0.333 \\
0.298 \\
-0.143\end{array}$ & $\begin{array}{c}0.343 \\
0.338 \\
-0.014 \\
0.080(10) \mathrm{ns}\end{array}$ & $\begin{array}{c}\frac{0.000}{0.435} \\
1.000 \\
25(1)^{* *}\end{array}$ & $\begin{array}{c}\underline{0.000} \\
0.360 \\
1.000 \\
57(6)^{* *}\end{array}$ \\
\hline PO-1 & $\begin{array}{l}\mathrm{H}_{\mathrm{o}} \\
\mathrm{H}_{\mathrm{e}} \\
\mathrm{F} \\
\chi^{2}\end{array}$ & $\begin{array}{c}0.211 \\
0.301 \\
0.300 \\
3.42(1) \mathrm{ns}\end{array}$ & $\begin{array}{c}0.500 \\
0.375 \\
-0.333\end{array}$ & . & $\begin{array}{c}0.115 \\
0.286 \\
0.597 \\
9.267(1) * *\end{array}$ & $\begin{array}{c}0.318 \\
0.375 \\
0.152 \\
0.508(1) \mathrm{ns}\end{array}$ \\
\hline $\mathrm{PO}-2$ & $\begin{array}{c}\mathrm{H}_{\mathrm{o}} \\
\mathrm{H}_{\mathrm{e}} \\
\mathrm{F} \\
\chi^{2}\end{array}$ & $\begin{array}{c}0.150 \\
0.289 \\
0.481 \\
9.254(1)^{* *}\end{array}$ & $\begin{array}{c}0.000 \\
0.000 \\
1.000 \\
-\end{array}$ & $\begin{array}{c}0.343 \\
0.359 \\
0.043 \\
0.366(3) \mathrm{ns}\end{array}$ & $\begin{array}{c}\frac{0.000}{0.204} \\
1.000 \\
26(1)^{* *}\end{array}$ & $\begin{array}{c}0.048 \\
0.278 \\
0.829 \\
14.432(1)^{* *}\end{array}$ \\
\hline $\begin{array}{c}\text { SKDH- } \\
1\end{array}$ & $\begin{array}{c}\mathrm{H}_{\mathrm{o}} \\
\mathrm{H}_{\mathrm{e}} \\
\mathrm{F} \\
\chi^{2}\end{array}$ & $\begin{array}{c}0.341 \\
0.552 \\
0.381 \\
11.903(3) * *\end{array}$ & $\begin{array}{c}0.667 \\
0.611 \\
-0.091\end{array}$ & $\begin{array}{c}0.515 \\
\\
0.664 \\
0.225 \\
10.429(3) *\end{array}$ & $\begin{array}{c}0.222 \\
\\
0.316 \\
0.297 \\
4.763(3) \mathrm{ns} \\
\end{array}$ & $\begin{array}{c}0.261 \\
\\
0.328 \\
0.205 \\
1.933(3) \mathrm{ns} \\
\end{array}$ \\
\hline
\end{tabular}


Continuação da Tabela 5.

\begin{tabular}{|c|c|c|c|c|c|c|}
\hline & & \multicolumn{3}{|c|}{ C. multiflora } & \multicolumn{2}{|c|}{ C. guianensis } \\
\hline & & Adulto & Jovem & Progênie & Adulto & Jovem \\
\hline MÉDIA & $\mathrm{H}_{\mathrm{o}}$ & $\begin{array}{c}0.359 \\
(0.058)^{2}\end{array}$ & $\begin{array}{c}0.333 \\
(0.077)\end{array}$ & $\begin{array}{c}0.380 \\
(0.053)\end{array}$ & $\begin{array}{c}0.203 \\
(0.057)\end{array}$ & $\begin{array}{c}0.258 \\
(0.059)\end{array}$ \\
\hline & $\mathrm{H}_{\mathrm{e}}$ & $\begin{array}{c}0.431 \\
(0.053)\end{array}$ & $\begin{array}{c}0.349 \\
(0.070)\end{array}$ & $\begin{array}{c}0.429 \\
(0.072)\end{array}$ & $\begin{array}{c}0.420 \\
(0.060)\end{array}$ & $\begin{array}{c}0.415 \\
(0.044)\end{array}$ \\
\hline TOTAL & $\begin{array}{l}F_{\mathrm{m}} \\
\chi 2\end{array}$ & $\begin{array}{c}0.176 \mathrm{~ns} \\
2.795(3.6)\end{array}$ & 0.045 & $\begin{array}{c}0.114 \mathrm{~ns} \\
3.377(4.6)\end{array}$ & $\begin{array}{c}0.518^{* *} \\
12.021(2.4)\end{array}$ & $\begin{array}{c}0.377^{*} \\
5.913(3)\end{array}$ \\
\hline
\end{tabular}

Heterozigosidade observada $\left(\mathrm{H}_{\mathrm{o}}\right)$ e esperada $\left(\mathrm{H}_{\mathrm{e}}\right)$, número de indivíduos por loco $(\mathrm{N})$, índice de fixação de Wright $(\mathrm{F})$ : $^{*} \mathrm{P}<0.05 \mathrm{e}^{* *} \mathrm{P}<0.01$; número em parênteses igual aos graus de liberdade (1) e ao desvios padrão (2);

\subsection{Couratari multiflora}

A heterozigosidade observada e esperada média nos adultos e plântulas foram respectivamente 0.359-0.431 e 0.380-0.429, valores bem próximos nessas duas categorias. A heterozigosidade esperada ou diversidade gênica foi relativamente maior que a observada para ambas as categorias, evidenciando um excesso de homozigotos com relação ao EHW, com os índices de fixação médios $\left(\mathrm{F}_{\mathrm{m}}\right)$ iguais a 0.176 e 0.114 para adultos e jovens, respectivamente, considerados não significativos conforme teste de Li \& Horvitz. Os valores das heterozigosidades tanto esperada quanto observadas são bem altos com relação a outras espécies tropicais, e os indices de fixação relativamente baixos e típicos de espécies alógamas, como será exemplificado posteriormente. Os valores para os jovens, 0.333-0.349, para $\mathrm{H}_{o}$ e $\mathrm{H}_{e}$, respectivamente, são relativamente menores que as outras duas categorias, com essa diferença mais pronunciada na heterozigosidade esperada, provavelmente em função do menor número de alelos nessa categoria, mostrando que esta estimativa diminui com a diminuição do tamanho amostral.

Os adultos apresentaram 5 locos com índices de fixação positivos, PGI-1, PGM-1*, PO-1, PO-2* e SKDH-1*, 2 próximos a zero, MDH-1 e PGM-2, e um loco negativo, $\mathrm{MDH}-3^{*}$, com os asteriscos apontando os que desviaram-se significativamente do EHW. As progênies apresentaram 2 locos com valores de F positivos, PGI-1* e SKDH-1*, e 5 locos com valores bem proximos a zero, MDH-1, MDH-3, PGM-1, PGM-2 e PO-2. Desconsiderando a significância quanto ao EHW, esta não congruência dos valores de $\mathrm{F}$, ou seja, valores positivos ou negativos ao mesmo tempo, evidenciam que outras forças evolucionárias, que não o sistema reprodutivo ou seleção diferencial de heterozigotos, estão atuando. Quando a endogamia está ocorrendo, espera-se que os locos tenham sempre valores positivos de $\mathrm{F}$ e, no segundo caso, 
valores negativos, com excesso de heterozigotos. Os valores de $F_{m}$ dos adultos e progênies não são significativamente diferentes de zero e a maioria dos locos das progênies com $\mathrm{F}$ próximos a zero inferem que a população está bem próxima à panmixia. De qualquer forma, a população adulta mostra-se na média mais endogâmica que as progênies. Em função da germinação de cerca de $40 \%$ das sementes e mortalidade de plântulas no viveiro, não se pode descartar que tenha ocorrido alguma forma de seleção a favor de heterozigotos nas progênies.

\subsection{Couratari guianensis}

As heterozigosidades observada e esperada média de adultos e jovens foram, respectivamente, $0.203 / 0.420$ e 0.258/0.415. Dois locos nos adultos, PGM-2 e PO-2, e um nos jovens, PGM-2, apresentaram somente homozigotos, consequentemente com índices de fixação $\left(\mathrm{F}\right.$ ) iguais a 1 . Os $\mathrm{F}^{*}$ s por loco foram $100 \%$ positivos em adultos e jovens, e destes, somente um loco nos jovens com valores próximos a zero (EST-1). Houve uma diferença relativamente grande entre os valores de $\mathrm{H}_{0}$ e $\mathrm{H}_{e}$, evidenciada pelos índices de fixação médios altos $(0.518$ e 0.377$)$ para as duas categorias e significativos para os adultos. Essas quantidades, mais o fato de haver congruência quanto aos valores de $F$, evidenciam a presença de endogamia na população e esta é maior nos adultos que nos jovens. A diversidade gênica $\left(\mathrm{H}_{\mathrm{e}}\right)$, que de certa forma é independente do sistema reprodutivo, é alta, podendo ser explicada pela presença de certos locos em homozigosidade, mas com a presença de vários alelos.

\subsubsection{RESULTADOS GERAIS}

A nossa exploração quanto aos diferentes tipos de testes utilizados por pacotes estatísticos mostrou a necessidade de cuidado quanto às regras estatísticas de números pequenos na priorização da escolha desses testes, já que estes podem gerar diferentes probabilidades se não tiverem tamanho amostral suficiente. Quando os números esperados são pequenos ou a amostra é pequena o teste de Fisher deve ser o único empregado. No entanto, quando os os números dos genótipos reais (não agrupados em classes) estão bem representados nos números esperados, o teste qui-quadrado não agrupado deve ser priorizado. $O$ teste quiquadrado proposto por $\mathrm{Li} \&$ Horvitz a partir dos valores de $\mathrm{F}$ responde obviamente as propriedades de um qui-quadrado e parece rejeitar menos a hipótese nula do EHW com $F$ altos quando empregado em amostras pequenas.

Programas devem ser desenvolvidos para testar o ajuste ao modelo do EENW, através de testes exatos de Fisher e agrupamento de genótipos, pois o exame das expectativas desse modelo auxilia muito nas inferências que podem ser feitas sobre forças evolucionárias atuando nas populações. 
As estimativas de diversidade ( $\left.\mathrm{P}, \mathrm{A}, \mathrm{A}_{\mathrm{e}} \mathrm{e} \mathrm{H}\right)$ foram semelhantes entre progênies e adultos de $C$. multiflora e são bem altas quando comparadas a outras espécies arbóreas tropicais (TABELA 6). Os valores de F de cada loco variaram entre positivos, próximos a zero e negativos para ambas as categorias, mas a maioria dos locos tiveram valores positivos para os adultos e próximos a zero para as progênies. O estudo de duas populações de Bertholletia excelsa (BUCKLEY et al., 1988), uma outra lecitidácea, resultou em heterozigosidade média 0.190 .

A rejeição da hipótese nula de EHW para a distribuição dos genótipos foi maior nos adultos ( $50 \%$ dos locos) do que nas progênies $(28.6 \%)$, e com exceçãoão a um loco nos adultos com excesso de heterozigotos, os desvios ocorreram por excesso de homozigotos em ambas categorias. Os índices médios de $F\left(F_{m}\right)$ não desviaram-se das expectativas de acasalamento aleatório pelo teste de Li \& Horvitz.

Os adultos e jovens de $C$. guianensis foram semelhantes para as estimativas de diversidade, porém, os jovens, em geral, mostraram valores de maior variação que os adultos, como o número de alelos e a heterozigosidade média observada. Os desvios significativos das expectativas do EHW em $37.5 \%$ contra $75.0 \%$ dos locos, todos por excesso de homozigotos, os índices de fixação médios iguais a $0.377\left(^{*}\right)$ e $0.518\left(^{* *}\right)$, significativo a $1 \%$ somente no último caso, respectivamente nos jovens e adultos, sugerem que a população mais jovem está menos endogâmica que a adulta. A presença exclusiva em 3 jovens de 2 alelos em indivíduos homozigotos mostram que os mesmos não são filhos de nenhuma árvore representada na população considerada adulta, pois nenhum adulto possui esses alelos. Podem ser imigrantes via sementes de pais de fora da área de estudo ou são filhos de árvores que já morreram na área. Neste último caso, via pólen haveria a necessidade do cruzamento de dois individuos, apomixia ou reprodução vegetativa de individuos que não se encontram mais na população atual. Dois desses individuos têm respectivamente 13,0 e 10,0 cm de DAP e estão próximos um do outro (50 metros) e localizados ao lado da borda do levantamento. O terceiro indivíduo tem $19,8 \mathrm{~cm}$ de DAP e localiza-se a 500 metros da borda.

As heterozigosidades médias esperadas foram bem maiores que as observadas em ambas as categorias, com niveis iguais a $C$. multiflora. Esta diferença entre as quantidades médias de $\mathrm{H}_{\mathrm{o}}$ e $\mathrm{H}_{\mathrm{e}}$ mostra a importância do significado da diversidade gênica no sentido de NEI(1987) ou WEIR (1990a). Esta população apesar de $\mathrm{H}_{\mathrm{o}}$ bem menores que a população de C. multiflora, ou seja, tem menos heterozigotos por qualquer motivo (sistema reprodutivo, seleção, deriva), tem potencialidades evolucionárias ao nivel de variação semelhantes 
a esta outra espécie, refletindo fluxo gênico intenso ou alguma outra forma de manutenção da variação alélica.

Quando considerados somente os adultos, as duas espécies mostraram semelhanças quanto à porcentagem de locos polimórficos $(\mathrm{P})$, número médio e efetivo de alelos $\left(A, A_{e}\right)$ e heterozigosidades médias esperadas $\left(H_{e m}\right)$. Para ambas as espécies $A_{e}$ foi sempre menor que A. O primeiro parâmetro é uma medida composta do número de alelos em um loco e suas frequências relativas. Assim, quando $A_{e}$ é menor que $A$ a heterozigosidade atual pode ser mantida por menos alelos que os atuais representados (CHASE et al., 1995; MURAWSKI \& BAWA, 1994). As heterozigosidades observadas, no entanto, foram menores para C. guianensis (0.203 0.359), dois locos apresentaram somente homozigotos, apesar de não haver fixação de alelos e os indices de fixação foram na maioria dos locos, altos e positivos. Ao nivel de variação ou diversidade gênica as populações dessas espécies estão muito próximas como apontado anteriormente, porém há a presença de endogamia em C. guianensis por algum motivo, e cruzamentos aleatórios para C. multiflora, corroborada pela taxa de cruzamento multilocos igual a um para esta última espécie, discutida em LEPSCH-CUNHA-KAGEYAMA (1996d). Encontramos 2 alelos nas progênies de $C$. multiflora e jovens de $C$. guianensis ausentes na população adulta, portanto, mesmo considerando 385 ha de área, há migração de pólen e ou semente de fora da área levantada de adultos.

\subsection{DISCUSSÃO}

A revisão de estudos de variação genética de HAMRICK et al. (1979), com mais de 100 espécies de plantas de diversos hábitos e habitats, resultou em $37 \%$ de locos polimórficos, 1.69 alelos por locos e heterozigosidade média por individuo de 0,141 , porém com considerável heterogeneidade entre espécies para niveis de variação intrapopulacional.

O estudo preliminar de HAMRICK \& LOVELESS (1986a), com 29 espécies de arbustos e arbóreas tropicais, em geral abundantes em parcela de 50 ha da llha de Barro Colorado (IBC), Panamá, resultou em valores médios de $28 \%$ de polimorfismo nos locos (P) e 2.57 alelos por locos polimórficos (Ap), com heterozigosidade esperada média $\left(\mathrm{H}_{\mathrm{em}}\right)$ igual a $11 \%$. No entanto, a variação entre as espécies foi alta, com o polimorfismo variando de 0,0 para Faramea occidentalis, árvore de subbsoque muito comum, a 54.2\%, para Alseis blackiana, árvore de subbosque dominante na parcela. $\mathrm{O}$ número de alelos por locos polimórficos variou de 2.00 a 3.40 e a heterozigosidade esperada de 0,0 (novamente Faramea) a 21.6\% (Sorocea affinis, árvore pequena, dióica). 
Estudos posteriores, como de HAMRICK \& LOVELESS (1989) para 16 arbustos e árvores comuns tropicais e HAMRICK et al. (1981) para coniferas arbóreas resultaram em variação isoenzimática semelhante entre esses dois grupos. A porcentagem de locos polimórficos $(\mathrm{P})$, o número de alelos por loco polimórfico (Ap) e a heterozigosidade esperada média $\left(\mathrm{H}_{\mathrm{em}}\right)$ foram, respectivamente para arbóreas tropicais e coniferas, iguais a $60,9-67.7 \%(\mathrm{P})$, --2.29 (Ap) e $0.211-0,207\left(\mathrm{H}_{\mathrm{em}}\right)$.

Os valores médios mostrados acima são inferiores aos encontrados aqui para as duas courataris, e seus niveis altos de polimorfismo ( $87.5 \%$ a $100 \%$ ) podem ser consequência do pequeno número de locos analisados (8), bem menor que a média utilizada por esses outros trabalhos (20 a 30 ), apesar desses locos não terem sido selecionados. $\mathrm{O}$ número de alelos por loco polimórfico $\mathrm{e}$ as heterozigosidades médias $\left(\mathrm{H}_{\mathrm{o}} \mathrm{e} \mathrm{H}_{\mathrm{e}}\right)$ estão próximos às espécies com os maiores valores.

LOVELESS \& HAMRICK (1987) utilizaram 8 espécies das 29 indicadas acima em novo estudo que incluiu na amostragem, além da população na parcela de 50 ha, mais 2 populações fora dos limites da Ilha de Barro Colorado. Apesar do número de locos estudados permanecerem praticamente os mesmos, o polimorfismo médio aumentou para $65,6 \%(35,2 \%$ a $87.7 \%)$ e as heterozigosidades médias também, para $0,240(0,152-0,374)$. Ainda assim, os valores encontrados para as courataris são maiores que a média e próximos as espécies com os maiores valores, como também o número de alelos por locos e número efetivo de alelos, respectivamente $1.43-2.64$ e 1.19-1.78.

Posteriormente, para determinar se espécies com tamanhos populacionais pequenos têm diversidade aloenzimática menor que espécies mais comuns do mesmo local, HAMRICK \& MURAWSKI (1991) mediram a diversidade aloenzimática dentro de populações de 16 espécies arbóreas não comuns na parcela de IBC. Escolheram somente espécies que são não comuns tanto na parcela de 50 ha como em outras partes da ilha, incluindo espécies com $5-25$ individuos/parcela maiores a $1.5 \mathrm{~m}$ de altura. Uma média de 10 indivíduos $(6-22)$ por espécie foi analisada (26 locos em média), resultando em grandes diferenças entre as espécies. Duas figueiras estrangulantes mostrara $+\mathrm{m}$ valores relativamente altos, com $\mathrm{P}=84,2 \%$ enquanto os valores menores foram iguais a $14.3 \%$, ocorrendo o mesmo quanto as heterozigosidades esperadas, variando de 0,026 a 0,257 .

HAMRICK \& MURAWSKI (1991) compararam de duas formas os valores de $\mathrm{P}$ e $\mathrm{H}$ dessas espécies não comuns com aqueles das 16 espécies comuns (HAMRICK \& LOVELESS, 1989), citadas anteriomente. Primeiro, considerando as estimativas de diversidade das espécies comuns calculadas a partir da análise de 200 indivíduos por espécie (no mínimo, 
como no trabalho inicial) e, segundo, padronizando a comparação através da análise de amostra aleatória de 10 indivíduos dessas espécies comuns, aproximando o tamanho médio amostral das duas categorias analisadas. No geral, os valores das estimativas das espécies não comuns foram menores que aqueles das comuns. Os testes de comparação entre essas estimativas, para o primeiro caso, resultaram em diferenças significativas para os valores de $\mathrm{H}_{\mathrm{em}}$ (diversidade gênica). Considerando a amostra de 10 indivíduos, o teste resultou em somente proximidade à significância, com $P=0,09$. Esses resultados significam que as espécies comuns tiveram suas estimativas de parâmetros diminuídas com a diminuição do número de indivíduos analisados e estes aproximaram-se dos valores das não comuns.

A análise dos 6 jovens de $C$. multiflora em área de 385 ha respondeu da mesma forma, porém preservando altos valores de diversidade (TABELA 6). Desconsiderando-se os desvios padrões, as estimativas de heterozigosidade esperada média $\left(\mathrm{H}_{\mathrm{em}}\right)$, polimorfismo e número de alelos por loco, foram menores que aquelas da população adulta bem maior, com 41 indivíduos. Qual seria o resultado esperado se essas espécies não comuns de IBC fossem amostradas em áreas maiores e/ou com mais indivíduos analisados? Duas questões podem ser feitas com relação ao resultado dos 6 jovens de $C$. multiflora: i. a $\mathrm{H}_{\mathrm{em}}$ diminuiu com relação aos adultos em função de amostra menor de individuos (perda de alelos), mas permaneceu alta em função da amostragem em área grande quando comparadas às outras espécies, ou, ii. realmente esta espécie tem um padrão diferenciado de estrutura genética? Esses resutados indicam que pode existir alguma tendenciosidade com relação à deteç̧ão da variação genética em populações de baixa densidade e a área amostrada ou, consequentemente, número mínimo de indivíduos analisados representando a população. Uma área de tamanho $\mathrm{x}$ pode gerar amostragem populacional significativa para uma espécie arbórea comum, mas é provável que não ocorra 0 mesmo para uma espécie com indivíduos esparsos, cuja representatividade populacional possa requerer áreas de tamanho $2 \mathrm{x}, 3 \mathrm{x}$, etc. As estimativas das espécies comuns em IBC diminuíram também com a diminuição dos indivíduos analisados. Pode-se esperar que estas estimativas diminuíssem ainda mais se amostrássemos áreas menores, ou subpopulações dessas espécies comuns.

Os resultados de Pithecellobium pedicellare (O'MALLEY \& BAWA, 1987), árvore emergente, colonizadora de clareiras e relativamente rara em La Selva, Costa Rica (Tabela 6), parece concordar com a relação entre área e número de indivíduos amostrados e níveis altos de diversidade. A análise de 38 individuos em 600 ha resultou em heterozigosidades médias de 0,358 para os adultos. O mesmo pode ser dito do estudo de GANDARA (1996), com uma população de 34 indivíduos de Cedrella fissilis em 270 ha, no Estado de São Paulo. Esta 
Meliaceae, árvore emergente, colonizadora de clareiras pequenas, com dispersão anemocórica e rara na Floresta Tropical Atlântica (1 indivíduo a cada 8 ha), resultou valores de heterozigosidade média esperada de 0,243 e $76,9 \%$ de locos polimórficos.

Esta discussão um tanto pormenorizada sobre amostragem de espécies de baixa densidade é uma tentativa de questionar generalizações que vêm sendo feitas quanto a essas espécies e niveis baixos de variação genética. Em geral, esses trabalhos são feitos na parcela de 50 ha da IBC ou em áreas de tamanhos semelhantes ou menores.

A Tabela 6 mostra alguns resultados selecionados que relacionam algumas características ecológicas e da história de vida e seus valores de variação genética. $\mathrm{O}$ primeiro grupo (A) é representado pelas espécies de baixa densidade (não confundir com endêmicas), secundárias, emergentes, de dispersão pelo vento e polinização especializada por animais e é onde as courataris localizam-se. Os outros grupos estão mostrados a título de comparação. Esses resultados mostram a dificuldade de se traçar generalizações ou detectar padrões quanto às espécies de baixa densidade e padrões genéticos. Na média, as espécies raras de IBC (veja localização na Tabela 6), apresentam menor variação genética e indices de fixação mais variáveis, positivos a negativos, enquanto que as courataris fogem da média quanto à variação genética e diferem entre si quanto aos índices de fixação. 


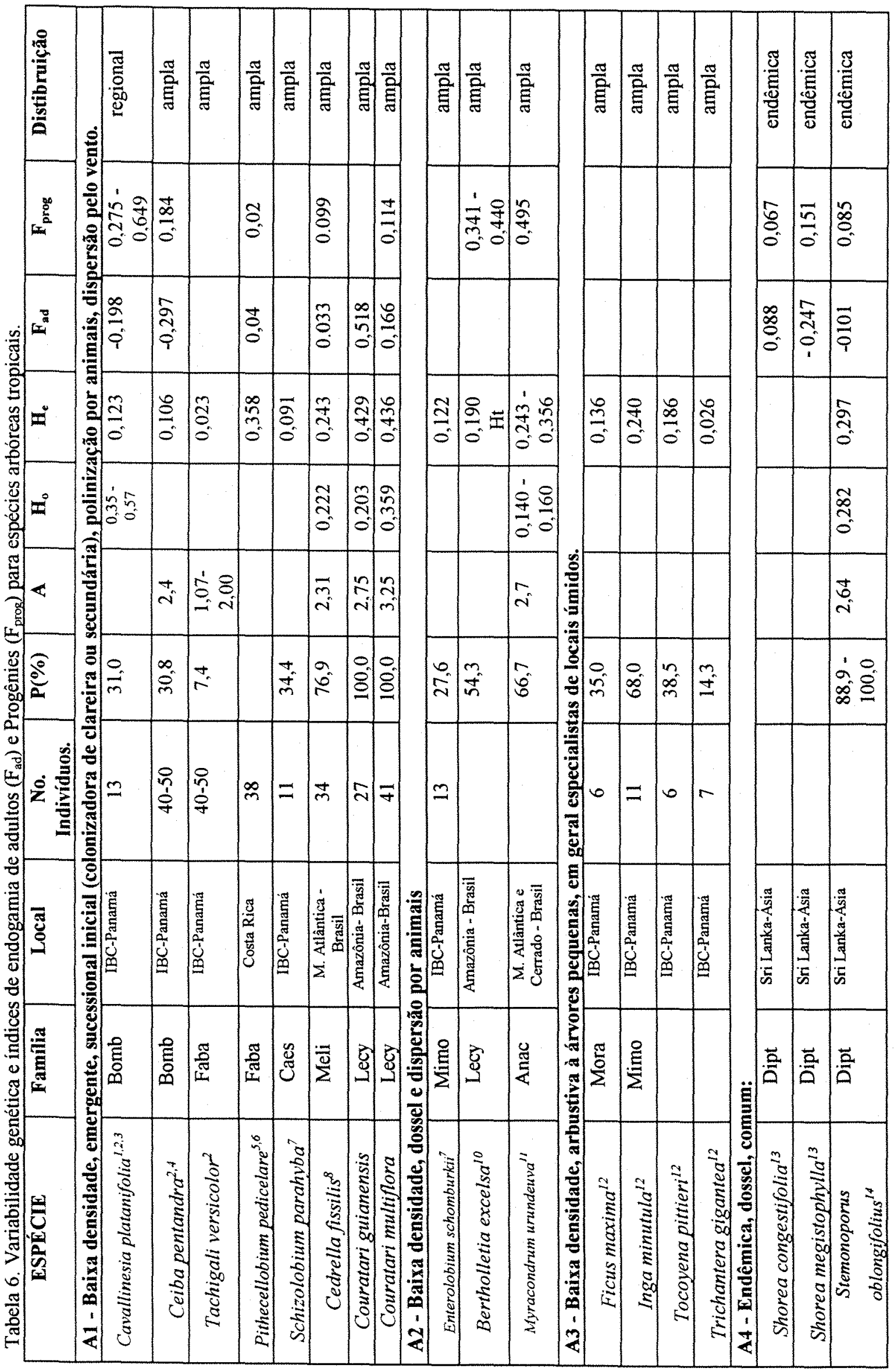




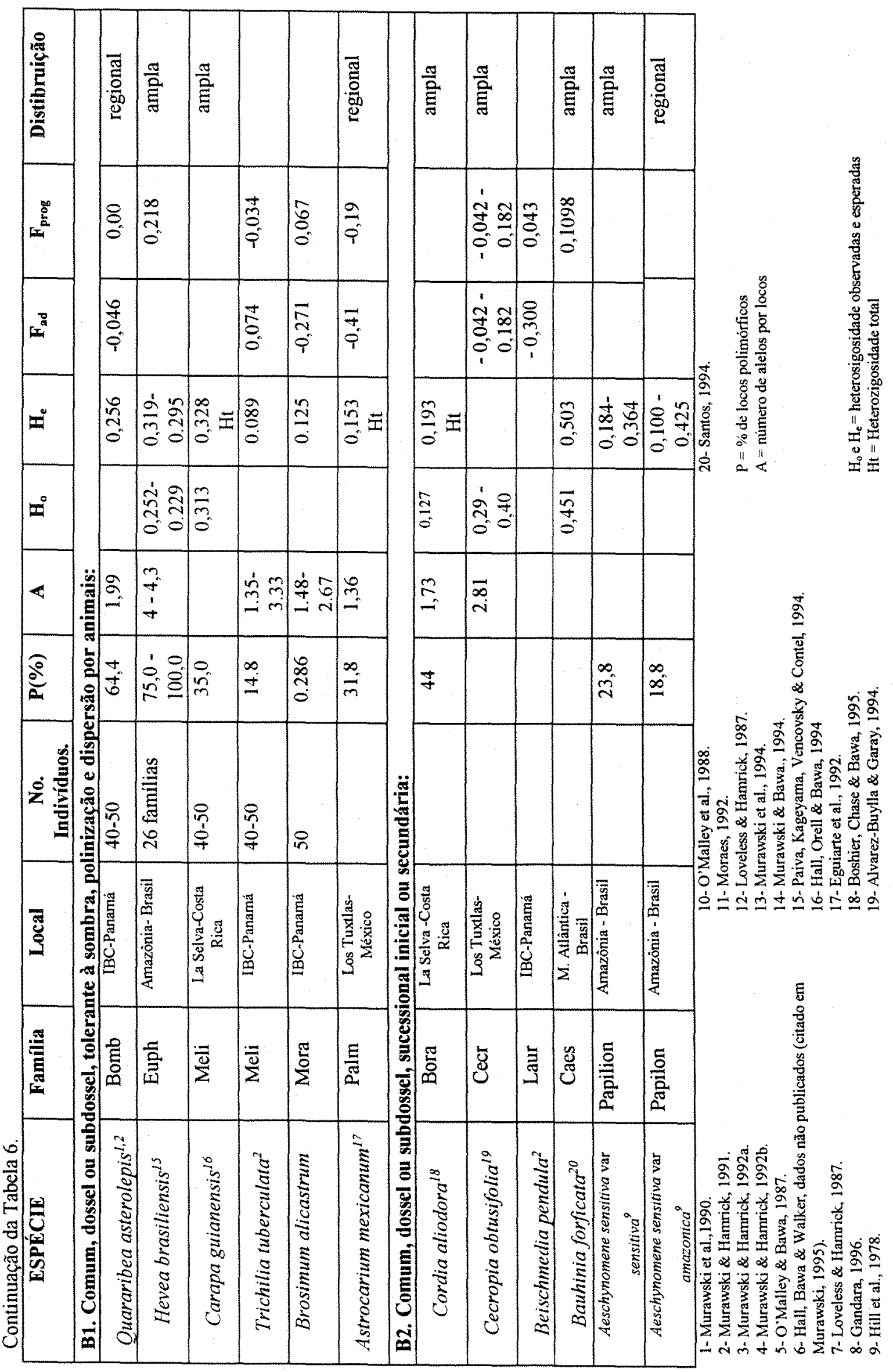


Algumas considerações devem ser colocadas quanto às espécies não comuns de IBC e os resultados de suas estimativas genéticas, além do problema amostral já apontado anteriormente. Primeiro, o tamanho mínimo de 1,5 $\mathrm{m}$ de altura e as densidades utilizadas pelos autores de 5 a 25 indivíduos em 50 ha podem representar "raras" extremas, já que são incluidas classes de tamanhos bem menores que aquelas consideradas em outros estudos, em geral, com individuos maiores a 10 e $15 \mathrm{~cm}$ de DAP. Essas espécies podem estar ou extinguindose ou colonizando o local recentemente. A quebra de continuidade com o continente e os problemas advindos do isolamento artificial sofrido pela IBC, mesmo que recente (100 anos), tem significado alteração das relações predador/presa pela extinção local de predadores de topo de cadeia trófica (TERBORGH, 1992). Esse fenômeno tem aumentado a população de roedores e outros animais de cadeias tróficas inferiores, o que pode resultar um aumento de predação, conforme sugerido pelo autor acima. Considerando o tamanho mínimo de $1,5 \mathrm{~m}$ de altura, ou em fase de regeneração ainda, essas mudanças podem já estar sendo detectadas principalmente por espécies com relações estreitas com predadores, ou que respondem a uma estrutura metapopulacional, dispersão de sementes de outros locais e/ou fenômenos reprodutivos aos surtos e episódicos.

Segundo, essas espécies podem estar nos limites de suas distribuições geográficas ao norte (vide a presença de várias delas (Tabela 6) com amplas distribuições dentro da América do Sul, incluindo a Amazônia Central). Terceiro, podem ter densidades diferentes em outras localidades como Enterolobium schomburgkii, Ficus maxima e Trichanthera gigantea (ROOSMALEN, 1985 ; SILVA et al., 1977), refletindo falta de maior disponibilidade de nichos especializados. Mesmo Schizolobium parahybum, o guapuruvú, apesar de raro em florestas fechadas, é presente em outros locais em populações maiores que 11 indivíduos acima de $1,5 \mathrm{~cm}$ altura em 50 ha (Tabela 6).

GENTRY $(1982,1986,1990)$ descreve, quanto às florestas equatoriais neotropicais, que "os taxa que são predominantemente árvores de dossel e lianas, sem exceção, tem distribuição e centros de diversidade amazônicos". A família Lecythidaceae, familia botânica arbórea, muito representada na Amazônia Central por número de espécies e abundância de individuos, é um exemplo (MORI \& PRANCE, 1990; MORI \& LEPSCH-CUNHA, 1995). Segundo GENTRY (1986), as florestas chuvosas de terras baixas da América Central refletem recente migração em direção ao norte por espécies essencialmente amazônicas.

HAMRICK \& GODT (1990) revisaram a literatura de alozimas em plantas através dos parâmetros de diversidade genética $(\mathrm{P}, \mathrm{H}$ classificando-as de acordo com oito caracteristicas de história de vida. Ao nivel populacional, o 
sistema reprodutivo em combinação com extensão geográfica descreveram a maior proporção da variância na diversidade genética. Espécies alógamas tiveram maiores valores para todos as estimativas, e as amplamente distribuidas tiveram os maiores valores de diversidade gênica, mais alelos por locos polimórficos e frequências alélicas menos assimétricas. As espécies dispersadas pelo vento e por animais, vida longa e de estágios sucessionais mais tardios mantiveram os maiores valores de variação. Várias dessas características são compartilhadas pelas courataris e por outras espécies raras (grupo A da Tabela 6).

A variação das estimativas de diversidade em espécies de ampla distribuição também tem que ser considerada. A título de exemplo, os índices de heterozigosidade esperadas em Aeschynomene sensitiva var. sensitiva, espécie amplamente distribuida com várias populações analisadas ao longo do Rio Solimões (HILL. et al, 1978), variaram de 0,184 a 0,364, enquanto a outra variedade, var. amazonica, bem mais regional geograficamente, variou de 0,100 a 0,425 .

Os resultados altíssimos de diversidade gênica e polimorfismo são função de amostragem bem maior tanto em área (400 ha) e, consequentemente, ao número maior de indivíduos analisados para as populações das courataris? Ou estão sendo amostradas em seus centros de diversidade e distribuição?

C. multiflora e C. guianensis diferiram quanto aos seus indices de fixação. A primeira espécie mostrou um padrão populacional derivado de acasalamentos aleatórios, com indice de fixação médio $\left(\mathrm{F}_{\mathrm{m}}\right)$ relativamente próximos a zero, enquanto a segunda apresentou presença de endogamia, com $F_{m}$ alto e significativamente diferente de zero. No entanto, suas diversidades gênicas (heterozigosidade panmítica) foram muito próximas e altas, como discutido anteriormente.

Os resultados de C. guianensis são parecidos com aqueles de Myracrodruon urundeuva (Anacardiaceae), estudado por MORAES (1990). Ele estudou a aroeira a partir de progênies, em duas áreas regeneradas naturalmente a partir de pasto. A espécie, árvore de dossel, dióica, secundária, tipicamente de baixa densidade na mata primária, tornou-se comum, fenômeno corrente em áreas perturbadas (com. pessoal KAGEYAMA, 1995). Apresentou valores altos de $F$ para a espécie $(0,513)$ e para as populações ( $f=0,495$ ), heterozigosidades observadas e esperadas médias respectivamente de 0,140 e $0,160\left(\mathrm{H}_{\mathrm{o}}\right), 0,243 \mathrm{e}$ $0,356\left(\mathrm{H}_{\mathrm{e}}\right)$ para duas populações. $\mathrm{O}$ autor discute as causas que levariam esta espécie dióica ter endogamia expressiva, entre elas, efeito estrangulamento ("bottlenecks"), fundação por poucos individuos remanescentes de derrubadas de florestas primárias, análise na fase de plântulas e apomixia. 
O efeito de estrangulamento, ou a redução populacional repentina, reduz grandemente o tamanho populacional efetivo (Ne), tendo como consequência o efeito fundador, onde um pequeno número de individuos estabece uma nova população (NUNNEY \& CAMPBELL, 1993). Com a diminuição de Ne, pode ocorrer o aumento da endogamia e/ou deriva. $\mathrm{O}$ grau em que a deriva ocorre dependerá tanto da taxa de migração e das características genéticas dos migrantes (BARRETT \& HUSBAND, 1990). A endogamia aumenta a homozigosidade nas populações acima dos níveis esperados por acasalamentos aleatórios (BARRETT \& KOHN, 1991). NEI et al.(1975) argumentaram que a heterozigosidade média por loco não é muito reduzida mesmo em fortes estrangulamentos, desde que o tamanho populacional aumente rapidamente. SLATKIN $(1977,1987)$ sugere que extinção e recolonização podem atuar como uma forma de fluxo gênico e limitar a diferenciação de populações. Ele propõe modelos para dois tipos de fundação de grupo: o modelo "migrant pool" e o "propagule pool", os quais geram diferentes consequências na estrutura genética populacional. BARRETT \& HUSBAND (1990) explicam essas consequências: o impacto do fluxo gênico durante a recolonização dependerá se os migrantes que estabelecem as novas colônias são da mesma população, tais como o banco de semente ou população vizinha (propagule model), ou se são vindos de uma amostra aleatória de populações, com frequências alélicas diferentes (migrant model). No modelo de propágulo, a deriva sobrepõe-se ao efeito do fluxo gênico, e as populações se diferenciam. No modelo de migrante, uma amostra aleatória de sementes de uma coleção de populações pode aumentar a variação dentro e reduzir os niveis de diferenciação entre populações. WADE \& MACCAULEY (1988) propõem que modelos de estrutura genética em populações experimentando colonização e extinção frequentes, sob certas circunstâncias, predizem que aumentando a frequência de colonização aumenta a diversidade genética dentro de populações. $O$ conceito de metapopulação, em que os parâmetros genéticos e demográficos intrapopulacionais dependem das outras populações e vice-versa, formando umas estrutura chamada por LEVINS (1970) de "populações de populações", discutido por SCHEMSKE et al. (1994), é similar ao modelo de migrante no sentido de explicar, em certos casos, a detenção da variação, mesmo numa estrutura aparente de desequilibrio, com expansões e diminuições populacionais, colonização e extinção locais.

C. guianensis, com variação genética alta, apresentou índices de fixação médios altos e positivos, ou seja, excesso de homozigotos. Os jovens apresentaram heterozigosidades observadas médias maiores, índices de fixação menores e alelos exclusivos quando comparados aos adultos, refletindo que a população mais jovem está menos endogâmica. Esses resultados podem ser explicados pelo efeito de estrangulamento e aumento populacional 
(NEI et al., 1975) concomitante com o modelo de migrante (SLATKIN, 1977), e podem ser consistentes com a seguinte hipótese: a presença de excesso de homozigotos (endogamia) pode ser resultante do processo de fundação, ocorrido ou por redução populacional ou colonização da área por poucos indivíduos (efeito fundador). A eliminação dos homozigotos com o tempo pode estar ocorrendo através da depressão endogâmica, gerando um aumento da heterozigosidade no tempo, - qual está sendo refletido na população de jovens (ELLSTRAND \& ELLAM, 1993; CHARLESWORTH \& CHARLESWORTH, 1987; ALVAREZ-BUYLLA \& GARAY, 1994), ou pelo aumento populacional e fluxo gênico intenso via pólen e sementes a longas distâncias, que restauram a diversidade genética. Os níveis altíssimos de diversidade concordam que as características dos fundadores podem ser do tipo modelo "migrante" ou metapopulacional. Isso é corroborado pela presença de alelos e indivíduos filhos de pais externos a área do levantamento. Com esses níveis de coeficientes de endogamia altos $\left(F_{m}\right)$ nos adultos, a manutenção de diversidade gênica muito alta e de heterozigosidade observada relativamente alta quando comparadas com outras espécies arbóreas tropicais, além da não fixação de alelos, sugere que esta espécie parece adaptada a sofrer diminuições de sua densidade populacional, e tem potencial para colonizar áreas a partir de poucos indivíduos, de forma que a deriva seja balanceada pela migração.

Cabe lembrar que esta espécie tem a mesma flor altamente especializada de C. multiflora, com polinizadores especializados e de vôo longo, com expectativa de taxas de cruzamento altas e dispersão de pólen à longa distância. C. guianensis é uma espécie de ampla distribuição geográfica e, conforme apontada por MITCHEL \& MORI (1990), citados na introdução, pode ser infrequente em alguns locais (Guiana Francesa) e muito comum em outras partes de sua extensão geográfica (Mocambo, Pará). Possui considerável variação morfológica nos frutos (MORI \& PRANCE, 1990), assim, que sua plasticidade fenotípica é alta. Na área de estudo foi mais observada em igarapés ou encostas próximas a eles, porém não exclusivamente.

Foi apontado por Asker \& Jerling (1992', cit. em MURAWSKI, in prep.) que plantas em ambientes perturbados são periodicamente reduzidas nos seus tamanhos populacionais, as quais estão sujeitas a efeito fundador, deriva genética e depressão endogâmica. A apomixia facultativa (agamospermia) pode conter o efeito da depressão endogâmica e deriva genética por prolongar o tempo de vida de um genótipo e assim conservar a heterozigosidade obtida pela reprodução sexual (Gustafsson, $1946^{2}$, cit. em MURAWSKI, in prep.). A apomixia tem sido apontada como solução potencial para árvores tropicais, apoiando as noções de

\footnotetext{
${ }^{1}$ ASKER, S.E. \& JERLING, L. Apomixis in plants. CRC Press, Ann Arbor. 1992.

${ }^{2}$ GUST AFSSON. A. Apomixis in higher plants. Lunds Universtets Arsskrift, 42:1-67.1946.
} 
combinações gênicas vantajosas e novas áreas de colonização (Rollins, 1967³ ; cit. em MURAWSKI, in prep.). Apesar de poucas espécies tropicais estudadas quanto ao sistema reprodutivo mostrarem evidência de apomixia, esta foi sugerida em duas espécies de dipterocarpáceas com altas taxas de cruzamento em Sri Lanka, Stemonoporus (MURAWSKI \& BAWA, 1994) e Shorea (MURAWSKI, et al., 1994) e, vários são os exemplos de evidências embriológicas nos gêneros Clusia, Hopea, Shorea, Garcinia (vários autores em MURAWSKI, in prep.).

O trabalho de HAMRICK \& GODT (1990), discutido anteriormente, mostraram que não houve diferença significativa entre espécies sexuais e aquelas que reproduzemse por mecanismos sexuais e assexuais. Ellstrand \& Roose $(1987)^{4}$, citados pelos autores acima, mostraram que espécies predominantemente clonais podem manter tanta diversidade genética dentro de populações como espécies reproduzindo sexuadamente.

Outro fenômeno possível para explicação da manutenção da diversidade genética é a reprodução vegetativa. Esta forma de reprodução mantém os vários tipos de genótipos, sejam eles homozigotos ou heterozigotos, contendo o efeito da deriva em pequenas populações. Observamos a presença de estolão expandidos por debaixo da terra em direção a áreas abertas (clareiras grandes) cerca de 20 a 30 metros da árvore produtora em Couratari stellata, outra espécie do gênero na área de estudo e relativamente comum. Existem essas possibilidades para C. guianensis.

As estimativas genéticas para $C$. multiflora refletem população de acasalamentos aleatórios, proveniente de intenso fluxo gênico a longas distâncias, propriedade que aumenta o tamanho e área de vizinhança (BARRETT \& KOHN, 1991). Como apontado por BAWA \& ASHTON (1991) na introdução, espécies uniformente raras não resultariam em depleção da variação genética dentro de populações. Assim, esta espécie encaixar-se-ia dentro dessa categoria pelas informações das estimativas dos parâmetros genéticos, apesar de não se ter informações reais sobre esses padrões populacionais para nenhuma espécie estudada até o momento.

C. guianensis manteve sua diversidade gênica tão alta quanto $C$. multiflora, porém com presença de endogamia. É possível que este resultado reflita a outra categoria de espécies raras dada por BAWA \& ASHTON (1991), com densidades populacionais variáveis. A falta de informação da taxa de cruzamento multilocos (tm) impede maiores inferências, pois se esta taxa for alta em população com indivíduos tão espaçados como a área de

\footnotetext{
${ }^{3}$ ROLLINS, R.C. The evolutionary fate of imbreeders and non-sexuals. American Naturalist, 101:342-51, 1967.

${ }^{4}$ ELLSTRAND, N.C. \& ROOSE, M.L. Patterns of genotypic diversity in clonal plant species. American Journal of Botany, 74:132$35,1987$.
} 
estudo, os índices de fixação altos podem ser explicados por colonização recente, já que redução populacional não implicaria em menores taxas de cruzamento, e sim acasalamento entre poucos indivíduos ou migrantes. Se a taxa de cruzamento for mista, em função da dispersão de pólen diminuida e aumento de autofertilização, os resultados da categoria de jovens não seriam esperados.

Em C. multiflora, os valores de $\mathrm{F}$ relativamente mais positivos para adultos do que para as progênies foi o inverso do esperado, pois são contrastantes com outros trabalhos de espécies arbóreas tropicais, nas quais as taxas de cruzamento são altas. Como exemplo, Astrocaryum mexicanum (EGULARTE et al., 1992), Pithecellobium pedicellare (O'MALLEY \& BAWA, 1987), Bertholletia excelsa (O'MALLEY et al., 1988), Cecropia obtusifolia (ALVAREZ-BUYLLA \& GARAY, 1994), todas com heterozigosidades e taxas de cruzamentos relativamente altas, apresentaram $F$ menores e ou negativos nos adultos quando comparados às progênies. No entanto, para C.multiflora os valores médios do índice de endogamia $\left(\mathrm{F}_{\mathrm{m}}\right)$ foram próximos nas duas categorias, indicando que esta população aparentemente não está sofrendo seleção que favoreça heterozigotos, entre esses estágios. Porém, há a possibilidade da seleção a favor de heterozigotos ocorrer antes da fase da amostragem das progênies, anterior a maturação dos frutos.

\subsection{CONCLUSÕES}

As duas espécies simpátricas estudadas, pertencentes a um mesmo gênero com flor altamente especializada e compartilhando baixa densidade de indivíduos na área de estudo, mostraram resultados muito próximos quanto à variação genética, mas diferentes quanto aos valores do índice de fixação.

Os valores da variação genética gerados aqui indicam que as duas espécies se não são sempre raras, como apontado por BARRETT \& KOHN (1991) na introdução desse trabalho, ocorrem naturalmente em populações de baixa densidade, pois parecem possuir sistemas genéticos ou ajustados à endogamia, com uma possivel estrutura metapopulacional ou de modelo de migrante (SLATKIN, 1977) permitindo a manutenção da variação, ou adaptações que sobrepujam a desvantagem da raridade, com dispersão de pólen à longa distância, através de mecanismos especializados de polinização. Essas diferenças terão importantes implicações na estrutura genética populacional, amostragem de material genético e tipos específicos de programas de melhoramento e conservação, que foram discutidos em conjunto na Conclusão da dissertação. 


\section{FENOLOGIA REPRODUTIVA E POTENCIALIDADE DE CRUZAMENTOS EM UMA POPULAÇÃO DE BAIXA DENSIDADE DE Couratari multiflora (J.E.Smith) Eyma NA AMAZÔNIA CENTRAL.}

\subsection{INTRODUÇÃO}

O sistema reprodutivo de espécies hermafroditas é determinado particularmente por fatores genéticos, como o grau de compatibilidade, por fatores ecológicos, como o movimento do polinizador, a fenologia floral e a densidade populacional, entre outros.

As observações sobre a fenologia e abundância da floração podem ser importantes para avaliar as contribuições relativas dos indivíduos na formação de sementes (BAWA \& O'MALLEY, 1987). Em geral, variações temporal e espacial na produção reprodutiva não têm sido correlacionadas com estabelecimento de plântulas ou variação na diversidade genética das plântulas resultantes (BAWA at al., 1990). Como apontado por MURAWSKI \& HAMRICK (1991), a densidade populacional deve ter papel determinante no comportamento do polinizador e, portanto, consequências importantes na estrutura reprodutiva de uma população de plantas. Todavia, a densidade de florescimento de árvores dentro de uma população pode afetar tanto as distâncias entre os pais potenciais, bem como o número disponivel deles no tempo.

O gênero Couratari possui a flor mais complexa e especializada dentro da familia Lecythidaceae, caracterizando-se por assimetria pronunciada e somente produção de néctar como recurso energético aos polinizadores (MORI \& PRANCE, 1990). MORI \& BOEKE (1987) apontam as abelhas euglossines como os principais polinizadores dessas espécies zigomórficas. JANZEN (1970) concluiu que essas abelhas podem viajar distâncias muito grandes 
na floresta e, aparentemente, visitam as mesmas plantas repetidamente ao longo de uma rota de alimentação. NELSON et al. (1985) estudaram C. tenuicarpa quanto à polinização (árvore típica de várzea e de baixa densidade) e observaram que esta foi efetuada por abelhas maiores e mais especializadas e, quase sem exceção, encontraram somente pólen dessa espécie no dorso das abelhas.

Couratari multiflora é representada por árvores emergentes, que produzem centenas de flores diariamente por um curto periodo de tempo, com estratégia do tipo "big-bang" (MORI at al. 1987; estratégias descritas em GENTRY. 1983). Perdem suas folhas também em curto periodo de tempo, permanecendo caducas durante a produção de flores e frutos. Possuem sementes aladas, dispersadas pelo vento. $\mathrm{Na}$ área de estudo, a densidade de adultos é de 1 indivíduo a cada 10 ha, os quais distribuem-se espacialmente com padrão agregado (LESPCHCUNHA \& KAGEYAMA, 1996b). O acompanhamento fenológico de árvores continuamente mapeadas pode trazer informações relevantes quanto as potencialidades de cruzamentos entre árvores e distância de vôo de polinizadores.

Em função da baixa densidade de indivíduos, os estudos fenológicos feitos com a espécie estão baseados em poucos individuos examinados (MORI et. al., 1987; MORI \& LEPSCH-CUNHA, 1995). Nossa preocupação geral é saber se o estudo ao nível populacional como o proposto aqui modifica as conclusões até agora elaboradas, sendo os objetivos principais deste trabalho:

1. Obter sementes (progênies) para a análise do sistema reprodutivo;

2. Descrever a fenologia reprodutiva geral da espécie;

3. Analisar as relações entre os individuos produtores de frutos e a produção de flores, tamanho das árvores, estratificação da copa e exposição da copa à luz; 
4. Analisar a sincronia de floração e o número de indivíduos potenciais de pais doadores de pólen nos cruzamentos (tempo);

5. Estimar as distâncias entre indivíduos sincronicamente em flor e dos pais potenciais conforme as distâncias das árvores-mãe (espaço);

\subsection{MATERIAL E MÉTODOS}

\subsubsection{COLETA DE DADOS}

O local de estudo, as características taxonômicas e o mapeamento dos individuos da espécie estão discutidos em Material e Métodos da dissertação.

Dos 41 individuos maiores de 20,0 cm de DAP, continuamente mapeados, da população levantada em 385 ha, acompanhamos 37 deles durante toda a fenologia. Encontramos os 4 indivíduos faltantes posteriormente, 3 (árvores 26, 27, 28) nos últimos meses de observação, e o outro restante nao foi acompanhado pelo estado da copa muito danificado. Dos 3 individuos saudáveis encontrados posteriormente, 2 entraram nas análises fenológicas por ter sido possivel o acompanhamento da frutificação. Assim, a fenologia incluiu 39 individuos considerados adultos e espacialmente contínuos na área indicada acima.

Observamos as árvores quinzenalmente, do inicio da floração até final da frutificação de 1993, coletando as seguintes informações:

1. Folhas: a. perda de folhas; b. mais de $80 \%$ sem folhas; c. folhas novas;

2. Flores: a. botões, flores imaturas; b. flores maduras;

3. Frutos: a. frutos imaturos; b. frutos maduros;

\section{Informações gerais}

1. Quantificação da produção de flores e frutos:

a. alta: copa toda preenchida com flores ou frutos de maneira copiosa;

b. média: relação intermediária entre alta e baixa;

c. baixa: flores ou frutos dispersos sob a copa ou 1 a poucos galhos preenchidos;

2. Estratificação da copa: a. emergente; b. dossel; c. sub-bosque;

3. Exposição da copa à luz: a. copa totalmente exposta; b. $50 \%$ exposta; c. $20 \%$ ou menos exposta; 
4. Diâmetro 'a altura do peito: DAP.

5. Altura: Utilizamos um clinômetro e medimos os ângulos da base do tronco e da copa superior e a distância com relação ao observador. Através de relações trigonométricas calcula-se a altura de cada árvore. Estimativas também foram feitas para cada árvore, visando comparação com as calculadas pela metodologia do clinômetro;

\subsubsection{DATAS FENOLÓGICAS}

Data fenológica é cada data de observação dos indivíduos, que neste estudo ocorreu a cada 15 dias: janeiro 1, janeiro 2, fevereiro 1, etc. Elas estão espaçadas pelo tempo de 15 dias.

Para as análises dos indices de sincronia, potencialidade de pais doadores de pólen no tempo e no espaço (distância entre indivíduos sincrônicos), todas relacionadas ao tempo que cada indivíduo encontra-se em floração e, portanto, dependentes do intervalo de tempo entre as observações (datas fenológicas), decidimos utilizar duas diferentes metodologias para a determinação da contribuição de cada indivíduo por data fenológica:

a) incluímos em cada data fenológica a contribuição dos indivíduos observados com flores na quinzena anterior e posterior a esta data, da seguinte forma:

Janeiro2 = (Janeiro2 + Fevereirol $)$;

Fevereirol $=($ Janeiro $2+$ Fevereirol $)+($ Fevereirol + Fevereiro2 $) ;$

Fevereiro2 $=($ Fevereirol + Fevereiro2 $)+($ Fevereiro $2+$ Marçol $)$, etc..

Nesta metodologia, todo individuo observado com flores em somente uma data fenólogica é considerado como reprodutivo por 30 dias. Esta opção de maximizar a contribuição dos individuos em floração teve como objetivo a obtenção de resultados máximos para sobreposição de individuos em floração e, consequentemente, mínimos para distâncias entre individuos sincrônicos. Como a espécie é de baixa densidade e tem taxa de cruzamento alta LEPSCH-CUNHA \& KAGEYAMA (1996d), esperamos valores altos para as distâncias, mesmo não tendo uma abordagem conservativa.

b) somamos 7,5 dias no inicio e final da floração para os indivíduos observados com flor em somente uma data fenológica. Para todos os outros, somamos 7,5 dias nos inicio e final da floração. 
Nesta segunda metodologia, todo individuo observado com flores em somente uma data fenológica é considerado como reprodutivo por 15 dias e, para todos os outros, houve um acréscido de 15 dias. Aqui a abordagem é no sentido de minimizar a sobreposição, relativamente ao método anterior, e ao mesmo tempo considerar um tempo de floração de cerca de 15 dias, como apontado por MORI (1983) e mais próximo às nossas observações de campo.

Sugerimos essas duas metodologias dessa forma, em função dos resultados de MORI \& cols. (1987) e MORI \& BOEKE(1983), citados anteriormente. Os autores descreveram a espécie com um comportamento de floração do tipo "big-bang", com a produção de centenas de flores em poucos dias (cerca de 10 dias). Nossos resultados revelaram inconstância no tempo de floração de cada árvore, com árvores florescendo até 60 dias.

Consideramos os eventos botões/flores imaturas e flores maduras como um único evento, floração, independentemente da maturidade das flores. Decidimos dessa forma, pois houve alternância de uma mesma árvore com flores maduras em uma data fenológica, seguida de botões/flores imaturas em data fenológica posterior, ou mesmo flores maduras, ausência de flores e posteriormente com flores maduras novamente (Figura 1). A observação no campo do amadurecimento contínuo e rápido de botões à flores maduras auxiliaram nossa decisão também.

\subsubsection{SINCRONIA DE FLORAÇÃO E NÚMERO DE PAIS POTENCIAIS DOADORES DE PÓLEN PARA CADA ÁRVORE}

Utilizamos o indice de sincronia de floração como sugerido por AUGSPURGER (1983) e modificado por Boshier (1992', cit. em BOSHIER et al., 1995), calculado para cada árvore em relação as árvores circundantes. A sincronia de um dado individuo com relação a seus conspecificos é dada por (BOSHIER et al., 1995):

$$
\begin{aligned}
& \mathrm{X}_{\mathrm{i}}=\text { índice de sincronia para o individuo } \mathrm{i} \text {, definido como: } \\
& \mathrm{X}_{\mathrm{i}}=\{1 /(\mathrm{n}-1)\}\left(1 / \mathrm{f}_{\mathrm{i}}\right) \sum \mathrm{e}_{\mathrm{j}} \# 1 \\
& \text { onde, } \\
& \mathrm{e}_{\mathrm{j}}=\text { número de dias em que os individuos } \mathrm{i} \text { e } \mathrm{j} \text { estão florescendo } \\
& \text { sincronicamente, } \mathrm{j} \# \mathrm{i} \text {; } \\
& \mathrm{fi}=\text { número de dias que o indivíduo i está florescendo; } \\
& \mathrm{n}=\text { número de indivíduos na população; } \mathrm{i}=1,2,3, \ldots \mathrm{n} ; \\
& \text { Quando } \mathrm{X}_{\mathrm{i}}=1 \text { ocorre perfeita sincronia, } \mathrm{p} . \text { ex., todos os dias de floração do }
\end{aligned}
$$

individuo i sobrepõem com todos os dias de floração de cada outro indivíduo, $\mathrm{j}$ \# $\mathrm{i}$ na população.

\footnotetext{
${ }^{1}$ BOSHIER. D.H. A study of the reproductive biology of Cordia alliodora (R. and P.) Oken. D. Phil. thesis, University of Oxford. Oxford. 1992.
} 
Quando $X_{\mathrm{i}}=0$ não ocorre sincronia, p.ex., não ocorre sobreposição entre qualquer dos dias de floração do individuo i e qualquer outro individuo, $\mathrm{j}$ \# i na população.

Para estes cálculos utilizamos as metodologias ' $a$ ' e 'b' do ítem 1 'datas fenológicas' a título de comparação. Através das frequências e frequências cumulativas do número de dias que diferentes individuos $\mathrm{i}$ e $\mathrm{j}$ floresceram sincronicamente, calculamos o número de pais potenciais ao cruzamento para cada árvore.

\subsubsection{ESTIMATIVA DAS DISTÂNCIAS ENTRE INDIVÍDUOS REPRODUTORES SINCRÔNICOS ATRAVÉS DO TEMPO}

Através de coordenadas $\mathrm{x}$ e y obtidas pelo mapeamento, calculamos as distâncias entre todas as combinações de indivíduos reprodutores (em flor) para cada data fenológica conforme metodologia 'a' do ítem 1 'datas fenológicas', ou seja, maximizando a presença de individuos e com isso obtendo resultados de distâncias mínimas. Para diminuir o erro causado pelos indivíduos nas bordas do levantamento, estipulamos uma borda de 100 metros onde os individuos ai encontrados não foram considerados nos cálculos.

Assim, para cada data fenológica, utilizamos as distâncias de cada árvore em flor com relação a seus conspecificos sincrônicos no cálculo das médias, medianas e seus desvios e quartis.

\subsubsection{PAIS POTENCIAIS CONFORME DISTÂNCIAS DAS ÁRVORES-MÃE}

Conforme metodologia ' $a$ ' do item 1 'datas fenológicas', computamos a frequência do número de indivíduos a cada 250,500,750, 1000 e mais de 1000 metros para cada indivíduo para cada data fenológica, não incluindo os indivíduos na borda de 100 metros conforme item anterior. Os resultados finais são apresentados em média para a população como um todo e para cada data fenológica.

\subsection{RESULTADOS E DISCUSSÃO}

\subsubsection{FENOLOGIA GERAL}

As observações fenológicas compreenderam os meses de janeiro a outubro de 1993, intervalo de tempo entre início da floração e término da frutificação neste ano. Esses resultados são concordantes com os de MORI \& LEPSCH-CUNHA (1995) na mesma localidade, com a floração observada de janeiro a março e a frutificação de julho a novembro. 
Em geral, os indivíduos perderam as folhas, floresceram e juntamente com o amadurecimento dos frutos produziram folhas novas. As folhas tornaram-se avermelhadas antes do inicio da perda das folhas, ficando as árvores bem diferenciadas no dossel. Assim, o florescimento e frutificação ocorreram com as copas em geral totalmente caducas (Figura 1).

A floração ocorreu entre janeiro e a primeira quinzena de julho, com o pico em março coincidente com o pico da estação chuvosa na região (LOVEJOY \& BIERREGAARD, 1990), e seu final com o início da seca (Figura 2). A distribuição da pluviosidade durante este ano foi similar à média apresentada por GENTRY (1990; pg. 01), com valores relativamente um pouco maiores do que a média. A frutificação ocorreu entre a segunda quinzena de fevereiro e segunda quinzena de setembro. A produção de frutos imaturos estendeu-se de fevereiro a agosto, com a maior concentração nos meses abril e maio, durante final da estação chuvosa. Frutos maduros foram vistos de maio a setembro, com a maior concentração em junho, no início da estação seca. A Figura 3 apresenta o acompanhamento de cada indivíduo reprodutivo através do tempo e a Figura 1, o acompanhamento das diversas fases fenológicas na população como um todo.

Dos 39 indivíduos observados, $27(69,2 \%)$ floresceram com 23 indivíduos vistos com flores maduras e 4 com imaturas , $18(46,2 \%)$ frutificaram com $9(23,1 \%)$ vistos com frutos maduros e $9(23,1 \%)$ com imaturos, e $4(10,3 \%)$ foram possíveis de coleta para a formação das familias (Figuras 4A e 4B). Dos 27 individuos que floresceram, 66,7\% frutificaram.

Não houve a presença de árvores com produção média de flores, sendo característico somente ver árvores com alto ou baixo florescimento, concordando com a estratégia "big bang" para as de alta produção. Dos 27 individuos que floresceram, $16(59,3 \%)$ e 11 $(40,7 \%)$ tiveram alta e baixa produção de flores, respectivamente, e dos 18 que frutificaram, 7 $(38,9 \%)$ e $5(27,8 \%)$ tiveram alta e baixa produção de frutos, não sendo possivel a quantificação de $6(33,3 \%$ ) árvores (Figuras $4 \mathrm{~A}$ e $4 \mathrm{~B})$. Os 7 indivíduos com alta produção de frutos tiveram alta produção de flores, porém não ocorreu a mesma relação para os de baixa produção de frutos. A Figura 5 mostra a distribuição espacial dos individuos observados e suas respostas fenológicas reprodutivas. 


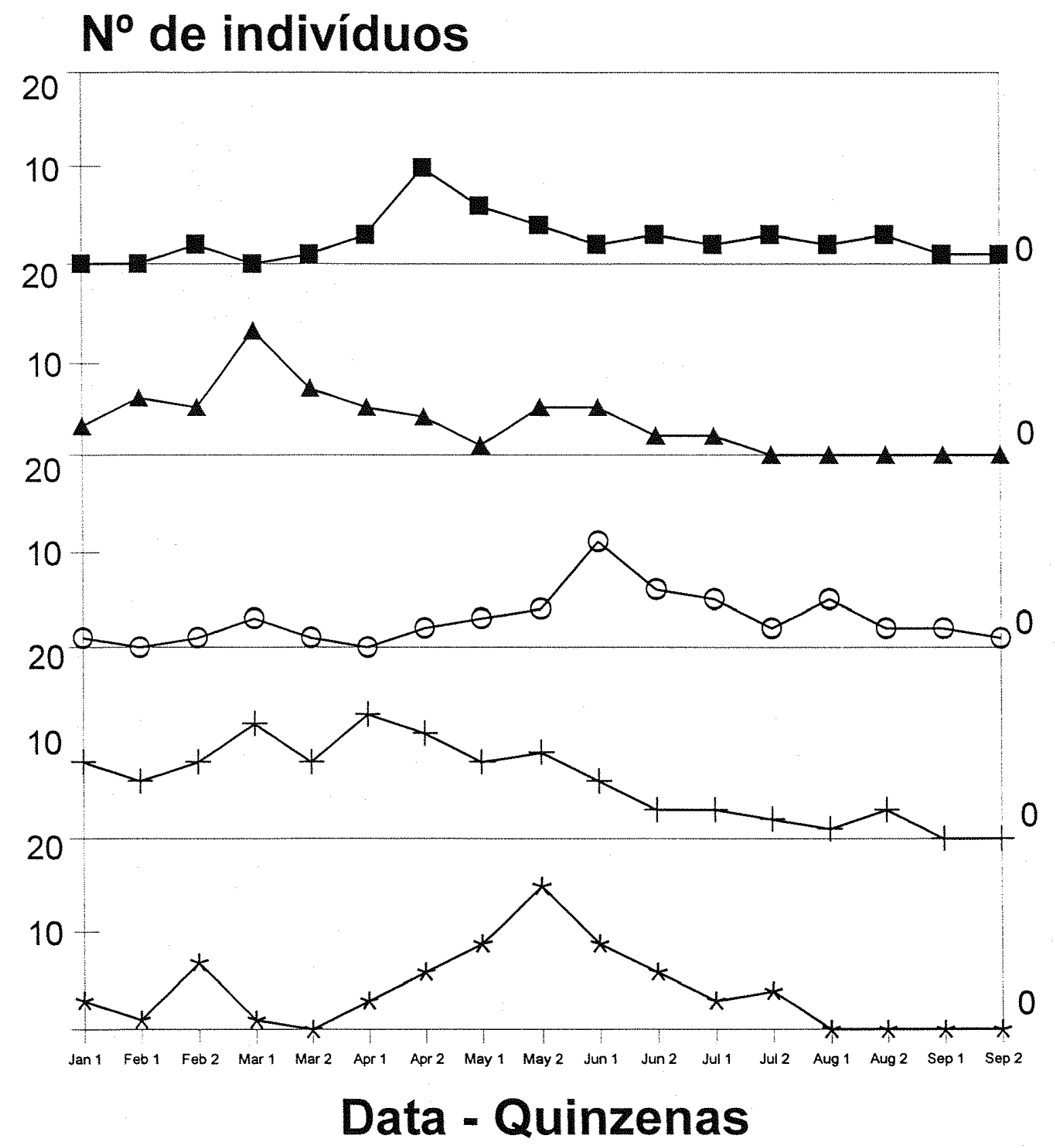

* Perda de folhas +Árvore caduca $\ominus$ Folhas novas

\Floração - Frutificação

Figura 1. Fenologia geral 


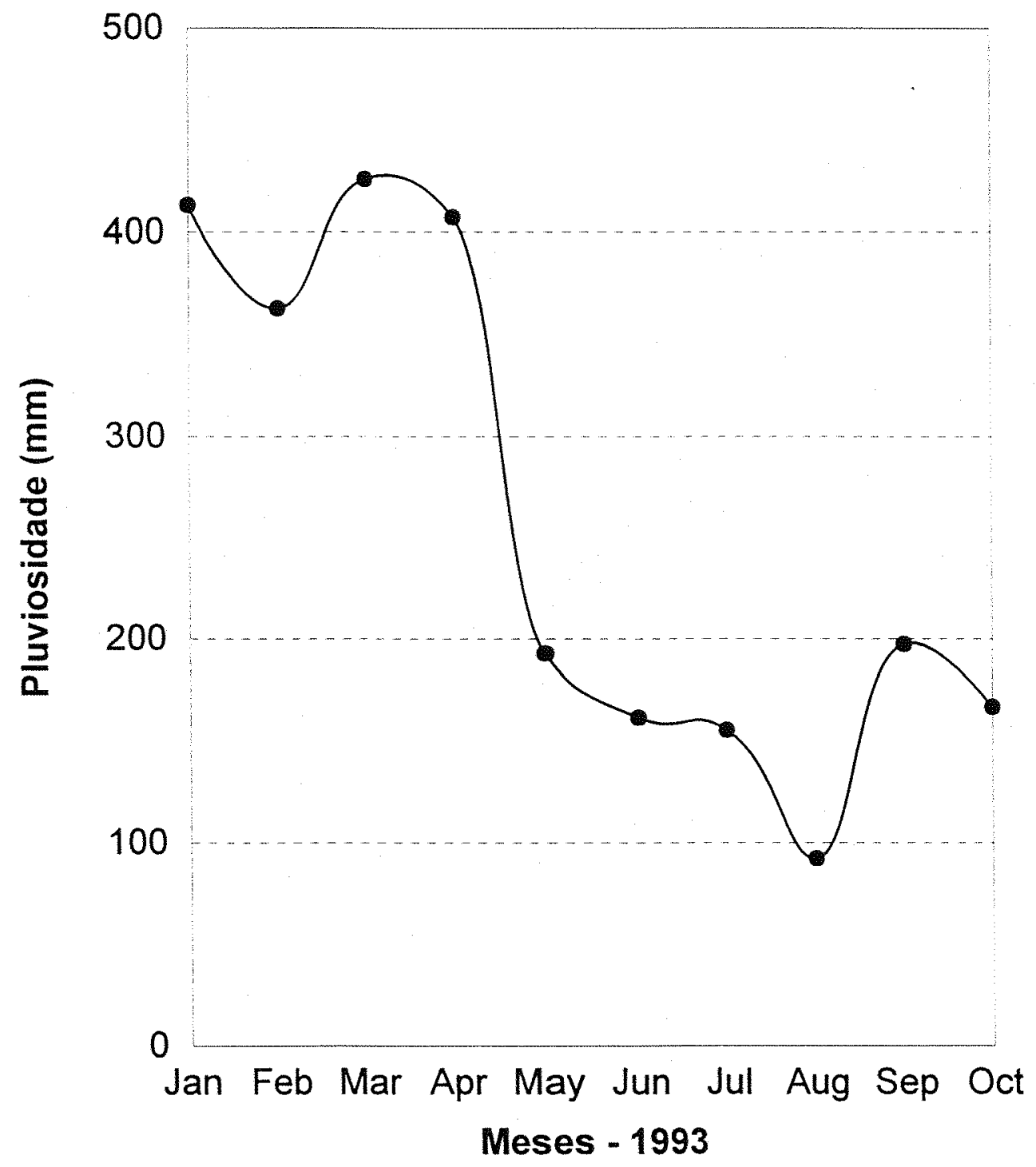

Figura 2. Pluviosidade durante 1993 na Reserva 1501, km 41. 


\section{Indivíduo}

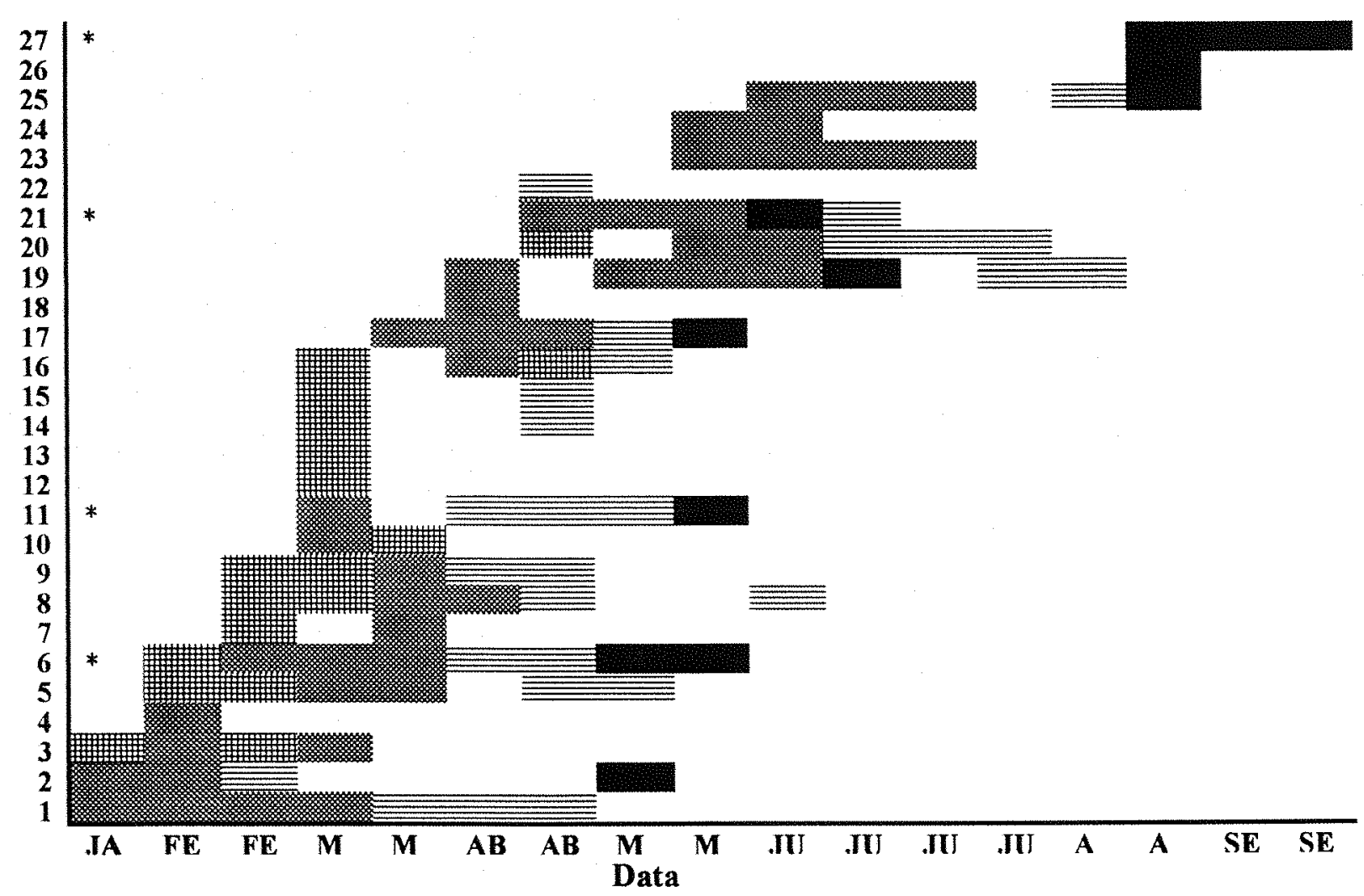

BOTÕES

FLOR MADURA

FRUTO IMATURO

FRUTO MADURO

Figura 3. Fenologia de todos os individuos reprodutivos de C. multiflora em 1993. Quando da sobreposição de eventos fenológicos, botões-flor madura e fruto imaturo-maduro, priorizou-se a representação de flores e frutos maduros. As árvores-mãe utilizadas nas análises do sistema reprodutivo estão apontadas por asterisco "*". 


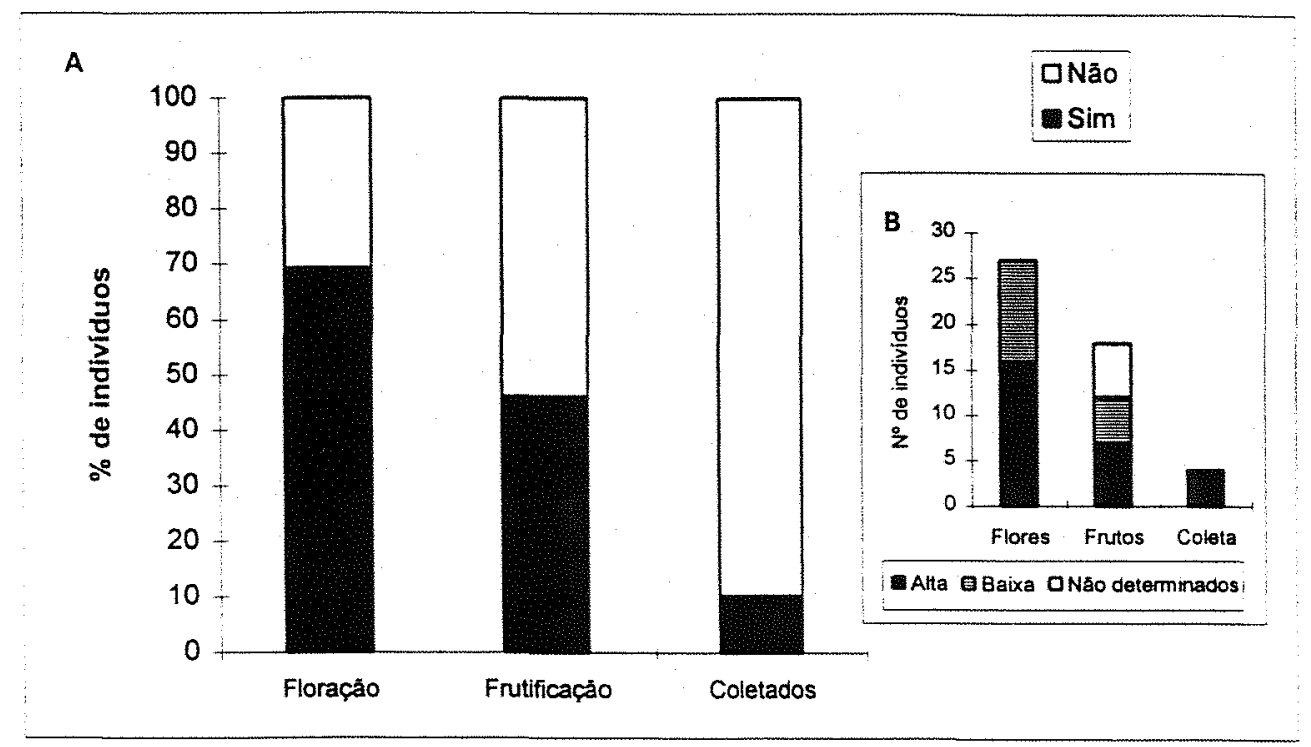

Figura 4. A. Porcentagem de indivíduos conforme suas respostas reprodutivas e coleta com relação à população total observada $(n=39)$. B. Número de individuos quanto à sua resposta reprodutiva e produção de flores e frutos com relação a população total observada $(\mathrm{n}=39)$. Alta = produção alta; baixa = produção baixa .

As causas observadas, mas não quantificadas, para o não amadurecimento de $50 \%(9 / 18)$ das árvores que produziram frutos foram a baixa produção de frutos e a alta predação destes ainda imaturos por macacos, araras e roedores, de maneira copiosa. A causa não observada pode ter sido o aborto e/ou não amadurecimento dos frutos. A espécie é de baixa densidade e pode estar adaptada ao exocruzamento, conforme taxas de cruzamento iguais a 1 para a população apresentadas em LEPSCH-CUNHA \& KAGEYAMA (1996d). Se mecanismos de autoincompatibilidade pós-zigóticos existirem, a autopolização pode gerar esse tipo de resultado (aborto ou barreiras fisiológicas ao desenvolvimento). Pelas mesmas causas explicamos a coleta de um número pequeno de árvores (4). A espera pelo amadurecimento de frutos por somente uma quinzena. com o intuito de se obter sementes maduras viáveis, foi suficiente para não se encontrar mais fruto algum sobre a copa, com muitos galhos de frutos imaturos no chão, bem como outros frutos roídos. 


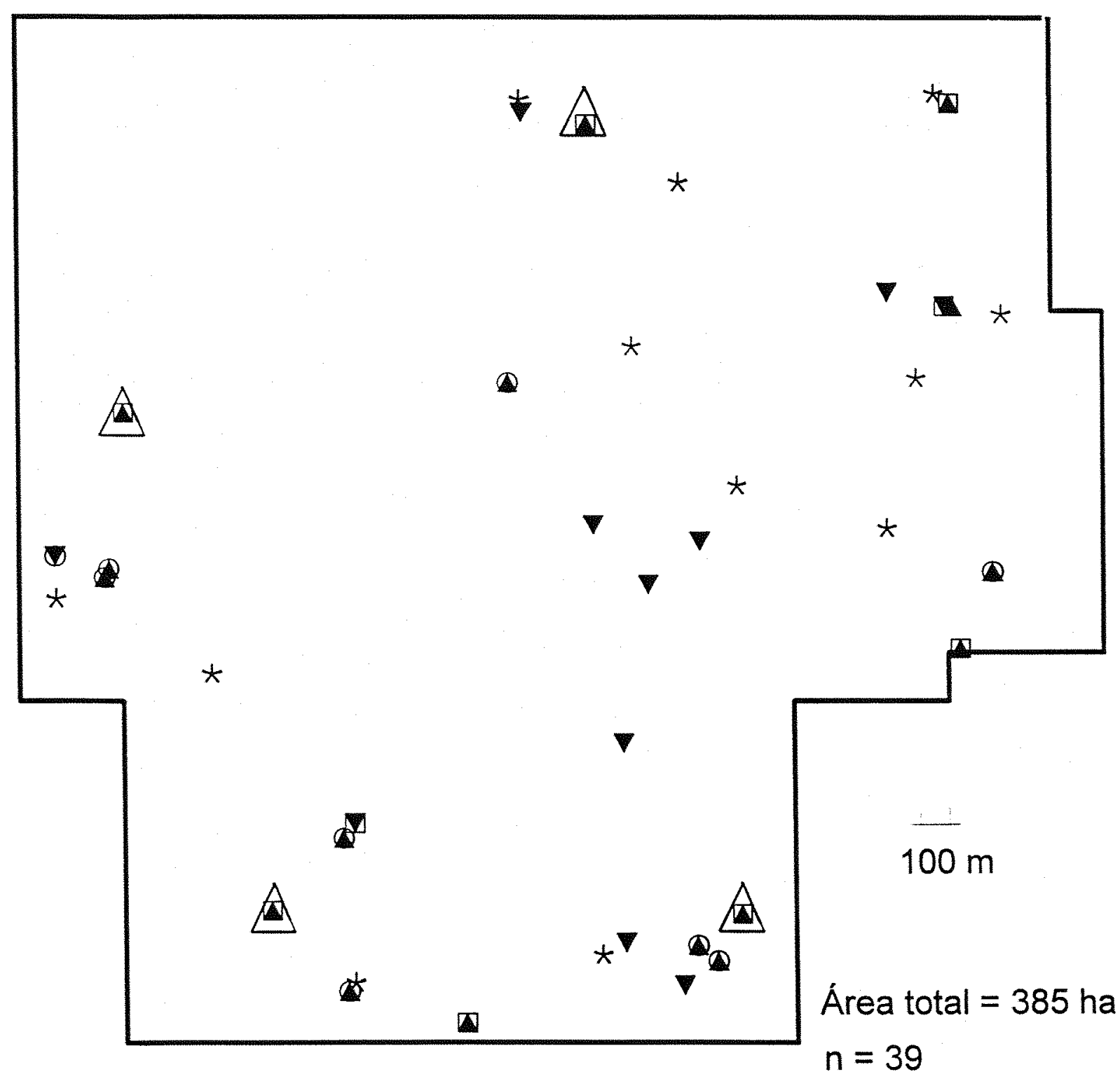
Alta prod. de flores
$\checkmark$ Baixa prod. de flores
O Frutos imaturos
$\square$ Frutos maduros
* Indivíduos não reprodutivos

$\triangle$ Árvores coletadas

Figura 6. Distribuição espacial dos individuos de C. multiflora observados na fenologia e sua: respostas reprodutivas. 


\subsubsection{RELAÇÕES ENTRE CARACTERÍSTICAS MORFOMÉTRICAS (ALTURA, DAP) E ECOLÓGICAS (ESTRATIFICAÇ̃̃o E EXPOSIÇ̃̃o DA COPA À LUZ) COM AS FASES REPRODUTIVAS (FLOR E FRUTO) E SUA PRODUÇÃO}

\subsubsection{Altura e DAP}

Todas as classes de altura estão representadas por individuos que floresceram ou não. Assim, o florescimento ocorreu em árvores a partir de $20,0 \mathrm{~m}$ de altura, altura mínima observada para o DAP mínimo de $20 \mathrm{~cm}$ estipulado para árvores adultas. As Figuras $6 \mathrm{~A}$ e $6 \mathrm{~B}$ mostram uma relação direta entre presença de floração e a altura das árvores, cujos individuos mais altos foram aqueles que mais floriram. Essa relação fica bem evidente na Figura 6B de porcentagens. No geral, foram os indivíduos acima de 30 metros de altura os que mais floresceram. O mesmo não ocorreu com as classes de DAP, conforme Figura 7A de número de indivíduos, onde a presença de florescimento diminui gradualmente com o aumento do diâmetro: o maior número de indivíduos com flores está representado nas classes intermediárias, entre 25 e $35 \mathrm{~cm}$ de DAP. Essa relação torna-se praticamente igual para as porcentagens (Figura 7B), revelando resposta não diferenciada do florescimento com relação ao diâmetro.

Esses resultados juntamente com a análise de correlação simples entre essas duas variáveis $(r=0.5295)$ evidenciam a ausência de correlação linear entre altura e DAP na população. Se enfocarmos somente o diâmetro, concluiremos que o florescimento é indiferente quanto ao tamanho, porém, se enfocarmos a altura, concluiremos o inverso. Assim, não necessariamente árvores mais grossas são as mais altas, refletindo a forma da árvore, muitas vezes, alta e fina. A Tabela 1 mostra a maior representação de individuos com alta produção de flores nas classes intermediárias de altura, entre 30 e $40 \mathrm{~m}$, sendo indiferente na maior classe e nas menores. Para o diâmetro, a produção também parece indiferente para as todas as classes, com a exceção a classe entre 30 e $35 \mathrm{~cm}$, com um número maior de indivíduos com alta produção de flores.

Tabela 1. Produção de flores na população para altura e DAP e suas relaçães com a produção. Classes conforme Figuras 6 e 7. Prod. = produção.

\begin{tabular}{|c|c|c|c|c|c|c|c|c|}
\hline \multirow[b]{2}{*}{ CLASSES } & \multicolumn{4}{|c|}{ ALTURA } & \multicolumn{4}{|c|}{$\mathbf{D A P}$} \\
\hline & $\begin{array}{c}\text { Prod. } \\
\text { alta }\end{array}$ & $\begin{array}{l}\text { Prod. } \\
\text { baixa }\end{array}$ & $\Sigma$ & $\begin{array}{l}\text { Não } \\
\text { prod. }\end{array}$ & $\begin{array}{c}\text { Prod. } \\
\text { alta }\end{array}$ & $\begin{array}{l}\text { Prod. } \\
\text { baixa }\end{array}$ & $\Sigma$ & $\begin{array}{l}\text { Não } \\
\text { prod. }\end{array}$ \\
\hline 5 & 3 & 4 & 7 & 1 & 3 & & 3 & 1 \\
\hline 4 & 5 & 1 & 6 & 1 & 2 & 2 & 4 & 1 \\
\hline 3 & 6 & 2 & 8 & 4 & 5 & 2 & 7 & 4 \\
\hline 2 & & 1 & 1 & 2 & 5 & 6 & 11 & 5 \\
\hline 1 & 2 & 3 & 5 & 4 & 1 & 1 & 2 & 1 \\
\hline Total & 16 & 11 & 27 & 12 & 16 & 11 & 27 & 12 \\
\hline
\end{tabular}



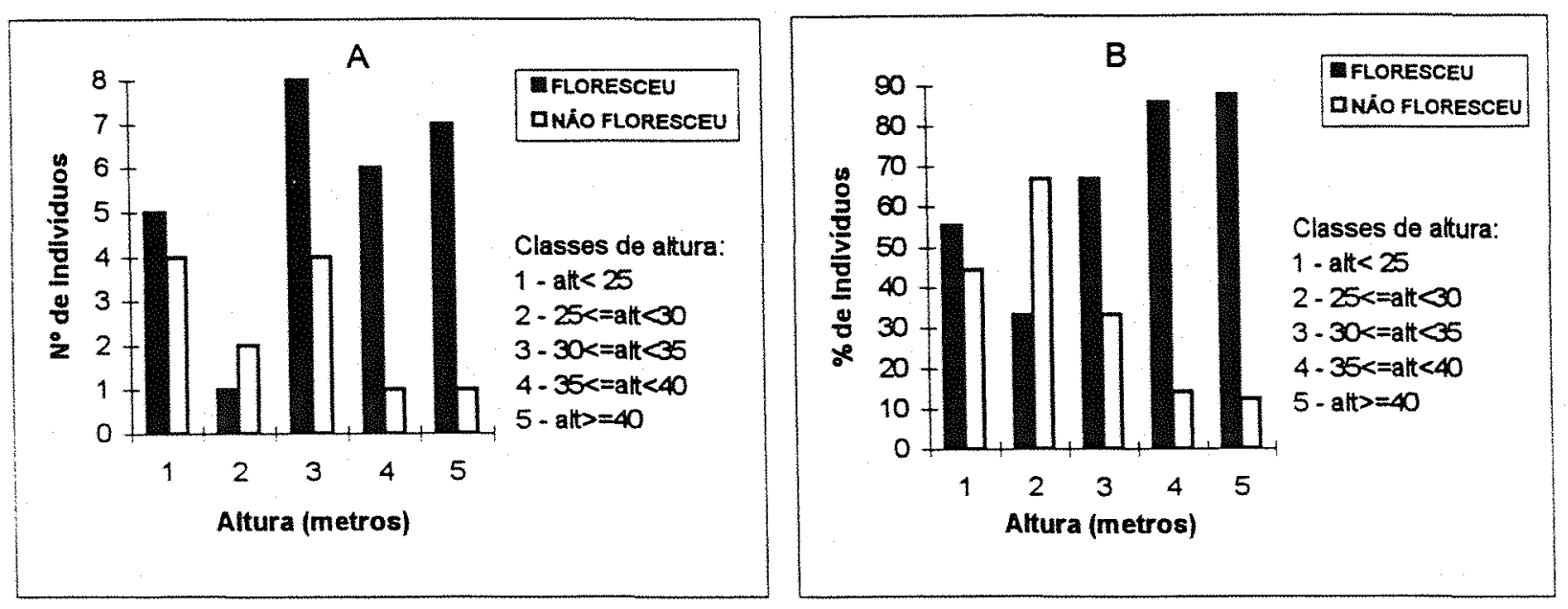

Figura 6. Número (A) e porcentagem (B) de individuos que floresceram conforme classes de altura.
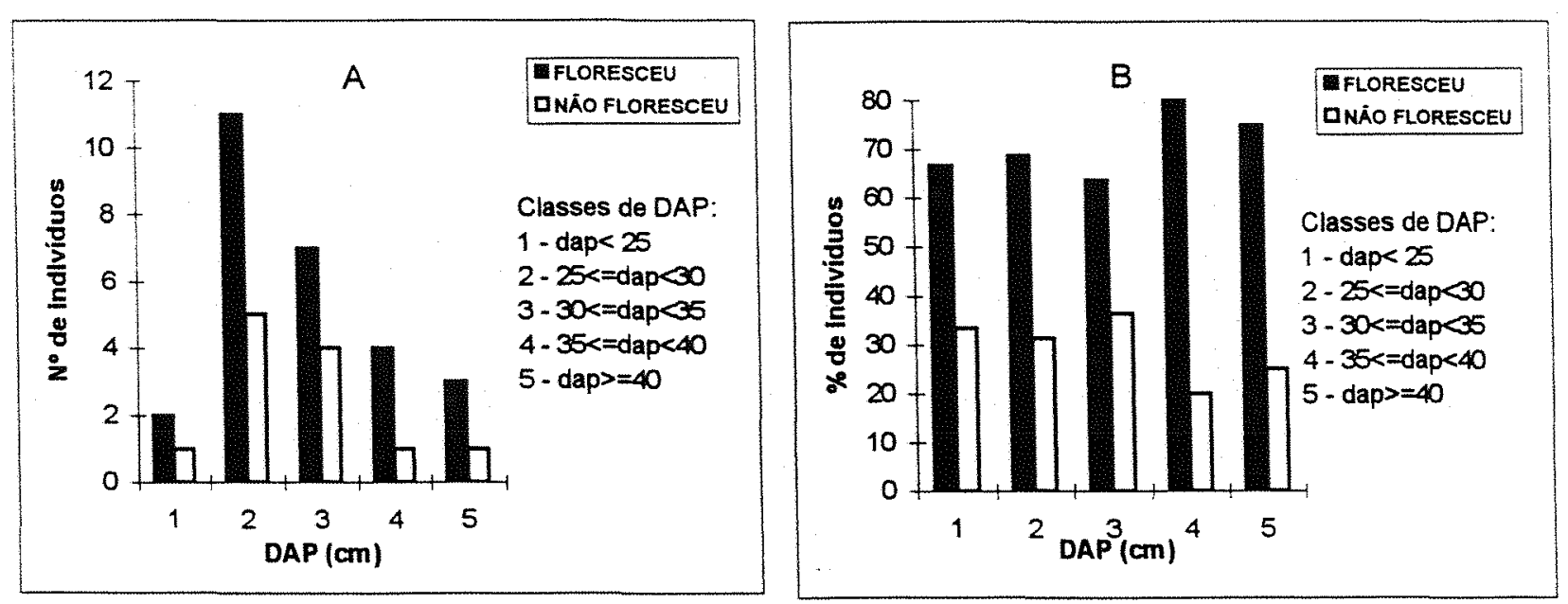

Figura 7. Número (A) e porcentagem (B) de individuos que floresceram conforme classes de DAP. 
Conforme a Tabela 2, as duas classes mais altas possuem o maior número de árvores frutificando (11) do que não (4). Nas classes seguintes, de menores alturas, verifica-se uma relação inversa, com aumento do número de árvores sem frutificar (17) e diminuição das produtoras (7). Quanto ao diâmetro, a relação persiste, porém de maneira não tão acentuada. A verificação da quantificação da frutificação ficou prejudicada pela predação e/ou aborto dos frutos imaturos em várias árvores. De qualquer forma, a Tabela 2 mostra os resultados possiveis e considerando somente as árvores que puderam ser quantificadas, vemos que não há muita diferença entre produção alta e baixa de frutos com relação às classes de altura e ao diâmetro das árvores, desconsiderada a presença ou não de frutos.

Tabela 2. Produção de frutos na população para altura e DAP e suas relações com a produção. A coluna " $\Sigma$ " inclui também as árvores que produziram frutos, mas não foram quantificadas quanto à quantidade alta e baixa. Classes conforme Figura 6 e 7 . Prod. $=$ produção.

\begin{tabular}{|c|c|c|c|c|c|c|c|c|}
\hline & \multicolumn{4}{|c|}{ ALTURA } & \multicolumn{3}{c|}{ DAP } \\
\hline CLASSES & $\begin{array}{c}\text { Prod. } \\
\text { alta }\end{array}$ & $\begin{array}{c}\text { Prod. } \\
\text { baixa }\end{array}$ & $\Sigma$ & $\begin{array}{c}\text { Não } \\
\text { prod. }\end{array}$ & $\begin{array}{c}\text { Prod. } \\
\text { alta }\end{array}$ & $\begin{array}{c}\text { Prod. } \\
\text { baixa }\end{array}$ & $\begin{array}{c}\text { Não } \\
\text { prod. }\end{array}$ \\
\hline 5 & 2 & 2 & 5 & 3 & 2 & 1 & 3 & 1 \\
\hline 4 & 3 & 1 & 6 & 1 & 1 & 1 & 3 & 2 \\
\hline 3 & 2 & 2 & 5 & 7 & 3 & 1 & 4 & 7 \\
\hline 2 & & & & 3 & 1 & 2 & 7 & 9 \\
\hline 1 & & & 2 & 7 & & & 1 & 2 \\
\hline Total & 7 & $\mathbf{5}$ & $\mathbf{1 8}$ & $\mathbf{2 1}$ & $\mathbf{7}$ & $\mathbf{5}$ & $\mathbf{1 8}$ & $\mathbf{2 1}$ \\
\hline
\end{tabular}

\subsubsection{Estratificação}

Dos 39 indivíduos observados, $21(53,8 \%)$ são árvores emergentes, 15 $(38,5 \%)$ são de dossel e $3(7,7 \%)$ são de subbosque. Assim, praticamente toda a população acima de 20,0 cm de DAP encontra-se ou no dossel ou acima deste. Dos 27 individuos que floresceram, $15(55,5 \%)$ são emergentes, $10(37,0 \%)$ são de dossel e $2(7,4 \%)$ são de subbosque, seguindo o mesmo padrão de distribuição que a população total (Figuras $8 \mathrm{~A}$ e $8 \mathrm{~B}$ ).

A Figura 9A mostra uma relação entre estratificação e produção de flores, com as emergentes representadas por número e porcentagem maior de indivíduos com alta produção de flores em detrimento das de dossel. Novamente pouca conclusão pode ser tomada para a produção de frutos, com exceção de que as árvores quantificadas com alta produção de frutos são as emergentes, sendo também as mais numerosas. 


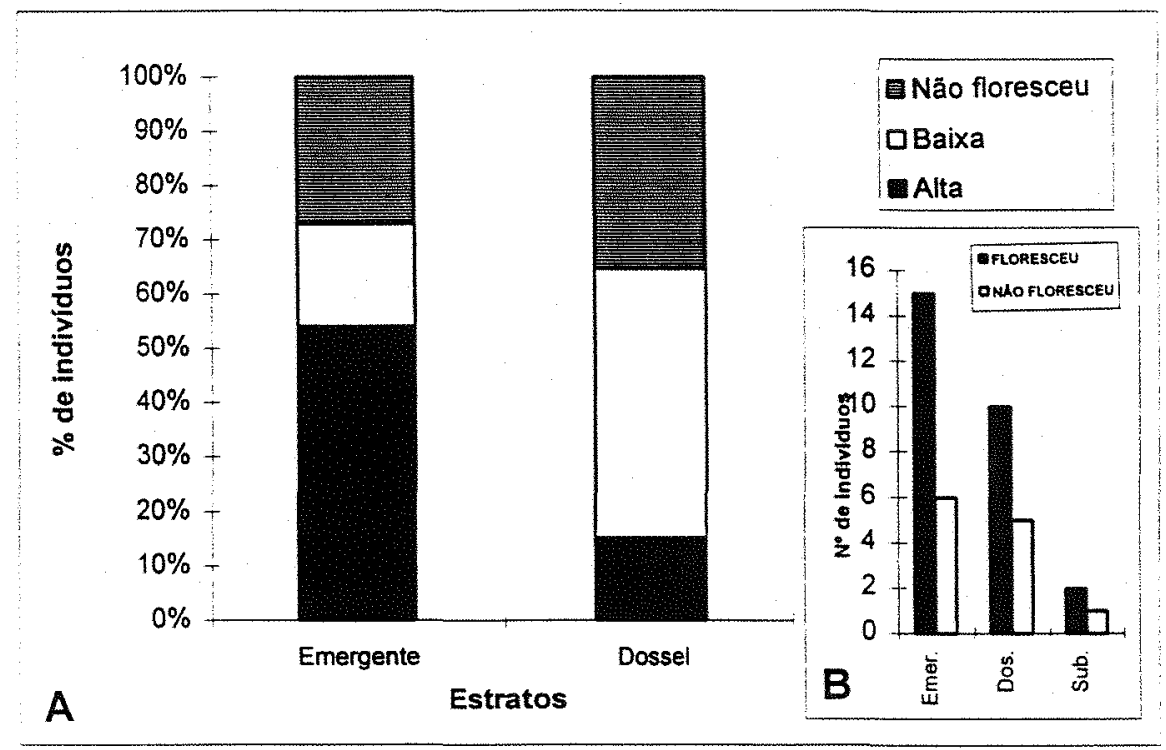

Figura 8. Representação da estratificação da copa com relação à quantificação da produção de flores em porcentagem da população geral (A) e da presença e ausência de florescimento para número de individuos $(\mathrm{B})$.

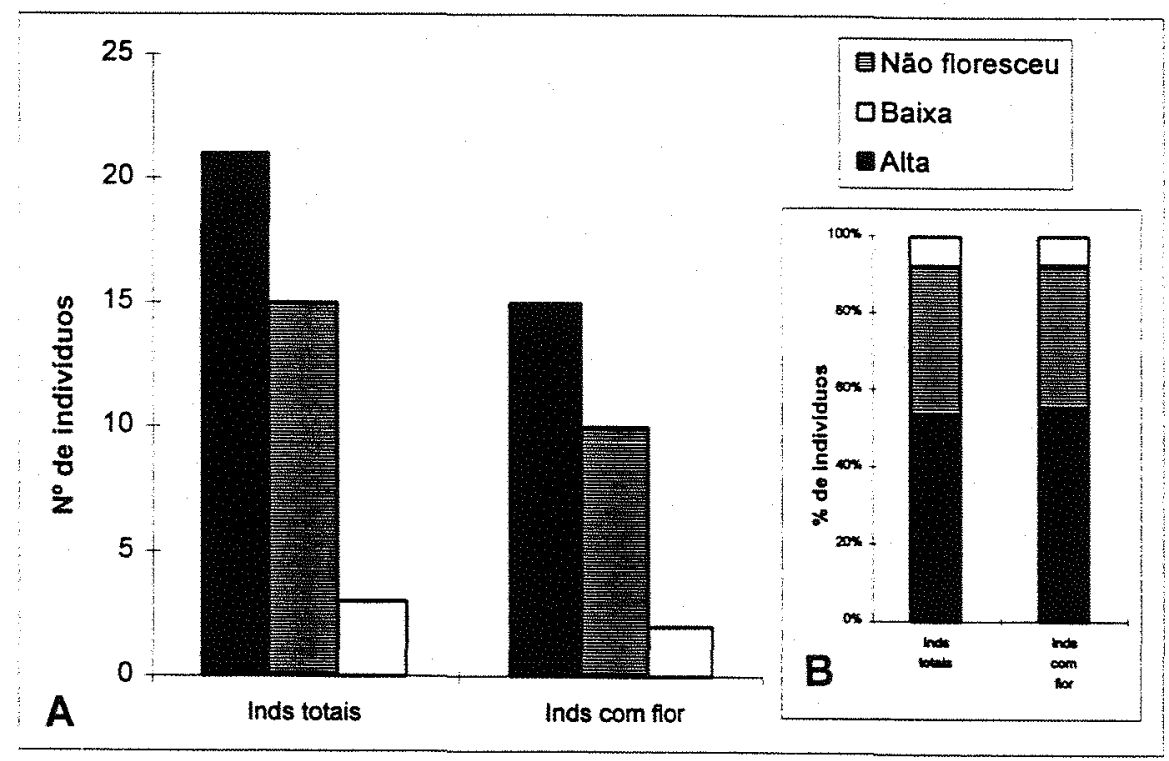

Figura 9. Respostas quanto ao florescimento dos individuos totais observados e somente daqueles que floresceram conforme a estratificação da copa para número $(\mathrm{A})$ e porcentagem (B) de individuos. 


\subsubsection{Exposição da copa à luz}

Das 27 árvores que floresceram, $19(70,4 \%)$ estavam com suas copas totalmente expostas à luz, $3(11,1 \%)$ parcialmente expostas e $5(18,5 \%)$ na sombra (Figura 10$)$. A relação entre produção de flores e a exposição da copa à luz fica evidenciada na Figura 11, onde verifica-se que são as árvores totalmente expostas à luz que produziram maior quantidade de flores.

Dos dois indivíduos baixos que tiveram alta produção de flores, um encontrava-se na sombra e não teve quantificação quanto à produção de frutos, e o outro, estava com a copa totalmente exposta e teve alta produção de frutos. Todos os outros indivíduos "baixos" tiveram produção baixa de flores e estavam com suas copas na sombra.

Esses resultados revelam a possibilidade de indivíduos baixos produzirem flores e frutos se forem manejados quanto à maior incidência de luz. Assim, parece possível detectar individuos fisiologicamente reprodutivos mas ecologicamente não, o que evidencia que o tamanho não necessariamente indica a idade da árvore. Geneticamente, estes dados mostram a presença de variação entre individuos e a alta potencialidade de melhoramento florestal.

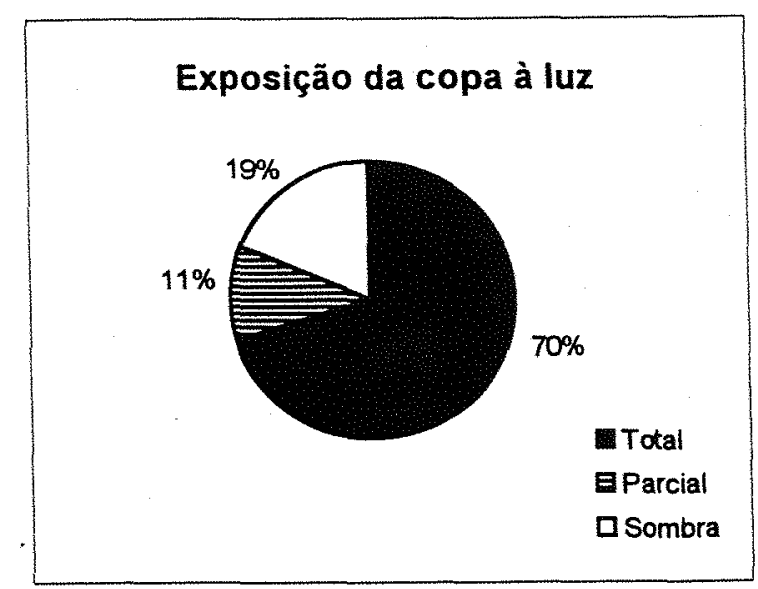

Figura 10. Representação da população em geral quanto à exposição da copa à luz. Total = totalmente exposta; Parcial $=$ parcialmente exposta. 


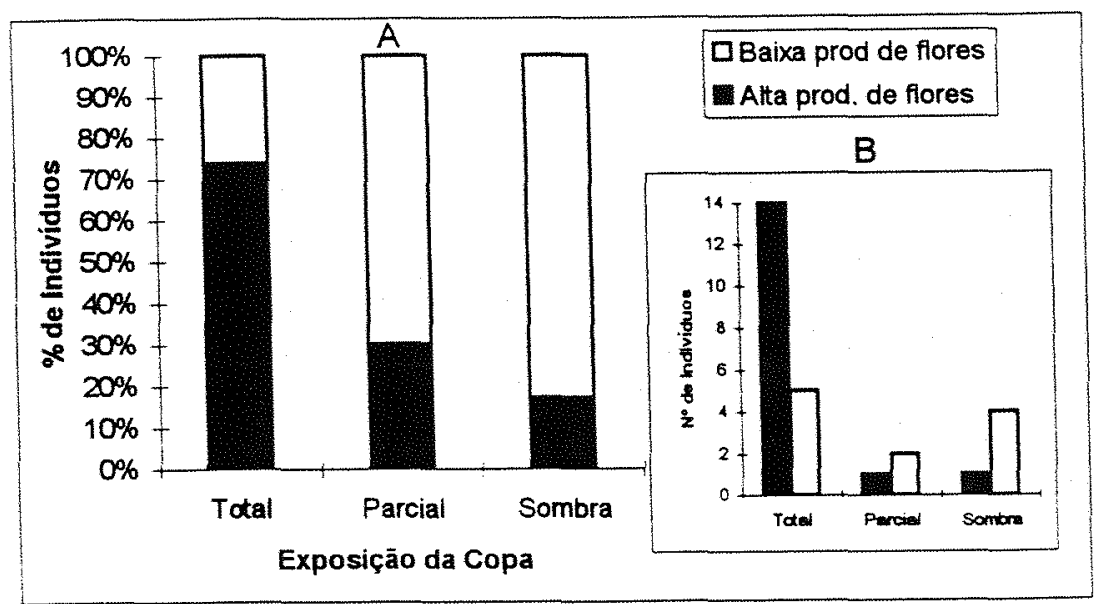

Figura 11. Relação entre exposição da copa à luz e a produção de flores quanto a porcentagem de indivíduos $(\mathrm{A})$ e $\mathrm{n}^{\circ}$ de individuos. Total = copa totalmente exposta; parcial $=$ parcialmente exposta.

\subsubsection{SINCRONIA DE FLORAÇÃO E NÚMERO DE INDIVIDUUOS POTENCIAIS DE PAIS DOADORES DE PÓLEN NOS CRUZAMENTOS}

As Tabelas 3 e 4 mostram, para o método 'a' e 'b' (ítem 1 da Metodologia), as árvores e seus números de dias em floração $\left(f_{1}\right)$, o indice de sincronia $\left(X_{i}\right)$, o número de indivíduos não sincrônicos (S0) e de individuos sincrônicos por no máximo $1,15,30,45 \mathrm{e}>=60$ dias (S1, S15, S30, S45, S60) para cada árvore, e a frequência cumulativa ou o número de individuos sincrônicos pelo um mínimo de 1 (máximo de indivíduos sincrônicos), $15,30,45$ e >= 60 dias (TOT1, TOT15, TOT30, TOT45, TOT60). As medidas de tendência central situam-se na base da tabelas. A ordem das árvores segue a sequência da floração; assim, a árvore 1 foi a primeira vista com flor e a árvore 24 , a última. As árvores 22,26 e 27 só foram vistas com frutos e, portanto, preferimos tirá-las dos cálculos. Cabe lembrar que a árvore 27 foi uma das 4 árvores coletadas para a análise do sistema reprodutivo. 
Tabela 3. Método a. Máximo de dias em floração $\left(\mathrm{f}_{\mathrm{i}}\right)$, índice de sincronia $\left(\mathrm{X}_{\mathrm{i}}\right), \mathrm{n}^{\circ}$ total de árvores sobrepondo-se em floração por 0 (S0 - no. de indivíduos não sincrônicos), 1(S1), 15(S15), 30(S30), 45(S45) e > $=60$ (S60) dias, e $\mathrm{n}^{\circ}$ total de árvores sobrepondo-se por no mímino 1 dia (TOT1=S1+S15+S30+S45+S60), 15 (TOT15), 30 (TOT30), 45 (TOT45) e 60 (TOT60) dias. $\mathrm{DP}=$ desvio padrão; $\mathrm{Q} 3=$ quartil $3(75 \%)$; $\mathrm{MED}=$ mediana; Q1 = quartil 1 .

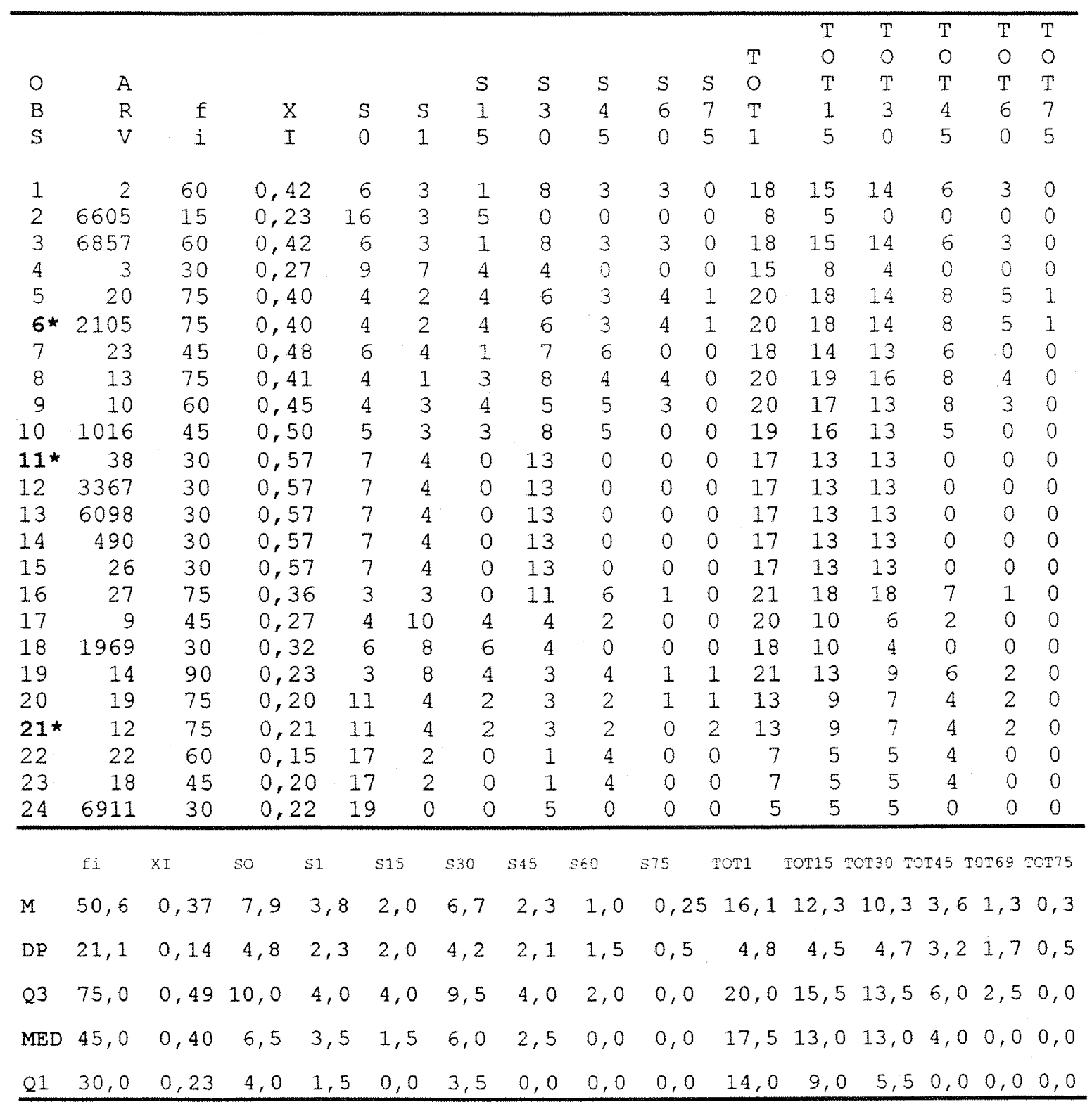

As árvores-mãe utilizadas nas análises do sistema reprodutivo estão apontadas por asterisco **". 
Tabela 4. Método $b$. Máximo de dias em floração $\left(\mathrm{f}_{\mathrm{i}}\right)$, índice de sincronia $\left(\mathrm{X}_{\mathrm{i}}\right), \mathrm{n}^{\circ}$ total de árvores sobrepondo-se em floração por 0 (S0 - no. de indivíduos não sincrônicos), 1(S1), 15(S15), 30(S30), 45(S45) e >=60 (S60) dias, e ${ }^{\circ}$ total de árvores sobrepondo-se por no mímino 1 dia (TOT1 $=\mathrm{S} 1+\mathrm{S} 15+\mathrm{S} 30+\mathrm{S} 45+\mathrm{S} 60$ ), 15 (TOT15), 30 (TOT30), 45 (TOT45) e 60 (TOT60) dias. DP = desvio padrão; $\mathrm{Q} 3=$ quartil $3(75 \%)$; MED = mediana; Q1 = quartil 1 .

\begin{tabular}{|c|c|c|c|c|c|c|c|c|c|c|c|c|c|c|c|}
\hline & & & & & & & & & & & \multirow[b]{2}{*}{$\mathrm{T}$} & $\mathrm{T}$ & $\mathrm{T}$ & $\mathrm{T}$ & $\mathrm{T}$ \\
\hline & & & & & & & & & & & & 0 & 0 & 0 & 0 \\
\hline 0 & A & & & & & & $S$ & $S$ & $S$ & $S$ & 0 & $\mathrm{~T}$ & $\mathrm{~T}$ & $T$ & $\mathrm{~T}$ \\
\hline$B$ & F & & $\mathrm{f}$ & $\mathrm{X}$ & $S$ & $S$ & 1 & 3 & 4 & 6 & $\mathrm{~T}$ & 1 & 3 & 4 & 6 \\
\hline$S$ & V & & $i$ & $I$ & 0 & 1 & 5 & 0 & 5 & 0 & 1 & 5 & 0 & 5 & 0 \\
\hline 1 & 2 & & 60 & 0,28 & 8 & 1 & 8 & 4 & 2 & 1 & 16 & 15 & 7 & 3 & 1 \\
\hline 2 & 6605 & & 30 & 0,12 & 16 & 3 & 3 & 2 & 0 & 0 & 8 & 5 & 2 & 0 & 0 \\
\hline 3 & 6857 & & 60 & 0,28 & 8 & 1 & 8 & 4 & 2 & 1 & 16 & 15 & 7 & 3 & 1 \\
\hline 4 & 3 & & 15 & 0,23 & 16 & 3 & 5 & 0 & 0 & 0 & 8 & 5 & 0 & 0 & 0 \\
\hline 5 & 20 & & 60 & 0,35 & 6 & 2 & 7 & 3 & 5 & 1 & 18 & 16 & 9 & 6 & 1 \\
\hline $6 *$ & 2105 & & 60 & 0,35 & 6 & 2 & 7 & 3 & 5 & 1 & 18 & 16 & 9 & 6 & 1 \\
\hline 7 & 23 & & 45 & 0,38 & 6 & 4 & 6 & 4 & 4 & 0 & 18 & 14 & 8 & 4 & 0 \\
\hline 8 & 13 & & 60 & 0,33 & 4 & 4 & 7 & 4 & 5 & 0 & 20 & 16 & 9 & 5 & 0 \\
\hline 9 & 10 & & 45 & 0,38 & 6 & 4 & 6 & 4 & 4 & 0 & 18 & 14 & 8 & 4 & 0 \\
\hline 10 & 1016 & & 30 & 0,44 & 8 & 2 & 8 & 6 & 0 & 0 & 16 & 14 & 6 & 0 & 0 \\
\hline 11 * & 38 & & 15 & 0,61 & 10 & 1 & 12 & 1 & 0 & 0 & 14 & 13 & 1 & 0 & 0 \\
\hline 12 & 3367 & & 15 & 0,61 & 10 & 1 & 12 & 1 & 0 & 0 & 14 & 13 & 1 & 0 & 0 \\
\hline 13 & 6098 & & 15 & 0,61 & 10 & 1 & 12 & 1 & 0 & 0 & 14 & 13 & 1 & 0 & 0 \\
\hline 14 & 490 & & 15 & 0,61 & 10 & 1 & 12 & 1 & 0 & 0 & 14 & 13 & 1 & 0 & 0 \\
\hline 15 & 26 & & 15 & 0,61 & 10 & 1 & 12 & 1 & 0 & 0 & 14 & 13 & 1 & 0 & 0 \\
\hline 16 & 27 & & 60 & 0,28 & 7 & 0 & 10 & 5 & 2 & 0 & 17 & 17 & 7 & 2 & 0 \\
\hline 17 & ؟ & & 45 & 0,22 & 6 & 7 & 8 & 2 & 1 & 0 & 18 & 11 & 3 & 1 & 0 \\
\hline 18 & 1960 & & 15 & 0,28 & 13 & 5 & 6 & 0 & 0 & 0 & 11 & 6 & 0 & 0 & 0 \\
\hline 19 & 14 & & 15 & 0,28 & 13 & 5 & 6 & -0 & 0 & 0 & 11 & 6 & 0 & 0 & 0 \\
\hline 20 & 15 & & 60 & 0,12 & 15 & 3 & 3 & 2 & 0 & 1 & 9 & 6 & 3 & 1 & 0 \\
\hline 21 * & 12 & & 60 & 0,12 & 15 & 3 & 3 & 2 & 0 & 1 & 9 & 6 & 3 & 1 & 0 \\
\hline 22 & 22 & & 45 & 0,14 & 19 & 0 & 0 & 5 & 0 & 0 & 5 & 5 & 5 & 0 & 0 \\
\hline 23 & 18 & & 30 & 0,22 & 19 & 0 & 0 & 5 & 0 & 0 & 5 & 5 & 5 & 0 & 0 \\
\hline 24 & 691 & & 30 & 0,07 & 19 & 0 & 4 & 1 & 0 & 0 & 5 & 5 & 1 & 0 & 0 \\
\hline & $F i$ & $X I$ & so & S1 & $S 15$ & 530 & 545 & 560 & & Tor1 & rot15 & OT 30 & 0 TOTA5 & & T69 \\
\hline$M$ & 37,5 & 0 , & & 10,8 & 2,25 & 6,9 & 2,5 & 1,25 & 0,25 & 13,2 & & 10,9 & 4,04 & 1,5 & 0,25 \\
\hline $\mathrm{DP}$ & 19,3 & 0 , & 17 & 4,7 & 1,90 & 3,6 & 1,8 & 1,90 & 0,44 & 4,7 & & 4,5 & 3,30 & 2,1 & 0,40 \\
\hline Q3 & 60,0 & 0 , & 41 & 15,0 & 3,50 & 9,0 & 4,0 & 2,00 & 0,50 & 17,5 & & 14,5 & 7,00 & 3,0 & 0,50 \\
\hline MED & 37,5 & 0 , & 28 & 10,0 & 2,00 & 7,0 & 2,0 & 0,00 & 0,00 & 14,0 & & 13,0 & 3,00 & 0,0 & 0,00 \\
\hline 01 & 15,0 & 0 , & 22 & 6,5 & 1,00 & 4,5 & 1,0 & 0,00 & 0,00 & 9,0 & & 6,0 & 1,00 & 0,0 & 0,00 \\
\hline
\end{tabular}


O método 'a' em geral apresentou 15 dias a mais de floração por árvore quando comparado ao método ' $\mathrm{b}$ ' $\mathrm{e}$ os índices de sincronia são relativamente menores, como esperado. Em ambas as Tabelas percebe-se uma tendência de índices maiores no pico da floração (árvores centrais) e menores nas árvores de final de floração. A distribuição de $X_{i}$, se normal, sugere o início da floração um pouco antes de janeiro. Nos cálculos de $\mathrm{X}_{\mathrm{i}}$ para cada árvore ficou evidente que este índice é influenciado por $f_{i}$, ou melhor, pela proximidade entre o número de dias que a árvore floresceu $\left(f_{i}\right)$ e o número de dias de sobreposição na floração com cada outra árvore $\left(\mathrm{e}_{\mathrm{j}}\right)$, e também pela distribuição equitativa desses últimos números $\left(\mathrm{e}_{\mathrm{j}}\right)$. Assim, uma árvore com um $f_{i}$ alto (florescimento longo), com relação ao número de dias em sobreposição com as outras árvores $\left(e_{j} s\right)$, terá seu indice diminuído com relação a outra árvore com $\mathrm{f}_{\mathrm{i}}$ menor, porém mais próximo a esses números $\left(\mathrm{e}_{\mathrm{j}} \mathrm{s}\right)$, mesmo sendo as mesmas árvores participantes na sobreposição. Essa tendência aumentará com a não equitabilidade dos valores $\left(f_{i}\right.$ e $\left.e_{j} s\right)$, independente de serem valores altos ou baixos.

Como exemplo, observa-se que os maiores valores de $X_{i}$ estão representados pelas árvores 11 a 15 , que tiveram os menores dias de florescimento, porém iguais e na mesma data, resultando em valores mais equitativos. Pelo método $b$, a árvore 6 , uma das árvores coletadas, teve $X_{i}$ menor que essas árvores centrais, no entanto, possuiu número de individuos sincrônicos dispersados nas categorias de 15,30,45, 60 dias. Comparando a árvore 6 com as outras centrais, 11-15, tem-se um total de 16 individuos sincrônicos contra 13, por um mínimo de 15 dias, 9 contra 1, para um mínimo de 30 dias, 6 contra 0 , para um mínimo de 45 dias, respectivamente. Devido a esses fatores, esse índice não reflete muito bem a potencialidade de pais doadores de pólen, já que não reflete sincronia com relações não equitativas.

As Figuras 12 e 13 , para o método 'a' e 'b', respectivamente, mostram essa tendência em número de indivíduos sincrônicos por um mínimo de 1 dia (TOT1) e os não sincrônicos ( $\mathrm{S} 0$ ) (Gráfico $\mathrm{A}$ ) e em número de individuos sincrônicos conforme número mínimo de dias em sobreposição para todas as classes (TOT1, TOT15, ...; Gráfico B) por árvore. As barras dos gráficos B para ambas as figuras é cumulativa a partir das classes com maior número de dias em sobreposição. Essas figuras mostram que, para 1993, os individuos iniciais e de pico de floração (\#1-17, exceções árvore \#2 e \#4) tiveram potencialidades semelhantes de sobreposição no espaço (sincronia espacial $-\mathrm{n}^{\circ}$ de individuos ), com as menores porcentagens representadas pelas árvores com maiores índices de sincronia Xi (11-15). Os individuos iniciais e finais da floração parecem compensar a menor sobreposição espacial pelo aumento de $f_{i}$, ou o número de dias em floração (sincronia temporal). 

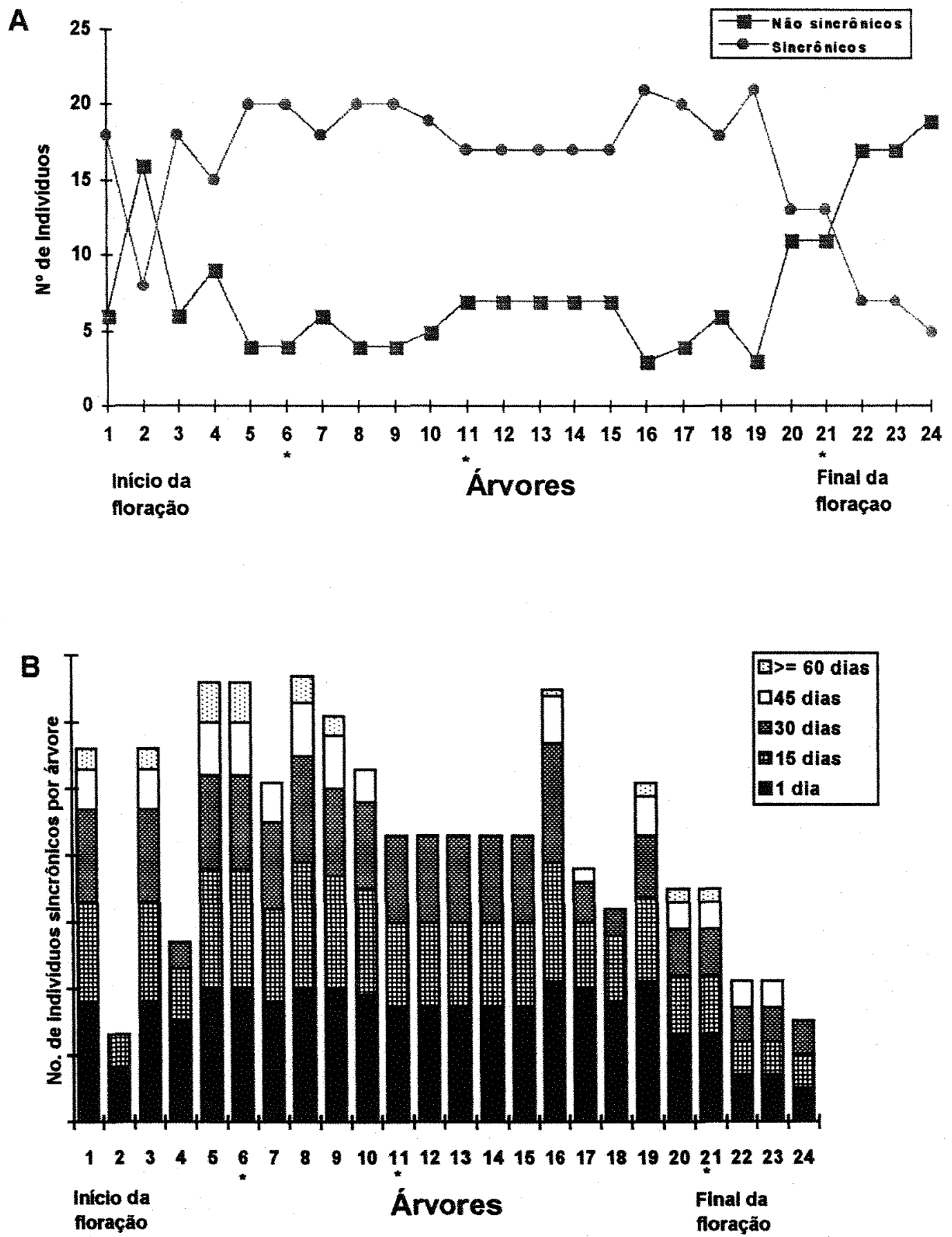

Figura 12, Método a. Gráfico A: número de indivíduos sincrônicos (TOT1) e nao sincrônicos (S0) por árvore; as árvores estão em ordem de florescimento. Gráfico B. Número de indivíduos sincrônicos para cada árvore conforme classe de sobreposição em dias. 1 dia $=$ TOT1; 15 dias $=$ TOT15; 30 dias $=$ TOT30; 45 dias $=$ TOT45; 60 dias = TOT60 (veja Tabela 3 e 4). Árvores-mãe apontadas por “*”. 

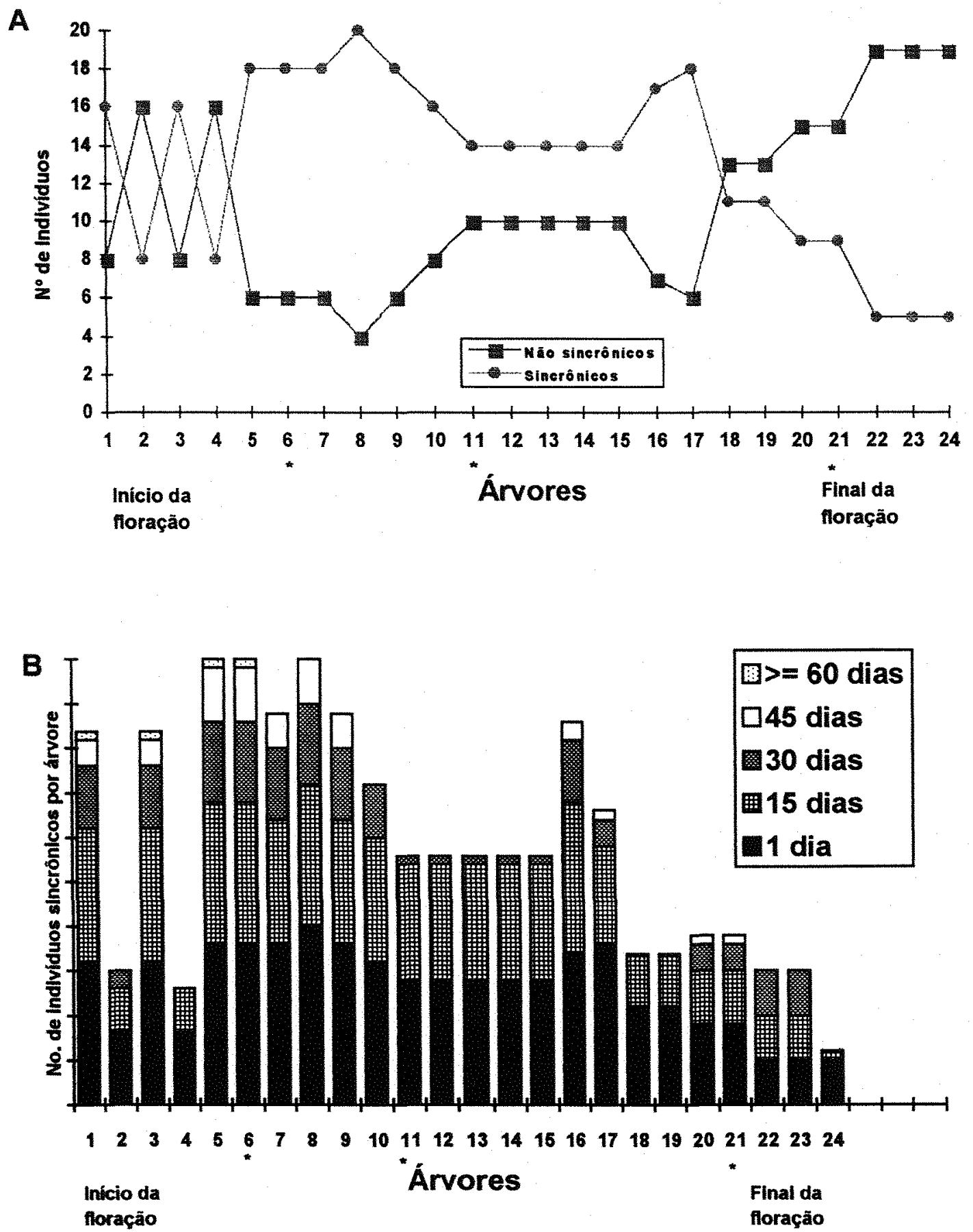

Figura 13. Método b. Gráfico A: número de individuos sincrônicos (TOT1) e nao sincrônicos (S0) por árvore; as árvores estão em ordem de florescimento. Gráfico B. Número de indivíduos sincrônicos para cada árvore conforme classe de sobreposição em dias. 1 dia $=$ TOT $1 ; 15$ dias $=$ TOT $15 ; 30$ dias $=$ TOT30; 45 dias $=$ TOT45; 60 dias = TOT60 (veja Tabela 3 e 4). Árvores-mãe apontadas por “*”. 
As 4 familias coletadas e estudadas quanto ao sistema reprodutivo (LEPSCH-CUNHA \& KAGEYAMA, 1996d), árvores \#6, \#11, \#21 e \#27, nas Figuras 1, 12 e 13, distribuem-se pelo período de pico de floração, com uma mais inicial (\#6), uma central (\#11), e duas finais (\#21 e \#27). As taxas de cruzamento multilocos, mostradas nesta última citação (Tabela 7), não variam muito entre as 4 progênies, diferenciando-se a familia 1 , ou árvore \#11, com valores menores. Essa árvore, como citada acima, possui o maior índice de sincronia $X_{i}(0,61$ ou 0,57 , met. ' $a$ ' e 'b'), porém é a que possui menores dias de floração $\left(f_{i}=15\right.$, met. 'b') quando comparada com as outras duas $\left(X_{i} \# 6=0,35\right.$ e 0,$40 ; X_{i} \# 21=0,12$ e 0,21$)$, com os maiores $f_{i} s(60$ dias). A árvore 27 , devido ao comportamento de alta produção de frutos e por periodo relativamente longo, sugere ter tido uma floração longa também, e por isso não representada nas Figuras 12 e 13.

Parece que C. multiflora tem uma estratégia que "iguala" a potencialidade de cruzamentos ou de pais doadores de pólen durante todo seu periodo de floração, mesmo com uma produção de flores aparentemente assincrônica, exceção feita ao final da floração. $O$ índice de sincronia utilizado aqui não refletiu esse resultado. A distribuição espacial sincrônica dos individuos em floração não revela maior distância entre os individuos do final da floração, como será mostrado a seguir.

A sobreposição de indivíduos por um mínimo de 1 dia resultou em mediana de 17,5 e 14 indivíduos, 13 e 13 individuos para 15 dias, 13 e 3 individuos para 30 dias, respectivamente, conforme os métodos ' $a$ ' e ' $b$ '. O distanciamento entre os 2 métodos ocorre a partir de 30 dias de sobreposição. Assim, para $50 \%$ dos 24 individuos analisados, na maior parte da floração, existe a potencialidade de cada um receber pólen de cerca de 14-17,5 indivíduos por 1 dia e de 13 individuos por 15 dias. Para $25 \%$ dessa população existe uma potencialidade de valores máximos de $20-17,5$ por 1 dia e $15,5-14,5$ por 15 dias, e mínimos de $14-9$ e 9-6, respectivamente conforme método.

A floração, apesar de relativamente longa e assincrônica, permite a potencialidade de cruzamento de vários individuos em função da floração longa de certos individuos que sempre se somam à sobreposição. As taxas de cruzamento multilocos altas juntamente com essas informações revelam a polinização a longa distância. 


\subsubsection{ESTIMATIVA DAS DISTÂNCIAS ENTRE INDIVÍDUOS SINCRONICAMENTE REPRODUTIVOS E DOS PAIS POTENCIAIS CONFORME ÀS DISTÂNCIAS DAS ÁRVORES-MÃE}

A Figura 14 mostra que as medianas das distâncias entre os indivíduos sobrepostos por data fenológica encontram-se entre 575 e 973 metros durante toda a floração, com os maiores valores (920-973 m) coincidindo com o pico da floração. Os quartis primeiros ( $25 \%$ das informações) estão entre 707 e $785 \mathrm{~m}$ até março2, e de 243 a 575 posteriormente. De janeiro a maiol, as medianas encontraram-se no mínimo a mais de 750 e $950 \mathrm{~m}$. Do mesmo modo, somente $25 \%$ (quartis 1) das distâncias entre os individuos nos meses de pico de floração foram menores que 700 metros. Somente nas últimas datas fenológicas que este número decaiu devido a poucos individuos agrupados próximos a borda.

A análise da distribuição espacial da população feita em LEPSCHCUNHA \& KAGEYAMA (1996b) resultou em padrão agregado. Durante início e pico da floração os indivíduos florescendo encontravam-se tanto dispersos como agrupados e localizados mais ao centro e norte da reserva. Conforme a floração foi dirigindo-se ao final, o florescimento dos indivíduos ficou mais agrupado e mais ao sul.

O número potencial de pais sincrônicos por raio, a densidade e os valores cumulativos da mediana desse número, conforme a distância de cada árvore em floração, são mostradas no Figura 15, Observa-se que em 50\% (medianas) dos casos houve 1 individuo potencial nos raios 250 e $500 \mathrm{~m}, 2$ a 3 , nos raios de 750 e $1000 \mathrm{~m}$ e de 4 indivíduos no raio > $1000 \mathrm{~m}$, respectivamente. A frequência cumulativa até $1000 \mathrm{~m}$ resultou em cerca de 7 individuos potenciais, e a densidade é maior no raio de $1000 \mathrm{~m}$, excetuando-se o primeiro raio.

O número potencial de pais sincrônicos até 1000 metros durante a floração é mostrado na Figura 16. De fevereiro 2 a abril 2, meses mais produtivos, o número de pais potenciais até $1000 \mathrm{~m}$ de raio de qualquer árvore-mãe está, para $50 \%$ dos casos, entre 6 e 7 indivíduos e, para $25 \%$ dos casos, entre 6 a 11 indivíduos. No início e final da floração a mediana fica entre 4-6 individuos. 


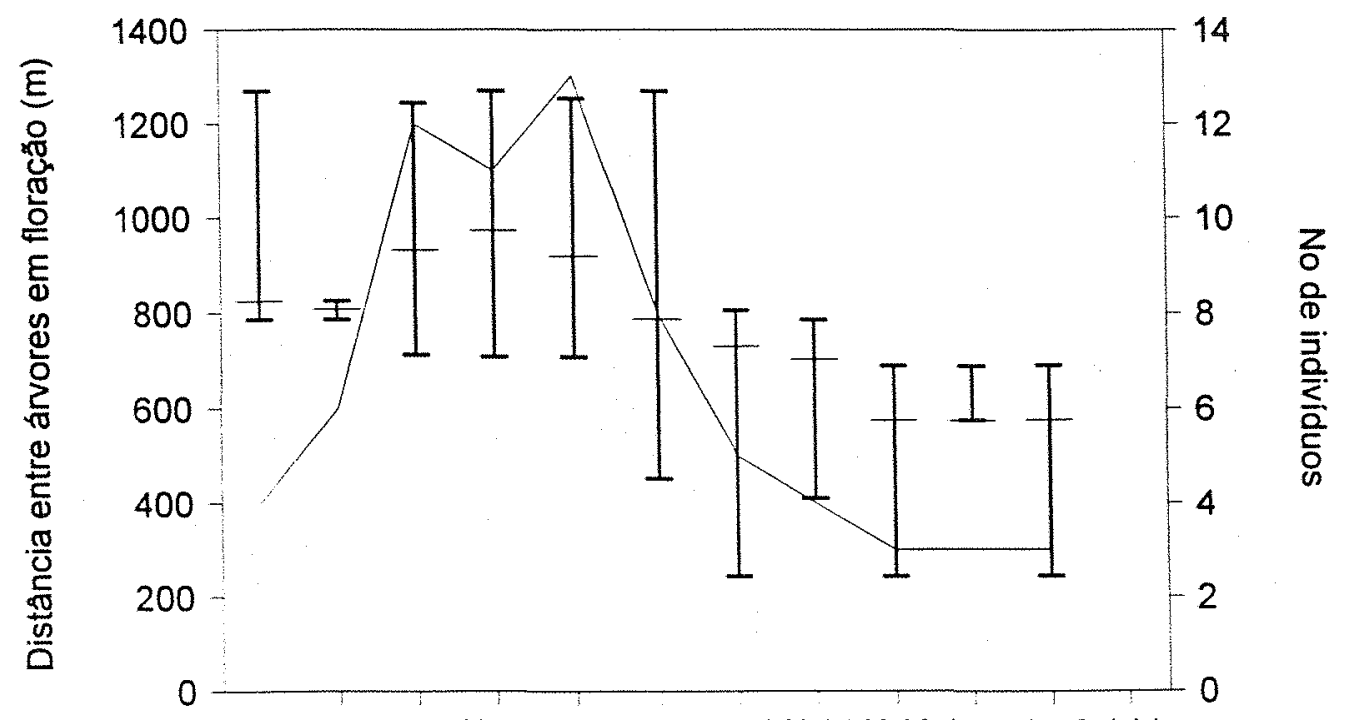

Jan 1 Fev 1 Fev 2 Mar 1 Mar 2 Abr 1 Abr 2 Mai 1 Mai 2 Jun 1 Jun 2 Jul 1

Data - Quinzenas

I Quartil3/Quartil1/. I Mediana $-\mathrm{N}^{\circ}$ de individuos

Figura 14. Distância entre individuos com sobreposição de floração por data fenológica.

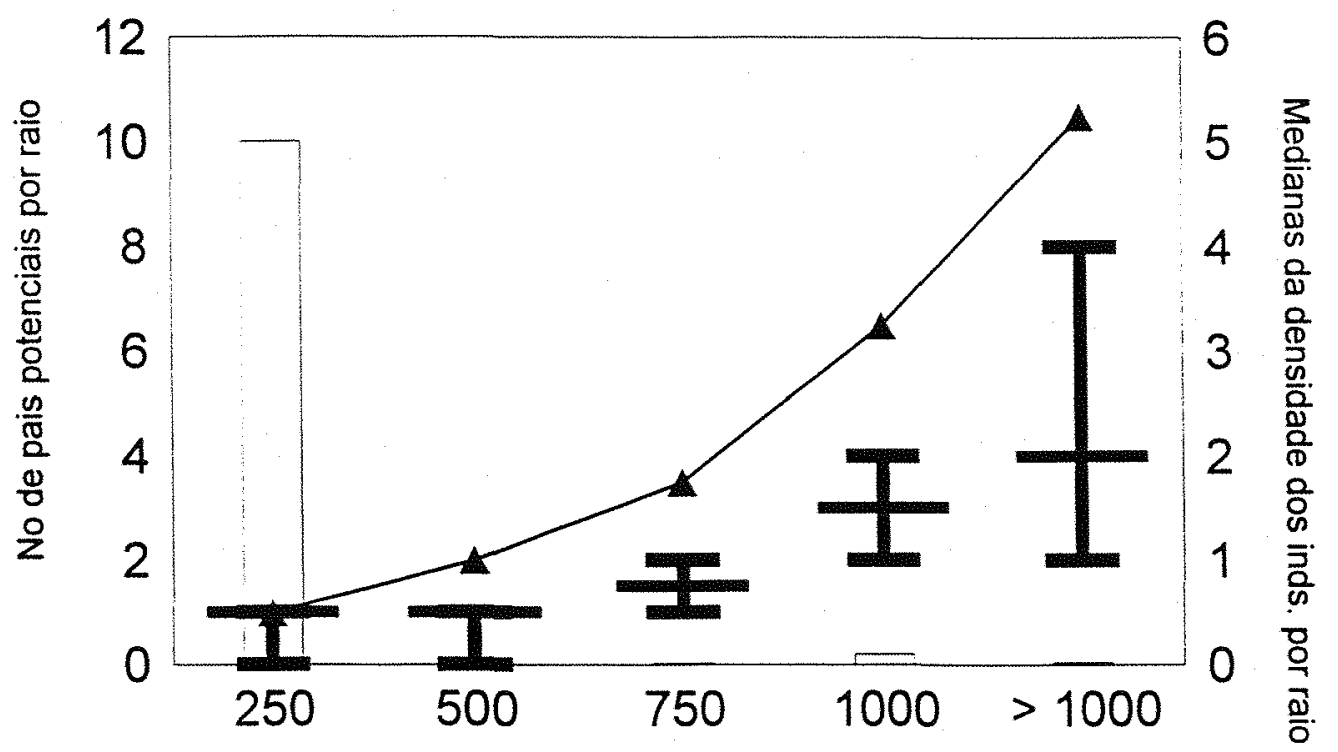

Distâncias em raios $(\mathrm{m})$ de cada árvore em floração

xQuartil3/Quartil1/. Mediana *Freq. cumulativa. DDensidade/raio

Figura 15. Número de pais potenciais e seu número cumulativo para cada árvore em floração sincrônica. A densidade é dada por barras. 


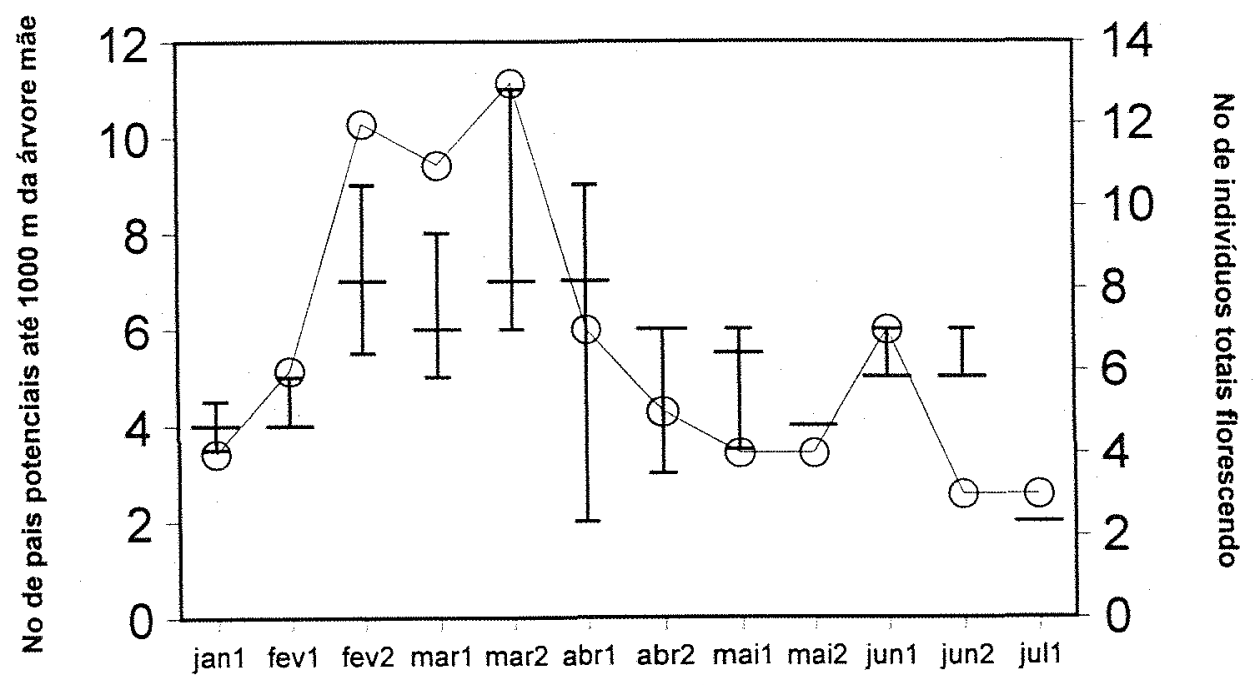

Data - Quinzenas

I Quartil3/Quartil1 I Mediana $\bigcirc \mathrm{N}^{\circ}$ de inds. totais

Figura 16. Número de pais potenciais sincrônicos até $1000 \mathrm{~m}$ por data fenológica.

\subsection{CONCLUSÕES}

C. multiflora apresentou uma floração relativamente longa (6 meses) com - pico durante a estação chuvosa. A frutificação teve seu pico no início da estação seca. Esses dados são diferentes daqueles de MORI \& PRANCE (1987) na Guiana Francesa, onde o pico de floração ocorre durante a estação seca e da frutificação no final dela. Apesar de algumas árvores apresentarem a estratégia de "big-bang", com a produção massiva de flores por poucos dias (cerca de uma quinzena), outras árvores produziram flores por muito mais tempo (cerca de 60 dias), com uma tendência a estratégia "cornucópia", com muitas flores produzidas em tempo relativamente longo (2 meses).

A resposta da população para florescimento foi alta, com cerca de $70 \%$ das árvores consideradas adultas florescendo, mas somente $41 \%$ delas com produção alta de flores. Cerca de $46 \%$ das árvores frutificaram e $23 \%$ foram vistas com frutos maduros. Somente $10 \%$ das árvores (4) foram coletadas devido à alta predação dos frutos por macacos, araras e roedores. Há uma grande possibilidade de aborto de frutos imaturos também. 
O gênero Cariniana juntamente com Couratari são os dois únicos dentro da familia Lecythidaceae que possuem frutos alados dispersados pelo vento. No entanto, ambos frutos, apesar de alados, possuem semente relativamente grande, com gosto muito similar a castanha-do-Pará, muito rica em proteínas.

PERES (1991) estudou Cariniana micrantha na Amazônia central, espécie também emergente, rara $(0,6$ inds/ha), observando diretamente 10 árvores num estudo exaustivo com relação à predação de frutos. $\mathrm{O}$ autor estimou que $69,5 \%$ dos frutos foram destruídos diretamente devido à predação pelo macaco-prego Cebus apella. Outros 30\% tomaram-se inviáveis por causa de pertubações do único mecanismo de dispersão, o vento, quando as sementes permaneceram encarceradas dentro dos pixidíos derrubados pelos predadores com os opérculos ainda lacrados. Onde predadores de semente são raros ou ausentes, devido à caça ou fragmentação, comenta o autor que uma grande proporção de frutos abertos vazios são frequentemente observados, evidenciando dispersão efetiva. Cita também Couratari guianensis, mais comum (1,2 inds/ha), como espécie que sofre considerável perda de sementes jovens devido a araras, macacos-prego e outros primatas predadores de sementes. Seus resultados concordam com o modelo de JANZEN (1970), que prediz que a eficiência da predação aumenta com a densidade e diminue com a distância da árvore mãe

O florescimento das árvores respondeu positivamente quanto à altura maior de árvores, porém foi indiferente quanto ao diâmetro. As árvores emergentes foram as que tiveram o maior número de individuos com alta produção de flores e frutos. Resultados revelaram que individuos baixos produzem flores e frutos se tiverem suas copas expostas à luz, mostrando potencialidade de manejo e melhoramento para a produção de frutos.

O índice de sincronia de Augspurger, modificado por BOSHIER (1995), não refletiu muito bem a potencialidade de pais doadores de pólen nos cruzamentos, já que não reflete sincronia com relações não equitativas. Assim, árvores com indices altos não necessariamente são as que mais sobrepõem florescimento com outros individuos no tempo.

As medianas de individuos sobrepostos na floração foram de um minimo de 14-17,5 por um dia, 13 por 15 dias, 3-13 por 30 dias e 4 por 45 dias, conforme métodos mais ou menos conservativos quanto ao tempo de floração de árvores.

A floração apesar de relativamente longa e assincrônica, permite a potencialidade de cruzamento de vários individuos em função da floração longa de alguns que sempre se somam à sobreposição. A maioria dos locos isoenzimáticos estudados por LEPSCHCUNHA \& KAGEYAMA (1996d) na análise do sistema reprodutivo das progênies está em equilíbrio de Hardy-Weinberg, concordando com essas observações. 
As medianas das distâncias entre os indivíduos sobrepostos por data fenológica ficaram entre 575-970 metros durante toda a floração, com os maiores valores, 950 metros, coincidindo com o pico da floração. Em 50\% dos casos, 6-7 indivíduos foram sincrônicos até 1000 metros de distância de qualquer árvore-mãe, com a densidade maior no raio de 1000 metros de distância. Esses valores permaneceram constantes na maioria dos casos durante toda a floração.

Essas distâncias evidenciam vôo a longas distâncias pelos polinizadores confirmado pela taxa de cruzamento multilocos próxima a 1 no trabalho de LEPSCH-CUNHA \& KAGEYAMA (1996d) citado anteriormente. Esses dados jutamente com os de Tachigali versicolor (MURAWSKI \& HAMRICK, 1991) e Pithecellobium pedicelare (O'MALLEY \& BAWA, 1987) mostram que distância de 1000 metros entre árvores não impede o fluxo de pólen, e os polinizadores estão adaptados a forragearem em distâncias dessa dimensão. 


\section{SISTEMA REPRODUTIVO DE ESPÉCIE ARBÓREA DE BAIXA DENSIDADE Couratari multiflora (J. Smith) Eyma (LECYTHIDACEAE) NA AMAZÔNIA CENTRAL.}

\subsection{INTRODUÇÃO}

Sistemas reprodutivos determinam o modo de transmissão de genes de uma geração à próxima (BROWN, 1990). Consequentemente, investigações sobre a dinâmica da mudança genética está concernida, direta ou indiretamente, com o processo de acasalamento (CLEGG. 1980). Conforme HAMRICK (1990), o sistema reprodutivo não somente determina as frequências genotípicas em gerações subsequentes mas também afeta os parâmetros genéticos populacionais, tais como tamanho de vizinhança, fluxo gênico e seleção.

HAMRICK \& GODT (1990) revisaram a literatura de aloenzimas em plantas e concluíram que, ao nível populacional, o sistema reprodutivo em combinação com a extensão geográfica descrevem a maior proporção da variância da diversidade genética.

Estudos de sistemas reprodutivos em florestas tropicais têm revelado uma extensão do sistema misto de reprodução, o qual combina endogamia com exocruzamento, até exocruzamento completo ou predominante (MURAWSKI, et al., 1990; 0'MALLEY \& BAWA, 1987; 0'MALLEY et al., 1988; MURAWSKI, 1990; MURAWSKI et al., 1994).

Muitas espécies arbóreas tropicais ocorrem a baixas densidades, e estudos com essas espécies são poucos e têm revelado sistema de exocruzamento predominante ou completo em algumas espécies como, por exemplo, Pithecellobium pedicellare, Tachigali versicolor, Platypodium elegans (O'MALLEY \& BAWA, 1987; O'MALLEY et al. 1988; 1988; MURAWSKI \& HAMRICK, 1991) e espécies com sistemas mistos de reprodução, como 
Cavallinesia platanifolia e Ceiba pentandra (MURAWSKI et al., 1990; MURAWSKI \& HAMRICK, 1994).

Couratari multiflora é encontrada com uma densidade de 1 indivíduo a cada 10 hectares na área de estudo (LEPSCH-CUNHA \& KAGEYAMA, 1996b;) e possui uma flor extremamente especializada adaptada à polinização por abelhas euglossines (MORI \& BOEKE, 1987). Nesta parte da dissertação, analisaremos o sistema reprodutivo desta espécie através da determinação da sua taxa de cruzamento multilocos e do comportamento das familias (progênie de cada árvore mãe) com relação ao equilibrio de Hardy-Weinberg e às pressuposições do modelo de acasalamento misto.

\subsection{MATERIAIS E MÉTODOS}

\subsubsection{LOCAL DE ESTUDO E ESPÉCIE}

Os caracteres taxonômicos da espécie e o local de estudo estão em "Material e Métodos" da dissertação.

\subsubsection{COLETA E GERMINAÇÃO DAS SEMENTES}

Procuramos todos indivíduos maiores de $20 \mathrm{~cm}$ de DAP, tamanho mínimo estimado para os adultos da espécie, objetivando a obtenção de um mínimo de 30 possíveis matrizes de forma contínua no espaço. Dos 41 individuos que encontramos em 385 ha, 27 individuos floresceram, 9 foram vistos com frutos imaturos e 9 com frutos maduros, conforme trabalho fenológico de LEPSCH-CUNHA \& KAGEYAMA (1996c). Desses últimos, coletamos somente 4 familias para a análise do sistema reprodutivo, devido à alta predação por animais e/ou aborto dos frutos/sementes imaturos, conforme discutido na última citação. Compreendemos por família a progênie, ou conjunto de sementes ou plântulas filhas, de uma árvore-mãe.

Coletamos folhas das árvores-mãe e as sementes de pelo menos 2 galhos opostos dentro da copa de cada uma delas e no chão, quando disponiveis, e não houve a mínima 
possibilidade de mistura de frutos entre árvores reprodutoras devido à distância entre elas. Secamos os frutos à sombra, em Manaus, no PDBFF, e enviamos em seguida ao Laboratório de Reprodução e Genética de Espécies Arbóreas Tropicais em Piracicaba - SP, o mais rápido possivel, para a germinação. Utilizamos cerca de 200 sementes para 2 árvores, cerca de 100 e 50 para a $3^{\mathrm{a}}$ e $4^{\mathrm{a}}$ árvores, por essas últimas possuirem muitos frutos predados, com a maioria das sementes danificada. Pusemos as sementes para germinar em gerbox com vermiculita em câmara de germinação na luz natural e depois transferimos para o Viveiro do Departamento de Ciências Florestais da ESALQ/USP, em sacos com terra composta, após emissão das primeiras folhas.

\subsubsection{PROCEDIMENTOS DA ELETROFORESE}

Com folhas jovens das plântulas testamos 26 sistemas isoenzimáticos e 5 sistemas tampões em gel horizontal de penetrose a $13 \%$, conforme metodologia e protocolos laboratoriais descritos em LEPSCH-CUNHA \& KAGEYAMA (1996b). De 6 sistemas que mostraram resolução, 5 tiveram padrões consistentes de coloração e interpretação. Utilizamos o tampão de extração de Liriodendron do laboratório do Prof. Namkoong (ALFENAS et al., 1991), e testamos o tampão completo e com a exclusão de DTT e mercaptoetanol. Quando obtivemos mais de um loco por sistema enzimático, o loco com a posição relativa mais anodal no gel foi designado pelo menor número na enzima e assim sucessivamente. A designação alélica seguiu o mesmo critério.

\subsubsection{ANÁLISE DO SISTEMA REPRODUTTVO}

Para as análises do sistema reprodutivo utilizamos os programas MLT e VTP de RITLAND (1990), que empregam o modelo de acasalamento misto (mixed mating model) de CLEGG (1980) e RITLAND \& JAIN (1981), no qual estimam-se:

1. Taxa de cruzamento multilocos para a população e familias, $t_{m}$, pelo método Newton-Raphson;

2. Taxa de cruzamento para cada loco, $t_{\mathrm{s}}$ (unilocos), para comparação com as estimativas multilocos;

3. Frequências alélicas de pólen (p) e óvulo pelo método de máxima verossimilhança;

4. As variâncias das estimativas acima, usando o método de "bootstrap", onde as plântulas dentro das familias são a unidade de reamostragem (1000 "bootstrap" utilizados), obtendo-se, então, os desvios padrões a 95\% de intervalo de confiança e, com isso, a significância dos valores das taxas de cruzamento. Para obtenção das variâncias das taxas de 
cruzamento multilocos de cada família individual há a necessidade de "rodá-las" ("run") no programa individualmente e, neste caso, mantivemos as frequências alélicas de pólen constantes (p). 0 programa calcula também a variância esperada das estimativas das taxas de cruzamento entre familias, assumindo tamanho familiar grande e sob a hipótese nula de que não existe variação do sistema reprodutivo entre famílias. Assim, essa variância funciona como um "teste" de adequação dos dados (número de famílias, de plântulas/família, de locos, tamanho amostral) e será discutida nos resultados.

5. Genótipos maternais, os quais são inferidos das familias pelo método de BROWN \& ALLARD (1970);

A taxa de cruzamento unilocos média $\left(t_{\text {smédia }}\right)$ é calculada através de uma média aritmética dos valores de $t_{\mathrm{s}}$ (unilocos) de cada loco. Esta taxa é calculada para ser comparada com a taxa multilocos da população $t_{\mathrm{m}}$, pois, conforme SHAW \& ALLARD (1982), quando ocorre endogamia em adição à autofecundação, as estimativas multilocos de $t$ são esperadas ser maiores do que as estimativas unilocos.

O programa MLT testa também, para cada loco, o ajuste ao modelo de acasalamento misto dos valores esperados aos números de genótipos observados das progênies para cada categoria genotípica das mães através de testes $\chi 2$ (EL-KASSABY \& RITLAND, 1987)

O programa de RITLAND (1990) utiliza para as análises no máximo a combinação de 3 alelos e consequentemente 6 genótipos. Assim, quando da presença de mais de 3 alelos, esses devem ser combinados de forma a pertencer a uma das classes genotípicas formadas pelas combinações dos alelos mais comuns (veja BROWN et al., 1984; 1990a). Procura-se, então, obter equiparação das frequências dos 3 alelos, conforme proposto por BROWN \& WEIR (1989), aumentando a eficiência através das combinações (alelos sintéticos) que forneçam as estimativas de variâncias mínimas (SHAW \& ALLARD, 1981).

Agrupamos os alelos de número $4 \mathrm{em}$ diante, em geral raros em frequência mais presentes na maioria dos locos, de forma a serem inseridos os homozigotos na categoria "alelo 2" e os heterozigotos na categoria "alelo 3 ", respectivamente. Testamos outras formas de agrupamento, mas estas mostraram ajustes piores.

O modelo de acasalamento misto (CLEGG, 1980; RITLAND \& JAIN, 1981; BROWN et al, 1984) estipula as seguintes pressuposições:

1. Todos os genótipos maternais cruzam na mesma taxa a partir de um conjunto ("pool") de pólen homogêneo na populacão; 
2. Alelos de diferentes locos segregam independentemente;

3. Segregação dos alelos em plantas maternais heterozigotas é estritamente mendeliana em uma razão de 1:1 tanto para produção de pólen como de óvulo;

4. Os marcadores genéticos não são afetados por seleção e mutação entre o tempo de cruzamento e a amostragem das progênies.

Fizemos testes para a verificação das pressuposições indicadas acima. Primeiro, testamos se os genótipos maternais cruzam na mesma taxa e se o "pool" de pólen na população é homogêneo, ou seja, se a frequência alélica polínica que cada árvore recebe é semelhante às outras árvores. Assumindo segregação mendeliana e acasalamentos aleatórios, espera-se uma mesma taxa de progênies vindas de exocruzamento. Usamos, então, um teste $\chi^{2}$ de heterogeneidade, sugerido por MURAWSKI et al.(1990), para testar as diferenças entre as frequências alélicas polínicas contribuindo aos genótipos das progênies de cada familia, agrupando-as pelos genótipos maternos. Assim, se o genótipo maternal é homozigoto, espera-se a mesma razão entre familias de plântulas heterozigóticas dentro de cada família, ou uma razão de 1:1. Para árvores matemais heterozigotas, espera-se uma segregação de 1:1 dos alelos matemais, assim, calcula-se as frequências de alelos de pólen através da subtração dos alelos matemais dos genótipos das plântulas, comparando-as entre as famílias. Segundo, tratamos as famílias como subpopulações, conforme sugerido por MURAWSKI \& HAMRICK (1991) e, assim, pudemos usar o $F_{S t}$ de Wright para examinar a diversidade entre familias nas frequências alélicas polínicas contribuindo às progênies. Um valor de $F_{s t}$ para cada loco foi calculado baseado em:

$$
F_{s t}=\sigma^{2} /\left[p_{i}\left(1-p_{i}\right)\right]
$$

onde $\sigma^{2}$ é a variância nas frequências alélicas polínicas entre familias e $p_{i}$ é a frequência no iésimo alelo polínico para todas as árvores maternais. Para 3 alelos, o caso de todos os locos aqui, esses parâmetros podem ser calculados da seguinte forma (VENCOVSKY, 1993):

$$
F_{s t}=1-\overline{H e} / 2(\bar{p} \bar{q}+\bar{p} \bar{r}+\bar{q} \bar{r})
$$

onde, $\overline{H e}$ é a média das heterozigosidades esperadas de cada família $\left(H_{e}\right)$ por loco, e $\bar{p}, \bar{q}$ e $\bar{r}$ as médias das frequências alélicas de todas as familias, com:

$$
H_{e}=1-2(p q+p r+q r)
$$

$p, q$ e $r=$ as frequências alélicas para alelos 1,2 e 3 respectivamente;

Para testar se os valores de $F_{s t}$ foram significativamente diferentes de zero usamos a estatística $\chi 2$ de WORKMAN \& NISWANDER (1970), $\chi 2=2 N F_{s t}(k-1)$ com $[(k-1)(s-$ 1)] graus de liberdade, onde $k=$ número de alelos e $s=$ número de subpopulações (famílias) e $N=$ número total de plântulas. 
Testamos as diferenças entre frequências alélicas de pólen e de óvulo contribuindo ao conjunto ("pool") gênico de sementes através da estatística $\chi 2$, onde $\chi 2=N F_{s t}(k$ 1) com $(k-1)$ graus de liberdade. $N$ é o número de gametas nos dois grupos (pólen e óvulo), $k$ é o número de alelos para o loco, e $F_{s t}$ a medida da diversidade genética entre populações, tratando pólen e óvulo como populações separadas (MURAWSKI \& HAMRICK, 1992b, MURAWSKI et $a l ., 1994)$. Fizemos os cálculos para o $F_{S t}$ da mesma forma que o ítem anterior com a diferença de se calcularmos $H_{e}$ para as frequências de pólen e óvulo.

\subsection{RESULTADOS}

\subsubsection{GERMINAÇÃO}

Depois de no mínimo 1 mês de plantio, as plântulas iniciaram a germinação, extendendo-se por mais 6 meses. As plântulas foram germinando aos poucos, com mortalidade após o plantio (inverno paulista) e cerca de $40 \%$ de germinação. Assim, obtivemos 2 familias com 30 plântulas e 2 com 27 e 16 plântulas, respectivamente.

\subsubsection{INTERPRETACÕES GENÉTICAS}

Dos 6 sistemas e 12 locos enzimáticos com resolução (MDH-1, $\mathrm{MDH}-2$, MDH-3, PO-1, PO-2, ACP-1, ACP-2, PGM-1, PGM-2, PGI-1, PGI-2, SKDH-1), utilizamos somente 5 sistemas e 7 locos devido à baixa definição ou sobreposição de bandas e/ou muitos individuos sem apresentarem coloração. Consideramos os locos polimórficos pelo critério de $99 \%$, ou seja, quando o alelo mais comum não excedeu mais de $99 \%$ de frequência. Os resultados dos sistemas isoenzimáticos são concordantes com os padrões de subunidades publicados: 1) malato desidrogenase revelou 3 locos, com o central sem interpretação possivel devido à sobreposição de bandas, e os dois marginais diméricos com padrões interpretáveis (MDH-1, MDH-3); 2) fosfoglucoisomerase com dois locos, sendo PGI-1 dimérico e de ótima resolução e PGI-2 aparentemente monomérico mas sem definição; 3) fosfoglucomutase com 2 locos monoméricos, PGM-1 e PGM-2; 4) peroxidase com 2 locos marginais monoméricos com resolução, um ou vários centrais de dificil interpretação e somente PO-2 apresentou coloração para todos individuos; 5) shiquimato desidrogenase, SKDH-1, com um padrão monomérico e duplicado conforme descrito por WEEDEN \& GOTTLIEB (1980), mas com interpretação possível. Os padrões isoenzimáticos $\mathrm{e}$ as frequências alélicas estão pormenorizadamente descritos em LEPSCH-CUNHA \& KAGEYAMA (1996b). 
Todas as enzimas, exceto peroxidase (PO), foram indiferentes ou com melhores resoluções utilizando-se o tampão completo de extração de Liriodendrum (com MTT e mercaptoetanol). PO só mostrou coloração interpretável sem a inclusão de mercaptoetanol, sendo negativamente sensivel as concentrações maiores a $3 \%$ de água oxigenada. PGM e SKDH tiveram colorações prejudicadas quando da exclusão de mercaptoetanol e MTT.

\subsubsection{ANÁLISE DO SISTEMA REPRODUTIVO}

\subsubsection{Pressuposições do modelo}

Como dito anteriormente, o número de plântulas heterozigóticas deve ser igual nas famílias de mesmos genótipos maternais homozigóticos quando ocorre acasalamentos aleatórios. Não detectamos diferença significativa entre os testes possiveis, conforme mostram as tabelas de contingências $\chi 2$ na Tabela 1 . As frequências esperadas nos testes com gl $>1$ não foram menores que 5 em cerca de $30 \%$ das células.

Tabela 1. Testes para verificação de acasalamento aletório nas familias de mães com genótipos homozigóticos idênticos através da homogeneidade de números de plântulas heterozigotas. ns = não significativo.

\begin{tabular}{ccccc}
\hline Locos & Genótipo materno & $\chi 2$ & gl & \\
\hline MDH-3 & $1 / 1$ & 2.862 & 3 & ns \\
PGM-1 & $2 / 2$ & 0.348 & 1 & ns \\
PGM-2 & $3 / 3$ & 1.466 & 2 & ns \\
PO-2 & $2 / 2$ & 3.480 & 1 & ns \\
\hline
\end{tabular}

Não pudemos realizar os testes para as mães heterozigóticas, pois as tabelas com as frequências de alelos de pólen calculadas, conforme a metodologia, apresentaram células com valores esperados baixos.

Os testes $\chi 2$ dos desvios do conjunto ("pool") de pólen do acasalamento aleatório na população resultaram em altamente significativos $(\mathrm{P}<0.01)$ para todos os locos, com exceção a PGM-2 (Tabela 2). Assim, as famílias estão recebendo um conjunto ("pool") de pólen diferenciado.

As estimativas das frequências alélicas atribuídas a pólen e óvulo nas progênies estão apresentadas na Tabela 3 , bem como os testes $\chi 2$ de heterogeneidade das duas frequências contribuindo ao conjunto ("pool") gênico de sementes. Somente o loco SKDH-1 resultou em diferença significativa ao nível de 5\%, seguido dos locos $\mathrm{MDH}-3$ e PGM-2, ao nível 
de significância de 1\%. Segundo MURAWSKI \& HAMRICK (1992b), essas diferenças observadas podem ser devidas a: 1 . diferenças relativas na função masculina e feminina entre árvores; 2. pólen imigrante à população amostrada; 3. seleção entre o tempo da polinização e amostragem das progênies; ou 4. amostragem não representativa de árvores maternais.

Conforme Tabela 3 as frequências dos dois locos significativos a $5 \%$ (MDH-3 e PGM-2) mostram a presença de alelos polínicos que não estão representados no "pool" de óvulos. LEPSCH-CUNHA \& KAGEYAMA (1996b) mostraram a presença nessas progênies de dois alelos imigrantes à população (locos MDH-1 e PO-1; Tabela 1 desta citação), porém esses não pertencem aos 2 locos significativos acima, não sendo, portanto, as diferenças significativas explicadas pela presença de pólen migrante à população amostrada. Os mesmos autores fizeram

Tabela 2. Frequências alélicas e testes $\chi 2$ para verificação dos desvios de conjunto ("pool") polínico ao acasalamento aleatório populacional, utilizando $F_{s t}$ e considerando as famílias como subpopulações.

\begin{tabular}{lccccccc}
\hline LOCO & ALELO & Familia 1 & Familia 2 & Família 3 & Família 4 & Média & F $_{\text {st }}$ \\
\hline MDH-1 & 1 & 0.790 & 0.750 & 0.330 & 0.310 & 0.545 & \\
& 2 & 0.180 & 0.250 & 0.670 & 0.690 & 0.448 & \\
& 3 & 0.030 & $\mathbf{0 . 0 0 0}$ & $\mathbf{0 . 0 0 0}$ & $\mathbf{0 . 0 0 0}$ & 0.008 & $0.210^{* * *}$ \\
MDH-3 & 1 & 0.970 & 0.870 & 0.840 & 0.930 & 0.903 & \\
& 2 & $\mathbf{0 . 0 0 0}$ & $\mathbf{0 . 0 0 0}$ & 0.016 & 0.070 & 0.058 & \\
& 3 & 0.030 & 0.130 & $\mathbf{0 . 0 0 0}$ & $\mathbf{0 . 0 0 0}$ & 0.040 & $0.054^{* *}$ \\
PGI-1 & 1 & 0.390 & 0.200 & 0.880 & 0.080 & 0.388 & \\
& 2 & 0.370 & 0.550 & 0.120 & 0.800 & 0.460 & \\
& 3 & 0.240 & 0.250 & $\mathbf{0 . 0 0 0}$ & 0.110 & 0.150 & $0.271^{* * *}$ \\
PGM-1 & 1 & 0.830 & 0.660 & 0.340 & 0.680 & 0.628 & \\
& 2 & 0.140 & 0.250 & 0.660 & 0.210 & 0.315 & \\
& 3 & 0.030 & 0.090 & $\mathbf{0 . 0 0 0}$ & 0.110 & 0.058 & $0.150^{* * *}$ \\
PGM-2 & 1 & 0.780 & 0.810 & 0.880 & 0.790 & 0.815 & \\
& 2 & 0.010 & 0.030 & $\mathbf{0 . 0 0 0}$ & 0.070 & 0.028 & \\
& 3 & 0.210 & 0.160 & 0.120 & 0.140 & 0.158 & $0.011 \mathrm{~ns}$ \\
PO-1 & 1 & 0.960 & 0.590 & 0.640 & 0.750 & 0.735 & \\
& 2 & 0.040 & 0.410 & 0.032 & 0.250 & 0.255 & \\
& 3 & $\mathbf{0 . 0 0 0}$ & $\mathbf{0 . 0 0 0}$ & 0.040 & $\mathbf{0 . 0 0 0}$ & 0.010 & $0.099 * * *$ \\
& & & & & & & \\
SKH-1 & 1 & 0.110 & 0.330 & 0.090 & 0.330 & 0.215 & \\
& 2 & 0.590 & 0.060 & 0.290 & 0.670 & 0.403 & \\
& 3 & 0.300 & 0.610 & 0.620 & $\mathbf{0 . 0 0 0}$ & 0.383 & $0.213^{* * *}$ \\
& & & & & & & 0.144 \\
\hline
\end{tabular}


testes para verificação de ajuste ao equilíbrio de Hardy-Weinberg (EHW) para essas progênies: a maioria ( $72 \%$ ) dos locos dessas plântulas ajustaram-se ao EHW, com excessão aos locos PGI-1 e SKDH-1. Somando-se todos esses resultados, concluímos que o motivo da significância é a representatividade pequena das árvores maternais. Considerando ainda esses resultados mais a homogeneidade entre as mães homozigotas com relação às suas progênies heterozigóticas, concluímos também que as árvores cruzam a uma mesma taxa. Para SKDH-1 esses resultados não são conclusivos.

Tabela 3. Estimativas das frequências alélicas atribuidas a pólen e óvulo nas progênies de 4 árvores de $C$. multiflora e testes $\chi 2$ de heterogeneidades das duas frequências contribuindo ao "pool' gênico de sementes.

\begin{tabular}{|c|c|c|c|c|c|c|}
\hline LOCO & $\mathbf{N}$ & ALELO & P. POLLEN & P. ÓVULO & $F_{S T}$ & $x^{2}$ \\
\hline \multirow[t]{3}{*}{ MDH-1 } & 103 & 1 & 0.640 & 0.625 & & \\
\hline & & 2 & 0.355 & 0.375 & & \\
\hline & & 3 & $0.005 a$ & 0.000 & 0.00035 & $0.0745 \mathrm{~ns}$ \\
\hline \multirow[t]{3}{*}{ MDH-3 } & 103 & 1 & 0.897 & 1 & & \\
\hline & & 2 & 0.052 & 0.000 & & \\
\hline & & 3 & 0.052 & 0.000 & 0.04004 & $8.5690^{*}$ \\
\hline \multirow[t]{3}{*}{ PGI-1 } & 103 & 1 & 0.451 & 0.500 & & \\
\hline & & 2 & 0.364 & 0.250 & & \\
\hline & & 3 & 0.185 & 0.250 & 0.00776 & $1.6602 \mathrm{~ns}$ \\
\hline \multirow[t]{3}{*}{ PGM-1 } & 95 & 1 & 0.605 & 0.625 & & \\
\hline & & 2 & 0.338 & 0.250 & & \\
\hline & & 3 & 0.057 & 0.125 & 0.00606 & $1.2960 \mathrm{~ns}$ \\
\hline \multirow[t]{3}{*}{ PGM-2 } & 102 & 1 & 0.781 & 0.875 & & \\
\hline & & 2 & 0.042 & 0.125 & & \\
\hline & & 3 & 0.177 & 0.000 & 0.03926 & $8.4022^{*}$ \\
\hline \multirow[t]{3}{*}{ PRX-2 } & 99 & 1 & 0.718 & 0.750 & & \\
\hline & & 2 & 0276 & 0.250 & & \\
\hline & & 3 & $0.005 @$ & 0.000 & 0.00110 & $0.2359 \mathrm{~ns}$ \\
\hline \multirow[t]{3}{*}{ SKH-1 } & 103 & 1 & 0.247 & 0.625 & & \\
\hline & & 2 & 0.343 & 0.250 & & \\
\hline & & 3 & 0.410 & 0.125 & 0.08946 & $19.1449^{* *}$ \\
\hline
\end{tabular}

Frequências alélicas de pólen e óvulo diferem significativamente: ${ }^{*} \mathrm{P}<0.05, * * \mathrm{P}<0.01$, testes $\chi 2$ para heterogeneidade onde $\chi^{2}=\mathrm{NF}_{\mathrm{st}}(\mathrm{k}-1) ; \mathrm{GL}=(\mathrm{k}-1) . \mathrm{F}_{\mathrm{st}}$ é a medida da diversidade genética entre os "pools"de pólen e óvulo: $\mathrm{N}=$ número de gametas nos dois grupos; $\mathrm{k}=$ número de alelos; $(a)$ alelo ausente na população adulta. portanto, vindo de fora da área de estudo. 
O conjunto ("pool") de pólen diferenciado que cada árvore recebe (Tabela 2) parece consequência do pequeno número de árvores analisadas e da variação da época e duração de florescimento de cada árvore, como apontado por LEPSCH-CUNHA \& KAGEYAMA (1996c). Neste trabalho, os autores analisaram a fenologia reprodutiva de todos indivíduos da área de estudo e tiveram os seguintes resultados quanto às árvores aqui estudadas: as familias 1, 2, 3 e 4 (árvores 06, 11, 21 e 27) floresceram, respectivamente, por cerca de: árvore \#06 - 45-60 dias, do inicio ao pico da floração; árvore \#11 - de 1 a 15 dias, durante pico de floração floração; árvore \#21 - 45-60 dias no final da floração; e árvore \#27 provavelmentefloresceu como a familia anterior, já que produziu boa quantidade de frutos por tempo relativamente longo, porém, foi a última árvore a frutificar. A Tabela 4 é uma reprodução da Tabela 3 desta última citação, considerando apenas as árvores estudadas aqui.

Tabela 4. Máximo de dias em floração (fi), índices de sincronia (XI), número total de árvores sobrepondo-se em floração até $1(\mathrm{~S} 1), 15$ (S15), 30 (S30), > 45 dias (S45) e número total de árvores sobrepondo-se por no mínimo 1 dia (TOT1=S1+S15+S30+S45) para as 4 árvores desse estudo. Total de árvores possiveis de acompanhar toda floração $=$ 24. $\sim$ Fam $3=$ semelhante à familia 3 .

\begin{tabular}{c|c|ccccc|c}
\hline Familia & $\mathbf{f i}$ & $\mathbf{X I}$ & S1 & S15 & S30 & S45 & TOT1 \\
\hline $1(\# 06)$ & $45-60$ & 0.35 & 2 & 7 & 3 & 6 & 18 \\
$2(\# 11) 38$ & $1-15$ & 0.61 & 1 & 12 & 1 & 0 & 14 \\
$3(\# 21)$ & $45-60$ & 0.12 & 3 & 3 & 2 & 1 & 9 \\
$4(\# 26)$ & $\sim$ Fam3 & $\sim$ Fam3 & $\sim$ Fam3 & $\sim$ Fam3 & $\sim$ Fam3 & $\sim$ Fam3 & $\sim$ Fam3 \\
\hline
\end{tabular}

Utilizou-se aqui a metodologia $b$, mais conservadora com relação à extrapolação dos dias de florescimento, conforme LEPSCH-CUNHA \& KAGEYAMA (1996c).

Os resultados das análises da potencialidade de cruzamentos entre as árvores apresentados pelos autores acima revelaram, de maneira geral, que as árvores compensam a floração populacional relativamente longa (assincrônica) pela variação individual nos dias máximos de floração $\left(\mathrm{f}_{\mathrm{i}}\right)$ e época de floração (início, pico, final). Essas características conferiram números similares de pais potenciais em praticamente toda a floração, excetuando-se uma diminuição para as árvores finais, que é o caso das famílias 3 e principalmente da 4 , acrescentando diminuição das distâncias entre os individuos (maior agregação de floração). A Tabela 2 mostra que a familial (\#06) não possui apenas 2 alelos polínicos nas suas frequências, contra a ausência de 3,4 e 5 alelos polínicos das outras árvores respectivamente. A familia 2 (\#11) floresceu bem menos tempo que as outras árvores, porém, no pico da floração, onde a maioria das distâncias (medianas) entre os individuos foram máximas (>900 m) (mesma citação). 
Os índices de sincronia (XI), modificados por BOSHIER et al. (1995) e utilizados nesta ultima citação acima, não mostraram relação inversa com as distâncias entre individuos conforme proposto por este autor, ou seja, aqui as árvores com índices de sincronia maiores e intermediários tenderam a estar mais distantes do que próximas (exemplo acima). Esclarecendo mais uma vez, no pico da floração, as árvores que floresceram encontraram-se, na sua maioria, com distâncias maiores entre si do que no final, quando estavam mais agrupadas.

CLEGG (1980) discute a violação da pressuposição da distribuição espacial uniforme das frequências gênicas de pólen, mostrando que quando isto ocorre, esperariamos maior variação entre as familias e, possivelmente, essa heterogeneidade espacial é originada se a população for subestruturada em unidades mais ou menos relacionadas. Os resultados acima mais as taxas de cruzamento das familias mostradas abaixo, sugerem fortemente que as árvores cruzam a uma mesma taxa, que os cruzamentos são na maioria aleatórios. 0 pequeno número de árvores analisadas (4), com 2 delas de final de floração, ocasionou um conjunto de pólen diferenciado em função da tendenciosidade causada pela distância entre árvores em florescimento menores no final da floração, seguida da diminuição de pais potenciais nesta mesma época.

\subsubsection{Estimativas das taxas de cruzamento}

Dentre todos os problemas que podem afetar as estimativas das taxas de cruzamento, como, por exemplo, o não ajuste às várias pressuposições do modelo, RITLAND \& JAIN (1981) e RITLAND (1985, 1990) apontaram a não convergência das estimativas de máxima verossimilhança como o mais importante $(t>2.0$ ou iterações maiores que 50 e não diminuição da negatividade do logarítmo natural das probabilidades de verossimilhança). Os mesmos autores apontaram como causas principais da não convergência das estimativas: 1. a interpretação errônea dos genótipos maternos; 2 o número pequeno de plântulas por familia; 3 . pequeno número de famílias; 4. proporção alta de genótipos matemos heterozigóticos e heterozigosidade alta. Com exceção ao item 1 , onde $50 \%$ dos genótipos maternos foram deduzidos das progênies e os outros $50 \%$ determinados pela interpretação clara das bandas eletroforéticas das mães, os outros itens estão presentes neste estudo. Assim, optamos por um estudo mais atencioso das diferentes estimativas dadas pelo método de máxima verossimilhança.

Conforme Tabela 5 , os testes $\chi^{2}$ para verificação do ajuste aos valores esperados pelo modelo de acasalamento misto para cada loco, resultaram em altamente significativos para PGI-1 e SKDH-1. Esses são os mesmos locos das progênies que não se ajustaram ao equilibrio de Hardy-Weinberg apresentados por LEPSCH-CUNHA \& 
KAGEYAMA (1996b), citados anteriormente. No entanto, o loco SKDH-1 ajustou-se ao Equilibrio de Endogamia de Wright testado nesta última citação, o que contradiz os resultados do modelo de acasalamento misto, o qual assume o mesmo equilíbrio. As taxas de cruzamentos unilocos (locos individuais), $\mathrm{t}_{\mathrm{s}}$, variaram de 0.480 a 1.999 , com a não convergência do logaritmo natural das probabilidades de verossimilhança somente para $\mathrm{MDH}-1$. Valores de $\mathrm{t}>1$ serão discutidos abaixo.

Os locos MDH-1 e PGM-2 mostraram não convergência nas estimativas $t_{s}$ para familias individuais, com o primeiro loco apresentando $t_{s}=2$ em uma familia, e o segundo, em três. Os locos PGI-1 e SKDH-1 não se ajustaram ao modelo multilocos de acasalamento misto e desviaram-se significativamente do equilíbrio de Hardy-Weinberg, como discutido anteriormente. Esses últimos pressupostos parecem não afetar muito as estimativas, conforme vários trabalhos publicados após recomendação de RITLAND (1990), ao contrário daquele para MDH-1 e PGM-2. Os locos SKDH-1 (a 1\%), MDH-3 e PGM-2 (a 5\%) possuem frequências alélicas de óvulo e pólen desviando-se de acasalamento aleatório, outra pressuposição do modelo. Como apontado por RITLAND \& JAIN (1981) esta violação tem um efeito não mensurável mas relativamente menor sobre a estimativa da taxa verdadeira de cruzamento.

A partir desses resultados, resolvemos combinar diferentes locos (Tabela 6) para o cálculo da estimativas de taxa de cruzamento multilocos, $t_{m}$ e $t_{\text {smédio, por dois motivos }}$ principais, além da não convergência das taxas $t_{s}$ de famílias mostradas acima: 1 . verificação do poder da amostragem do número de locos; 2. a exclusão de locos que não se ajustam às pressuposições do modelo, conforme recomendado por RITLAND (1990). Fizemos os cálculos utilizando as estimativas das frequências alélicas de pólen e óvulo conjuntamente $(p+t)$, a forma mais recomendada quando o "pool" de pólen é diferenciado (RITLAND, 1985, 1990), e já que as variâncias das taxas de cruzamento multilocos populacional foram pequenas e não dissimilares quando da imposição de $\mathrm{p}$ constante. A priorização das combinações foram as seguintes:

0. Todos os locos;

1. Sem PGM-2, loco com 3 familias apresentando $t_{s}$ igual a 2, não convergentes;

2. Sem PGM-2 e MDH-1, mesmo motivo anterior, com o último loco com $t_{s}$ igual a 2 para uma familia;

3. Sem PGM-2, MDH-1 e SKDH-1, o último loco sem ajuste geral ao modelo e com frequências alélicas de pólen e óvulo diferenciadas a $5 \%$;

4. Sem PGM-2, SKDH-1 e PGI-1, o último loco sem ajuste ao modelo; 
5. Sem PGM-2, MDH-1, SKDH-1 e MDH-3, último loco com $t_{s}$ baixo quando comparado aos demais;

6. Sem PGM-2, MDH-1, SKDH-1 e PGI-1, locos com $t_{s}$ de familias não convergentes e/ou locos sem ajuste ao modelo;

7. Somente com PGM-1 e PO-2;

Tabela 5. Teste $\chi 2$ para verificação do ajuste aos valores esperados pelo modelo de acasalamento misto e taxas de cruzamento para as estimativas unilocos $\left(t_{\mathrm{s}}\right)$ na população e em cada família, com os erros padrões em parênteses (ep).

\begin{tabular}{|c|c|c|c|c|c|c|}
\hline LOCOS & $\chi^{2}$ & $t_{s}(e p)$ & Família1 & Familia2 & Família3 & Familia4 \\
\hline MDH-1 & $0.044 \mathrm{~ns}$ & $0.705(0.126) \mathrm{nc}$ & 0.69 & 2.00 & 0.00 & 0.00 \\
\hline MDH-3 & $0.000 \mathrm{~ns}$ & $0.480(0.195) \mathrm{c}$ & 0.66 & 0.00 & 0.73 & 0.31 \\
\hline PGI-1 & $45.25 * *$ & $1.313(0.099) \mathrm{c}$ & 1.26 & 1.48 & 1.22 & 1.31 \\
\hline PGM-1 & $2.222 \mathrm{~ns}$ & $0.970(0.108) \mathrm{c}$ & 1.42 & 0.46 & 1.48 & 0.93 \\
\hline PGM-2 & $7.848 \mathrm{~ns}$ & $1.999(0.124) \mathrm{c}$ & $\underline{\mathbf{2 . 0 0}}$ & $\underline{2.00}$ & 1.12 & $\underline{2.00}$ \\
\hline PO-2 & $9.551 \mathrm{~ns}$ & $1.478(0.148) \mathrm{c}$ & 1.72 & 1.93 & 1.04 & 0.85 \\
\hline SKDH-1 & $39.77 * *$ & $0.598(0.086) \mathrm{c}$ & 0.20 & 0.71 & 0.83 & 0.00 \\
\hline
\end{tabular}

"c" e "nc" -convergência e não convergência das iterações;

A Tabela 6 mostra combinações desde a mais conservadora, com apenas 2 locos e a exclusão de todos os locos acima citados, até a exclusão apenas de PGM-2. A familia 1 (\#06) e 3 (\#21) começam a ter problemas de convergência a partir dos cálculos feitos com 4 locos ou menos, e a variância esperada das estimativas das taxas de cruzamento entre famílias começam a aparecer (última coluna da tabela). Como dito anteriormente na metodologia, essa variância esperada assume tamanho familiar grande e está sob a hipótese nula de que não existe variação do sistema reprodutivo entre familias, funcionando como um "teste" de adequação dos dados. Considerando que nas combinações 0,1 e 2 as taxas de cruzamento multilocos $t_{m}$ são todas muito próximas a 1 , os erros padrão são os mais baixos e as variâncias esperadas entre familias são iguais a zero, optamos entre elas a combinação de número 2 ( 5 locos) como a mais apropriada por não incluir estimativas unilocos (locos individuais) e multilocos por árvore que não convergiram.

Esses resultados concordam com os analisados por RITLAND \& JAIN (1981), onde um número acima de 4 ou 5 locos são necessários para espécies com taxas de cruzamentos altas, e as estimativas unilocos podem ser bem diferentes de loco para loco, conforme várias publicações (SHAW \& ALLARD, 1982; RITLAND \& EL-KASSABY, 1985). 
CLEGG (1980) aponta fatores que podem causar estimativas heterogêneas da taxa de cruzamento unilocos: i. aberração estatística; ii. há a possibilidade que determinado(s) loco(s) exerça algum controle direto sobre o processo de cruzamento; iii. seleção diferencial interferindo entre a união de gametas. BROWN et al. (1984) apontam as seguintes causas: i. a variâncias amostrais das estimativas unilocos são subestimativas dessas variâncias; ii. quando o número de plantas maternais é restrito, a variância amostral entre locos pode ser aumentada, porque cada loco marcador pode amostrar conjuntos de sobreposição de eventos de cruzamentos e com precisão desigual.

Tabela 06. Taxas médias de cruzamento unilocos $\left(t_{\text {smédia }}\right)$ e taxas de cruzamento multilocos $\left(t_{m}\right)$ com diferentes combinações conforme ajuste ao modelo e convergência das iterações nas estimativas das probabilidades de verossimilhança; ep = erro padrão; $(p+t)$ : frequências alélicas de pólen e óvulo estimadas para o cálculo das estiativas de $t_{m} ; \sigma^{2}$ :variância esperada das estimativas de taxa de cruzamento multilocos entre familias.

\begin{tabular}{cc|c|c|c|c|c|c|c}
\hline Combinaçöes & $t_{s}( \pm e p)$ & $\begin{array}{c}t_{\mathbf{m}}( \pm \mathbf{e p})- \\
(\mathbf{p}+\mathbf{t})\end{array}$ & FAM01 & FAM02 & FAM03 & FAM04 & $\sigma^{2}$ \\
\hline 7 locos(0) & $1.074(0.131)$ & $1.021(0.017)$ & 1.58 & 1.20 & 0.90 & 0.94 & 0.000 \\
\hline 6 & $"(1)$ & $0.924(0.133)$ & $1.044(0.030)$ & 1.65 & 0.83 & 1.10 & 1.06 & 0.000 \\
\hline 5 & $"(2)$ & $0.968(0.132)$ & $\underline{0.953(0.040)}$ & 1.33 & 0.69 & 0.89 & 1.03 & 0.000 \\
\hline 4 & $"(3)$ & $1.060(0.143)$ & $1.262(0.047)$ & $\mathbf{2 . 0 0}$ & 0.72 & $\mathbf{2 . 0 0}$ & 1.06 & 0.000 \\
\hline 4 & $"(4)$ & $0.908(0.148)$ & $1.289(0.049)$ & $\mathbf{2 . 0 0}$ & 0.83 & 1.74 & 1.34 & 0.136 \\
\hline 3 & $"(5)$ & $1.254(0.120)$ & $1.295(0.047)$ & $\mathbf{2 . 0 0}$ & 0.82 & $\mathbf{2 . 0 0}$ & 1.09 & 0.061 \\
\hline 3 & $"(6)$ & $0.976(0.154)$ & $1.288(0.055)$ & $\mathbf{2 . 0 0}$ & 0.69 & 1.65 & 1.41 & 0.256 \\
\hline 2 & $"(7)$ & $1.224(0.129)$ & $1.354(0.077)$ & $\mathbf{2 . 0 0}$ & 1.73 & 1.87 & 1.50 & 0.394 \\
\hline
\end{tabular}

As taxas sublinhadas são as consideradas como as mais apropriadas para a população;

(0) Todos os locos: MDH-1, MDH-3, PGI-1, PGM-1, PGM-2, PO-2, SKDH-1;

(1) MDH-1, MDH-3, PGI-1, PGM-1, PO-2, SKDH-1;

(2) MDH-3, PGI-1, PGM-1, PO-2, SKDH-1;

(3) MDH-3, PGI-1, PGM-1, PO-2;

(4) MDH1, MDH-3, PGM-1, PO-2;

(5) PGI-1, PGM-1, PO-2;

(6) MDH-3, PGM-1, PO-2;

(7) PGM-1, PO-2;

Segundo BROWN et al. (1984), estimativas de " $\mathrm{t}$ " excedendo a unidade não se originam pelo efeito Wahlund ou necessariamente da invalidade do modelo de cruzamento misto. As duas principais causas citadas por eles são: i. efeitos de amostragem; ii. cruzamento "disassortativo". RITLAND \& EL-KASSABY (1985, página 383), descrevendo o método de 
verossimilhança e auxiliares (Newton-Raphson), argumentaram da mesma forma, escrevendo que a restrição de $t$ estimado menor do que um $(t<1)$ não é estatisticamente válida para populações exogâmicas ou com conjunto pequeno de dados, as quais geram $t$ estimados maiores do $1(t>1)$, em função de dados incompletos ou cruzamento "disassortativo". A restrição de t estimado $<1$, segundo eles, pode subestimar tanto a variância quanto a média de t estimado entre famílias. No caso de cruzamento "disassortativo", há o exemplo de uma espécie heterostílica com distribuição no nordeste do Brasil, Eichhornia paniculada (BARRETT et al., 1989). As plântulas de polinização aberta de plantas maternais de estilete longo conhecidas foram classificadas, resultando em estimativas de taxas de cruzamento no modelo de cruzamento misto excedendo a unidade. Entretanto, quando as expectativas de $t$ das progênies foram ajustadas ao modelo de cruzamento "disassortativo" proposto pelos autores, no qual há a quantificação desses cruzamentos "disassortativos", valores de t menores foram obtidos, próximos a unidade.

As estimativas multilocos com seus erros padrão para familias individuais estimadas a partir de $\mathrm{p}$ (frequência de pólen) constante resultaram em taxas de cruzamento $t_{m}$ iguais a 1 para as 4 familias, independentemente de serem calculadas com todos os 7 locos ou com 5, sem PGM-2 e MDH-1 (combinação 2) (Tabela 7). Esses valores semelhantes confirmam as informações obtidas no trabalho de fenologia de LEPSCH-CUNHA \& KAGEYAMA (1996c) e vice-versa quanto à "estratégia que iguala" a potencialidade de cruzamentos ou de pais doadores de pólen durante todo seu período de floração, além do fluxo de pólen à longa distância. Variação nas taxas de cruzamento entre familias é esperada quando há fatores temporais, espaciais mais densidade populacional e genótipo maternal diferenciados (BROWN et al., 1984; pg 37)

Tabela 7. Taxas de cruzamento multilocos $\left(t_{m}\right)$ para familias individuais com frequência de pólen constante (p).

\begin{tabular}{c|c|c|}
\hline \multirow{2}{*}{ Famílias } & \multicolumn{2}{|c|}{$\mathbf{t}_{\mathrm{m}}$ ( \pm erro padrão) } \\
\cline { 2 - 3 } & $\mathbf{7 \text { locos }}$ & 5 locos (combinacão 2) \\
\hline 01 & $1.159(0.000)$ & $1.135(0.076)$ \\
02 & $1.139(0.044)$ & $1.116(0.075)$ \\
03 & $1.032(0.057)$ & $1.019(0.076)$ \\
04 & $0.999(0.080)$ & $1.032(0.103)$ \\
\hline
\end{tabular}

Conforme as considerações acima, a taxa de cruzamento multilocos para C.multiflora resultou em $t_{\mathrm{m}}=0.953(0.040)$ e a média de unilocos de $t_{\text {smédio }}=0.968(0.133)$ conferindo exocruzamento quase que total. A comparação dos dois parâmetros evidencia a ausência de acasalamentos entre parentes, já que $t_{m}$ é menor que $t_{s}$ (SHAW \& ALLARD 1982), 
apesar dessa comparação estar dificultada pelo erro padrão alto de $t_{\mathrm{s}}$. A significância de $t_{\mathrm{m}}$ menor que 1 reflete acasalamento entre indivíduos provavelmente mais aparentados no final da floração, influenciada pelo pequeno número de árvores analisadas e, principalmente, pela família 4 , com a árvore-mãe florescendo bem no final da floração e com sobreposição de floração com um menor número de indivíduos mais agrupados.

\subsection{DISCUSSÃO E CONCLUSÃO}

As progênies de C. multiflora apresentaram um padrão de espécie alógama com valores altos de heterozigosidade observada e esperada, número de alelos por loco e polimorfismo (LEPSCH-CUNHA \& KAGEYAMA, 1996b). A população em conjunto resulta de acasalamentos aleatórios e apenas 2 dos 8 locos mostraram excesso significativo de homozigotos $(F>0)$ e com desvios significativos do equilibrio de Hardy-Weinberg, estando um deles em equilíbrio de endogamia de Wright (mesma citação). Através dos testes possiveis, as mães estão cruzando a uma mesma taxa e, no geral, não está ocorrendo heterogeneidade nas frequências de pólen e óvulo (com $\mathrm{P}<0.05$, somente $\mathrm{SKDH}$ foi significativo). No entanto, o "pool" de pólen foi diferenciado entre as familias. Em função dos resultados acima, distribuição dos alelos de pólen nas familias e locos e os dados da fenologia, não concordamos quanto à estruturação ou subdivisão da população apontada por CLEGG (1980) como uma das causas possíveis dessa diferenciação, sendo descartada em função do conjunto de informações.

Entre as poucas espécies de árvores tropicais de baixa densidade estudadas até o momento quanto ao seu sistema reprodutivo (Tabela 8), Cavallinesia platanifolia e Ceiba pentandra mostram sistema misto de reprodução, enquanto as outras, sistema predominantemente de exocruzamento.

Tabela 8. Taxa de cruzamento multilocos $\left(t_{m}\right)$ de espécies tropicais; a presença de mais de um valor significa mais do que uma população, ou amostragens em tempos diferentes. $t_{\text {eq }}=$ taxa de cruzamento de equilíbrio ou aparente, calculada a partir dos valores de F. Erro padrão entre parênteses.

\begin{tabular}{|c|c|c|c|c|}
\hline ESPÉCIE & Família & Local & $\begin{array}{c}\text { Distribuição } \\
\text { geográfica }\end{array}$ & $t_{m}$ \\
\hline \multicolumn{5}{|c|}{$\begin{array}{l}\text { A1 - Baixa densidade, emergente, sucessional inicial (colonizadora de clareira ou secundária), } \\
\text { polinização por animais, dispersão pelo vento. }\end{array}$} \\
\hline $\begin{array}{c}\text { Cavallinesia } \\
\text { platanifolia }\end{array}$ & Bomb & IBC-Panamá & regional & $0,213(0.052)-0.568(0.024)$ \\
\hline Ceiba pentandra ${ }^{2,3}$ & Bomb & IBC-Panamá & ampla & $0.689(0.03)$ \\
\hline Tachigali versicolor $^{2}$ & Faba & IBC-Panamá & ampla & $0.937(0.044)$ \\
\hline
\end{tabular}




\begin{tabular}{|c|c|c|c|c|}
\hline ESPÉCIE & Família & Local & $\begin{array}{c}\text { Distribuição } \\
\text { geográfica }\end{array}$ & $\mathfrak{t}_{\mathfrak{m}}$ \\
\hline
\end{tabular}

A1 (continuação) - Baixa densidade, emergente, sucessional inicial (colonizadora de clareira ou secundária), polinização por animais, dispersão pelo vento.

\begin{tabular}{|c|c|c|c|c|}
\hline $\begin{array}{c}\text { Pithecellobium } \\
\text { pedicelare }\end{array}$ & Faba & Costa Rica & ampla & $\begin{array}{l}0.951(0.021) \\
0.986(0.014)\end{array}$ \\
\hline Cedrella fissilis $^{6}$ & Meli & $\begin{array}{l}\text { M. Atlântica - } \\
\text { Brasil }\end{array}$ & ampla & $0.92(0.05)$ \\
\hline Couratari multiflora & Lecy & Amazônia-Brasil & ampla & $0.953(0.04)$ \\
\hline Platypodium elegans $^{2}$ & Faba & IBC-Panamá & & $0.898(0.043)-0.924(0.043)$ \\
\hline \multicolumn{5}{|c|}{ A2 - Baixa densidade, dossel e dispersão por animais } \\
\hline Bertholletia excelsa $^{8}$ & Lecy & Amazônia - Brasil & ampla & $0.849(0.033)$ \\
\hline Myracondrum urundeuva ${ }^{9}$ & Anac & $\begin{array}{c}\text { M. Atlântica e } \\
\text { Cerrado-Brasil } \\
\end{array}$ & ampla & $0.338 \mathrm{t}_{\mathrm{eq}}$ \\
\hline \multicolumn{5}{|c|}{ A4 - Endêmica, dossel, comum: } \\
\hline Shorea congestifolia ${ }^{12}$ & Dipt & Sri Lanka-Asia & endêmica & $0.852(0.023)$ \\
\hline Shorea megistophylla ${ }^{13}$ & Dipt & Sri Lanka-Ásia & endêmica & $0.737(0.035)$ \\
\hline $\begin{array}{c}\text { Stemonoporus }^{12} \\
\text { oblongifolius }\end{array}$ & Dipt & Sri Lanka-Asia & endêmica & $0.844(0.021)$ \\
\hline
\end{tabular}

B1. Comum, dossel ou subdossel, tolerante à sombra, polinização e dispersão por animais:

\begin{tabular}{|c|c|c|c|c|}
\hline Quararibea asterolepis $^{1.2}$ & Bomb & IBC-Panama & regional & $1.008(0.010)$ \\
\hline Hevea brasiliensis $^{14}$ & Euph & Amazónia- Brasil & ampla & $0.645 \mathrm{t}_{\text {eq }}$ \\
\hline Carapa guianensis $^{15}$ & Meli & $\begin{array}{c}\text { La Selva-Costa } \\
\text { Rica }\end{array}$ & ampla & $\begin{array}{c}0.967(0.022) \\
-0.986(0.028)\end{array}$ \\
\hline Trichilia tuberculata $^{2}$ & Meli & IBC-Panama & & $1.077(0.028)$ \\
\hline Brosimum alicastrum $^{15}$ & & IBC-Panamá & & $0.875(0.035)$ \\
\hline Astrocarium mexicanum $^{16}$ & Palm & $\begin{array}{c}\text { Los Tuxtlas- } \\
\text { Mexico }\end{array}$ & regional & $0.933-1.050$ \\
\hline Sorocea affinis $^{2}$ & Mora & IBC-Panama & & $1.089(0.045)-0.969(0.0201)$ \\
\hline
\end{tabular}

B2. Comum, dossel ou subdossel, sucessional inicial ou secundária:

\begin{tabular}{|c|c|c|c|c|}
\hline Cordia aliodora $^{17}$ & Bora & $\begin{array}{c}\text { La Selva -Costa } \\
\text { Rica }\end{array}$ & ampla & $0.97(0.027)$ \\
\hline Cecropia obtusifolia $^{18}$ & Cecr & $\begin{array}{c}\text { Los Tuxtlas- } \\
\text { México }\end{array}$ & ampla & $0.974(0.024)$ \\
\hline Beischmedia pendula $^{2}$ & Laur & IBC-Panamá & & $0.918(0.058)$ \\
\hline Bauhinia forficata $^{10}$ & Caes & $\begin{array}{c}\text { M. Atlântica- } \\
\text { Brasil }\end{array}$ & ampla & $0.982(0.034)$ \\
\hline
\end{tabular}

1- Murawski et al, 1990 .

2- Murawski \& Hamrick, 1991.

3- Murawski \& Hamrick, 1992 b.

4- O’Malley \& Bawa, 1987.

5- Hall, Bawa \& Walker, dados não publicados (citado em Murawski, 1995)

6- Gandara, 1996.

7- Loveless \& Hamrick, 1987.

8- O'Malley et al., 1988.

9- Moraes, 1992.

10- Santos, 1994

11- Loveless \& Hamrick, 1987

12- Murawski et al., 1994.
13- Murawski \& Bawa., 1994.

14- Paiva, Kageyama, Vencovsky \& Contel, 1994.

15- Hall, Orell \& Bawa, 1994.

16- Eguiarte et al., 1992.

17- Boshier, Chase \& Bawa, 1995.

18-Alvarez-Buylla \& Garay., 1994.
$\mathrm{P}=\%$ de locos polimórficos

$\mathrm{A}=$ número de alelos por locos

Ho e $\mathrm{He}=$ heterosigosidade observadas e esperadas 
MURAWSKI et al. (1990) e MURAWSKI \& HAMRICK (1992a) mostraram que Cavallinesia platanifolia aumentava seus niveis de endogamia com a diminuição da densidade de florescimento de árvores. As taxas de cruzamento de árvores individuais foram similarmente menores nos anos em que vizinhos conspecificos falharam em florescer. MURAWSKI \& HAMRICK (1991) estudaram o efeito da densidade de florescimento de nove árvores tropicais sobre sistema reprodutivo. A espécie acima mais Quararibea asterolepis (comum) e Ceiba pentandra (baixa densidade), todas da familia Bombacaceae, tiveram relação entre densidade de florescimento e taxa de cruzamento. As outras 6 espécies estudadas não mostraram relação, sendo 4 espécies comuns e 2 de baixa densidade. Platypodium elegans e Tachigali versicolor, as duas raras, tiveram taxas de cruzamento próximas a 1, considerando que esta última espécie foi a mais esparsa entre todas as outras. Os autores explicaram esse resultado pela certa agregação e longos periodos de tempo de florescimento de árvores de Tachigali e evidências substanciais de fluxo de pólen em distâncias maiores a 500 metros. Esse padrão está bem próximo de C. multiflora (veja distâncias entre árvores reprodutivas em LEPSCH-CUNHA \& KAGEYAMA, 1996c).

O'MALLEY \& BAWA (1987) obtiveram taxa de cruzamento próxima a 1 para Pithecellobium pedicellare, árvore também de baixa densidade, emergente, colonizadora de clareira, polinizada por animais e dispersa pelo vento, características compartilhadas com todas as espécies citadas anteriormente. Os autores fazem duas questões relevantes sobre sistema reprodutivo e indivíduos espaçados: $i$. se esses indivíduos espaçados representam adultos isolados com potencial reprodutivo pequeno, estabelecidos aleatoriamente de uma fonte de sementes distantes ou, ii. se são membros de espécies adaptadas à existência de individuos grandemente espaçados.

BAWA et al. (1985) especulam que exocruzamento pode ser relaxado em algumas espécies de baixa densidade e ASHTON (1984) aponta que sem essa concessão, o isolamento espacial dos individuos constrangeriam a habilidade de uma espécie de exocruzamento reproduzir. HAMRICK \& MURAWSKI (1991) sugeriram que espécies não comuns possuiriam variação genética menor que as comuns.

Os resultados atuais demonstram o aparecimento de pelo menos 2 padrões distintos quanto às espécies com baixas densidades. Primeiro, espécies com indivíduos "naturalmente" espaçados e com taxas de cruzamento altas, mostrando possuírem dispersão de pólen a longas distâncias, juntamente com variação genética alta, refletindo fluxo gênico contínuo (C. multiflora, $P$. pedicelare, $T$, versicolor). Essas espécies parecem adaptadas à condição de baixa densidade pelo menos no que diz respeito às potencialidades de cruzamento. BAWA \& 
ASHTON (1991) propõem 4 categorias de espécies tropicais raras, e essas espécies seriam representativas da categoria de espécies uniformente raras através de ampla extensão geográfica (veja LEPSCH-CUNHA\& KAGEYAMA, 1996a). Segundo, espécies com sistema misto de reprodução, encaixando-se mais nas opiniões anteriores dos autores acima e provavelmente pertencentes à categoria de espécies com densidades populacionais oscilantes, com as consequências genéticas dependentes do padrão predominante de densidade. Neste panorama, 0 que diferenciaria Ceiba pentandra, C. platanifolia (e provavelmente C. guianensis) das outras espécies acima? Estão elas adaptadas à condição mista de sistema reprodutivo ou estão tornandose endogâmicas com possibilidade de perda de "fitness" (depressão endogâmica) e possível extinção em função do grande espaçamento entre indivíduos?

MURAWSKI et al. (1994) estudou Shorea megistophylla, uma árvore endêmica e naturalmente comum, comparando as taxas de cruzamento em áreas não perturbadas e com corte seletivo. Encontrou niveis de endogamia maiores nas áreas de corte seletivo, embora essa espécie seja primariamente de exocruzamento. A presença de apomixia juntamente com autofertilização também foi constatada em árvore isolada.

É provável que esta espécie seja ainda outro grupo com relação aos outros dois anteriores. Hipoteticamente deve haver diferença entre espécie historicamente e localmente comum que se torna espaçada por motivos antrópicos e/ou estocásticos e espécies que experimentam mudanças nas suas densidades populacionais no tempo e espaço, em função de seu padrão sucessional e de regeneração. Esse último fenômeno pode ser bem caracterizado por estrutura metapopulacional, ou populações de populações como descrita por LEVINS (1970), em que fatores influenciando o número de populações pode ser tão importante quanto as dinâmicas intemas populacionais. Neste caso, a persistência populacional ocorre através de dispersão, a qual inclui migração em localidades habitadas e colonização das desocupadas (SCHENSKE et al., 1994)

Uma questão relevante é o quanto suportariam de perturbação ou espaçamentos maiores espécies com as características de C. multiflora, ou o quanto a redução de tamanho populacional delas afetariam o comportamento de seus polinizadores e dispersores, e como consequência, a regeneração e estabelecimento de suas plântulas, em função da produção de frutos.

Os adultos dessa espécie não apresentaram índices de fixação menores que as progênies, refletindo a ausência da seleção atuando no sentido de eliminação de homozigotos (LEPSCH-CUNHA \& KAGEYAMA, 1996b). No entanto, a maioria das outras espécies discutidas acima apresentaram redução nos índices de fixação dos adultos com relação às 
progênies. Os autores em geral sugerem seleção a favor de heterozigotos (EGUIARTE et al., 1992).e, neste caso, endogamia aumentada deve ser importante no sentido da conservação dessas espécies, podendo ocasionar problemas de depressão endogâmica pelo aumento dos genótipos homozigotos. 


\section{CONCLUSÕES}

\section{CONSIDERAÇÕES QUANTO À CONSERVAÇÃO}

$\mathrm{Na}$ Introdução da dissertação discutimos a presença da raridade como caracteristica de comunidades naturais maduras e a presença marcante dela em comunidades tropicais. Ficou claro, não só pela revisão da literatura, mas também pelo estudo das duas courataris, a necessidade prioritária de diferenciação dos tipos de raridade para que conclusões e decisões sejam tomadas quanto à conservação e manejo dessas espécies. Considerando a alta porcentagem delas em comunidades tropicais, deve-se incluí-las em planos de conservação e manejo ao nível de comunidades. Como apontado por KAGEYAMA \& GANDARA (1994), conservando essas espécies, as outras espécies da comunidade também estarão sendo preservadas.

Os trabalhos que questionam o equilíbrio ou não equilíbrio de florestas têm revelado que algumas espécies mudam suas densidades populacionais em respostas a fenômenos de curta duração, como é o caso do fenômeno El Niño, documentado no ano de 1982-83 na Ilha de Barro Colorado (IBC), o qual prolongou a estação seca por seis semanas (HUBBELL \& FOSTER, 1992b). Em contrapartida, outras espécies não sofrem alteração nenhuma. As respostas quanto à dependência da densidade têm mostrado resultados não conclusivos, mas algumas espécies de maior densidade na IBC respondem positivamente a este fenômeno (CONDIT et al., 1992a, b; 1994; HUBBELL et al., 1990). Apesar das abundâncias de certas espécies dentro dessa comunidade ter mudado rapidamente, possivelmente em resposta a esse efeito climático curto, a comunidade em si tem respondido de maneira a manter sua riqueza de espécies e suas taxas de "turnover" (CONDIT et al., 1992b). Muito resta ainda a fazer para responder melhor sobre esta questão de equilíbrio, mas parece que a oscilação populacional não é um fenômeno raro e a floresta tropical úmida tem potencialidades muito altas de restabelecer sua estrutura e dinâmica quando há a disponibilidade de propágulos de uma fonte madura (UHL, 1988, 1991).

Deve-se considerar especificamente, no entanto, que as florestas neotropicais equatoriais ainda mantém uma matriz de floresta, ao contrário, da Floresta Tropical Atlântica, onde pequenos fragmentos fazem parte de uma matriz degradada. Esses fragmentos são 
invadidos por poucas espécies de cipós que dominam grande parte da área, tornando o manejo necessário para a manutenção da estrutura florestal (TABANEZ, 1995). Além disso, a presença de várias espécies representadas por um ou poucos indivíduos é alta, e as distâncias do isolamento atual desses fragmentos dificilmente permitiria fluxo de pólen e semente.

Quanto à Amazônia, a questão da não fragilidade de suas comunidades parece amplamente aceita depois do grande debate sobre o manejo sustentável. No entanto, exemplos vindos do hemisfério norte (SCHENSKE et al., 1994), mostram a necessidade de uma visão metapopulacional e/ou de ecologia de paisagem, onde conservação e manejo de comunidades não podem ser pensados de maneira pontual, mas sim geográfica e com o envolvimento de uma matriz que permita fluxo não só genético, mas também demográfico, de forma que as espécies possam se adaptar a mudanças ocasionadas seja por fatores naturais ou humanos. No caso específico de florestas tropicais, onde uma grande maioria das espécies contém menos que 1 individuo por ha. tamanho de fragmentos florestais sustentáveis caem na ordem minima de milhar. Esta constatação é devida aos problemas advindos da estocasticidade genética (deriva e consequentemente depressão endogâmica), como da estocasticidade demográfica e a aleatoriedade de locais apropriados à regeneração, como clareiras de diferentes tamanhos.

A análise de uma população de $C$. multiflora, com 1 individuo a cada 10 ha, resultou em estatísticas de parâmetros genéticos de espécie completamente adaptada a esta condição de baixa densidade, panmítica e com reprodução cruzada mesmo com individuos localizados a distâncias de cerca de 1000 metros durante a reprodução. O tamanho da área estudada (400ha) e o número de indivíduos adultos analisados permitem-nos tirar essas conclusões.

Muitas são as restrições apontadas por LANDE (1988), MENGES (1991), NUNNEY \& CAMPBELL (1993), SIMBERLOFF (1988), entre outros, quanto à regra do número populacional mínimo para manter uma populacão mínima viável, os chamados números mágicos 50/500 de FRANKEL \& SOULÉ (1981) e FRANKLIN (1980). As críticas dos autores acima são muitas e, em geral, significam preocupação com outras estocasticidades que não a genética (deriva), como a demográfica, ambiental e/ou catástrofica, o que resulta na necessidade de números maiores de indivíduos ou de áreas interligadas permitindo a extinção e colonização local. comuns em muitas espécies que "caminham" ou utilizam áreas diferenciadas para reprodução e crescimento. Sem ter outra referência e considerando esses números, seria necessária uma área mínima isolada de 500 ha e próxima à ideal de 5000 ha para C. multiflora, desconsiderarando a necessidade de várias populacões. 
A análise de uma população de $C$. guianensis, com 1 indivíduo a cada 15 ha, apresentou valores de diversidade genética semelhantes a $C$. multiflora, no entanto, com índices altos de fixação. Conforme discussão do ítem 3.1. de Resultados da dissertação (LEPSCH-CUNHA \& KAGEYAMA, 1996b), hipotetizamos que esta espécie possa estar colonizando o local recentemente, tendo sido fundada por população pequena de indivíduos diferenciados, provavelmente representantes de várias populações. As estimativas indicam que esta espécie parece também adaptada a esta condição de baixa densidade em função das altas heterozigosidades médias, provavelmente como resultado de fluxo gênico intenso. A comparação das estimativas de adultos e jovens quanto aos índices de fixação indicam que a espécie está adaptada a oscilação populacional, já que os mais jovens contém mais heterozigosidade. $\mathrm{O}$ mesmo cálculo para os números mágicos acima, resultaria em área minima de 750-7500 ha.

Os exemplos de outras espécies arbóreas tropicais mostrados nas tabelas 6 e 11 dos itens 3.1 e 3.3 de Resultados da dissertação, respectivamente, e os resultados aqui obtidos, evidenciam quantidades altas de diversidade gênica e, na maioria dos casos, taxas altas de cruzamento. A hipótese "não adaptativa" de FEDOROV (1966) não responde a esses resultados. As estimativas dos parâmetros genéticos para as courataris estudadas evidenciam tamanhos efetivos e de vizinhança grandes, apesar de suas densidades baixas locais.

\section{C. multiflora parece ajustar-se à categoria tipo 1 de BAWA \& ASTHON}

(1991) das espécies uniformemente raras e, neste caso, requerem grandes áreas para sua conservação, já que os indivíduos espaçados são mantidos como uma população por fluxo gênico. Isolamento completo em áreas com poucos indivíduos pode ocasionar endogamia, porém a possibilidade de conecção com outros fragmentos ou o aumento posterior da população podem conter a perda da variação genética. Como apontado pelos autores acima, a fragmentação em áreas reduzidas pode levar diminuição da produção reprodutiva resultante tanto de endogamia quanto de movimento insuficiente de pólen entre árvores amplamente espaçadas. A diminuição em área é provável também afetar adversamente o tamanho populacional dos polinizadores e dispersores de semente. Foi visto a presença alta de predadores de semente para $C$. multiflora. Se ocorrer o aumento do tamanho populacional de predadores, estas espécies podem ter suas regenerações comprometidas, mesmo que reproduzindo bastante. Ao contrário, a diminuição deles pode beneficiá-las e sabemos que ambos fenômenos são possíveis com a fragmentação.

As conclusões que poderiamos tirar para C. guianensis ficam muito dependentes das taxas de cruzamento possíveis para populações com esta densidade baixa. Se a endogamia alta observada na população for realmente devida à fundação por poucos colonizadores ao invés de problemas advindos de cruzamentos diminuídos em função da baixa 
densidade, espera-se que exista pouca carga genética e consequentemente maior adaptação a oscilações na densidade populacional. Se a estrutura genética e demográfica for dependente de uma estrutura metapopulacional, há a necessidade de identificação de áreas fontes (source) e escoadouras (sink) ao nível populacional e genético. Assim, esta espécie pertenceria ao tipo 2 de BAWA \& ASTHON (1991), porém muito pouco se sabe sobre elas como apontado pelos autores. Seria importante estudar as populações com diferentes densidades para determinar o efeito na diversidade genética e nos índices de fixação. No entanto, se os índices de endogamia observados são uma função da diminuição populacional ou taxas de cruzamento diminuidas em função do maior espaçamento entre os individuos, observações de campo quanto à diminuição das taxas reprodutivas permitiriam analisar a presença ou não da depressão endogâmica. Neste caso, se esta ocorrer, há a neccssidade de se preservar areas onde as populações tenham densidades maiores. A heterozigosidade maior nos jovens não seria esperada neste último caso, portanto, esta última explicação não parece a mais provável.

A verificação do sistema reprodutivo de C. guianensis, da análise da distribuição espacial dos genótipos e do componente entre populações para ambas as espécies testariam varias das hipóteses acima colocadas e muito auxiliariam na compreensão da estrutura demográfica, genética e, consequentemente, da conservação dessas espécies.

\section{CONCLUSÃO FINAL}

A diversidade genética da população estudada de cada uma das espécies, C. multiflora e C. guianensis, foi muito próxima e encontra-se entre os maiores valores quando comparadas a outras espécies arbóreas tropicais.

A população de C.multiflora apresentou-se como espécie alógama, com taxa de cruzamento multilocos igual a um, permanecendo este valor constante para as diferentes familias estudadas. Os índices de fixação baixos e próximos a zero, a maioria dos locos apresentando Equilíbrio de Hardy-Weinberg para a população de adultos e progênies e as altas taxas de diversidade genética sugerem que esta espécie esteja muito próxima à panmixia, resultado de tamanho de vizinhança e fluxo gênico amplo. Os dados da fenologia juntamente com os do sistema reprodutivo mostram que a distância de $1000 \mathrm{~m}$ não impede fluxo de pólen. Desta forma, esta população está adaptada a baixa densidade de indivíduos observada no local. 
A população de C. guianensis apresenta endogamia, sendo esta menos pronunciada nos individuos mais jovens. Os valores altos da diversidade genética para esta espécie confrontados com os coeficientes de endogamia sugere fluxo de pólen intenso e/ou fundação por individuos vindos de diferentes populações. Esse dados também sugerem adaptação à presença de endogamia (homozigosidade maior) juntamente com alta diversidade.

Os resultados sugerem que essas duas populações tem histórias de vida diferentes, mas estão adaptadas à condição de baixa densidade. $C$. multiflora ajusta-se à categoria das espécies uniformemente raras e, neste caso, requer grandes áreas para sua conservação. Para C. guianensis, há necessidade de se conhecer sobre seu sistema reprodutivo para maiores sugestões. Se o sistema reprodutivo estiver adaptado a cruzamentos a longas distâncias como $C$. multiflora, a espécie deve suportar mais estrangulamentos populacionais e/ou fragmentação, desde que a variabilidade seja mantida pela conecção de populações.

Os diferentes resultados de estrutura genética das duas espécies mostram a necessidade de distinção entre diferente tipos de espécie rara. 


\section{REFERÊNCIAS BIBLIOGRÁFICAS}

ALFENAS, A.C.; PETERS, I., BRUNE, W.; PASSADOR, G.C. Eletroforese de Proteínas e Isoenzimas de Fungos e Essências Florestais. Imprensa Universitária, Universidade Federal de Viçosa. Viçosa, 1991. 242 p.

ALVAREZ-BUYLLA, E. \& GARAY, A. A. Population genetic struture of Cecropia obtusifolia, a tropical pioneer tree species. Evolution, 48(2):437-453, 1994.

ASHTON, P.S. Biosystematics of tropical forest plants: a problem of rare species. In: GRANT, W.F., ed., Plant Biosystematics. Londres, Academic Press, 1984, p.497-518.

AUGSPURGER, C.K. Phenology, flowering synchrony, and fruit set of six neotropical shrubs. Biotropica, 15:257-267. 1983.

BARRETT, S.C.H. \& HUSBAND, B.C. The genetics of plant migration and colonization. In: BROWN, A.H.D.; CLEGG, M.T.; KAHLER, A.L.; WEIR, B.S., eds., Plant population genetics, breeding, and genetic resources. Sunderland, MA, Sinauer Associates, Inc., 1990, p. 254-277.

BARRETT, S.C.H. \& KOHN, J.R. Genetic and evolutionary consequences of small population size in plants: implication for conservation. In:. FALK, D.A. \& HOLSINGER, K.E., eds., Genetics and conservation of rare plants. Center for plant conservation. Oxford University Press. 1991, p.3-30.

BARRETT, S.C.H.; MORGAN, M.T.; HUSBAND, B.C. The dissolution of a complex genetic polymorphism: The evolution of self-fertilization in Eichhornia paniculata (Ponteriaceae). Evolution, 41:1398-1416. 1989.

BAWA, K.S. \& ASTHON, P.S. Conservation of rare tree in tropical rain forests: a genetic perspective. In:. FALK, D.A. \& HOLSINGER, K.E., eds., Genetics and Conservation of rare plants. Center for plant conservation. Oxford University Press. 1991, p. 62-74.

BAWA, K.S. \& O'MALLEY, D.M. Estudios genéticos y de sistemas de cruzamiento en algunas especies arbóreas de bosques tropicales. Revista de Biologia Tropical, 35(Supl. 1):177-188. 1987.

BAWA, K.S.; ASHTON, P.S.; NOR, S.M. Reproductive Ecology of tropical forest plants: management issues. In: BAWA, K.S. \& HADLEY, M., eds., Reproductive ecology of tropical forest plants. Man and the biosphere series, vol. 7. 1990. p. 3-16.

BAWA, K.S ; PERRY, D.R.; BEACH, J.H. Reproductive biology of tropical lowland rain forest trees. I. Sexual systems and incompatibility mechanisms. American Journal of Botany., 72:331-345. 1985 .

BOSHIER, D.H.; CHASE, M.R.; BAWA, K.S. Population genetics of Cordia Alliodora (Boraginaceae), a neotropical tree. 2. Mating system. American Journal of Botany, 82(4):476-483. 1995. 
BROWN. A.H.D. Genetic characterization of plant mating systems. In: BROWN, A.H.D.; CLEGG, M.T.; KAHLER, A.L.; WEIR, B.S., eds., Plant population genetics, breeding, and genetic resources. Sunderland, MA, Sinauer Associates, Inc., 1990, p. 145-162.

BROWN, A.H.D. \& ALLARD, R.W. Estimation of the mating system in open-pollinated maize populations using isozyme polymorphisms. Genetics, 66:133-145, 1970.

BROWN, A.H.D. \& WEIR, B.S. Measuring genetic variability in plant populations. In: TANSKLEY, S.D. \& ORTON, T.J., eds., Isozymes in plants genetics and breeding, part A Elsevier, Amsterdan. 1983.

BROWN, A.H.D.; BARRETT, S.C.H.; MORAN, G.F. Mating system estimation in forest trees: models, methods and meanings. In: GREGORIUS, H.R., ed., Population genetics in forestry, Springer-Verlag, Berlin. 1984, , p. 32-49.

BROWN. A.H.D.; BURDON,J.J.: JAROSZ, A.M. Isozyme analysis of plant mating systems. In: D.E. SOLTIS \& P.S. SOLTIS, Isozyme in Plant Biology, eds., Chapman and Hall Press Ltda.. 1990, p.73-86.

BROWN, A.H.D.; MATHESON, A.C.; ELDRIDGE, K.G. Estimation of the mating system of Eucalyptus obliqua L'Herit using allozyme polymorphisms. Australian Journal of Botany, 23:931-49, 1975 .

BUCKLEY, D.P.; O,MALLEY, D.M.; APSIT, V.; PRANCE, G.T.; BAWA, K.S. Genetics of Brazil nut (Bertholletia excelsa Humb. \& Bonpl.: Lecythidaceae). 1. Genetic variation in natural populations. Theor. Appl. Genet., 76:923-928. 1988.

CHARLESWORTH, D.; CHARLESWORTH, B. Imbreeding depression and its evolutionary consequences. Annual Review of Ecology and Systematics, 18:237-268, 1987.

CHASE, M.R. BOSHIER, D. H. BAWA, K. S. Population genetics of Cordia Alliodora (Boraginaceae), a neotropical tree. 1. Genetic variation in natural populations. American Journal of Botany, 82(4):468-475, 1995.

CLARK, P.J. \& EVANS, F.C. Distance to nearest neighbour as a measure of spatial relationships in populations. Ecology, 35:445-453, 1954.

CLAYTON, J. \& TRETIAK, D. Amine-citrate buffers for $\mathrm{pH}$ control in starch gel electrophoresis. J. Fisheries Res. Board. Can., 29:1169-1172, 1972.

CLEGG, M. T. Measuring plant mating systems. Bioscience, 30(12):814-18, 1980.

CONDIT, R.; HUBBELL, S.P.;FOSTER, R.B. Recruitment near conspecific adults and the maintenence of tree and shrub diversity in a neotropical forest. The American Naturalist, 140(2):261-286, 1992a.

CONDIT, R.; HUBBELL, S.P.; FOSTER, R.B. Short term dynamics of a neotropical forest. BioScience, 42(11):822-828, $1992 \mathrm{~b}$. 
CONDIT, R.; HUBBELL, S.P.; FOSTER, R.B. Density dependence in two understory tree species in a neotropical forest. Ecology, 75(3):671-680. 1994.

CONNELL, J.H. On the role of natural enemies in preventing competitive exclusion in some marine animals and in rain forest trees. In: DEN BOER, P.J. \& GRADWELL, G.R., eds., Dynamics of numbers in populations, Center for Agricultural Publication and Documentation, Wageningen, Netherlands, 1971, p. 298-312.

CONNELL, J. H. Diversity in tropical rain forest and coral reefs. Science, 199:1302-1309, 1978.

DANTAS, M.; RODRIGUES, I.A.; MULLER, N.M. Estudos Fitoecológicos do trópico úmido brasileiro. EMBRAPA. Boletim de Pesquisa, 9, 1980.

DENSLOW, J.S. Tropical rainforest gaps and the tree specie diversity. Annual Review of Ecology and Systematics, 18: 431-51, 1987.

DOBZHANSKY, T. Evolution in the tropics. American Scientist, 32:209-221, 1950.

EGUIARTE, L.E.; PEREZ-NASSER. N.; PINERO, D. Genetic structure, outcrossing rate and heterosis in Astrocaryum mexicanum (tropical palm): implications for evolution and conservation. Heredity, 69:217-228, 1992.

ELLSTRAND, N.C. \& ELAM, D.R. Population genetic consequences of small population size: implications for plant conservation. Annual Review of Ecology and Systematics, 24:21742. 1993.

EYMA, P.J. The Polygonaccae, Guttiferae and Lecythidaceae of Surinam. Meded. Bot. Mus. Herb.Rijks Univ. Utrecht. 4:1-77. 1932.

FAO. Data book on endangered forest tree species and provenances. Rome. 1981, 64p.

FEDOROV, A.A. The structure of the tropical rain forest and speciation in the humid tropics. Journal of Ecology, 54:1-11. 1966.

FERRAZ, E.M.; GANDARA, F.B.; LEPSCH-CUNHA, N.; REIS, M.S.; KAGEYAMA, P.Y. Eletroforese de isoenzimas para as espécies arbóreas - Manual de Laboratório (versão 1994). Piracicaba, ESALQ, Depto de Ciências Florestais, Laboratório de Biologia Reprodutiva e Genética de Espécies Arbóreas, 1994. 23 p.

FISHER, R.A., CORBET, A. S., WILLIAMS, C. B. The relation between the number of species and the number of individuals in a random sample of an animal population. Journal of Animal Ecology, 12:42-58, 1943.

FRANKEL, O.H. \& SOULÉ, M.E. Conservation and evolution. Cambridge University Press, Cambridge, 1981. 
FRANKLIN, I.R. Evolutionary change in small populations. In: SOULÉ, M.E. \& WILCOX, B.A., eds., Conservation biology: an evolutionary-ecological perspective. Sinauer Associates, sunderland, Massachussets, 1980, p.135-149.

FUTUYMA, D.J. Biologia evolutiva. Ribeirão Preto, Sociedade Brasileira de Genética. 1992. $631 \mathrm{p}$.

GANDARA, F.B. Diversidade genética, taxa de cruzamento e estrutura espacial dos genótipos em uma populaçào de Cedrela fissilis Vell. (Meliaceae). Piracicaba, 1996.69 p. (Mestrado - Escola Superior de Agrucultura "Luiz de Queiroz"/USP).

GENTRY, A.H. Neotropical floristic diversity: phytogeographical connections between Central and South America, Pleistocene climatic flutuations, or an accident of the Andean orogeny? Ann. Missouri Bot. Garden, 69:557-93. 1982.

GENTRY, A.H. Dispersal and distribution in Bignoniaceae. Sonderbd. Naturwiss. Ver. Hamburg, 7:187-99, 1983.

GENTRY, A. H. An overview of neotropical phytogeografic patterns with an emphasis on Amazonia. Anais do $\mathbf{1 0}^{\circ}$ Simpósio do Trópico Úmido, 2:19-35, 1986.

GENTRY, A. H. Changes in plant community diversity and floristic composition on environmental and geographical gradients. Annals of Missouri Botanical Garden., 75:1-34. 1988.

GENTRY, A. H. Speciation in tropical forests. In: L. B. HOLM-NIELSEN, I. C. NIELSEN AND H. BALSLEV, EDS., Tropical forests: botanical dynamics, speciation and diversity, 1989, p.113-134.

GENTRY, A. H. (ed.) Four Neotropical rainforests. Yale University Press. London, 1990, $627 \mathrm{p}$.

GOMES, F.P. Curso de Estatística Experimental. Piracicaba, USP/ESALQ, 13a. ed., 1990.

HALL, P.; ORRELL, L. C.; BAWA, K. S. Genetic diversity and mating system in a tropical tree, Carapa guianensis (Meliaceae). American Journal of Botany, 81(9);1104-1111. 1994.

HAMRICK, J.L. Isozymes and Analysis of Genetic Structure in Plant populations. In: SOLTIS, D.E. \& SOLTIS, P., eds, Isozymes and the analysis of genetic structure in plant populations. Chapman and Hall Ltd. 1990, p 87-105.

HAMRICK, J.L. \& GODT, M.T. Allozyme diversity in plant species. In: BROWN, A.H.D.; CLEGG, M.T.; KAHLER, A.L.; WEIR, B.S. (eds). Plant population genetics, breeding and genetic resources. Sunderland, MA, Sinauer Associates Inc., 1990, p 43-63.

HAMRICK, J.L. \& LOVELESS, M.D. Isozyme variation in tropical trees: procedures and preliminary results. Biotropica, 18:201-207. 1986a. 
HAMRICK, J.L. \& LOVELESS, M.D. The influence of seed dispersal mechanisms on the genetic structure of plant populations. In: ESTRADA, A. \& FLEMING, T.H. (eds.) Frugivores and Seed Dispersal. Junk Publishers. 1986b, Cap. 17, 392 p.

HAMRICK, J.L. \& LOVELESS, M.D. The genetic structure of tropical tree populations: association with reproductive biology. In: BOCK, J.H. \& LINHART, Y.B. eds. The evolutionary ecology of plants. Westview Press, Boulder, CO, USA., 1989, p. 129-146.

HAMRICK, J.L. \& MURAWSKI, D.A. Levels of allozyme diversity in populations of uncommon neotropical tree species. Journal of Tropical Ecology, 7:395-399. 1991.

HAMRICK, J.L.; LINHART, Y.B.; MITTON, J.B. Relationships between life history characteristcs and eletrophoretically detectable genetic variation in plants. Annual Review of Ecology and Systematics, 10:173-200. 1979.

HAMRICK, J.L.; MITTON, J.B; LINHART, Y.B. Levels of genetic variation in trees: influence of life history characteristics. In: M.T. CONCKLE, (ed), Isozymes of north-american forests trees and forest insects, 35-41. Pacific SW For. Range Expt. Sta Tech. Report \# 48. 1981 .

HARTSHORN, G.S. Neotropical forest dynamics. Biotropica, 2 (Supl.):23-30. 1980.

HILL, R. J.; PRANCE, G. T; MORI, S A.; STEWARD, W. C.; SHIMABUKURU, D.; BERNARDI, J. Estudo eletroforético da dinâmica de variação genética em três taxa ribeirinhos ao longo do rio Solimões, América do Sul. Acta Amazônica. 8(2):183-199. 1978.

HUBBELL, S.P. \& FOSTER, R.B. Commonness and rarity in a neotropical forest: implications for tropical tree conservation. In: SOULÉ, M.E., ed., Conservation biology: science of scarcity and diversity. Sunderland, Massachusetts: Sinauer Associates. 1986, p. 205-231.

HUBBELL, S.P. \& FOSTER, R.B. Structure, dynamics, and equilibrium status of old-growth forest on Barro Colorado Island. In: GENTRY, A.H. ed. Four neotropical rainforest, Yale University Press, London, 1990a. p.522-41.

HUBBELL, S.P. \& FOSTER, R.B. The fate of juvenile trees in a neotropical forest: implications for the natural maintenance of tropical tree diversity. In: HADLEY, M. \& BAWA, K. S., EDS., Reproductive biology of tropical forest plants, Paris and Parthenon Publishers Press. 1990b, v.7, p. 325-349.

HUBBELL, S.P. \& FOSTER, R.B. Short-term dynamics of a neotropical forest: why ecological research matters to tropical conservation and management. Oikos, 63:48-61, 1992.

HUBBELL, S.P.; CONDIT, R.; FOSTER, R.B. Presence and absence of density dependence in a neotropical tree community. Philos. Trans. R. Soc. Lond. B., p. 147-159. 1990.

JANZEN, D. H. Herbivores and the number of tree species in tropical forests. The American Naturalist, 104(940):501-528. 1970. 
JANZEN, D.H. Euglosinae bees as long-distance pollinators of tropical plants. Science, 171: 203-205. 1971.

KAGEYAMA, P. Y., GANDARA, F. B. Dinâmica de populações de espécies arbóreas: implicações para o manejo e a conservação. III Simpósio de Ecossistemas da Costa Brasileira - Anais, Academia de Ciências do Estado de São Paulo. 1994.

KAGEYAMA, P. Y., NAMKOONG, G., ROBERDS, J. Genetic diversity in tropical forests in the state of São Paulo - Brazil. (não publicado).

KEPHART, S.R. Starch Gel Eletrophoresis of Plant Isozymes: A Comparative Analysis of Techniques. American Journal of Botany, 77(5):693-712. 1990

KNUTH, R. Lecythidaceae. Pflanzenreich IV, 291a:1-146. 1939.

LANDE, R. Genetics and demography in biological conservation. Science, 241:1455-61. 1988

LEPSCH-CUNHA, N; KAGEYAMA, P. Y. Raridade na Floresta Tropical. Ítem 1. da Introdução da Dissertação "Estrutura Genética e Fenologia de Espécies Raras de Couratari spp. (Lecythidaceae) na Amazônia Central". Dissertação de Mestrado. ESALQ/USP, Piracicaba, SP. 1996a.

LEPSCH-CUNHA, N.; KAGEYAMA, P. Y. Variabilidade genética intrapopulacional de duas espécies de baixa densidade na Amazônia Central: Couratari multiflora (J.E. Smith) Eyma e Couratari guianensis Aublet. İtem 1. de Resultados da Dissertação "Estrutura Genética e Fenologia de Espécies Raras de Couratari spp. (Lecythidaceae) na Amazônia Central". Dissertação de Mestrado. ESALQ/USP, Piracicaba, SP. 1996 b.

LEPSCH-CUNHA, N.; KAGEYAMA, P. Y. Fenologia reprodutiva e potencialidade de cruzamentos em uma população de baixa densidade de Couratari multiflora (J.E. Smith) Eyma na Amazônia Central. Ítem 2. de Resultados da Dissertação "Estrutura Genética e Fenologia de Espécies Raras de Couratari spp. (Lecythidaceae) na Amazônia Central". Dissertação de Mestrado. ESALQ/USP, Piracicaba, SP. 1996c.

LEPSCH-CUNHA, N; KAGEYAMA, P. Y. Sistema reprodutivo de espécie de baixa densidade de Couratari multiflora (J.E. Smith) Eyma na Amazônia Central. İtem 3 de Resultados da Dissertação "Estrutura Genética e Fenologia de Espécies Raras de Couratari spp. (Lecythidaceae) na Amazônia Central". Dissertação de Mestrado. ESALQ/USP, Piracicaba, SP. 1996d.

LEVINS, R. Extinction. Lectures on Mathematics in the Life Sciences, 2:75-107.

LI, C.C. \& HORVITZ, D.G. Some methods of estimating the inbreeding coefficient. American Journal of Human Genetics 5:107-117..1953.

LOVEJOY, T.E.R. \& BIERREGARD, R.O. Central Amazonian forests and the Minimum Critical Size od Ecosystems Project. In: GENTRY, A.H. ed. Four neotropical rainforest. Yale University Press, London, 1990, 627 p. 
LOVEJOY, T.E.R.; BIERREGAARD, R.O. Jr.; RYLANDS, A.B.; MALCOLN, J.R.:QUINTELA, C.E.; HARPER, L.H.; SCHUBART, H.O.R.; HAYS, M.B. Edge and others effects of isolation on Amazonian forest fragments. In: SOULÉ, M.E. ed. Conservation biology: the science of scarcity and diversity. Sinauer Associates, Inc., Publishers, Massachusetetts.1986, p 257-285.

LOVELESS, M.D. \& HAMRICK, J.L. Distribucion de la variation genetica en especies arbóreas tropicales. Revista de Biologia Tropical, 35:165-176. 1987.

LUDWIG, J. A., REYNOLDS, J. F. Statistical Ecology. John Wiley \& Sons. 1988.

MAGURRAN, A. Ecological diversity and its measurement. Princeton University Press. 1988. $179 \mathrm{p}$.

MAY, R. M. Patterns of species abundance and diversity. In: CODY, M. L. \& DIAMOND, J.M., eds., Ecology and Evolution of Communities, Harvard University Press, Cambridge, MA, 1975, p. 81-120.

MAY, R. M. Patterns in multi-species communities. In: MAY, R.M., ed., Theoretical Ecology: Principles and Applications, Blackwell, Oxoford, 1981, p.197-227.

McCAULEY, D.E. Genetic consequences of local population extintion and recolonization. Tree, 6(1): 5-8. 1991.

MENDES, N.B.; NELSON, B.W; MILLER, R.P. Levantamento das espécies arbóreas da região de Manaus-Amazonas. ANAIS $2^{\circ}$ CONGRESSO NACIONAL SOBRE ESSÊNCIAS NATIVAS, 4:333-338. 1992.

MENGES, E.S. The application of minimum viable population theory to plants. In: FALK, D.A. \& HOLSINGER, K.E., eds., Genetics and Conservation of rare plants. Center for plant conservation. Oxford University Press. 1991, p. 45-61.

MITCHELL, J.D. \& MORI, S.A. Chapter. X. Ecology. In: MORI, S.A. \& COLLABORATORS. The Lecythidaceae of a lowland neotropical forest: La Fumée Mountain, French Guiana. Mem.New. York. Bot. Gard., 44:137-155. 1987.

MORAES, M.L.T. Variabilidade genética por isoenzimas e caracteres quantitativos em duas populações naturais de aroeira Myracrodruon urundeuva F. F. \& M. F. Allemão Anacardiaceae. Tese de Doutorado. ESALQ/USP. 1992.

MORI, S.A. Diversity of Lecythidacae in the Guianas. In: HOLM-NIELSEN, L.B.; NIELSEN, I.C.; BALSLEV, H. eds. Tropical Forests: botanical dynamics, speciation and diversity. Academic Press. 1989, p.319-332.

MORI, S.A. \& BOEKE, J. Chapter XII. Pollination. In: MORI, S.A. \& COLLABORATORS. The Lecythidaceae of a lowland neotropical forest: La Fumée Mountain, French Guiana. Mem.New. York. Bot. Gard., 44:137-155. 1987. 
MORI, S.A. \& COLLABORATORS. The Lecythidaceae of a lowland neotropical forest: La Fumée Mountain, French Guiana. Mem. New York Bot. Garden, 44:1-190. 1987.

MORI, S.A \& LEPSCH-CUNHA, N. Lecythidaceae of a Central Amazonian moist forest. Memoirs of New York Botanical Garden. 1995, vol.75, 55p.

MORI, S.A. \& PRANCE, G.T. Chapter XI: Phenology. In: MORI, S.A. \& COLLABORATORS. The Lecythidaceae of a lowland neotropical forest: La Fumée Mountain, French Guiana. Mem.New. York. Bot. Gard., 44: 124-136, 1987.

MORI, S.A. \& PRANCE, G.T. Lecythidaceae - Part II. The zygomorphic-flowered New World Genera (Couropita. Corythophora, Berthollethia, Couratari, Eschweilera \& Lecythis). Flora Neotropica, 21(II). 1990, 376p.

MORI, S.A.; ORCHARD, J.E; PRANCE, G.T. Intrafloral pollen differentiation in the New World Lecythidaceae. Science, 209: 400-403. 1980.

MURAWSKI, D.A. Reproductive biology and genetics of tropical trees from a canopy perspective. Manuscrito. 1995.

MURAWSKI, D.A. \& BAWA, K.S. Genetic structure and mating system of Stemonoporus oblongifolius (Dipterocarpaceae) in Sri Lanka. American Journal of Botany, 81(2):155-160. 1994.

MURAWSKI, D.A. \& HAMRICK, J.L. The effect of the density of flowering individuals on the mating systems of nine tropical tree species. Heredity, 67:167-174. 1991.

MURAWSKI, D.A. \& HAMRICK, J.L. The mating system of Cavallinesia platanifolia under extremes of flowering-tree density: a test of predictions. Biotropica, 24(1):99-101. 1992a.

MURAWSKI, D.A. \& HAMRICK, J.L. Mating system and phenology of Ceiba pentandra (Bombacaceae) in Central Panama. J. Hered, 83:401-404. 1992b.

MURAWSKI, D.A.; DAYANANDAN, B.; BAWA, K.S. Outcrossing rates of two endemic Shorea species from Sri Lankan tropical rain forests. Biotropica, 26:23-29. 1994.

MURAWSKI, D.A.; HAMRICK, J.L.; HUBBELL, S. P. FOSTER, R.B. Mating system of two bombacaceous trees of a neotropical moist forest. Oecologia. 82:501-506. 1990.

MURPHY, R.W.; SITES, J.W.; BUTH, D.G.; HAUFLER, C.H. Proteins I: Isozyme Electrophoresis. In: HILLIS, D.M. \& MORITZ, C., eds., Molecular Systematics. Sinauer Associates, Inc Publishers. 1990, 373-409 p.

MYERS, N. Threatened biotas: "Hotsposts"in tropical forests. Environmentalist, 8:1-20. 1988.

NEI, M. The bottleneck effect and genetic variability in populations. Evolution, 29(1):1-10, 1975. 
NEI, M. Molecular population genetics and evolution. In: NEUBERGER, A. \& TATUM, E.L., eds., Frontiers of Biology. Elsevier, New York. 1975, v. 40.

NEI, M. Molecular evolutionary genetics. New York, Columbia University Press. 1987, 512 p.

NELSON, B.W.; ABSY, M.L.; BARBOSA, E.M.; PRANCE, G.T. Observations on flower visitors to Berthollethia excelsa H.B.K. and Couratari tenuicarpaA.C.Sm. (Lecythidaceae). Acta Amazonica (Supl.), 15(1/2): 225-234. 1985.

NUNNEY, L., CAMPBELL, K. A. Assessing minimum viable population size: demography meets population genetics. Tree, 8(7):234-239. 1993.

O,MALLEY, D.M. \& BAWA, K.S. Matyng system of a tropical rain forest tree species.American Journal of Botany, 74(8):1143-49. 1987.

O MALLEY, D.M.; BUCKLEY, D.P.: PRANCE, G.T.; BAWA, K.S. Genetics of Brazil nut (Bertholletia excelsa Humb \& Bonpl.: Lecythidaceae. 2. Mating system. Theor. Appl. Genet., 76:929-932. 1988.

PAIVA, J.R.; KAGEYAMA, P. Y.; VENCOVSKY, R. Genetics of rubber tree (Hevea brasiliensis (Willd.ex Adr. de Juss.)Müll. Arg.). 2. Mating system. Silvae Genetica, 43(5/6):373-76, 1994.

PAIVA, J.R.; KAGEYAMA, P. Y.; VENCOVSKY, R.; CONTEL, E.P.B. Genetics of rubber tree (Hevea brasiliensis (Willd.ex Adr. de Juss.)Müll. Arg.). 1. Genetic variation in natural populations . Silvae Genetica, 43(5/6):307-12, 1994.

PERES, C.A. Seed predation of Cariniana micrantha (Lecythidaceae) by brown capuchin monkeys in Central Amazonia. Biotropica, 23(3):262-70, 1991.

PIMM, S.L. Community stability and structure. In: SOULÉ, M.E., ed., Conservation biology: science of scarcity and diversity. Sunderland, Massachusetts: Sinauer Associates. 1986, p. 309-329.

PRANCE, G.T. The pollination and androphore structue of some Amazonian Lecythidaceae. Biotropica, 8(4):235-241, 1976.

PRANCE, G.T.; RODRIGUES, W.A.; SILVA, M.F. Inventário Florestal de 1 hectare de Mata de terra firme - km 30 da Estrada Manaus-Itacoatiara. Acta Amazonica, 6(1):9-35. 1976.

PRESTON, F. W. The canonical distribution of comoness and rarity: part II. Ecology, 43(3):410-31, 1962.

RABINOWITZ, D.; CAIRNS, S.; DILLON, T. Seven forms of rarity and their frequency inthe flora of British Isles. In: SOULÉ, M.E., ed., Conservation biology: science of scarcity and diversity. Sunderland, Massachusetts: Sinauer Associates. 1986, p. 182-204. 
RANKIN-DE-MERONA, J.M. \& ACKERLY, D.D. 1987. Estudos populacionais de árvores em florestas fragmentadas e as implicações para a conservação "in situ" das mesmas na floresta tropical da Amazônia Central._Revista IPEF, Edição Especial. 35:47-59. 1987.

RANKIN-DE-MERONA, J.M.; HUTCHINGS, R.W.; LOVEJOY, T. The tree and recruitment over a five-year period in undisturbed upland rainforest of the Central Amazon. In: GENTRY, A. H. (ed.) Four Neotropical rainforests. Yale University Press, London, 1990, $627 \mathrm{p}$.

REID, W.V. \& MILLER, K.R. Keepinp options alive: The scientific basis for conserving biodiversity. World Resources Institute. A center for policy research. 1989, 129p.

RITLAND, K. Estimation of mating systems. In: TANKSLEY, S.D. \& ORTON, T.J., eds., Isozymes in plant genetics and breeding. Part A. Amsterdam, The Netherlands, Elsevier Science Publishers, 1983, p:289-302.

RITLAND, K. The effective proportion of self-fertilization with consanguineous mating in inbred populations. Genetics, 106: 139-152. 1984.

RITLAND, K. The genetic mating structure of subdivided populations. I. Open mating model. Theoretical Population Biology, 27:51-74. 1985.

RITLAND, K. A series of FORTRAN computer programs for estimating plant mating systems. The Journal of Heredity, 81(3):235-237. 1990.

RITLAND, K. \& EL-KASSABY, Y. A. The nature of inbreeding in a seed orchard of Douglas fir as shown by efficient multilocus model. Theor. Appl. Genet. 71: p. 375-384, 1985.

RITLAND, K. \& JAIN, S. A model for the estimation of outcrossing rate and gene frequencies using $n$ independent loci. Heredity, 47:35-52. 1981.

ROOSMALEN, M.G.M. Fruits of the Guianan Flora. Institute os Systematic Botany, Utrcht University. 1985.

SANTOS, E. M. G. Ecologia da polinização, fluxo de pólen e taxa de cruzamento em Bauhinia forficata Link. (Caesalpinaceae). Tese de Mestrado. ESALQ/USP. 1994.

SCANDALIOUS, J.G. Genetic control of multiple molecular forms of isozymes inplants. Biochemical Genetic, 3:37-79, 1969.

SCHEMSKE, D.W.; HUSBAND, B.C.; RUCKELHAUS, M.H.; GOODWILLIE, C.; PARKER, I.M.; BISHOP, J.G. Evaluating approaches to the conservatoin of rare and endangered plants. Ecology, 75 (3):584-606. 1994.

SHAW, D. V.; ALLARD, R. W. Estimation of outcrossing rates in Douglas-fir using isozyme markers. Theor. Appl. Genet. 62:113-120. 1981.

SHORROCKS, B. A origem da diversidade. São Paulo, Editora da Universidade de São Paulo. 1980. $181 \mathrm{p}$. 
SIEGEL, S. Estatística não-paramétrica: para as ciências do comportamento. McGraw-Hill. 1975.

SILVA, M. F. da, LISBOA, P. L. B., LISBOA, R. C. L. Nomes Vulgares de Plantas Amazônicas. Instituto Nacional de Pesquisas da Amazônia (INPA). Manaus. 1977.

SIMBERLOFF, D. The contribution of population and community biology to conservation sciense. Annual Review of Ecology and systematics, 19:473-511. 1988.

SLATKIN, M. Gene flow and genetic drift in a species subject to frequent local extinctions. Theoret. Popul. Biol., 12:253-62. 1977.

SLATKIN, M. Gene flow and the geographic structure of natural populations. Science, 236:787-92. 1987.

SOKAL. R.R. \& ROHLF, F.J. Biometry. W.H. Freeman and Company, New York, $2^{\circ}$ ed., $1981,860 \mathrm{p}$.

SOLTIS, D.E. \& SOLTIS, P.S. Isozymes in plant biology. Chapman and Hall Ltda., 1990.

SOLTIS, D.E.; HAUFLER, C.H.; DARROW, D.C.; GASTONY, G.L. 1983. Starch gel electrophoresis of ferns: a compilation of griding buffers, gel and electrode buffers, and staining schedules. American Fern Journal, 73(1):9-26. 1983.

SOULE, M. ed. Conservation Biology - The science of scarcity and diversity. Sinauer Associates, Inc. Publishers. 1986, 584p.

SWOFFORD, D.L. \& SELANDER, Byosys-1. A computer program for the analysis of allelic variation in population genetics and biochemical systematics. Release 1,7, Illinois Natural History Survey, Illinois. 1989.

TABANEZ, A.A.J. Ecologia e manejo de ecounidades em um fragmento florestal da região de Piracicaba, SP. Piracicaba, 1995. p. (Mestrado - Escola Superior de Agricultura "Luiz de Queiroz"/USP).

TERBORGH, J. Maintenance of diversity in tropical forests. Biotropica, 24(2): 283-292. 1992.

TORGGLER, M.G.F.; CONTEL, E.P.B.; TORGGLER, S.P. Isoenzimas: variabilidade genética em plantas. Ribeirão Preto, Sociedade Brasileira de Genética, Série Monografias, 1. $1995,186 \mathrm{p}$.

UHL, C., BUSCHBACHER, R., SERRÃO, E. A. S. Abandoned pastures in eastern Amazonia. I. Patterns of plant sucession. Journal of Ecology, 76:633-681. 1988.

UHL, C., NEPSTAD, D., SILVA, J.M.C., VIEIRA. I. Restauração de floresta em pastagens degradadas. Ciência Hoje. 13(78):23-31. 1991. 
VENCOVSKY, R. Estimadores de diversidade. In: KAGEYAMA, P.Y.; REIS, M.S.; GANDARA, F.B., coordenadores do curso: "Estimação de variação genética e taxa de cruzamento em populações de espécies arbóreas". Promoção: Laboratório de Reprodução e Genética de Espécies Arbóreas, Depto de Ciências Florestais-ESALQ/USP. Manuscrito não publicado, 1993. 82p.

VENCOVSKY, R. Variance of an estimate of outcrossing rate. Revista Brasileira de Genética, 17(3):349-51. 1994.

WADE, M.J. \& McCAULEY, D.E. Extinction and recolonization: their effects on the genetic differentiation of local populations. Evolution, 42(5):995-1005. 1988.

WEEDEN, N.F. \& GOTTLIEB, L.D. The genetics of chloroplast enzymes. The Journal of Heredity, 71:392-96, 1980.

WEIR, B.S. Genetic data analysis. Sinauer Assoc., Inc. Publ. 1990a, 377p.

WEIR, B.S. Intraspecific differentiation. In: HILLIS, D.M. \& MORITZ, C. Molecular Systematics. Sinauer Associates, Inc Publishers. 1990b, p.373-409.

WELDEN, C. W., HEWETT, S. W., HUBBELl, S. P., FOSTER, R. B. Sapling survival, growth, and recruitment: relationship to canopy height in a neotropical forest. Ecology. 72(1): 35-50. 1991.

WORKMAN, P. \& NISWANDER, J.L. Population studies on southwestern Indian tribes. II. Local genetic differentiation in the Papago. Am. J. Hum. Genet., 22:24-49.

WRIGHT, S. Coefficients of imbreeding and relationship. American Naturalist, 56:330-38. 1922.

WRIGHT, S. The interpretation of population structure by F-statistics with special regard to systems of mating. Evolution. 19: 395-420. 1965.

WRIGHT, S. Evolution and the genetics of populations. Volume 4. Variability within and among natural populaions. University of Chicago Press, Chicago. 1978. 